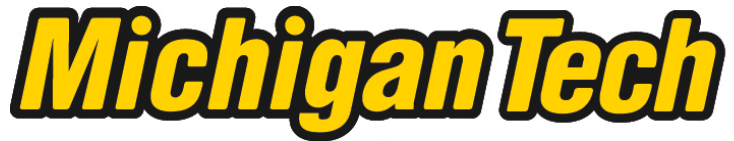 \\ Michigan Technological University Create the Future Digital Commons @ Michigan Tech
}

Dissertations, Master's Theses and Master's Reports - Open

Dissertations, Master's Theses and Master's

Reports

2010

Risk analysis of light-frame wood construction due to multiple hazards

Yue-Jun Yin

Michigan Technological University

Follow this and additional works at: https://digitalcommons.mtu.edu/etds

Part of the Civil and Environmental Engineering Commons

Copyright 2010 Yue-Jun Yin

\section{Recommended Citation}

Yin, Yue-Jun, "Risk analysis of light-frame wood construction due to multiple hazards ", Dissertation, Michigan Technological University, 2010.

https://doi.org/10.37099/mtu.dc.etds/283

Follow this and additional works at: https://digitalcommons.mtu.edu/etds

3 Part of the Civil and Environmental Engineering Commons 


\title{
RISK ANALYSIS OF LIGHT-FRAME WOOD CONSTRUCTION DUE TO
}

\section{MULTIPLE HAZARDS}

\section{By}

YUE-JUN YIN

\author{
A DISSERTATION \\ Submitted in partial fulfillment of the requirements \\ for the degree of \\ DOCTOR OF PHILOSOPHY
}

(Civil Engineering)

MICHIGAN TECHNOLOGICAL UNIVERSITY

2010

(C) 2010 Yue-Jun Yin 

This dissertation, "Risk analysis of light-frame wood construction due to multiple hazards", is hereby approved in partial fulfillment of the requirements for the degree of DOCTOR OF PHILOSOPHY in the field of Civil Engineering.

DEPARTMENT:

Civil and Environmental Engineering

Signatures:

Dissertation Advisor

Dr. Yue Li

Department Chair

Dr. William M. Bulleit

Date 

To my parents, Juan, Leroy and Sarah! 



\title{
Contents
}

\author{
List of Figures
}

xvii

List of Tables

$\mathbf{x x}$

Acknowledgments

xxi

Abstract

xxiii

1 Introduction

1

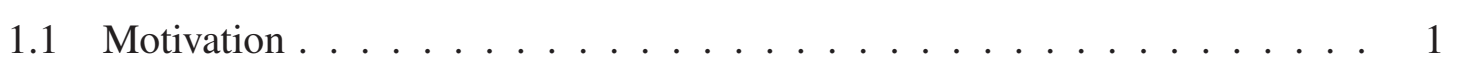

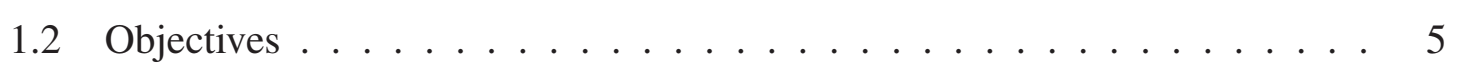

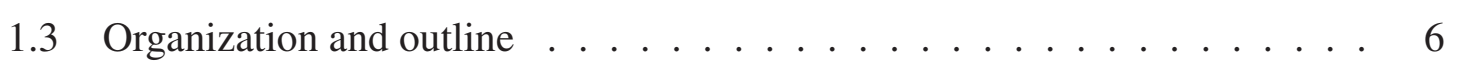

2 Collapse capacity and collapse risk of light-frame wood construction

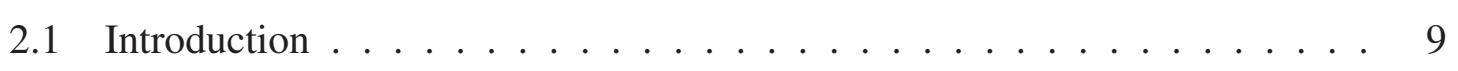

2.2 Prototype light-frame wood residential construction . . . . . . . . . . 10 
2.3 Earthquake ground motions . . . . . . . . . . . . . . . 12

2.4 Seismic demand analysis for light-frame wood construction . . . . . . . 13

2.5 Seismic collapse fragility and margin of collapse $\ldots \ldots \ldots \ldots$

2.6 Probability of collapse considering only uncertainty from ground motions . 25

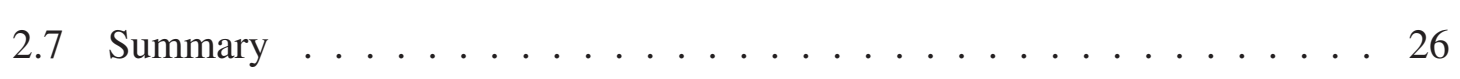

3 Seismic collapse risk of light-frame wood construction considering aleatoric and epistemic uncertainties 29

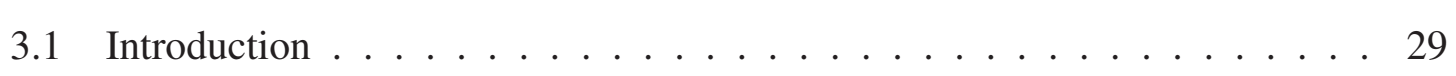

3.2 Structural model . . . . . . . . . . . . . . . . . . . . 31

3.3 Collapse risk with uncertainty in ground motion records . . . . . . . . 34

3.3.1 Record-to-record uncertainty . . . . . . . . . . . . . . . 34

3.3.2 Effects of spectra shape of ground motion records on collapse capacity . . . . . . . . . . . . . . . 35

3.3.3 Collapse capacity with adjustment for epsilon . . . . . . . . 4 40

3.4 Collapse capacity considering resistance uncertainty . . . . . . . . . 42

3.4.1 Resistance uncertainty . . . . . . . . . . . . . . . 44

3.4.2 Monte Carlo simulation with Latin Hypercube Sampling . . . . . 45

3.5 Collapse risk with aleatoric and epistemic uncertainties . . . . . . . . . 49 
3.5.1 Collapse fragility with uncertainty ............... 49

3.5.2 Probability of collapse at MCE ................ 50

3.5.3 Annual and 50-year collapse probabilities ......... 54

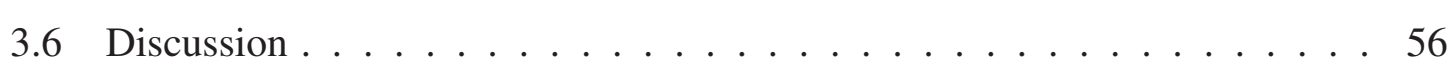

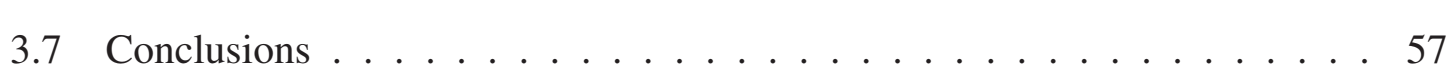

4 Stochastic modeling of snow loads using a Filtered Poisson process 59

4.1 Introduction . . . . . . . . . . . . . . . . . 59

4.2 Bernoulli model and its limitations . . . . . . . . . . . . 60 60

4.3 Filtered Poisson Process $\ldots \ldots \ldots \ldots$

4.4 Genetic algorithm . . . . . . . . . . . . . . . . . 63

$4.5 \mathrm{NCDC}$ weather records $\ldots \ldots \ldots \ldots . \ldots . \ldots 6$

4.5.1 NCDC weather stations ................... 66

4.5.2 WTEQ estimation using climatological data .......... 68

4.6 Fitting model parameters ....................... 69

4.7 Case studies ............................. 70

4.7.1 Tahoe City, CA ...................... 71

4.7 .2 Stampede, WA .......................... 72 
4.7 .3 Buffalo, $\mathrm{NY} \ldots \ldots \ldots \ldots \ldots \ldots \ldots \ldots$

4.7 .4 Discussion $\ldots \ldots \ldots \ldots \ldots \ldots \ldots$

4.8 Future work . . . . . . . . . . . . . . . . . . . 80

4.9 Summary $\ldots \ldots \ldots \ldots \ldots \ldots$

5 Loss estimation of light-frame wood construction subjected to mainshock-aftershock sequences 83

5.1 Introduction $\ldots \ldots \ldots \ldots \ldots \ldots \ldots$

5.2 Framework for seismic risk assessment . . . . . . . . . . . . . 86

5.2.1 Simulation of mainshock-aftershock sequences . . . . . . . 8 87

5.2.1.1 Mainshock simulation . . . . . . . . . . . . 87

5.2.1.2 Aftershock simulation . . . . . . . . . . . . 89

5.2.1.3 Selecting and scaling of ground motions ....... 90

5.2.2 Structural model and nonlinear dynamic analysis . . . . . . . 92

5.2.3 Damage and loss estimation . . . . . . . . . . . . 95

5.3 Uncertainty in seismic loss estimation . . . . . . . . . . 98

5.4 Illustrative example $\ldots \ldots \ldots \ldots \ldots \ldots$

5.5 Discussions and future work $\ldots \ldots \ldots \ldots \ldots \ldots$

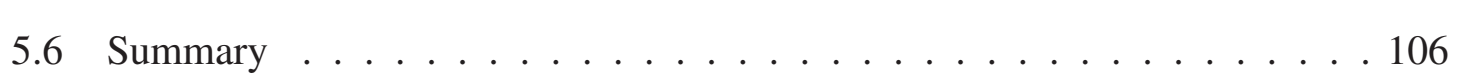


6 Probabilistic loss assessment of light-frame wood construction subjected to combined seismic and snow loads

6.1 Introduction . . . . . . . . . . . . . . . . . . . 109

6.2 Framework of risk analysis . . . . . . . . . . . . . . . 111

6.3 Hazard modules . . . . . . . . . . . . . . . . . . 115

6.3 .1 Earthquake load .............................

6.3.1.1 Occurrence of earthquake ................ 115

6.3.1.2 Intensity of earthquake ................ 115

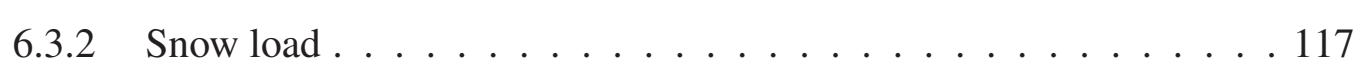

6.3.2.1 Bernoulli model and its limitations .......... 117

6.3.2.2 Filtered Poisson Process model . . . . . . . . . . . 119

6.3.3 Uncertainty in hazard load . . . . . . . . . . . . . . 121

6.4 Structural module . . . . . . . . . . . . . . . . . 121

6.5 Loss module . . . . . . . . . . . . . . . . . . . . . 123

6.6 Case study ... . . . . . . . . . . . . . . . . 125

6.6.1 Limit states exceedance probabilities ............ 127

6.6.2 Estimation of economic losses .................... 128

6.7 Summary . . . . . . . . . . . . . . . . . . . . . 132 
7 Summary, conclusions and future work

7.1 Summary and conclusions $\ldots \ldots \ldots \ldots \ldots$

7.2 Future work . . . . . . . . . . . . . . . . . . . . 137 


\section{List of Figures}

1.1 A one-story light-frame building in the U.S. . . . . . . . . . . . 2

2.1 Schematic of one-story wood frame residence . . . . . . . . . 11

2.2 Hysteresis and backbone curves for conventional and engineered shear walls 11

2.3 Response spectra for records la21-40 . . . . . . . . . . . . 14

2.4 IDA curves for engineered construction in Los Angeles, CA (LA2/50 ground motions) . . . . . . . . . . . . . . . . . . 17

2.5 IDA percentile curves for engineered construction in Los Angeles, CA (LA2/50 ground motions) . . . . . . . . . . . . . . 18

2.6 IDA curves for engineered construction in Los Angeles, CA (LA10/50 ground motions) . . . . . . . . . . . . . . . 19

2.7 IDA percentile curves for engineered construction in Los Angeles, CA (LA10/50 ground motions) $\ldots \ldots \ldots$

2.8 IDA curves for conventional construction in Los Angeles, CA (LA2/50 ground motions) . . . . . . . . . . . . . . . . 21

2.9 IDA percentile curves for conventional construction in Los Angeles, CA (LA2/50 ground motions) . . . . . . . . . . . . . . . . 22 
2.10 Collapse fragility curves and probability of collapse at $S_{a}$ of $2 \% / 50$-yr and $10 \% / 50-y r \ldots \ldots \ldots \ldots \ldots 23$

2.11 Collapse fragility curves with lognormal distribution . . . . . . . . 24

2.12 Collapse risks of light-frame wood buildings in 4 sites . . . . . . . . 26

3.1 Schematic of one-story wood frame residence . . . . . . . . . 32

3.2 Hysteresis model of light-frame wood shear wall ......... 33

3.3 IDA and fragility curves of the building A subjected to Los Angeles 2/50 ground motions .......................... 36

3.4 (a) Acceleration spectra of a ground motion with a positive $\varepsilon$; (b) Spectra of LA2/50 ground motions and expected spectra . . . . . . . . . . . 38

3.5 Collapse capacity of building A subjected to LA2/50 ground motions (target $\varepsilon=2) \ldots \ldots \ldots \ldots \ldots \ldots$

3.6 Regression of $\varepsilon$ and $\ln S_{a, c c}$ for LA2/50 ground motions (at the period $0.2 \mathrm{~s}$ ) 41

3.7 Effect of uncertainty in hysteresis parameter $r_{3}$ (shown in Figure 3.2) on the median collapse capacity . . . . . . . . . . . . . 47

3.8 Effect of hysteresis parameters on dispersion of collapse capacity . . . . . 47

3.9 Collapse fragility of the light-frame wood building at four sites (building A in Los Angeles and building B at the other three sites) . . . . . . . . . 52 52

3.10 Collapse fragility adjusted with $\varepsilon$ of the light-frame wood construction at four sites (building A in Los Angeles and building B at the other three sites) 53

4.1 Ground snow load record of Buffalo, NY . . . . . . . . . . . . 61 
4.2 Ground snow load records of Stampede, WA . . . . . . . . . . . . . 62

4.3 Generic Poisson events . . . . . . . . . . . . . . . . . . 63

4.4 Flow chart of the hazard simulation program HASP . . . . . . . . . 67

4.5 Estimated water equivalent snow depth (WTEQ) vs. recorded WTEQ for Blue Canyon ......................... . . . 70

4.6 Ground snow load records of Tahoe City, CA . . . . . . . . . . 73

4.7 CDF plot of snow load of Tahoe City, CA . . . . . . . . . . 74

4.8 Ground snow load records of Stampede, WA . . . . . . . . . . . . . 76

4.9 CDF plot of the annual maximum ground snow load of Stampede, WA . . 77

$4.10 \mathrm{CDF}$ plot of the daily ground snow load for Stampede, WA . . . . . . . 77

4.11 Ground snow load records of Buffalo, NY . . . . . . . . . . . . 78

$4.12 \mathrm{CDF}$ of the annual maximum ground snow load for Buffalo, NY . . . . . 79

$4.13 \mathrm{CDF}$ of the daily ground snow load for Buffalo, NY . . . . . . . . 79

5.1 Recorded aftershocks in the 1999 Taiwan Chi-chi earthquake . . . . . . . 84

5.2 Fragility-based frameworks for seismic loss estimation . . . . . . . 86

5.3 Object-oriented risk analysis procedure for mainshock and aftershock se-

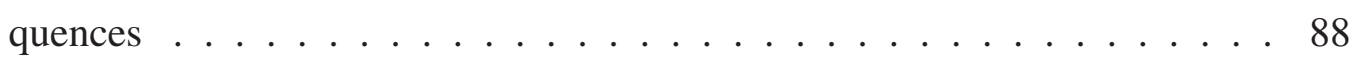

5.4 Daily aftershock rate after a mainshock of $M_{m}=7.3$ in California (only aftershocks with magnitudes $M \geq 5$ are considered in the simulation) . . . . 91 
5.5 Histogram of simulated number of aftershocks following a mainshock with the magnitude $M_{m}=7.3$ in California (only aftershocks with magnitudes $M \geq 5$ are considered in the simulation) . . . . . . . . . . 91

5.6 Simulated aftershocks following a mainshock with magnitude $M_{m}=7.3$ (only aftershocks with magnitudes $M \geq 5$ are considered in the simulation) 92

5.7 Schematic of one-story wood frame residence . . . . . . . . . . 93

5.8 Hysteresis model of light-frame wood shear wall . . . . . . . . . . 94

5.9 Drift time history of the building subjected to a back-to-back ground motion 95

5.10 Damage state fragility of the light-frame wood building . . . . . . . . 96

5.11 Monte Carlo Simulation scheme for seismic loss estimation considering mainshock and aftershock . . . . . . . . . . . . . . 101

5.12 Expected seismic losses (in percentage of the total replacement value) of a light-frame wood building in California . . . . . . . . . . . 102

5.13 Expected seismic losses of the one-story building at a site in California . . 103

5.14 Histogram of economic losses in 50 years considering mainshock and aftershock sequences (DC set 2 is considered) . . . . . . . . . . . 105

5.15 Exceedance probability of seismic losses of the building (DC set 2 is con-

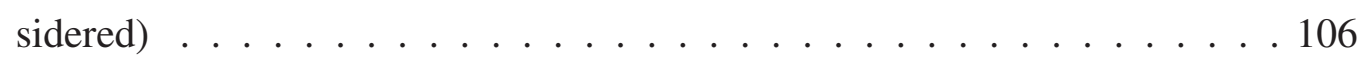

6.1 Risk assessment for a single hazard . . . . . . . . . . . . . . . 112

6.2 Object oriented framework (OOF) of risk assessment for combined seismic and snow hazards ............................ 114 
6.3 Ground snow load records of Buffalo, NY . . . . . . . . . . . . . 118

6.4 Ground snow load records of Stampede, WA . . . . . . . . . . . . . . 118

6.5 Generic Poisson events . . . . . . . . . . . . . . . . . . . . . . . . . 119

6.6 FPP simulated ground snow load records for Stampede, WA . . . . . . . 120

6.7 Schematic of one-story wood frame residence . . . . . . . . . . . 122

6.8 Damage state fragility of a light-frame wood building . . . . . . . . . . 123

6.9 Uniform hazard spectra of Seattle and Stampede, WA . . . . . . . . . . . 125

6.10 Expected annual exceedance probabilities of four limit states in Stampede,

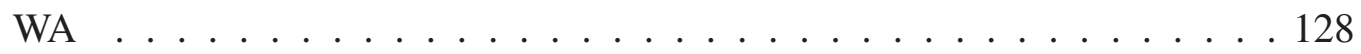

$6.1190^{\text {th }}$ percentile of the simulated economic losses (in percentage of the total replacement value) of the one-story light-frame building in Stampede, WA $\left(\alpha_{s}\right.$ : snow participation factor $) \ldots \ldots$. . . . . . . . . . . . 130

6.12 Expected economic losses (in percentage of the total replacement value) of the one-story light-frame building in Stampede, WA ( $\alpha_{s}$ is the snow participation factor $\ldots \ldots \ldots \ldots$. . . . . . . . . . . . . . . . . . . .

6.13 (a) Histogram of the simulated economic losses (in percentage of the total replacement value) in 50 years of the one-story building in Stampede, WA; (b) Exceedance probabilities of the 50-year economic loss (in percentage of the total replacement value) of the one-story building in Stampede, WA (the snow participation factor $\alpha_{s}=1$ ) . . . . . . . . . . . 133 


\section{List of Tables}

2.1 Seismic demand (drift) on wood structures . . . . . . . . . . . 15

2.2 Median collapse capacity and associated $S_{a} \ldots \ldots \ldots \ldots$

2.3 Probability of collapse at $S_{a}$ at MCE and 10\%/50-yr earthquake . . . . . 21

2.4 Lognormal model parameters for probability of collapse . . . . . . 22

2.5 Median capacity and demand and margin of collapse ....... 24

3.1 Epsilon $(\varepsilon)$ values of LA2/50 ground motions (at the period of $0.20 \mathrm{sec}$ ) . . 40

3.2 Collapse fragilities for the building located at four sites . . . . . . 43

3.3 Probabilistic distributions of the hysteresis parameters (Units: $\mathrm{kN}-\mathrm{mm}$ ) . . . 45

3.4 Single shear wall collapse capacity $S_{a, c c}$ statistics due to resistance uncer-

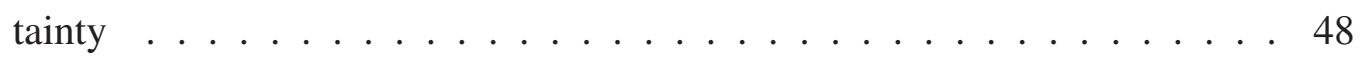

3.5 Collapse probability for light-frame wood construction at four sites considering aleatoric and epistemic uncertainties . . . . . . . . . 51

3.6 Collapse probability (\%) of the light-frame wood building at four Sites in the United States at MCE . . . . . . . . . . . . . . . . . . 54 
$4.1 \quad$ Selected weather stations $\ldots \ldots \ldots$

4.2 Weather correlation analysis results $\ldots \ldots \ldots$. . . . . . . . 69

4.3 Nonlinear regression analysis results . . . . . . . . . . . . . . 69 69

4.4 Statistics of the annual maximum ground snow load for three sites . . . 72

5.1 Downtime and transition costs for three damage states . . . . . . . . 997

5.2 Expected losses (in percentage of the total replacement value) of the onestory residential building in California . . . . . . . . . . . . . 104

6.1 Seismic hazard parameters for the earthquake intensity $\ldots . . . . . .116$

6.2 Damage state fragility and repair cost distribution parameters for lightframe wood construction . . . . . . . . . . . . 124

6.3 Annual exceedance probabilities of four drift limit states of a light-frame wood building in Stampede, WA . . . . . . . . . . 128

6.4 Economic losses (in percentage of the total replacement value) of the onestory building in Stampede, WA . . . . . . . . . . . . 131 


\section{Acknowledgments}

Thank God my Lord!

This research is partially supported by the Department of Defense University Research Instrumentation Program (DURIP) (FA-9550-07-1-0500). Additional support is from the Department of Civil and Environmental Engineering and Michigan Tech Finishing Fellowship. All support is greatly appreciated.

The author is grateful to his committee member, Professor William Bulleit, for sharing the Genetic Algorithm code and his constructional comments on the studied subject. The author would like to thank his committee members, Dr. Devin Harris and Dr. Madhukar Vable, for taking time to review this work. Thanks to Dr. Amlan Mukherjee for his help on the $\mathrm{IAT}_{\mathrm{E}} \mathrm{X}$ documentation and system modeling techniques. The author would like to thank Dr. Qing Ling and Dr. Zhi Tian, for their strong work ethic and knowledge.

Thanks to all of the students, staff, and faculty of the Department of Civil and Environmental Engineering. The atmosphere of academic excellence and collegiality fostered in the department played a big role in my productivity and my enjoyment of the $\mathrm{PhD}$ experience. In particular, Pei Tang, Yinghong Qin, Matt Smith, Amanda Cadwell, Kim Besonen, Dr. Yogini Deshpande, Corrine Leppen, Dr. Zhanping You, Dr. Qing Ling, Dr. Zhi Tian, Dr. David Watkins, and Jeff Hilss have provided valuable support.

Thanks to my dear wife Juan, who has taken care of our family and kids with love. Thanks to my parents to whom I owe much.

Most importantly the author thanks his advisor and mentor, Dr. Yue Li, whose insight and enthusiasm have made this research experience incredibly rewarding. It was an honor to be his student. 


\section{Abstract}

Light-frame wood buildings are widely built in the United States (U.S.). Natural hazards cause huge losses to light-frame wood construction. This study proposes methodologies and a framework to evaluate the performance and risk of light-frame wood construction.

Performance-based engineering (PBE) aims to ensure that a building achieves the desired performance objectives when subjected to hazard loads. In this study, the collapse risk of a typical one-story light-frame wood building is determined using the Incremental Dynamic Analysis method. The collapse risks of buildings at four sites in the Eastern, Western, and Central regions of U.S. are evaluated. Various sources of uncertainties are considered in the collapse risk assessment so that the influence of uncertainties on the collapse risk of lightframe wood construction is evaluated. The collapse risks of the same building subjected to maximum considered earthquakes at different seismic zones are found to be non-uniform.

In certain areas in the U.S., the snow accumulation is significant and causes huge economic losses and threatens life safety. Limited study has been performed to investigate the snow hazard when combined with a seismic hazard. A Filtered Poisson Process (FPP) model is developed in this study, overcoming the shortcomings of the typically used Bernoulli model. The FPP model is validated by comparing the simulation results to weather records obtained from the National Climatic Data Center. The FPP model is applied in the proposed framework to assess the risk of a light-frame wood building subjected to combined snow and earthquake loads. The snow accumulation has a significant influence on the seismic losses of the building. The Bernoulli snow model underestimates the seismic loss of buildings in areas with snow accumulation.

An object-oriented framework is proposed in this study to perform risk assessment for lightframe wood construction. For home owners and stake holders, risks in terms of economic losses is much easier to understand than engineering parameters (e.g., inter story drift). The proposed framework is used in two applications. One is to assess the loss of the building subjected to mainshock-aftershock sequences. Aftershock and downtime costs are found to be important factors in the assessment of seismic losses. The framework is also applied 
to a wood building in the state of Washington to assess the loss of the building subjected to combined earthquake and snow loads. The proposed framework is proven to be an appropriate tool for risk assessment of buildings subjected to multiple hazards. Limitations and future works are also identified. 


\section{Chapter 1}

\section{Introduction}

\subsection{Motivation}

Woodframe construction is the most common type of building for homes and apartments in the U.S. Approximately $90 \%$ of the residences in the U.S. are light-frame wood construction [1]. Figure 1.1] shows a typical one-story light-frame wood building in the United States (U.S.). As can be seen from Figure 1.1, woodframe shear walls are the primary components of the lateral load resisting system of the light-frame wood structure. Typically, a shear wall is composed of framing members (stud, sill plate, and top plate), sheathing panels (not shown in the figure), sheathing-to-framing connectors (nails) and hold-down anchorages (e.g., anchor bolts).

Natural hazards including earthquakes, snow, and hurricanes have caused catastrophic losses to wood construction. In the 1994 Northridge earthquake, about $\$ 20$ billion of property losses [1, 2] and 24 out of 25 deaths were due to damage or collapse of wood construction [1]. In the 1995 Kobe earthquake, collapse of residential wood buildings contributed significantly to death and economic losses [2]. Three fatalities were reported in the winter of 1999-2000 due to roof collapses as a result of heavy snow loads at Bardufoss Community Center in northern Norway [3]. The March 1993 east coast storm in the United States caused $\$ 1.75$ billion economic losses [4]. On January 28, 2006, at least 66 were killed and 160 were injured in the Katowice Trade Hall roof collapse due to heavy 


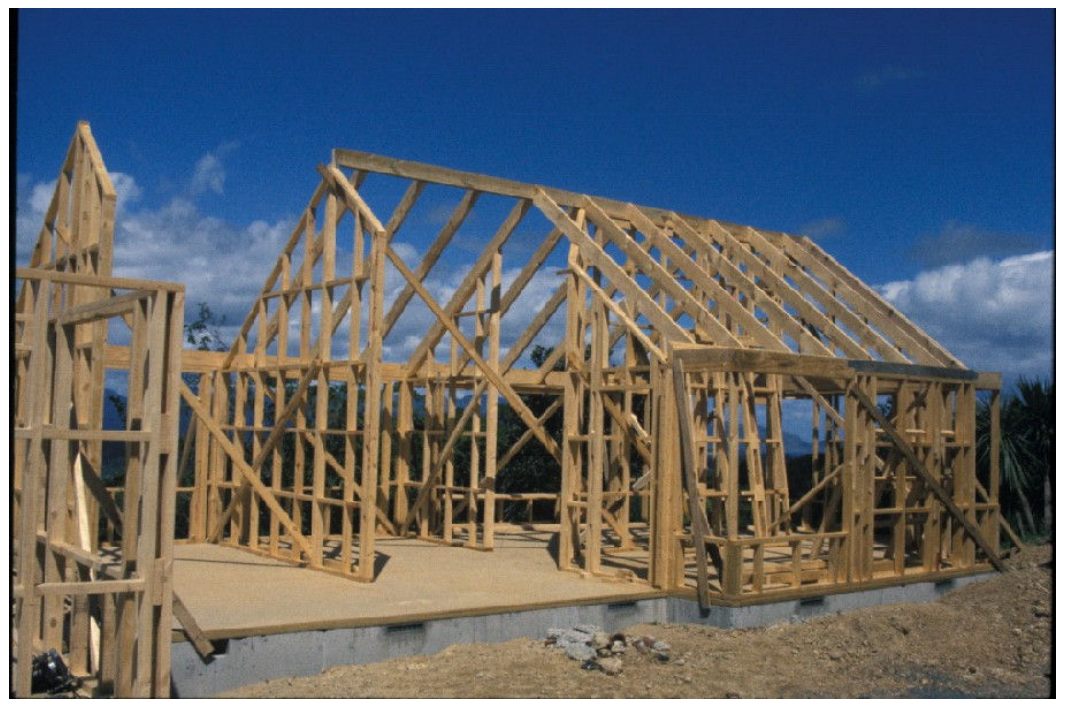

Figure 1.1: A one-story light-frame building in the U.S.

snow loads in Poland [5]. In January 2006, a roof collapsed due to heavy snow loads in Bad Reichenhall, Germany, killing 15 (including 8 children) and injuring more than 30 [6]. In February 2008, a snow storm in southern China caused a direct economic loss of 54 billion yuan (\$7.7 billion) [7].

The unacceptable economic losses from these hazards to woodframe construction have compelled the industry and academia to evaluate the performance of existing woodframe construction and to develop a performance-based seismic design (PBSD) philosophy so that the economic losses can be predicted and controlled. The CUREE-Caltech woodframe project [8, 9], funded by the Federal Emergency Management Agency (FEMA), aimed to significantly reduce earthquake induced economic losses to woodframe construction, by experimental testing and analysis, field investigations, and building codes and standards development. This project laid the groundwork for PBE of wood buildings in the U.S [10]. In addition, the NEESWOOD project [11], funded by the National Science Foundation (NSF), aimed to develop a PBSD philosophy for mid-rise woodframe construction. The SEI/ASCE Committee on Reliability-based Design of Wood Structures initiated a two-year 
special project in 2005 entitled 'The next step for AF\&PA/ASCE 16-95: performancebased design of wood structures' [10]. The objective of this project was to formulate a performance-based format for ASCE 16-95 standard [12]. Filiatrault and Folz [13] proposed the PBSD of woodframe buildings through displacement-based approach that was based on the direct-displacement method [14-16]. Rosowsky and Ellingwood [17] made an overview of PBE of woodframe buildings and proposed fragility analysis as a tool to assess building performance, as shown by:

$$
P[L S]=\sum P[L S \mid D=x] P[D=x]
$$

in which $D$ is the engineering demand parameter (EDP) (e.g., spectral acceleration $S_{a}$ at the fundamental period of a building). $P[D=x]$ is the hazard function. $P[L S \mid D=x]$ is the fragility, a limit state (LS) probability conditioned on a certain hazard level $D=x$. Fragility analysis was then applied to light-frame wood construction subjected to a variety of natural hazards (e.g., [1, 18-20]).

Post-earthquake disaster surveys have shown that a large portion of structural and nonstructural damage to light-frame wood residential construction can be related to excessive lateral drifts in the building system. The lateral deformation of the structural system is an appropriate performance metric when system behavior must be measured by one global structural response quantity, particularly when the structural response is in the nonlinear range, which is the usual case in wood-frame structures. Building performance levels have been defined in terms of drift limits for wood-framed buildings in NEHRP guidelines [21, 22] and in other recent literature [13, 23]. For example, in FEMA report 356 [22] and ASCE Standard 41-06 [23], the immediate occupancy (IO), life-safety (LS), and collapse prevention $(\mathrm{CP})$ performance levels for lateral force-resisting structural elements in lightframe wood construction subjected to seismic effects are related to transient lateral drifts of $1 \%, 2 \%$, and $3 \%$ of the story height, respectively. The seismic testing of a full-scale two-story light-frame wood buildings at the University of Buffalo, a benchmark test for the NEESWood project [11], supports the IO and LS limits, but not the CP limit. The twostory building exceeded a drift of $3.6 \%$ without being close to incipient collapse. Other recent studies have also found that the drift limit for CP is larger than $3 \%$. The SEI/ASCE Committee on Reliability based Design of Wood Structures proposed 4-7\% drift limit for $\mathrm{CP}$ in the PBE of light-frame wood construction.

Aftershocks occur following an earthquake of large magnitude (referred to as the main- 
shock). In 24 hours after the 8.8 earthquake in Chile on Feb. 27, 2010, about 90 aftershocks with magnitudes equal to or larger than 5.0 were recorded by the United States Geological Survey (USGS) [24]. In the Wen-Chuan earthquake on May 122008 in China, 12 aftershocks with magnitudes larger than 5.0 were observed on the day [25] after the mainshock. In the 1999 Taiwan Chi-chi earthquake [26], there were 3 aftershocks with magnitudes around 6.0 within 4 hours after the mainshock. Therefore, it is not realistic that the building is rebuilt to its intact state immediately, or before the next earthquake event, which is typically assumed in seismic loss estimation (e.g., 27, 28). Depending on the damaged building status and the aftershock intensities, it can take 2 years or longer before reopening the mainshock damaged building [29], which results significant economic losses. Li and Ellingwood [30] investigated the potential additional damage caused to a steel building by aftershocks. Yeo and Cornell [29] investigated life-cycle cost of a steel commercial building in California using Markov models.

Risk in terms of economic loss is much easier to understand for building owners and stake holders, rather than engineering parameters (e.g., a drift limit state). The life-cycle cost (LCC) analysis has been applied in infrastructure management [31] and bridge management [32]. Earthquake induced cost analysis was performed using a category-based methodology [33, 34], which categorizes buildings based on their lateral force resisting system and height. Costs are calculated using some pre-established functions. The categorybased methodology is incorporated in the HAZUS software developed by the Federal Emergency Management Agency (FEMA). A substantial database is included in HAZUS, including nationwide inventory of buildings, lifeline systems, and demographic data [35]. Based on this database, HAZUS is capable of loss (direct and induced) assessment for a regional area.

A generic seismic loss estimation framework was proposed by the Pacific Earthquake Engineering Research (PEER) Center [36-38]. Based on the PEER framework, an assemblybased vulnerability (ABV) methodology was developed by Porter [39] and Porter et al. [40]. Pei and van de Lindt [27] incorporated the ABV method into a framework for long-term seismic caused loss assessment for light-frame wood construction. The ATC58 project [41] developed three methods, i.e., intensity-, scenario-, and time-based assessments for structural performance quantification.

Although some studies have been performed to investigate the performance and economic 
losses of light-frame wood construction subjected to earthquakes, snow, or hurricanes, the following issues have not been well investigated.

1. The collapse risks at different seismicity zones and the influence of various sources of uncertainties on the collapse risk of light-frame wood buildings.

2. The influence of snow accumulation on the performance and economic risk of lightframe wood construction.

3. The performance and economic risk of light-frame wood construction subjected to combined snow and seismic loads.

4. The performance and economic risk of light-frame wood construction subjected to mainshock and aftershock sequences.

\subsection{Objectives}

The goal of this study is to develop framework and methodologies to investigate the performance and risk assessment of light-frame wood construction subjected to multiple hazards. The specific objectives are to:

1. Investigate collapse risks of different light-frame wood buildings at different seismicity zones, considering various sources of uncertainties.

2. Develop a new snow load simulation model to capture snow accumulation characteristics. Examine the influence of snow accumulation on the risk of light-frame wood construction using the snow model.

3. Examine the performance and risk of light-frame wood buildings subjected to combined seismic and snow loads.

4. Assess the risk of light-frame wood buildings subjected to mainshock and aftershock sequences. 


\subsection{Organization and outline}

Each chapter (except Chapter $2^{*}$ ) is a single paper that has either been accepted by a journal or submitted to a journal. Chapters 2,6 are summarized as follows.

Chapter 2 examines the collapse risk of light-frame wood residential construction subjected to earthquakes in the United States. Using simple structural models of onestory residences with typical lateral force-resisting systems (shear walls) found in buildings in western, eastern and central regions of the United States as illustrations, the seismic demands are determined using nonlinear dynamic time-history analyses. The collapse capacities are determined using incremental dynamic analyses. The probabilities of collapse, conditioned on the occurrence of the maximum considered earthquakes and design earthquakes stipulated in ASCE Standard 7-05, and the collapse margins of these typical residential structures are compared for typical construction practices in different regions in the United States. The calculated collapse inter-story drifts are compared with the limits stipulated in FEMA 356/ASCE Standard 41-06 and observed in recent experimental testing. The results of this study provide insights into residential building risk assessment and the relation between building seismic performance implied by the current earthquake-resistant design and construction practices and performance levels in performance-based engineering of light-frame wood construction being considered by the SEI/ASCE committee on reliability-based design of wood structures. Further code developments are necessary to achieve the goal of uniform risk in earthquake-resistant residential construction.

Chapter $3 \dagger$ examines the effects of both aleatoric and epistemic uncertainties on the collapse risk of wood structures due to seismic loads. Record-to-record uncertainty and effect of the spectral shape $(\varepsilon)$ of ground motion records are examined. Uncertainties in structural resistance are represented in for typical wood-frame shear walls, which are modeled by a hysteresis model with 10 parameters, each of which is treated as a random variable. Epistemic uncertainty that is introduced by the modeling process

\footnotetext{
${ }^{*}$ Chapter 2 is an abridged version of a publication by $\mathrm{Li}$ et al. [42]. Some contents of the publication are contributed by other coauthors and removed from this chapter. Only the contribution of the second author (Yin) is kept. The copyright permission is included in Appendix A.

${ }^{\dagger}$ Chapter 3 has been published by Structural Safety, 2010, 32:250-261. The copyright permission is included in Appendix B.
} 
is examined in this study. The implications of inclusion of all sources of uncertainties on collapse risk are investigated and discussed in the context of comparison with the collapse risk in concrete and steel structures. It is found that the resistance uncertainty as well as modeling uncertainty have significant impacts on the seismic collapse risk of light-frame wood buildings. Some previous studies that neglected the effect of resistance uncertainty in seismic performance evaluation may lead to unconservative results.

Chapter 4 proposes a new model to simulate snow load. The Bernoulli pulse process has been used in the past for modeling snow loads. However, it is not an appropriate model for heavy snow load areas as the snow accumulation cannot be simulated, which may lead to unconservative assessment of buildings in such areas. In this study, a filtered Poisson process (FPP) is investigated and demonstrated to be an effective stochastic model capable of simulating snow loads with or without accumulation. Weather records obtained from the National Climatic Data Center are used to calibrate the simulated ground snow load records using the FPP model. A genetic algorithm is employed to determine the parameters of the FPP model. Illustrated by three selected sites in the United States, the annual maximum and daily ground snow load characteristics are well captured by the FPP model. Potential applications of the model in reliability analysis and risk assessment are discussed.

Chapter $5 \S$ examines the seismic losses of light-frame wood construction subjected to mainshock and aftershock sequences. Aftershocks occur following an earthquake of large magnitude (referred to as the mainshock) and cause further damage to buildings that may have sustained damage in the mainshock. In this chapter, an object-oriented framework is proposed to estimate seismic losses of light-frame wood buildings subjected to mainshock and aftershock sequences. Mainshocks are simulated as a homogeneous Poisson process, while aftershocks are simulated as a nonhomogeneous Poisson process. Back-to-back mainshock-aftershock nonlinear dynamic analysis is performed to determine the maximum inter-story drift due to each earthquake occurrence (either mainshock or aftershock). Seismic risk is quantified in terms of economic losses in this chapter. The damage loss (transition cost) and downtime cost are included in the loss estimation, considering a time discount factor. The proposed framework is demonstrated by an example that examines the seismic loss of typical

\footnotetext{
${ }^{\ddagger}$ Chapter 4 has been accepted by Journal of Cold Regions Engineering. Preview online. http://dx. doi. org/10.1061/(ASCE) CR.1943-5495.0000021

${ }^{\S}$ Chapter 5 has been reviewed, revised and resubmitted to Journal of Performance of Constructed Facilities.
} 
light-frame wood residential buildings in the United States. The results show that aftershocks and downtime cost are important contributor to total seismic losses. Future work is identified to further investigate the effect of mainshock and aftershock sequences on the seismic loss.

Chapter 6 investigates the performance and economic risks of light-frame wood construction subjected to combined seismic and snow loads. In some areas, e.g., mountainous areas in the western United States, both seismic and snow loads are significant. Limited research has been done to investigate the seismic risk of lightframe wood construction in those areas considering the combined loads, particularly snow accumulation. An object-oriented framework of risk assessment for light-frame wood construction subjected to combined seismic and snow hazards is proposed in this study. A typical one-story light-frame wood residential building is selected to demonstrate the proposed framework. Quantified risks of the building in terms of economic losses due to the combined hazards are evaluated for the building. It is found that for areas with significant snow load accumulation, the snow load has significant effects on the seismic risk assessment for light-frame wood construction.

ฯ Chapter 6 has been reviewed, revised, and resubmitted to Engineering Structures. 


\section{Chapter 2}

\section{Collapse capacity and collapse risk of light-frame wood construction}

\subsection{Introduction}

This chapter investigates the collapse risk of light-frame wood residential construction subjected to earthquakes in the United States. Using simple structural models of one-story residences with typical lateral force-resisting systems (shear walls) found in buildings in western, eastern and central regions of the United States as illustrations, the seismic demands are determined using nonlinear dynamic time-history analyses, whereas the collapse capacities are determined using incremental dynamic analyses. The probabilities of collapse, conditioned on the occurrence of the maximum considered earthquakes and design earthquakes stipulated in ASCE Standard 7-05, and the collapse margins of these typical residential structures are compared for typical construction practices in different regions in the United States. The calculated collapse inter-story drifts are compared with the limits stipulated in FEMA 356/ASCE Standard 41-06 and observed in the recent experimental testing. The results of this study provide insights into residential building risk assessment and the relation between building seismic performance implied by the current earthquake-resistant design and construction practices and performance levels in performance-based engineering of light-frame wood construction being considered by the SEI/ASCE committee on 
reliability-based design of wood structures. Further code developments are necessary to achieve the goal of uniform risk in earthquake-resistant residential construction.

\subsection{Prototype light-frame wood residential construction}

Collapse capacities and collapse risks of 'engineered' and 'conventional' buildings located in four cities (Los Angeles, CA; Seattle, WA; Boston, MA; St. Louis MO) are assessed in this study. Buildings identified as 'conventional' are assumed to be constructed to minimum historically acceptable standards of earthquake protection, in which shear walls are typically anchored to the foundation at spacing from $0.6 \mathrm{~m}$ to $1.2 \mathrm{~m}(2-4 \mathrm{ft})$ with bolts ranging from 13 to $16 \mathrm{~mm}$ (1/2-5/8 in) in diameter. Buildings identified as 'engineered' are constructed to an enhanced standard to comply (at least partially) with modern codes (e.g., NAHB [43]; WFCM [44]) and to offer higher seismic resistance.

The fundamental configurations of both conventional and engineered residential buildings are illustrated in Figure 2.1. These buildings are 9.75m (32 ft) long, 6.10m (20 ft) wide and $2.44 \mathrm{~m}(8 \mathrm{ft})$ high. The fundamental dimensional unit for their shear walls is a $1.22 \times 2.44 \mathrm{~m}$ $(4 \times 8 \mathrm{ft})$ sheathing panel modified, as appropriate, to allow for door and window openings. The opening details and dimensions of the wall systems are illustrated in Figure 2.1. The sheathing of the shear walls is provided by $9.5 \mathrm{~mm}(0.375 \mathrm{in})$ oriented strand board panels. Studs are spaced at $610 \mathrm{~mm}$ ( $24 \mathrm{in}$ ) on centers. The sheathing is connected to the studs with $8 \mathrm{~d}$ nails, which are $3.33 \mathrm{~mm}(0.131 \mathrm{in})$ in diameter. The nails are spaced $152.4 \mathrm{~mm}$ (6 in) along the sheathing panel perimeter and 304.8mm (12 in) in the panel interior. The fundamental period of both the conventional and engineered versions of the buildings is $0.25 \mathrm{~s}$, as the initial stiffness of the shear walls for both buildings are the same, which is shown in the hysteresis curves for the shear walls in Figure 2.2, Both residences are regular in plan and have the same configurations, with mean roof height of $3.20 \mathrm{~m} \mathrm{(12} \mathrm{ft).}$ Both residences have gable roofs with a slope of 6:12. The construction details for the residences represent common light-frame wood construction practice in the U.S.

Each shear wall in Figure 2.1(a) is modeled by a spring that is connected to the roof diaphragm. The diaphragm has three degrees of freedom: two in-plane displacements and one in-plane rotation. The south shear wall of the building is shown in Figure 2.1(b), The 


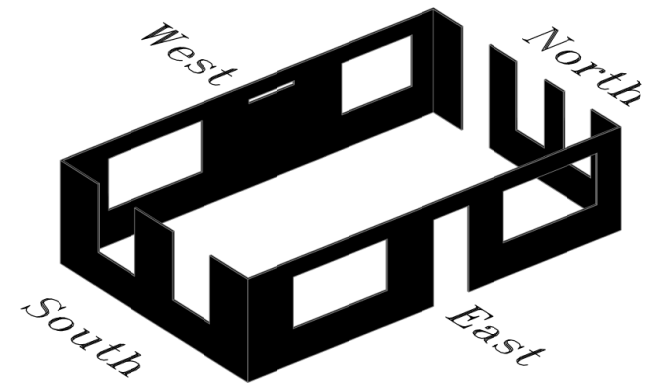

(a) 3-D model for the light-frame wood building (roof is not illustrated)

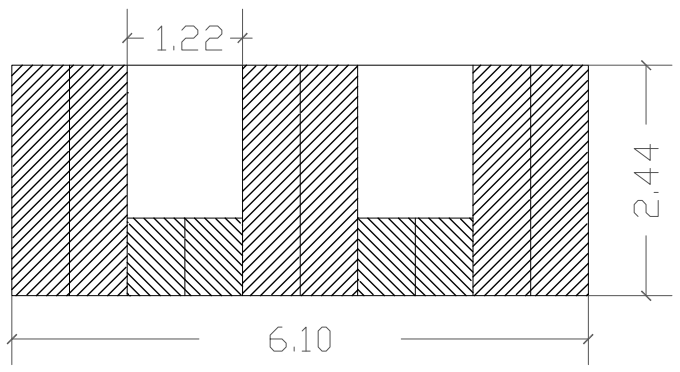

(b) South shear wall (unit: meter)

Figure 2.1: Schematic of one-story wood frame residence

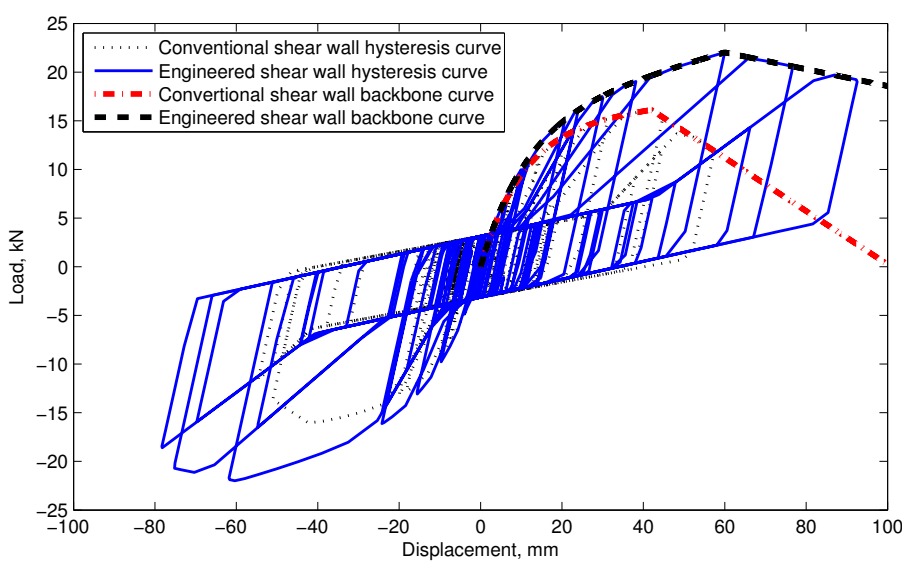

Figure 2.2: Hysteresis and backbone curves for conventional and engineered shear walls

response of wood-frame shear walls during minor earthquakes is essentially linear elastic. However, under severe earthquake ground motion, such systems exhibit highly nonlinear hysteretic behavior, with significant stiffness degradation, pinching of the hysteretic loops, and corresponding energy dissipation, as shown in Figure 2.2. The hysteretic behavior of the shear wall in Figure 2.1 is determined using CASHEW [45], a numerical model developed as the part of the CUREE-Caltech Wood-frame Project that is capable of predicting the force-displacement response of wood shear walls under quasi-static cyclic loading. This force-displacement response is used, in turn, to define the hysteretic behavior of the wall, including pinching and degradation in stiffness, in subsequent nonlinear dynamic analysis (NDA). Filiatrault et al. [46] have shown that drywall and other non-structural finishing 
materials increase the lateral stiffness of shear walls. For simplicity and conservatism, the effect of such finishing materials is not modeled in the lateral force-resisting systems considered herein.

In regions of high seismicity in the Western United States (WUS), current design and construction practice (e.g. WFCM [44]) are to anchor shear walls of wood-frame residences to the foundation with seismically qualified anchors, which resist both wall uplift and sliding and ensure a racking mode of deformation. In this study, engineered shear walls are assumed fully anchored to the foundation with seismically qualified anchorage. However, many older houses in the WUS were not built in this manner, and extensive damage to the sill plates and posts connected to hold-downs were observed following the 1994 Northridge earthquake. Furthermore, in the CEUS, the walls in residential construction seldom are seismically anchored to the foundation. Non-seismically qualified anchorage of the shear wall in the building prevents sliding but does not prevent uplift. There is only limited data to describe the hysteretic behavior of non-seismically anchored light-frame shear walls. Accordingly, in this study, the cyclic stiffness and strength of a non-seismically anchored shear walls in conventional construction have been assumed to be $70 \%$ of the correspond-

ing values for shear walls with fully anchored hold-down [47]. Figure 2.2 compares the backbone curves of the engineered and conventional shear walls, along with hysteresis curves obtained by performing the nonlinear dynamic analysis proposed by Folz and Filiatrault [48]. Additional support for this approach to modeling conventional (non-seismic) construction is provided by a NAHB study [49], which revealed that the shear walls with flexible foundations provide only $70 \%$ of the lateral load support provided by walls on rigid foundations. Finally, the models used in Ellingwood et al. [50] for partially anchored shear walls typical of construction practices in regions of low-to-moderate seismicity indicated similar reductions. The hysteresis curves in Figure 2.2 show the resulting effect on behavior for a one-story shear wall that is fully and partially anchored to the foundation, engineered and conventional shear wall, respectively.

\subsection{Earthquake ground motions}

Structural performance during an earthquake is impacted by uncertainties in both seismic loading and structural resistance. The uncertainty in seismic demand is known to be 
very large in comparison with the inherent variability in the capacity of the structural system [50], and is the dominant (aleatoric) uncertainty in the structural performance assessment described subsequently. The uncertainty in seismic demand in this study is reflected in the suite of ground motions chosen for structural performance assessment. The ground motions developed in the SAC project Phase II [51] for Los Angeles, CA, Seattle, WA, and Boston, MA are used in the NDA for residential building structures at those sites. Six ground motion ensembles were utilized; each ensemble has 20 ground motions that aggregate earthquake events of different magnitudes and epicentral distances and collectively represent ground motions with probabilities of 10\%/50-yr (la01-20, se01-20, bo01-20 for Los Angeles, CA, Seattle,WA, and Boston, MA, respectively) and 2\%/50-yr (la21-40, se2140, and bo21-40). For residences in St Louis, MO, which is located within 150 miles of multiple earthquake sources including the New Madrid Seismic Zone (NMSZ), synthetic ground motion ensembles generated by Wen and Wu [52] having exceedance probabilities of $10 \%$ and $2 \%$ in 50-yr were used. The dispersion in the response spectra from ground motions la21 through la40 for Los Angeles, illustrated in Figure 2.3, represents the uncertainty in the random amplitude and phasing from an ensemble of ground motions corresponding to a return period of approximately 2500 years. The median spectral acceleration is highlighted in the heavy dash curve.

\subsection{Seismic demand analysis for light-frame wood con- struction}

The seismic demands are determined by the NDA. The response quantity of most interest in measuring damage in one-story residential construction is the maximum drift sustained at the top of the shear wall during the earthquake ground motion, expressed as the ratio of the top of shear wall displacement to the height of the shear wall. These maximum drifts reflect only the uncertainty in ground motions, as discussed previously. While it has been customary to assume that uncertainties in capacity have a marginal impact on the

fragilities (e.g. [50]), recent research [53, 54] has suggested that this source of uncertainty may be non-negligible in engineered steel and concrete frames. The implication of this finding, as well as the modeling of uncertainty, including shear wall hysteresis models must await the completion of current large-scale testing programs and is a topic of future 


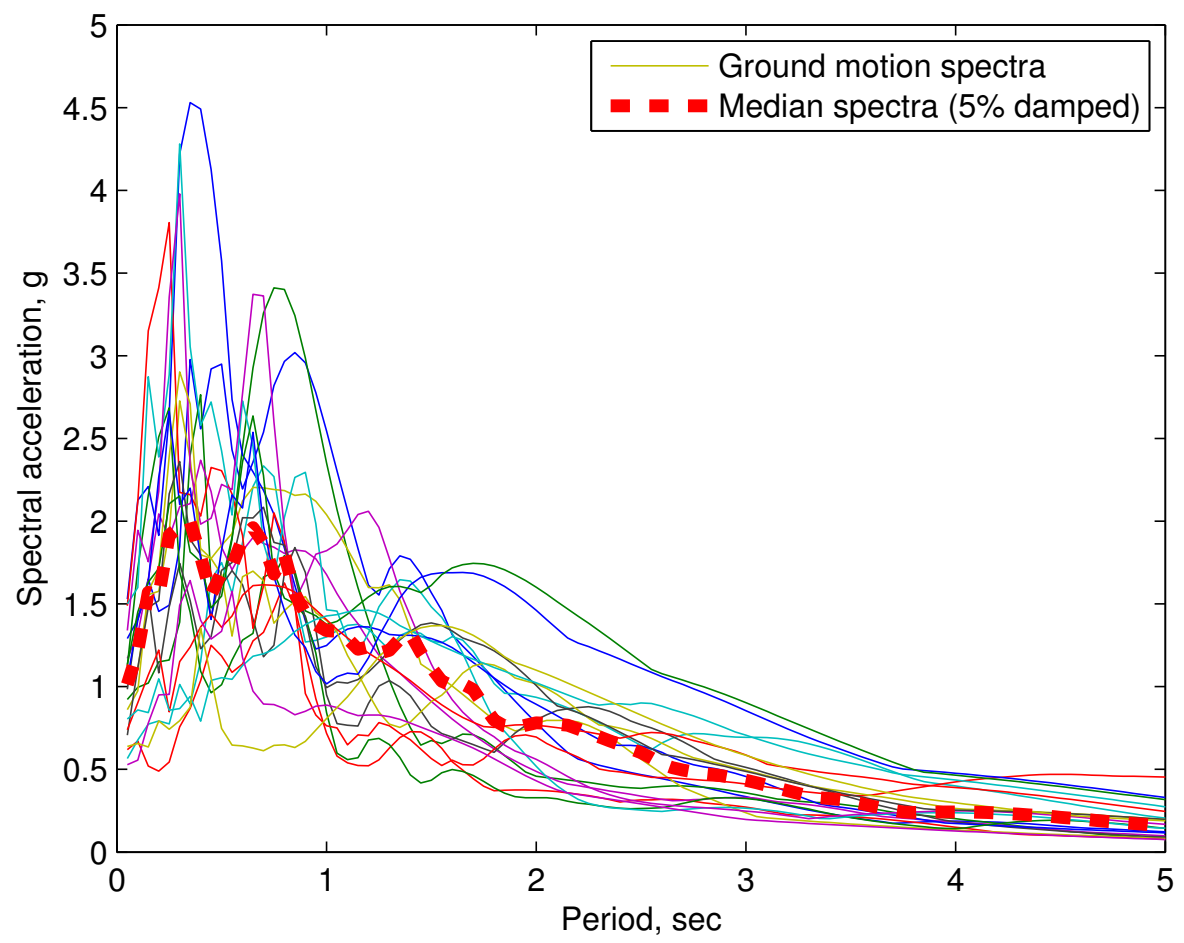

Figure 2.3: Response spectra for records la21-40

investigation. Preliminary analyses revealed that the south and north shear walls sustained almost identical deformations, and that these are larger than those of the east and west shear walls. Subsequently, the ground motions were applied in the east-west directions, and the maximum drifts of the south shear wall are presented in the following sections. The NDA was conducted using the program SAWS [55], a finite element platform developed to perform NDA of wood structural systems subjected to earthquake ground motions.

Table 2.1 summarizes the mean, median $\left(50^{\text {th }}\right.$ percentile), and coefficient of variation (COV) of the maximum drifts for light-frame wood structures in the selected cities subjected to the 2\%/50-yr and 10\%/50-yr earthquake ground motions. The mean drift is larger than the median drift in most instances, indicating that the distribution of drift is strongly skewed in the positive direction. The COV in drift can be as high as about $170 \%$ as a result of aleatoric uncertainty in the earthquake ground motions. The difference in seismic demand between engineered and conventional construction in Seattle highlights the vulnerability of shear walls without proper anchorage in regions of moderate seismicity. The difference is even more evident for areas with high seismicity, such as Los Angeles. In 
contrast, the benefit of seismic anchorage are less apparent in Boston and St. Louis.

The relationship between maximum drift $D$ and $S_{a}$ can be expressed as [56]:

$$
D=a\left(S_{a}\right)^{b}
$$

in which $D$ is the maximum drift (in percent of story height) from the NDA, $a$ and $b$ are constants, and $S_{a}$ is the spectral acceleration at the fundamental period of the structure with 5\% damping ratio (this damping is selected to make the seismic intensity consistent with the specification of seismic hazard by the United States Geological Survey (USGS)). The same damping ratio allows one to calculate the annual probability of collapse without adjusting the seismic hazard curve, as described in Section 2.6, The logarithmic standard deviation of $D$ for a given $S_{a}$ is around 30-60\% for similar shear walls [1].

Table 2.1: Seismic demand (drift) on wood structures

\begin{tabular}{|c|c|c|c|c|c|c|c|}
\hline \multirow[b]{2}{*}{ City } & \multirow[b]{2}{*}{$\begin{array}{l}\text { Ground } \\
\text { Motion }\end{array}$} & \multicolumn{3}{|c|}{ Conventional Construction } & \multicolumn{3}{|c|}{ Engineered Construction } \\
\hline & & Mean $(\%)$ & Median(\%) & $\mathrm{COV}$ & $\operatorname{Mean}(\%)$ & Median(\%) & $\mathrm{COV}$ \\
\hline \multirow{2}{*}{$\begin{array}{l}\text { Los } \\
\text { Angeles }\end{array}$} & ${ }^{*} \mathrm{LA} 2 / 50$ & 10.88 & 3.61 & 1.18 & 5.60 & 2.40 & 1.37 \\
\hline & ${ }^{*} \mathrm{LA} 10 / 50$ & 3.58 & 1.31 & 1.70 & 1.35 & 1.11 & 0.65 \\
\hline \multirow{2}{*}{ Seattle } & ${ }^{*} \mathrm{SE} 2 / 50$ & 6.40 & 2.35 & 1.02 & 4.52 & 2.37 & 1.11 \\
\hline & *SE10/50 & 0.93 & 0.80 & 0.54 & 0.81 & 0.78 & 0.47 \\
\hline \multirow{2}{*}{ Boston } & ${ }^{*} \mathrm{BO} 2 / 50$ & 0.59 & 0.40 & 0.92 & 0.57 & 0.39 & 0.88 \\
\hline & ${ }^{*} \mathrm{BO} 10 / 50$ & 0.19 & 0.14 & 0.67 & 0.19 & 0.14 & 0.70 \\
\hline St & ${ }^{+} \mathrm{SL} 2 / 50$ & 0.17 & 0.16 & 0.17 & 0.17 & 0.17 & 0.18 \\
\hline Louis & ${ }^{+}$SL10/50 & 0.11 & 0.11 & 0.12 & 0.11 & 0.10 & 0.10 \\
\hline
\end{tabular}

*the SAC project ground motions (discussed in Section ).

${ }^{+}$the Wen-Wu ground motions (discussed in Section ).

\subsection{Seismic collapse fragility and margin of collapse}

The seismic capacity of a structural system can be determined by incremental dynamic analysis (IDA) [57]. An IDA involves a series of NDAs of the structure subjected to an ensemble of ground motion records, each record in the ensemble being scaled to multiple 
levels of intensity with respect to the $S_{a}$ at the fundamental period of the structure. The resulting family of curves describes the structural response (measured by maximum drift) versus earthquake intensity (measured by $S_{a}$ ). The point of incipient collapse is reached when a small increment in $S_{a}$ results in a large increment in maximum drift or when the drift becomes large enough that the NDA is suspended. In the following, shear wall collapse capacities for construction in the selected cities are presented in term of drifts at incipient collapse. Figure 2.4 illustrates the results of the IDA for engineered light-frame construction in Los Angeles obtained using the 2\%/50-yr suite ground motion ensemble, while Figure 2.5 shows the 14, 50, and 86 percentiles of the IDA curves from the same ground motions. The collapse limit state is defined from the IDA as the last point where the slope of the IDA curve is larger than $20 \%$ of the initial slope [57]. Note that collapse $S_{a}$ is relatively independent of the $20 \%$ value, whereas the collapse drift value is very dependent on the assumption of $80 \%$ loss in the initial slope. The median drift at incipient collapse of the shear wall in Los Angeles is approximately 3.5\%, while the median $S_{a}$ at that point (the $S_{a}$ 'corresponding to' the drift limit of incipient collapse) is $1.8 \mathrm{~g}$. The irregularities (reversals) in the IDA curves in Figure 2.4, which occur at drifts in the excess of approximately 0.06 , have been observed by other investigators; see Section 3 of Reference [57] for an explanation.

The IDA is repeated using the LA10/50 ground motions for engineered construction in Los Angeles, as shown in Figures 2.6 and 2.7. The median drift at collapse of the shear wall is $3.8 \%$ using the LA10/50 ground motions, while the capacity was around 3.5\% utilizing the suite of LA2/50 ground motions. The difference on the collapse capacities of the shear wall shows the effect of different earthquake ensembles. The median $S_{a}$ corresponding to the median collapse capacity generated with LA10/50 is $2.5 \mathrm{~g}$. In comparison, the median $S_{a}$ is $1.8 \mathrm{~g}$ using LA2/50 ground motions, which again demonstrates the uncertainty in ground motions in the ensembles.

The assumption that the building is fully anchored to the foundation is not always valid for older residential construction in the WUS. Figures 2.8 and 2.9 present the results of an IDA for conventional light-frame wood construction in Los Angeles subjected to the LA2/50 ground motions. The median drift at incipient collapse is $2.5 \%$ for convention construction, a value that is $30 \%$ less than that of engineered construction. The median $S_{a}$ associated with collapse capacity is $1.3 \mathrm{~g}$ for conventional construction, which is around $40 \%$ less than that for engineered construction. 


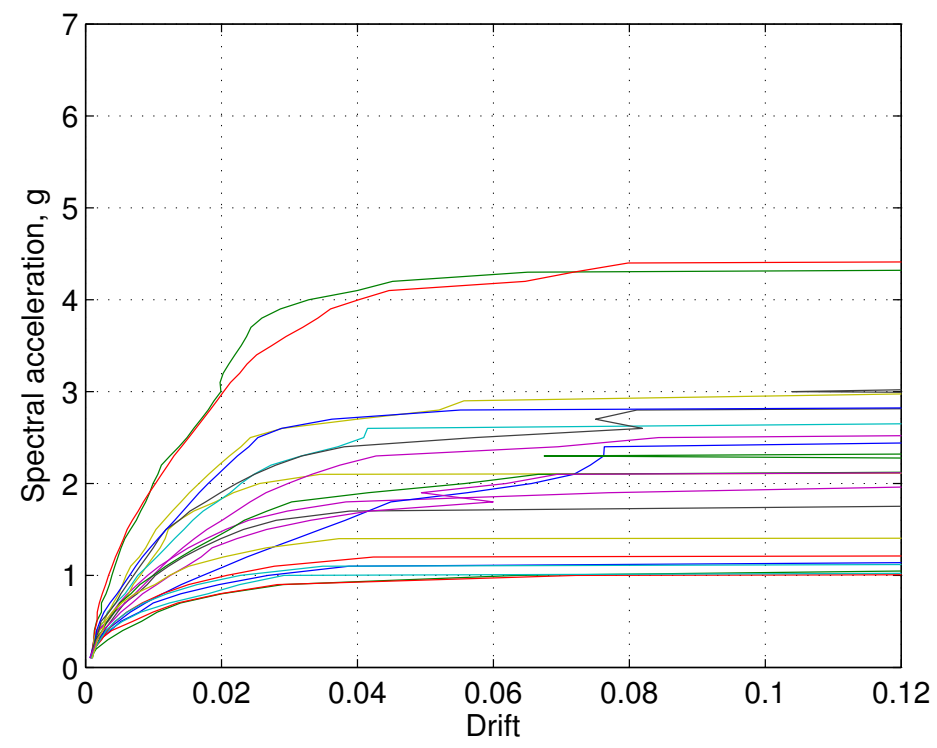

Figure 2.4: IDA curves for engineered construction in Los Angeles, CA (LA2/50 ground motions)

Similar analyses were performed for one-story residential buildings in other cities in the U.S. For example, the median collapse capacity for the shear wall in Seattle, WA using the SE2/50 ground motions is $4.1 \%$, which is close to that in Los Angeles. The median $S_{a}$ in Seattle corresponding to the collapse capacity is $2.2 \mathrm{~g}$ in comparison with $1.8 \mathrm{~g}$ in Los Angeles. Nevertheless, the MCE or design $S_{a}$ in Los Angeles (2.1 g) are higher than that in Seattle (1.6 g); the discrepancy in building collapse risk in both cities in the WUS is obvious. When IDA curves were developed for Boston, MA using the 2\%/50-yr and $10 \% / 50-\mathrm{yr}$ ensembles from the SAC project, it was found that the median capacity of the shear wall was approximately $4.3 \%$ and $4.7 \%$, respectively, for those ensembles. Finally, a total of 20 synthetic ground motions with 2\%/50-yr and 10\%/50-yr levels [52] were used to develop the IDA curves for St. Louis, MO. The median capacity of the engineered shear wall was found to be approximately $4.3 \%$, which is similar to the capacity for the same construction in Los Angeles, Seattle, and Boston. The median collapse capacities in terms of drift limits and the associated $S_{a}$ using 2\%/50-yr and 10\%/50-yr ensembles for the four cities are summarized in Table 2.2 .

The collapse fragility is the probability of incipient collapse, conditioned on $S_{a}$ at the fundamental period of the structure. The seismic fragilities for most building construction can be modeled by a lognormal distribution [58-60]. A series of tests were performed 


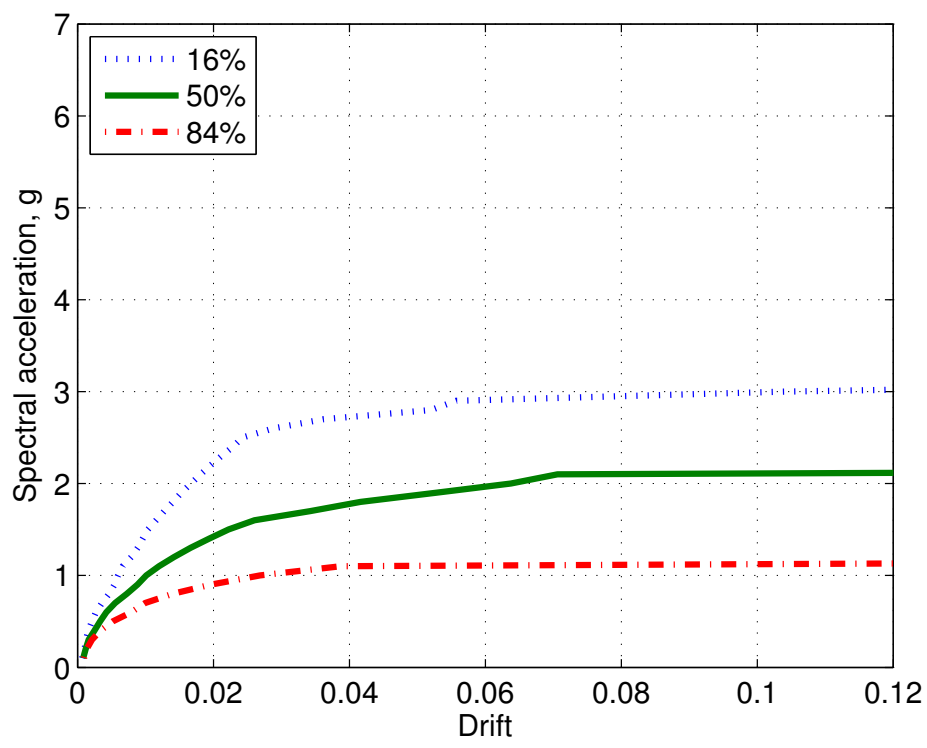

Figure 2.5: IDA percentile curves for engineered construction in Los Angeles, CA (LA2/50 ground motions)

Table 2.2: Median collapse capacity and associated $S_{a}$

\begin{tabular}{cccccc}
\hline \hline \multirow{2}{*}{ City } & \multirow{2}{*}{ Construction Type } & \multicolumn{2}{c}{$2 \% / 50-\mathrm{yr}$} & \multicolumn{2}{c}{$10 \% / 50-\mathrm{yr}$} \\
\cline { 3 - 6 } & & Capacity (Drift) & $S_{a}(\mathrm{~g})$ & Capacity (Drift) & $S_{a}(\mathrm{~g})$ \\
\hline \multirow{2}{*}{ Los Angeles } & Conventional & $2.5 \%$ & 1.3 & $2.8 \%$ & 1.9 \\
& Engineered & $3.5 \%$ & 1.8 & $3.8 \%$ & 2.5 \\
\hline \multirow{2}{*}{ Seattle } & Conventional & $2.3 \%$ & 1.5 & $2.8 \%$ & 2.0 \\
& Engineered & $4.1 \%$ & 2.2 & $4.3 \%$ & 2.8 \\
\hline \multirow{2}{*}{ Boston } & Conventional & $2.6 \%$ & 2.2 & $2.6 \%$ & 2.2 \\
& Engineered & $4.3 \%$ & 3.1 & $4.7 \%$ & 3.1 \\
\hline \multirow{2}{*}{ St. Louis } & Conventional & $3.5 \%$ & 3.2 & $3.0 \%$ & 4.3 \\
& Engineered & $4.3 \%$ & 4.3 & $4.4 \%$ & 6.1 \\
\hline \hline
\end{tabular}

to examine the hypothesis that the lognormal distribution is a suitable model for collapse fragility for light-frame wood construction. The seismic fragilities determined from a suite of IDAs first were plotted on lognormal paper, where a hypothesis test of the linearity of the plot provides support for the lognormal assumption. A subsequent series of KolmogorovSmirnov tests (at the 5\% significance level) confirmed that the lognormal CDF provides a reasonable model of collapse fragility for light-frame wood construction. The lognormal 


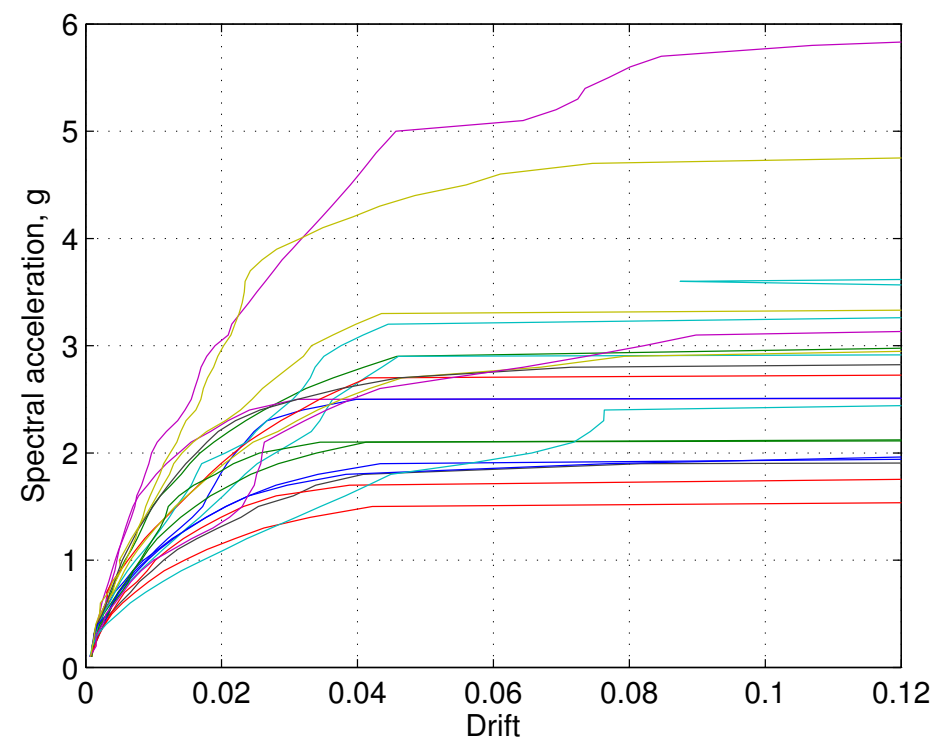

Figure 2.6: IDA curves for engineered construction in Los Angeles, CA (LA10/50 ground motions)

$\mathrm{CDF}$ is described by:

$$
F_{R}\left(S_{a}\right)=\Phi\left[\frac{\ln \left(S_{a} / m_{R}\right)}{\zeta_{R}}\right]
$$

in which $m_{R}$ is the median collapse capacity in terms of $S_{a}, \zeta_{R}$ is the logarithmic standard deviation of the capacity, and $\Phi(\cdot)$ is the standard normal probability integral. Figures 2.10 compares the collapse fragilities for the four cities for engineered and conventional construction practice. The fragility curve for engineered construction in St Louis is not shown because the probability of collapse is virtually zero even for the MCE at that location. The fragilities are obtained by rank-ordering the Sa obtained from each individual IDA (e.g. Figures 2.4 and 2.6) at the point that corresponds to incipient collapse of the shear wall. The probabilities of collapse under the MCE clearly are quite different at these sites. For example, the $\mathrm{Sa}$ at the period of $0.2 \mathrm{~s}$, defining the MCE at Los Angeles is $2.1 \mathrm{~g}$, which results in 58\% probability of collapse for engineered construction. In comparison, the probability of collapse is virtually zero when the MCE $(0.34 \mathrm{~g})$ occurs in Boston for similar construction.

The probabilities of collapse at $S_{a}$ associated with the MCE and 10\%/50-yr earthquakes are summarized in Table 2.3. The results for engineered construction in St. Louis are not presented, as the likelihood of collapse at MCE $S_{a}$ is negligible. It is evident that when 


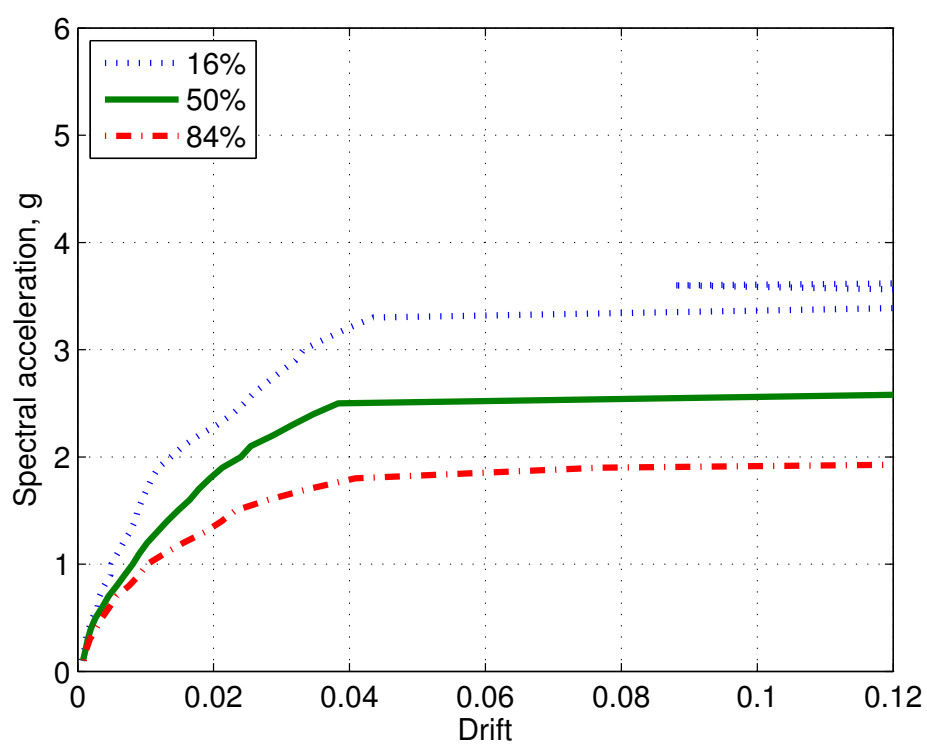

Figure 2.7: IDA percentile curves for engineered construction in Los Angeles, CA (LA10/50 ground motions)

the MCE is considered, both conventional and engineered construction in Los Angeles and Seattle will sustain substantial damage, with $22-80 \%$ probability of collapse. In Seattle, the probability of collapse for conventional construction is higher than that for engineered construction by an order of magnitude. In contrast, the probability of collapse at the MCE for the cities in the CEUS is on the order of $10^{-5}$.

The 2003 NEHRP Provisions [61] assert that when a structure experiences a level of ground motion 1.5 times the design level (i.e. if it experiences the MCE ground motion level), the structure should have a low likelihood of collapse. Based on the results of the FEMAfunded ATC-63 Project [62], this likelihood is approximately 10\%. It is apparent that this objective is not achieved in the light-frame wood construction illustrated in this study; the conditional collapse probability is higher that $10 \%$ in the WUS and much lower in the CEUS. The probabilities of collapse at 10\%/50-yr level earthquake are also shown in Table 2.3

The lognormal parameters for collapse fragility for conventional and engineered construction in selected cities are listed in Table 2.4, whereas the collapse fragility curves are summarized in Figure 2.11. The variation of lognormal collapse fragility $\zeta_{R}$ is between $35-52 \%$ for the one-story house, which is consistent with the average of 0.4 found in a study of a 


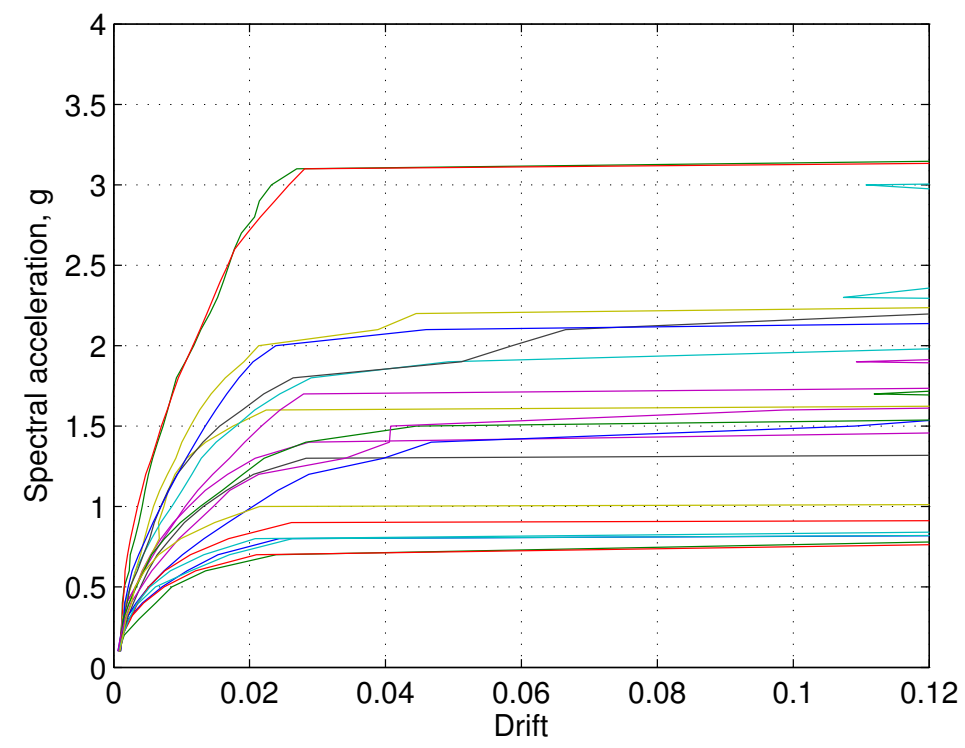

Figure 2.8: IDA curves for conventional construction in Los Angeles, CA (LA2/50 ground motions)

Table 2.3: Probability of collapse at $S_{a}$ at MCE and 10\%/50-yr earthquake

\begin{tabular}{ccclcl}
\hline \hline Location & Construction type & $S_{a}(\mathrm{MCE})$ & $\begin{array}{l}\text { Prob. of } \\
\text { collapse } \\
(\%)\end{array}$ & $S_{a}(10 \% / 50-\mathrm{yr})$ & $\begin{array}{l}\text { Prob. of } \\
\text { collapse } \\
(\%)\end{array}$ \\
\hline Los Angeles & Conventional & 2.1 & 80.0 & 1.26 & 44.0 \\
& Engineered & 2.1 & 58.0 & 1.26 & 22.0 \\
\hline \multirow{2}{*}{ Seattle } & Conventional & 1.61 & 47.0 & 0.75 & 4.0 \\
& Engineered & 1.61 & 22.0 & 0.75 & 0.6 \\
\hline Boston & Conventional & 0.34 & 0.00182 & 0.11 & 0 \\
& Engineered & 0.34 & 0.00263 & 0.11 & 0 \\
\hline St. Louis & Conventional & 0.55 & 0.00012 & 0.21 & 0 \\
\hline \hline
\end{tabular}

two-story house conducted by Christovasilis et al. [2]. In comparison, Luco [63] asserted that the variation to be between 0.4 and 0.8 for steel structures.

Table 2.5 summarizes the median collapse capacity in terms of drift determined from the IDA using the 2/50 ground motions and the median demand obtained by NDA. The ratios between median collapse capacity and the seismic demand from the MCE (seismic margin of collapse) vary significantly by construction and between cities. The margin of collapse 


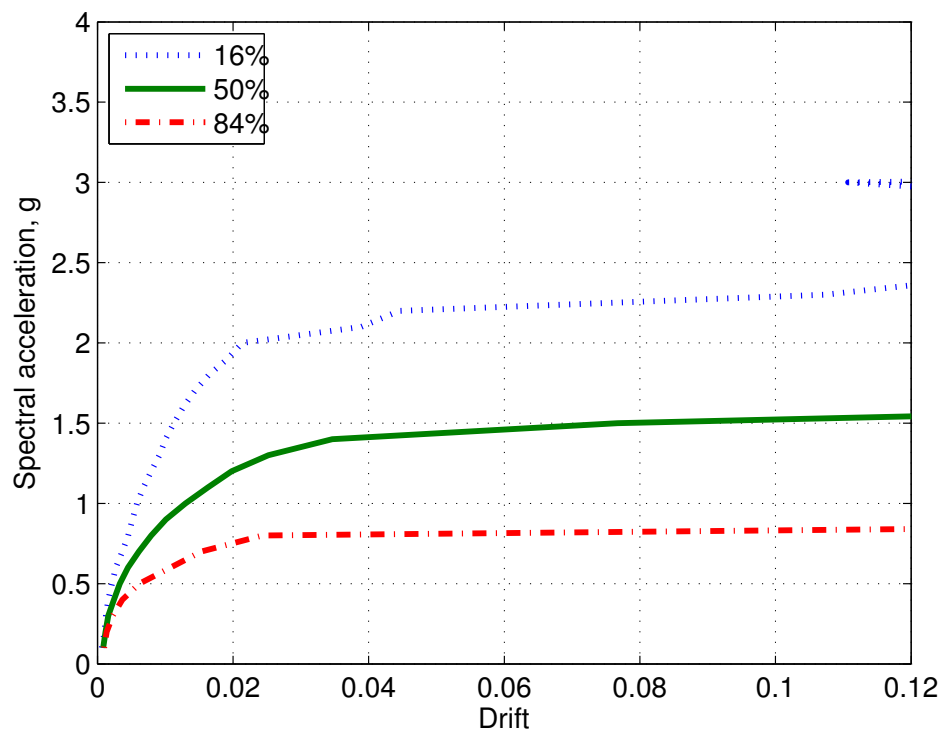

Figure 2.9: IDA percentile curves for conventional construction in Los Angeles, CA (LA2/50 ground motions)

Table 2.4: Lognormal model parameters for probability of collapse

\begin{tabular}{cccc}
\hline \hline Location & Type & $m_{R}(g)$ & $\zeta_{R}$ \\
\hline Los Angeles & Conventional & 1.36 & 0.51 \\
& Engineered & 1.89 & 0.52 \\
\hline \multirow{2}{*}{ Seattle } & Conventional & 1.66 & 0.47 \\
& Engineered & 2.24 & 0.43 \\
\hline \multirow{2}{*}{ Boston } & Conventional & 2.50 & 0.44 \\
& Engineered & 3.26 & 0.52 \\
\hline St. Louis & Conventional & 3.17 & 0.35 \\
\hline \hline
\end{tabular}

is less than 1.0 for conventional construction in Los Angeles and Seattle, implying that conventional construction in certain areas of the WUS may be vulnerable to seismic hazard. In comparison, for engineered construction, the ratio is around 1.5-1.7 in the WUS and more than 10 in the CEUS. The discrepancy in the margin of collapse in different seismic zones reflects the non-uniform risk to which the construction is exposed. In pursuit of a geographically uniform risk, the seismic hazard risk needs to be further modified and adjusted [64]. The collapse capacity of wood-frame construction is sensitive to the ground motions selected, which is a reflection of epistemic uncertainty. The interstory drift limits for incipient collapse of 3\% stipulated in FEMA 356 and ASCE 41-05 appear to be 


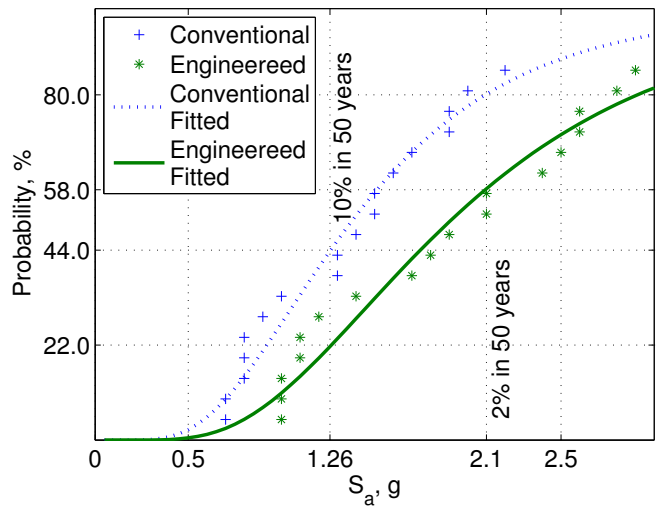

(a) Los Angeles

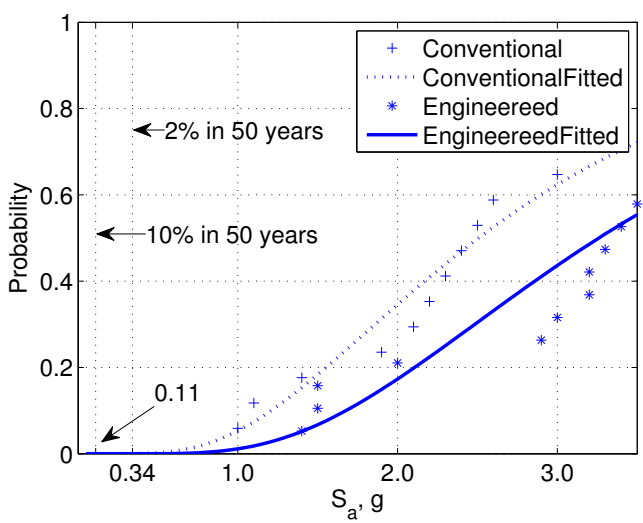

(c) Boston

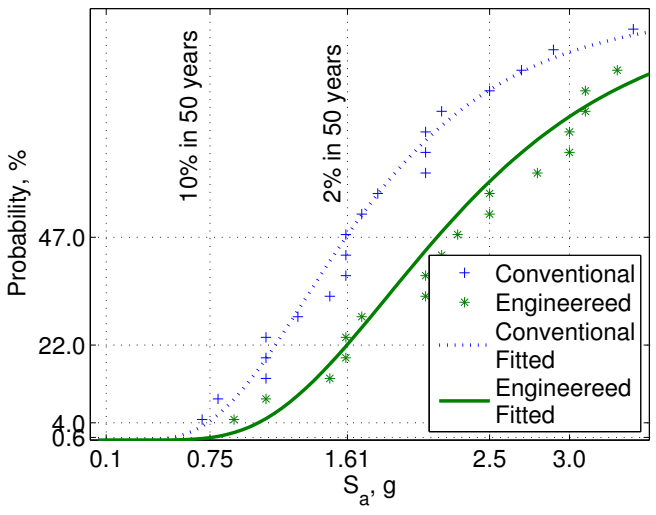

(b) Seattle

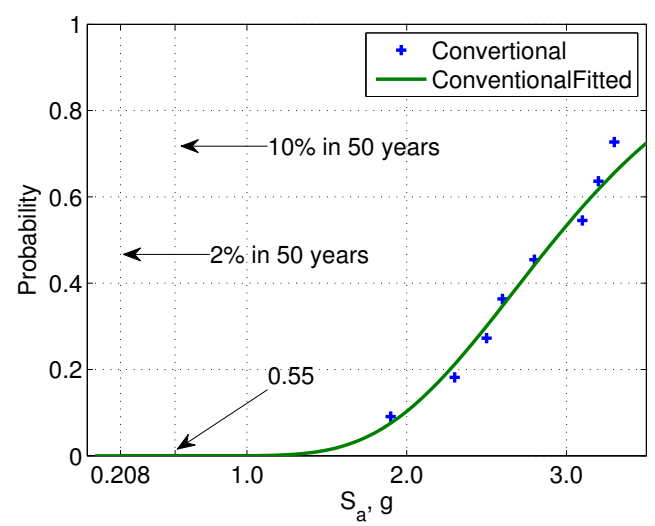

(d) St. Louis

Figure 2.10: Collapse fragility curves and probability of collapse at $S_{a}$ of $2 \% / 50-\mathrm{yr}$ and $10 \% / 50-y r$

conservative, as the current analysis indicated that engineered shear wall collapse did not occur until the drift exceeds $3.5 \%$. The recently completed full-scale experimental testing for wood-frame structures (NEESWood) and the study by Christovasilis et al. [2] also indicated shear walls would not necessarily collapse when drift exceeds $3.0 \%$. The variation in collapse capacity also contributes to the non-uniform risk. 


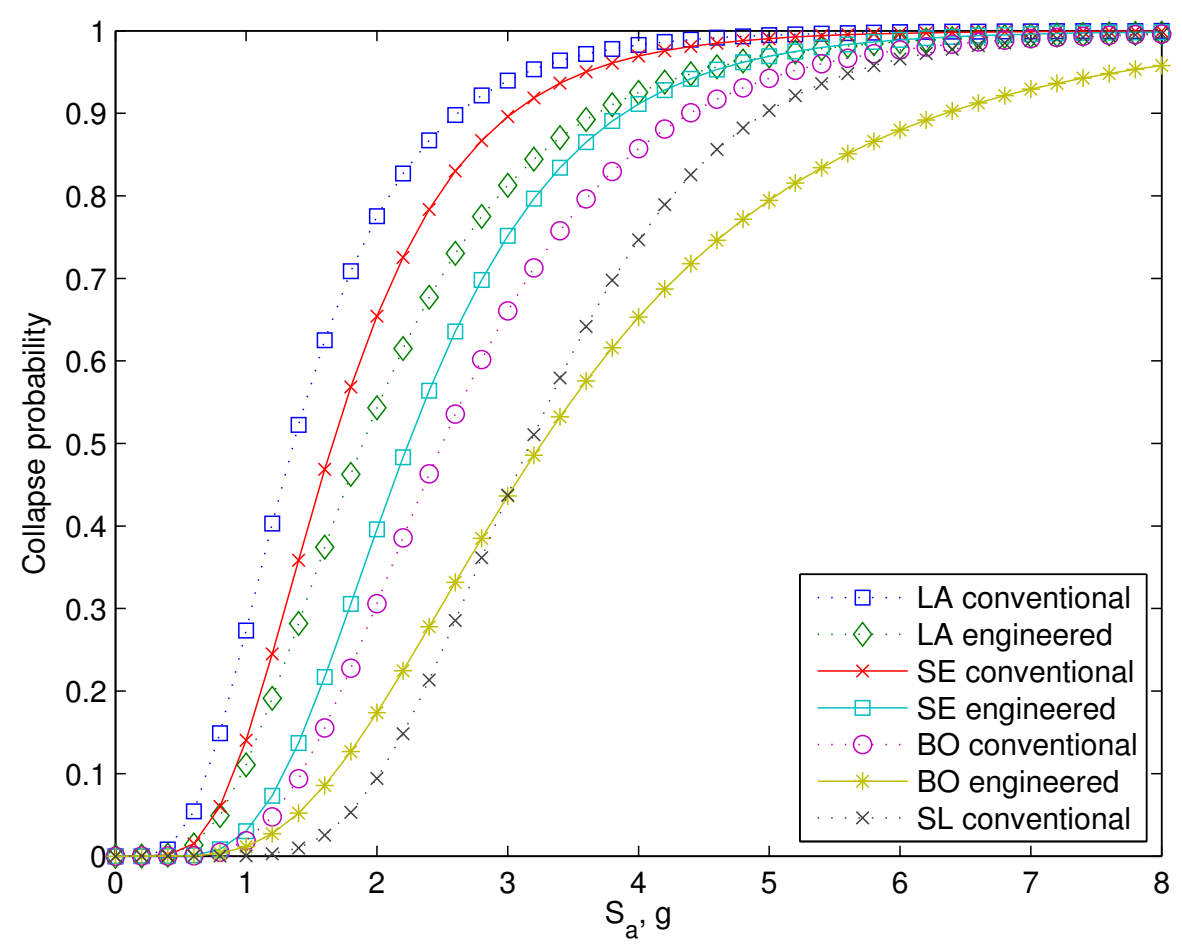

Figure 2.11: Collapse fragility curves with lognormal distribution

Table 2.5: Median capacity and demand and margin of collapse

\begin{tabular}{lllll}
\hline \hline \multirow{2}{*}{ Los Angeles } & $\begin{array}{l}\text { Construction } \\
\text { type }\end{array}$ & $\begin{array}{l}\text { Capacity } \\
(\text { Drift })(\%)\end{array}$ & $\begin{array}{l}\text { Demand } \\
(\text { Drift })(\%)\end{array}$ & $\begin{array}{l}\text { Margin } \\
\text { collapse }\end{array}$ \\
& Conventional & 2.5 & 3.61 & 0.70 \\
& Engineered & 3.5 & 2.40 & 1.46 \\
\hline \multirow{2}{*}{ Seattle } & Conventional & 2.3 & 2.35 & 0.98 \\
& Engineered & 4.1 & 2.37 & 1.71 \\
\hline \multirow{2}{*}{ Boston } & Conventional & 2.6 & 0.40 & 6.46 \\
& Engineered & 4.3 & 0.39 & 11.22 \\
\hline \multirow{2}{*}{ St. Louis } & Conventional & 3.5 & 0.16 & 21.88 \\
& Engineered & 4.3 & 0.17 & 25.48 \\
\hline \hline
\end{tabular}




\subsection{Probability of collapse considering only uncertainty from ground motions}

Seismic hazard curves determined by the USGS define the mean probability that spectral accelerations of 5\% damped oscillators (periods of $0.2,0.3$ and $1.0 \mathrm{~s}$ ) are exceeded at specific sites.

The seismic hazard $H(x)$, the probability that spectral acceleration $S_{a}$ exceeds $x$ can be approximately described over the range of significance for structural risk assessment by the Cauchy-Pareto relationship [56],

$$
H(x)=P\left[S_{a}>x\right]=k_{0} S_{a}^{-k}
$$

in which $k_{0}$ and $k$ are constants. Los Angeles, for example, $k_{0}=0.004663$ and $k=3.2$. Typical values of the constant $k$ range from 1 to 4 , the higher values being typical in the WUS, whereas the lower values are found in the CEUS. The unconditional probability of a wood-frame structure exceeding certain deformation limits or failing to meet a seismic performance objective can be obtained by convolving the fragility with the seismic hazard curve. The annual probability of collapse provides a metric for the evaluation of uniform risk, as it includes the site-specific seismic hazard. This probability is,

$$
P_{\text {collapse }}=\int P\left[\text { Collapse } \mid S_{a}=x\right]|d H(x)|
$$

which $P\left[\right.$ Collapse $\left.\mid S_{a}=x\right]$ is the collapse fragility, and $H(x)$ defines the seismic hazard. The annual probability of collapse can be estimated by the following expression [56, 64, 65]:

$$
P_{\text {collapse }}=\left(k_{0} m_{R}{ }^{-k}\right) e^{0.5\left(k \zeta_{R}\right)^{2}}
$$

The annual probabilities of collapse for the selected cities are illustrated in Figure 2.12(a), It should be noted that this estimate of collapse probability is a mean value, which does not include the epistemic uncertainties associated with the risk analysis; such uncertainties for light-frame wood construction are under investigation and the results will be reported at a later time. Nor does it include the influence of spectral shape (represented by the factor epsilon in seismic hazard analysis), the potential effect of which on collapse risk has 
recently been noted [66]. When comparing the probabilities of collapse for conventional and engineered construction, it should also be noted that the stiffness and strength for shear walls of conventional construction are assumed to be $70 \%$ of the corresponding values for engineered construction. For building code development purposes, the reference period typically is 50 years [67]. The probability of collapse in 50 years for the building at each site is shown in Figure 2.12(b). The probability of failing to meet the CP objective in 50 years for conventional light-frame construction is $250 \%$ of that for engineered construction in Los Angeles, while the difference is $90 \%$ for the two types of construction in Seattle. As a point of comparison, the annual probabilities of collapse for code-compliant steel frames in the CEUS [65] and code-conforming concrete structures [68] are typically in the order of $10^{-4}$.

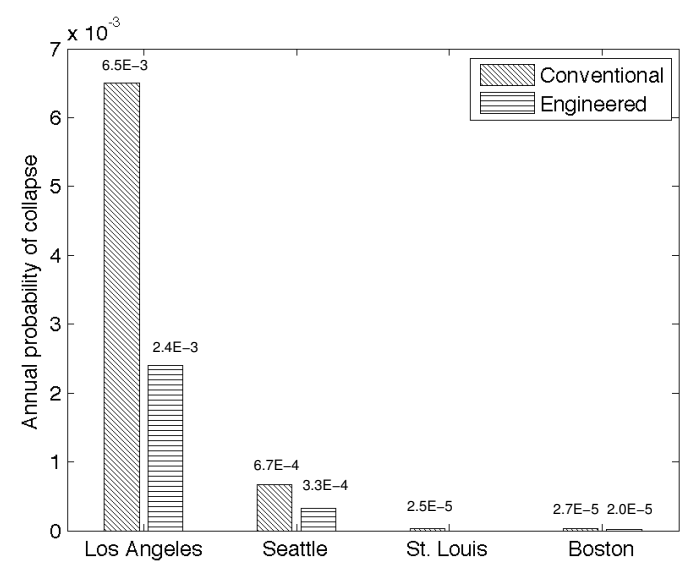

(a) Annual collapse probability

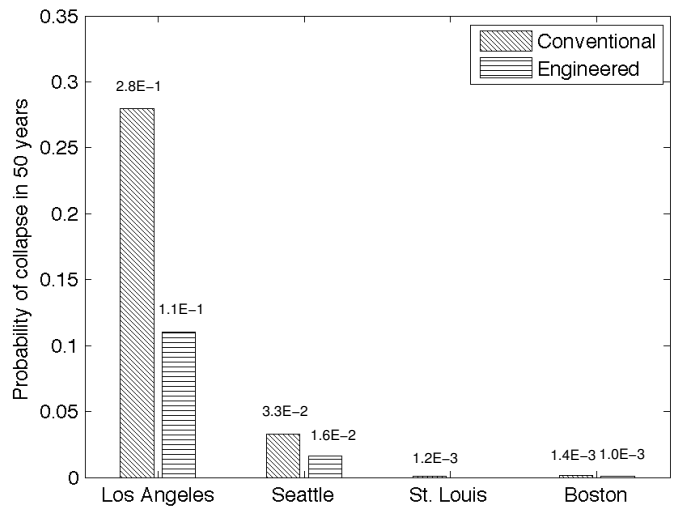

(b) 50-year collapse probability

Figure 2.12: Collapse risks of light-frame wood buildings in 4 sites

\subsection{Summary}

Collapse fragilities summarized in this chapter were obtained from a series of IDAs, and account for differences in construction practices and site-specific seismic hazard. The ground motions developed in the SAC project [51] and by Wen and $\mathrm{Wu}$ [52] were used to represent the inherent (aleatoric) uncertainty in earthquake demand. The collapse capacity of wood-frame construction was found to be sensitive to the ground motions selected for this analysis. Although research completed in the SAC project and in the more recent ATC 
63 study suggests that the general approach taken in this study is a reasonable one, the sensitivity of the risk assessment to the selection of ground motions (natural or synthetic) requires further investigation.

The probability of collapse under a spectrum of possible earthquakes was determined by convolving the collapse fragility with the seismic hazard specified by the USGS. Despite recent changes in seismic hazard mapping practices in ASCE Standard 7-05, the collapse probabilities of light-frame wood residential construction in western, eastern, and central regions of the U.S. remain geographically non-uniform, implying that current seismic design requirements in ASCE Standard 7-05 do not lead to uniform risk (where risk is measured by collapse probability). Collapse margins of typical shear walls in the WUS are significantly lower than those in the CEUS. If the goal of uniform risk for light-frame wood construction is to be achieved, the proposed performance levels in PBE and current seismic design maps may need to be modified. 


\section{Chapter 3}

\section{Seismic collapse risk of light-frame wood construction considering aleatoric and epistemic uncertainties}

\subsection{Introduction}

90\% of housing in the United States is light-frame wood construction. The damage or collapse of such construction under earthquake events has caused catastrophic losses. In the 1994 Northridge Earthquake, about \$20 billion of property losses [1, 2] and 24 out of 25 deaths were due to damage or collapse of wood construction [1]. In the 1995 Kobe earthquake in Japan collapse of residential wood buildings contributed significantly to the death and economic losses [2].

In order to evaluate the collapse risk of existing buildings or design new buildings with certain levels of margin against collapse, it is important to accurately estimate the seismic demand and structural capacity [56]. However, the inherent uncertainties in earthquake ground motions as well as structural systems make structural collapse risk evaluation a challenging task. Typically, uncertainty due to the inherent randomness is termed aleatoric uncertainty, while uncertainty due to the limitation of human knowledge is termed epistemic uncertainty. 
All sources of uncertainties need to be properly identified, modeled, and propagated in the seismic performance evaluation. A main source of demand uncertainty is due to seismic loads, which also is the largest source of uncertainty in seismic risk assessment [69]. The USGS (United States Geological Survey) seismic hazard curve represents the expected (mean) seismic hazard for a specific site. Aleatoric uncertainty in earthquake ground motion is inherent in the randomness of amplitudes, phase angle, and shape of the seismic hazard curve, while epistemic uncertainty exists in seismic models such as alternate attenuation models [65, 70]. In studies using ground motion records to perform nonlinear dynamic analysis (NDA), aleatoric uncertainties exist between ground motion records [71] and details of each ground motion [72]. In this study, uncertainties between ground motion is termed record-to-record uncertainty, while the ground motion spectral shape parameter $\varepsilon$ [66] is to be investigated for ground motions. Both record-to-record uncertainty and $\varepsilon$ will be discussed in Section 3.3. Considering the capacity part, aleatoric uncertainty exists in the damping, stiffness, mass, and energy dissipation characteristics of the structure, while epistemic uncertainty occurs in the ability of the numerical model to represent the actual structure as well as how well the drawings describe the real structure [41]. In this study, the aleatoric uncertainty in structure capacity is termed resistance uncertainty and will be discussed in Section 3.4. Epistemic uncertainty will be discussed in Section 3.5.

Studies (e.g. [72, 73]) indicate that uncertainties in the structural system has limited effect on structural seismic performance. However, those studies focused mainly on limit states other than collapse, which includes minor or moderate damage. Recent studies [53, 65, 69, 74] indicate that uncertainties associated with structure capacity (stiffness, strength, energy dissipation, etc.) have significant influence on structural collapse performance of steel and reinforced concrete structures. However, it is unclear whether the uncertainty in resistance has a significant impact on the collapse risk of light-frame wood construction, which is examined in this chapter. Some sources of uncertainties were investigated for seismic performance of wood construction. For example, Li and Ellingwood [1] studied wood shear wall fragilities against three limit states considering uncertainty from earthquake ground motion. Christovasilis et al. [2] quantified the seismic collapse fragilities of two-story and three-story wood buildings using Increment Dynamic Analysis (IDA) [57], where capacity variants were considered only by examining three levels: poor, typical and superior. Li et al. [42] investigated the collapse probabilities of a one-story wood building conditioned on the maximum considered earthquake (MCE, i.e. earthquake with a 2475-year return period) and design earthquakes stipulated in ASCE 7-05 [75]. 
While considering the uncertainty from earthquake ground motions, these studies have not systematically investigated the effect of aleatoric and epistemic uncertainties for the collapse risk of wood construction.

Epsilon $(\varepsilon)$ was investigated by Baker and Cornell [66] to measure the ground motion intensity and indicate spectral shape of the ground motion. Recent studies $([68,76])$ on concrete and steel structures found that structural collapse capacity determined using ground motion records with larger $\varepsilon$ tends to be higher than that determined using smaller $\varepsilon$ ground motion records. The ATC-63 project[62] determined the collapse capacity (defined as a peak inter-story drift of 7\%) and the collapse margin ratio for two archetypes (one for residential buildings and the other for office, retail, warehouse buildings). However, the $\varepsilon$ effect on structures with a fundamental period less than 0.5 second, which is typical for light-frame wood buildings, has not been investigated [69].

In this study, both aleatoric and epistemic uncertainties from demand and capacity are propagated into seismic collapse risk assessment of light-frame wood construction. A typical residence is assumed to be located at four sites in the United States. Los Angeles, CA, Seattle, WA, and Boston, MA represent high, moderate and low seismicity areas, respectively. St Louis, MO represents sites in the Central and Eastern United States (CEUS) where typically is referred to as low-to-moderate seismicity region [77]. The results obtained herein will provide insights into light-frame wood building collapse risk assessment considering aleatoric and epistemic uncertainties, and provide risk-informed tools for decision making including structural rehabilitation, retrofit or repair plans.

\subsection{Structural model}

The collapse risk evaluation is performed on a typical one-story residential house in the United States with wood shear walls as its main lateral force-resisting system. The configuration of the building is shown in Figure 3.1, where details of openings for the south

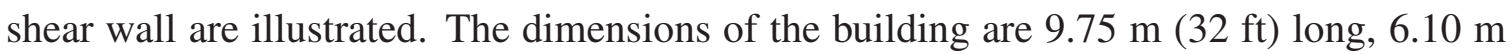
$(20 \mathrm{ft})$ wide and $2.44 \mathrm{~m}(8 \mathrm{ft})$ high. The shear walls are covered by $1.22 \times 2.44 \mathrm{~m}(4 \times 8 \mathrm{ft})$ sheathing panels, which might be modified, as appropriate, to allow for door and window openings. Studs are spaced at $610 \mathrm{~mm}$ (24 in) on centers. For the building located in Los 
Angeles, the sheathing of the shear walls is provided by $11.1 \mathrm{~mm}(7 / 16 \mathrm{in})$ oriented strand board (OSB) panels. For the other three sites, $9.5 \mathrm{~mm} \mathrm{(3/8} \mathrm{in)} \mathrm{OSB} \mathrm{panels} \mathrm{are} \mathrm{used.} \mathrm{The}$ sheathing is connected to the studs with $8 \mathrm{~d}$ common nails, which are $3.33 \mathrm{~mm}(0.131 \mathrm{in})$ in diameter. For the building located in Los Angeles (building A), 3/6 nailing schedule is used, which indicates that nails are spaced $76.2 \mathrm{~mm}$ (3 in) along the sheathing panel perimeter and $152.4 \mathrm{~mm}$ ( $6 \mathrm{in}$ ) in the panel interior. For the building in other three sites (building B), 6/12 nailing schedule is used. The fundamental period of the building $\mathrm{A}$ is 0.20 second, while it is 0.25 second for the building B.

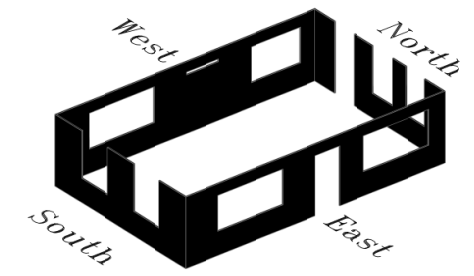

(a) 3-D model for the light-frame wood building (roof is not illustrated)

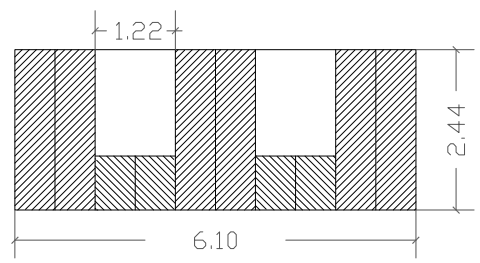

(b) South shear wall (unit: meter)

Figure 3.1: Schematic of one-story wood frame residence

The building has a gable roof but is not shown Figure 3.1(a), The roof is assumed to be rigid. The response of a wood-frame construction subjected to seismic load is highly nonlinear and shows pinched hysteretic behavior with strength and stiffness deterioration.

Figure 3.2 shows the load-displacement response of a typical wood-frame shear wall subjected to a ground motion record. The backbone curve (i.e. the envelope of the hysteresis curves) is defined by:

$$
F= \begin{cases}\operatorname{sgn}(\delta)\left(F_{0}+r_{1} K_{0}|\delta|\right)\left(1-e^{-K_{0}|\delta| / F_{0}}\right) & \text { if }|\delta| \leq\left|D_{u}\right| \\ \operatorname{sgn}(\delta) F_{u}+r_{2} K_{0}\left[\delta-\operatorname{sgn}(\delta) D_{u}\right] & \text { if }\left|D_{u}\right|<|\delta| \leq\left|D_{F}\right| \\ 0 & \text { if }|\delta|>\left|D_{F}\right|\end{cases}
$$

where $K_{0}$ is the initial stiffness, $D_{u}$ and $F_{u}$ correspond to the shear wall ultimate capacity, after which the load bearing capacity decreases with a slope of $r_{2}$. The hysteresis curves in Figure 3.2 are obtained using the model developed by Folz and Filiatrault [78], in which five more parameters $r_{3}, r_{4}, F_{1}, \alpha$, and $\beta$ were included. $r_{3}$ is the unloading stiffness 
from the backbone curve. $r_{4}$ is the pinching line slope. $F_{1}$ indicates the point where the pinched hysteresis curves pass through. $\alpha$ and $\beta$ are two parameters considering stiffness and strength degradation. Details about these parameters are provided in Folz and Filiatrault [78]. Using this hysteresis model, Folz and Filiatrault [79] developed the SAWS program to perform NDA for light-frame wood construction. In this study, the hysteresis parameters of the four shear walls in the building are determined using the CASHEW program [45, 78]. The CUREE-Caltech loading protocol [80] is used in the CASHEW program to determine the hysteresis parameters. By comparing the CUREE-Caltech loading protocol with other protocols, Gatto and Uang [81] concluded that the CUREE-Caltech loading protocol is appropriate for light-frame wood buildings. The dynamic response of the one-story light-frame wood building shown in Figure 3.1 is obtained using the SAWS program.

Two to four-story light-frame wood buildings are more susceptible to collapse risk, particularly those with garages and large openings, than one-story buildings. The one-story building examined herein is to demonstrate the relative contribution of various uncertainties to the overall collapse risk. Nevertheless, the numerical model can also be used to model wood building of more than one story. This is beyond the scope of the current study.

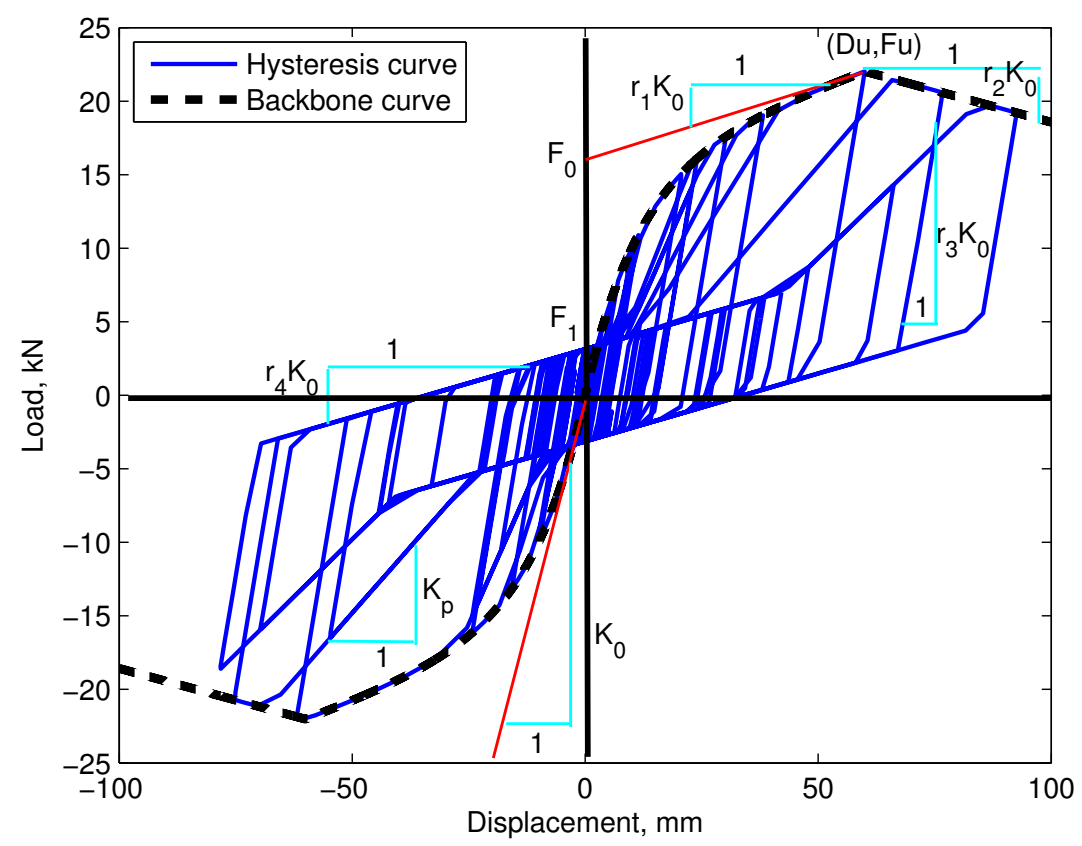

Figure 3.2: Hysteresis model of light-frame wood shear wall 


\subsection{Collapse risk with uncertainty in ground motion records}

\subsubsection{Record-to-record uncertainty}

One of the major challenges associated with performance-based seismic engineering [82] is the identification, characterization and appropriate treatment of the uncertainties in the ground motion prediction [70]. Earthquake events are typically predicted using attenuation equations (e.g. the one proposed by Abrahamson and Silva [83]), which consider the earthquake magnitude distribution, epicenter distance, soil type, rupture type, and other factors. In order to properly incorporate the inherent uncertainty of earthquake events in the structural collapse fragility evaluation, IDA has been found to be an effective tool [69, 71]. A set of appropriately selected ground motion records (e.g. suites of ground motions developed by the SAC project [51]) are used in IDA and the record-to-record variability is implicitly accounted for.

To perform an IDA, a ground motion record is scaled to multiple levels of intensity with respect to the $S_{a}$ at the fundamental period of the structure. NDA is then performed on the structure using each scaled ground motion record. IDA provides a family of IDA curves describing the relation between intensity measurement (IM, $S_{a}$ hereby) and engineering demand parameter (EDP, maximum incipient drift hereby). The point of incipient collapse is reached when a small increment in IM results in a large increment in EDP or the drift becomes so large (over 7\% [2] for wood structure) that the NDA fails to converge.

Analysis shows that the drift of the south and north shear walls are larger than those of the west and east shear walls. Ground motions are only applied along the east-west direction to estimate the building's collapse risk. For a given ground motion, the observed (based on dynamic analysis results) incipient drifts are very close for south and north shear walls. In the following sections, all the collapse capacity/fragilities are determined using the drift for the south shear wall. Figure 3.3(a) shows 20 IDA curves for drifts obtained for building A subjected to a suite of 20 ground motions, which were developed in the SAC project [51] and has a $2 \%$ exceedance probability in 50 years for Los Angeles. This suite of ground motions will be referred to as LA2/50. Similarly, SE2/50, BO2/50, and SL2/50 indicate ground motions with $2 \%$ exceedance probability in 50 years for Seattle, Boston, and St Louis, respectively. Note that the SAC ground motions [51] are used in the calculation for 
three sites: Los Angeles, Seattle, and Boston, while Wen-Wu ground motion [52] is used for St Louis.

The collapse fragility can be defined by a lognormal distribution [1] as shown by its cumulative distribution function $(\mathrm{CDF})$ :

$$
F_{R}\left(S_{a}\right)=\Phi\left[\frac{\ln S_{a}-\ln \bar{S}_{a, c c}}{\sigma_{\ln S_{a, c c}}}\right]
$$

in which the median collapse capacity $\bar{S}_{a, c c}$ and the standard deviation of logarithmic collapse capacity $\sigma_{l n S_{a, c c}}$ (also called dispersion of collapse capacity due to record-to-record uncertainty $\beta_{r 2 r}$ ) can be determined by regression analysis of a set of $S_{a, c c}$ determined by IDA. For Los Angeles, 20 collapse capacities $S_{a, c c}$ were determined from Figure 3.3(a), It is found that the lognormal distribution is an appropriate model for the collapse capacity, $S_{a, c c}$, of the light-frame wood building using Kolmogorov-Smirnov test at 5\% significance level. Figure 3.3(b) shows the collapse fragility obtained for the south shear wall of the residence in Los Angeles. The dispersion of the collapse capacity is found to be 0.39 , which indicates the effect of the record-to-record uncertainty of the LA2/50 ground motions.

\subsubsection{Effects of spectra shape of ground motion records on collapse capacity}

Other than the typical IM such as $S_{a}$ discussed in Section 3.3.1, recent studies have investigated which properties of a ground motion are most strongly related to the structural response. Baker and Cornell [66] found that the epsilon parameter $(\varepsilon)$ is an important parameter for measuring the intensity of a ground motion. Epsilon indicates the spectral shape of a ground motion and is a key characteristic of ground motions affecting collapse risk assessment [76]. Recent studies [68, 76, 84, 85] have found that selecting ground motions with peaked spectral shapes increases the predicted structural collapse capacity. However, these studies focused on steel or concrete structures with fundamental period around 1.0 second. The $\varepsilon$ effect on light-frame wood residences, typically with period between 0.2 and 0.5 seconds, has never been investigated. 


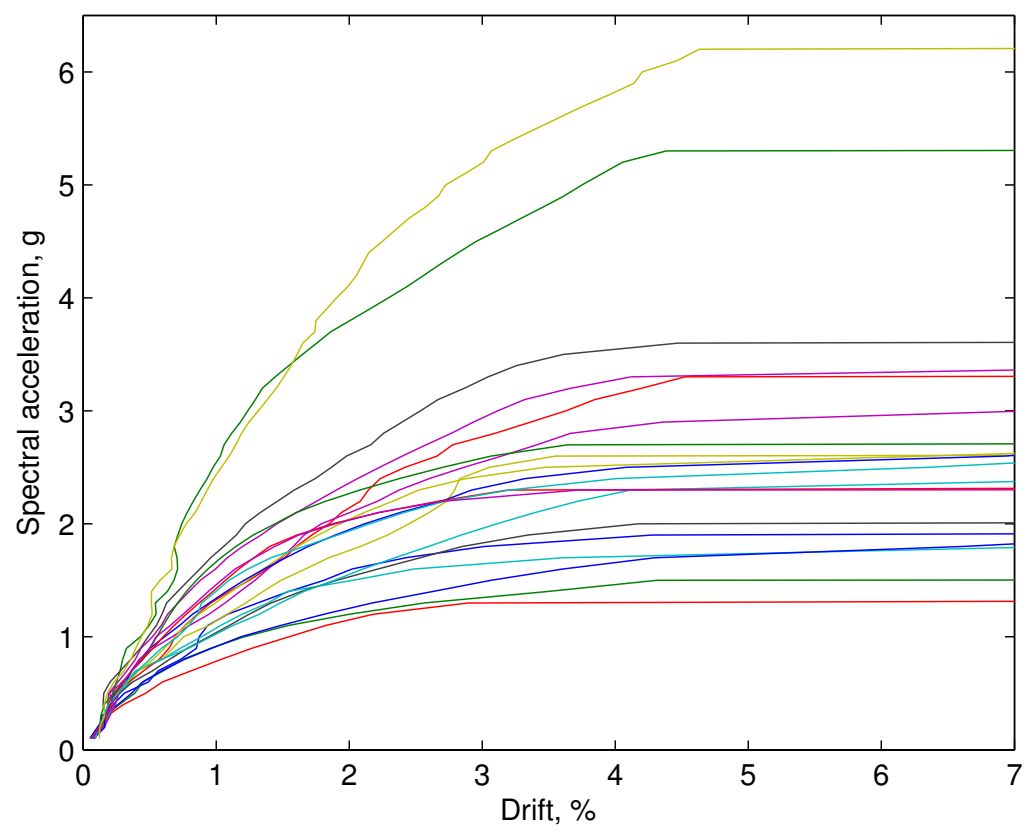

(a) IDA drift curves

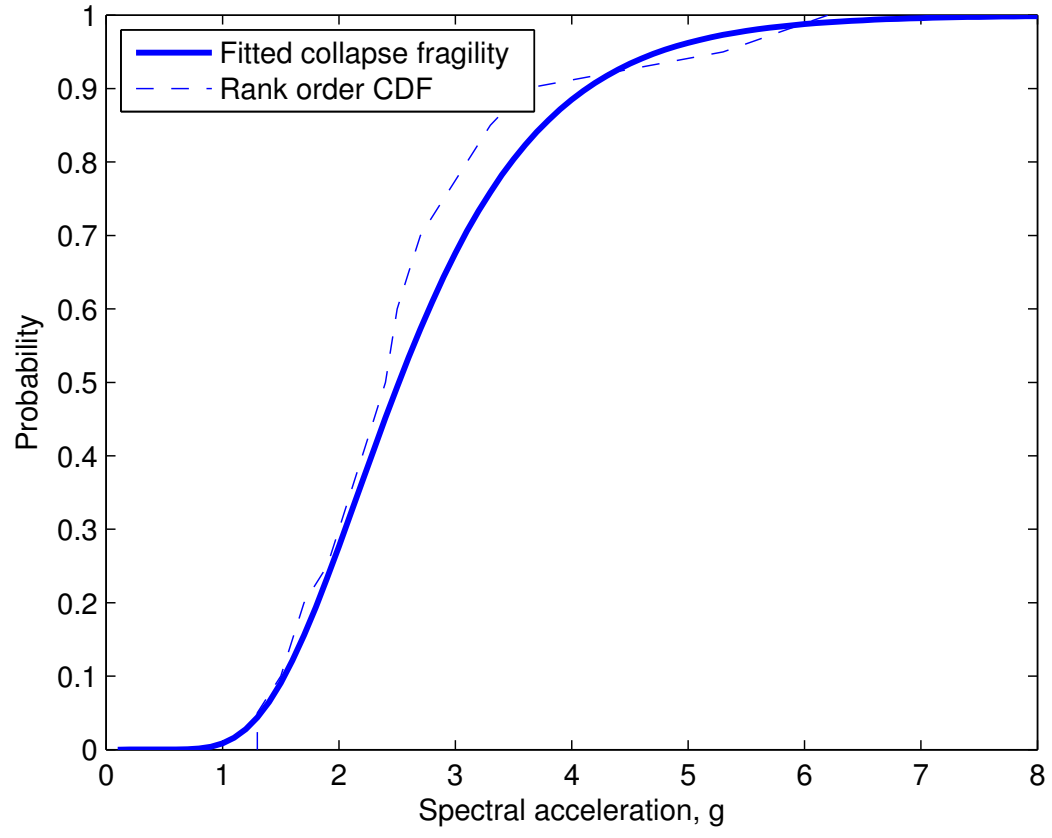

(b) Fragility curves (without considering $\varepsilon$ )

Figure 3.3: IDA and fragility curves of the building A subjected to Los Angeles 2/50 ground motions 
For a given ground motion with a spectral acceleration $S_{a}(T)$ at period $T$, the corresponding epsilon can be calculated by:

$$
\varepsilon(T)=\frac{\ln \left(S_{a}(T)\right)-E\left[\ln \widehat{S_{a}}(T)\right]}{S t d\left[\ln \widehat{S_{a}}(T)\right]}
$$

where $E\left[\ln \widehat{S_{a}}(T)\right]$ and $S t d\left[\ln \widehat{S_{a}}(T)\right]$ are the mean and standard deviation of logarithmic spectral acceleration, $\ln \widehat{S_{a}}(T)$, predicted by an attenuation equation. For a given ground motion record, $\varepsilon$ is a function of period and attenuation equations [66]. The attenuation equation proposed by Abrahamson and Silva [83] is used in this study. Using a different attenuation model for calculating $\varepsilon$ might only lead to a slightly different value [76].

Figure 3.4(a) shows the acceleration spectra of a ground motion record with a positive $\varepsilon$ at period $T=1.0$ second. The $\varepsilon$ value of a ground motion record at a period $T$ indicates the distance between its spectra and the expected spectra predicted by attenuation models. For example, in this case, $\varepsilon(1.0)>0$ indicates that this ground motion record has a larger spectral acceleration than the expected spectral acceleration. Such a ground motion record is termed 'Peak' record [66]. It has been found that the spectra of one ground motion record with a positive $\varepsilon$ value at a period tends to be peak shaped around that period [76].

A set of randomly selected ground motions will have an average $\varepsilon$ value around zero and a unit standard deviation [66]. However, this does not hold for suites of ground motions such as LA2/50, which are intentionally selected so that they represent a certain seismicity level for a given site (e.g., 2\% exceedance probability in 50 years for Los Angeles). Using Eq. (3.3), the $\varepsilon$ values for the LA2/50 ground motions are determined and listed in Table 3.1. The mean $\varepsilon$ value at $0.20 \mathrm{sec}$ (i.e., the fundamental period of building A in Los Angeles) of LA2/50 is 0.38 instead of zero for the reason descussed above. Figure 3.4(b) shows the spectra of LA2/50 ground motions, in which the expected spectra is determined by the attenuation model by Abrahamson and Silva [83]. Subsets 1 and 2 in Figure 3.4(b) are selected in order to compare collapse fragilities determined from ground motions with different $\varepsilon$. Subset one consists of LA40, LA24, LA39, and LA38 and has an $\varepsilon$ range of $-1.71 \sim-1.15$. Subset two includes LA28, LA30, LA34, and LA25 and has an $\varepsilon$ range of $1.06 \sim 1.39$. For each subset, collapse fragility can be obtained using the method discussed in Section 3.3.1. Collapse fragilities determined using subsets one and two are shown in Figure 3.5. The median collapse capacity obtained using subset two is $2.94 \mathrm{~g}, 16 \%$ larger than $2.52 \mathrm{~g}$ determined without considering $\varepsilon$. The median collapse capacity obtained us- 


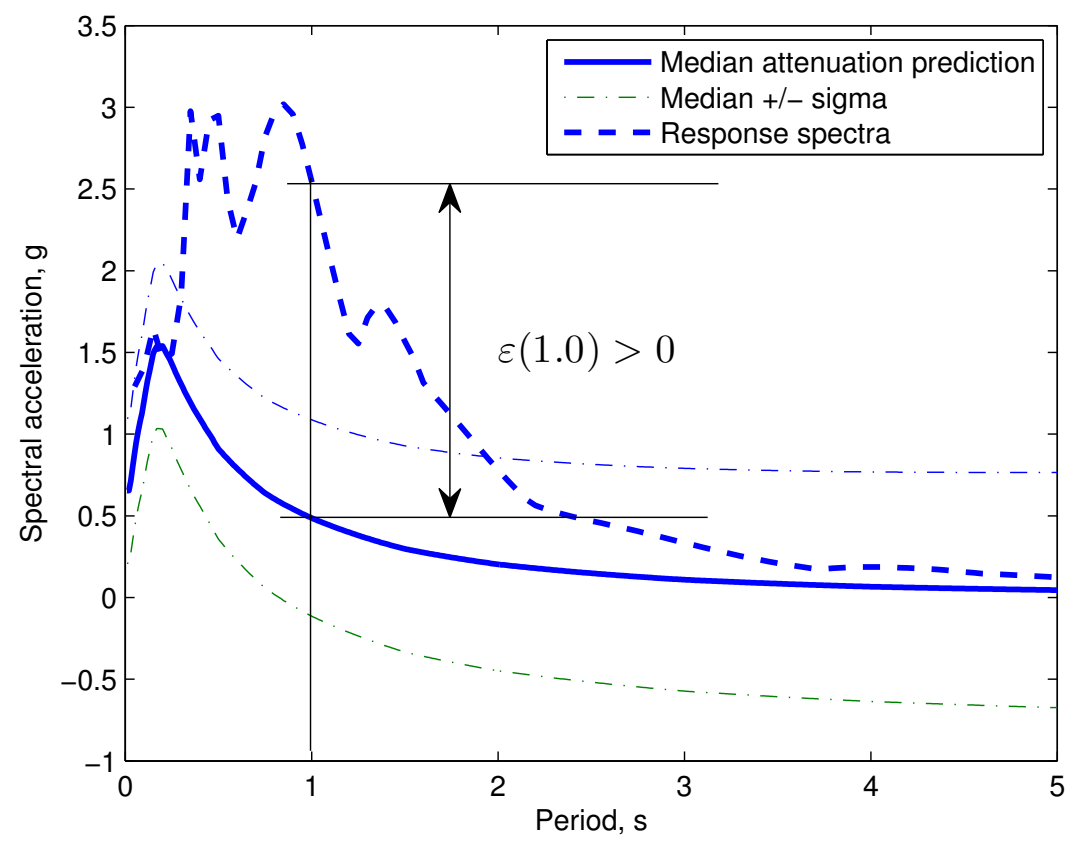

(a)

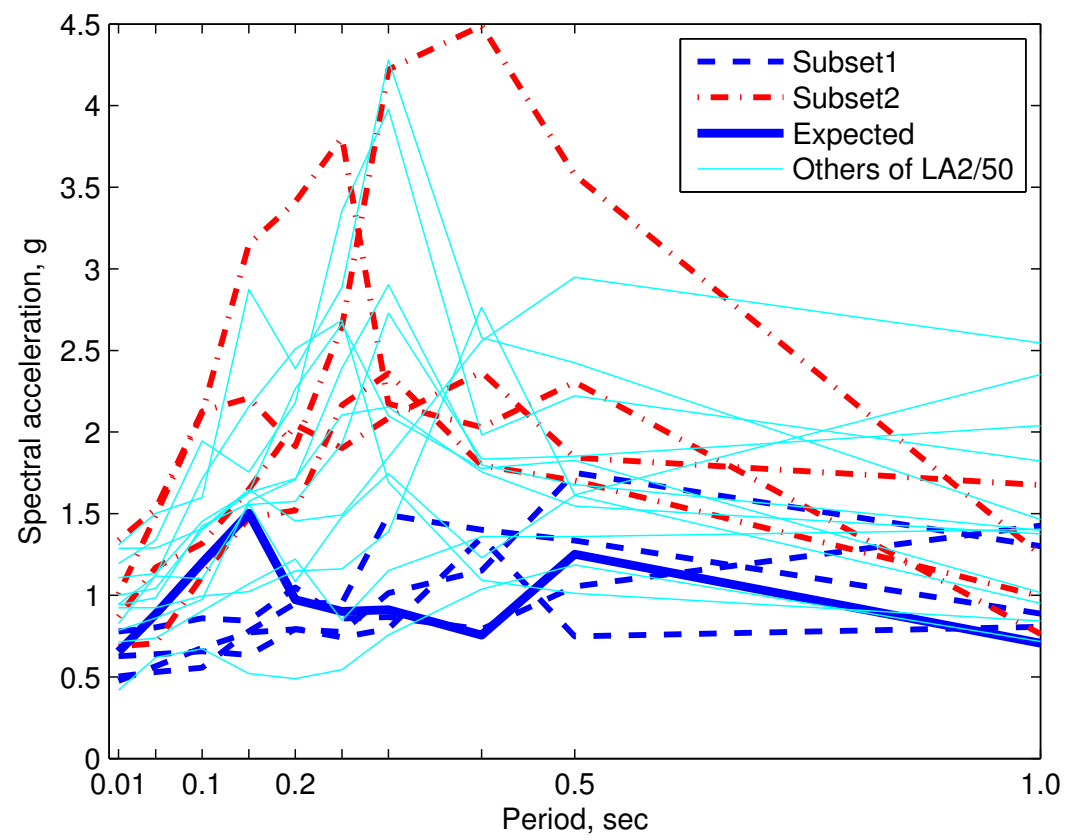

(b)

Figure 3.4: (a) Acceleration spectra of a ground motion with a positive $\varepsilon$; (b) Spectra of LA2/50 ground motions and expected spectra 
ing subset one is $2.15 \mathrm{~g}, 14 \%$ smaller than $2.52 \mathrm{~g}$. From the comparison, it can be observed that larger $\varepsilon$ leads to a larger collapse capacity prediction (i.e., lower probability of collapse) while smaller $\varepsilon$ leads to smaller collapse capacity prediction (i.e., higher probability of collapse). This is consistent with what has been found in studies [66, 68, 76, 84, 85] on steel and reinforced concrete structures. Note that only three ground motions are used in each subset. Accurate quantification of the effect of $\varepsilon$ on structural collapse capacity requires more ground motions with specific $\varepsilon$ at the fundamental period of the building of interest. In Figure 3.5, there is one fragility curve that is adjusted with a target $\varepsilon$ value of 2. The target $\varepsilon$ is discussed in Section 3.3.3 in which the collapse fragility adjustment technique introduced.

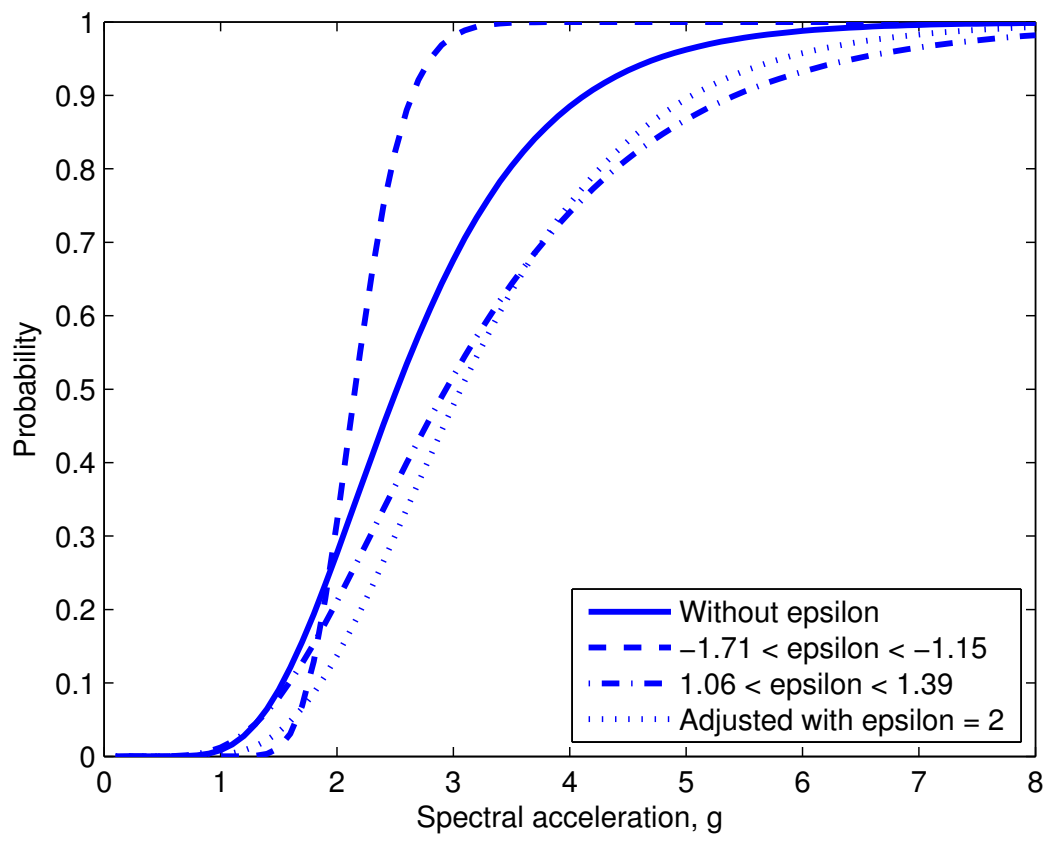

Figure 3.5: Collapse capacity of building A subjected to LA2/50 ground motions (target $\varepsilon=2$ )

The $\varepsilon$ values (listed in Table 3.1) for LA2/50 ground motions have a median value of 0.69 (at the period of $0.2 \mathrm{sec}$ ), while the median value is 1.38 if $\varepsilon$ is calculated at period of 0.25 sec. The reason of the difference is that $\varepsilon$ is a function of period [66]. There is quite a dispersion of $\varepsilon$ among the ground motions. The reason for the dispersion may be due to the fact that the SAC ground motions [51] were developed by matching the uniform hazard spectra for each site only in terms of $S_{a}$, without considering the spectra shape of each selected ground motion. 
Table 3.1: Epsilon $(\varepsilon)$ values of LA2/50 ground motions (at the period of $0.20 \mathrm{sec}$ )

\begin{tabular}{ll|ll|ll|ll}
\hline \hline $\begin{array}{l}\text { ground } \\
\text { motion }\end{array}$ & $\varepsilon$ & $\begin{array}{l}\text { ground } \\
\text { motion }\end{array}$ & $\varepsilon$ & $\begin{array}{l}\text { ground } \\
\text { motion }\end{array}$ & $\varepsilon$ & $\begin{array}{l}\text { ground } \\
\text { motion }\end{array}$ & $\varepsilon$ \\
\hline LA23 & -2.33 & LA37 & $-8.36 \mathrm{e}-1$ & LA26 & $8.99 \mathrm{e}-1$ & LA33 & 1.45 \\
LA40 & -1.71 & LA22 & $-5.77 \mathrm{e}-1$ & LA28 & $1.06^{2}$ & LA36 & 1.54 \\
LA24 & -1.36 & LA21 & $-1.12 \mathrm{e}-1$ & LA30 & $1.10^{2}$ & LA35 & 2.10 \\
LA39 & -1.34 & LA27 & $-1.44 \mathrm{e}-3$ & LA34 & $1.22^{2}$ & LA32 & 2.81 \\
\multicolumn{1}{l}{ LA38 ${ }^{1}$} & -1.15 & LA29 & $4.86 \mathrm{e}-1$ & LA25 & $1.39^{2}$ & LA31 & 3.00 \\
\hline \multicolumn{1}{l}{${ }^{1}$ subset one; ${ }^{2}$ subset two } \\
\hline
\end{tabular}

\subsubsection{Collapse capacity with adjustment for epsilon}

In Section 3.3.2, it was found that $\varepsilon$ has a significant effect on the collapse capacity evaluation of light-frame wood construction. It is necessary to properly account for the $+\varepsilon$ effect when evaluating structural collapse risk. One approach is to select a set of ground motion records with a specific $\varepsilon$ value at a specified period (e.g. the fundamental period), and then apply IDA methods to determine $S_{a, c c}$. However, this approach is not feasible for practical use because it might be difficult to obtain enough ground motion records with given target $\varepsilon$ values at specific periods [86]. An alternative approach was proposed by Haselton et al. [86], which uses a general set of ground motions without considering $\varepsilon$ and then adjusts the results distribution to account for $\varepsilon$ in the analysis of collapse risk.

In the beginning of the second approach, one needs to select a general set of ground motions without considering $\varepsilon$ and determine the $\varepsilon$ value and collapse capacity $S_{a, c c}$ for each ground motion record. Then regression analysis between $S_{a, c c}$ and $\varepsilon$ is performed according to:

$$
\ln S_{a, c c}=c_{1} \varepsilon+c_{0}
$$

where $c_{1}$ and $c_{0}$ are parameters determined by regression analysis. Figure 3.6 shows the regression results for LA2/50 ground motions. Coefficients $c_{0}$ and $c_{1}$ in Eq. (3.4) is found to be 0.88 and 0.12 respectively. The coefficient of determination, $R^{2}$, is found to be 0.24 . In this study, $c_{1}$ and $c_{0}$ will be taken as deterministic values for a specific site. Note the $\varepsilon$ of LA2/50 is calculated at the period of $0.20 \mathrm{sec}$ (i.e., the fundamental period of build- 
ing A. $\varepsilon$ for the other three sites should be calculated at the period of $0.25 \mathrm{sec}$ (i.e., the fundamental period of building B. Let $\left\{S_{a, c c}\right\}$ denote the observed collapse capacity vector for the building and $\left\{S_{a, c c}^{\prime}\right\}$ denote the calculated vector by Eq. (3.4) using the $\varepsilon$ values listed in Table 3.1. A residual vector is obtained by $\left\{S_{a, c c}\right\}-\left\{S_{a, c c}^{\prime}\right\}$ and will be used for collapse fragility adjustment discussed later in this section. The last step is to adjust the collapse fragility using the regression results. Assuming that the collapse capacity, $S_{a, c c}$, is lognormally distributed, the expected natural logarithm of the collapse capacity, $\widehat{\mu}_{\ln \left(S_{a, c c}\right)}$, can be obtained as:

$$
\widehat{\mu}_{l n\left(S_{a, c c}\right)}=c_{0}+c_{1} \varepsilon_{\text {target }}
$$

where $c_{0}$ and $c_{1}$ are the parameters shown in Eq. (3.4), while $\varepsilon_{\text {target }}$ is the target $\varepsilon$ of interest. The standard deviation of the natural logarithm of the collapse capacity, $\widehat{\sigma}_{\ln \left(S_{a, c c)}\right.}$, can be determined as:

$$
\widehat{\sigma}_{\ln \left(S_{a, c c}\right)}=\sqrt{\sigma_{\ln \left(\left(S_{a, c c}\right), r e g\right)}^{2}+c_{1}^{2} \sigma_{\varepsilon}^{2}}
$$

where $c_{1}$ is the regressed coefficient in Eq. (3.4), $\sigma_{\varepsilon}$ is the standard deviation of $\varepsilon$, and $\sigma_{\ln \left(\left(S_{a, c c}\right), r e g\right)}$ is the standard deviation of the regression residual of $\ln \left(S_{a, c c}\right)$.

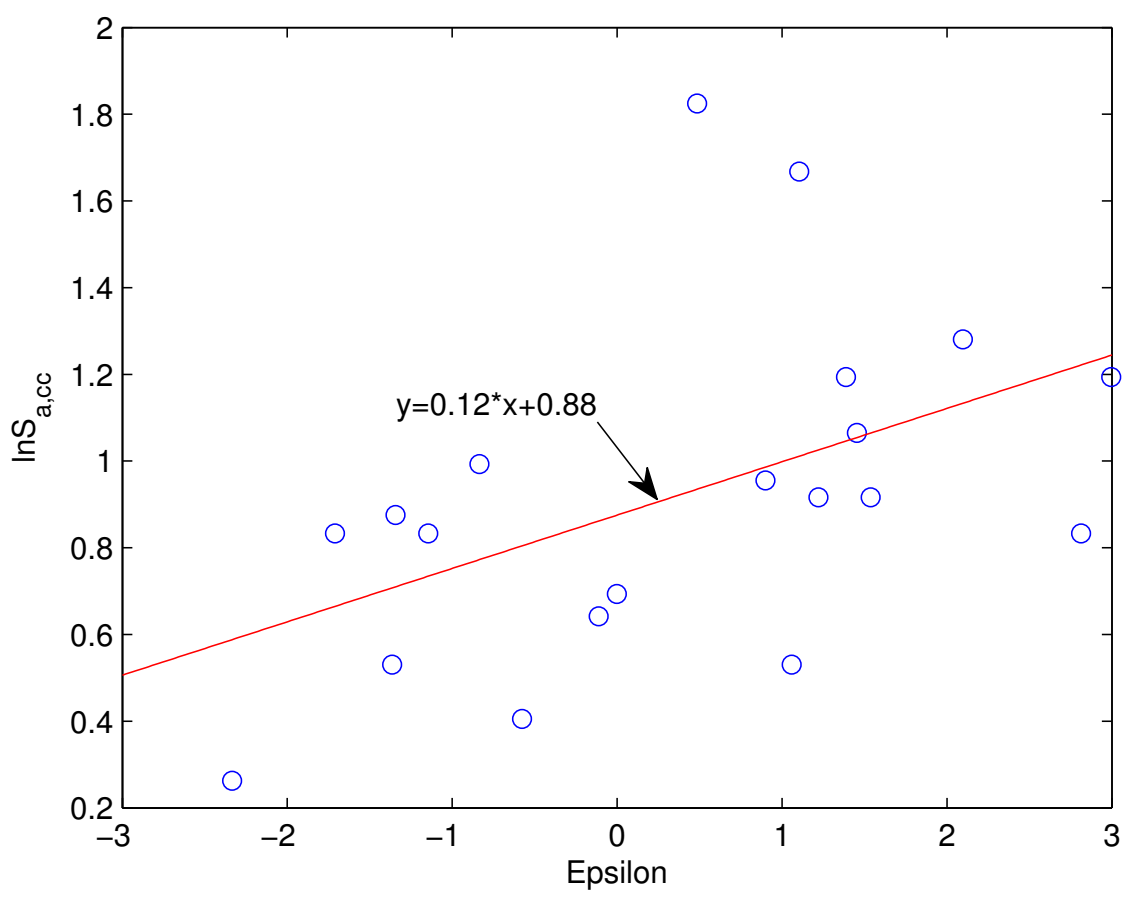

Figure 3.6: Regression of $\varepsilon$ and $\ln S_{a, c c}$ for LA $2 / 50$ ground motions (at the period $0.2 \mathrm{~s})$ 
For example, for the LA2/50 ground motion records, $c_{0}=0.88$ and $c_{1}=0.12$, the standard deviation $\sigma_{\varepsilon}=1.52$, and $\sigma_{\ln \left(\left(S_{a, c c}\right), r e g\right)}=0.34$. If $\varepsilon_{\text {target }}=2.0$, the adjusted lognormal parameters for collapse fragility can be calculated as

$$
\begin{gathered}
\widehat{\mu}_{\ln \left(S_{a, c c}\right)}=0.88+0.12 \times 2.0=1.12 \\
\widehat{\sigma}_{\ln \left(S_{a, c c}\right)}=\sqrt{0.34^{2}+0.12^{2} \times 1.52^{2}}=0.39
\end{gathered}
$$

The two parameters $\hat{\mu}_{\ln \left(S_{a, c c}\right)}=1.12$ and $\hat{\sigma}_{\ln \left(S_{a, c c}\right)}=0.39$ define the adjusted collapse fragility curve shown in Figure 3.5. The expected median collapse capacity with $\varepsilon=2$ is $3.06 \mathrm{~g}$, $21 \%$ larger than the median collapse capacity $2.52 \mathrm{~g}$ without considering $\varepsilon$. By performing the same process for Seattle, Boston, and St Louis, collapse fragilities of the residence with considering $\varepsilon$ are obtained and listed in Table 3.2. By comparing the collapse fragility curves in Figure 3.5, it can be observed that using this alternative approach to account for $\varepsilon$ effect in collapse fragility is effective. This alternative method is used later in this study to assess the collapse risk of the light-frame wood building.

The dispersion parameter $\sigma_{l n S_{a, c c}}$ listed in columns (4) and (6) of Table 3.2 reflects the record-to-record uncertainty as discussed in Section 3.3.1. Since the same suite of ground motions is used to determine the collapse fragility, the dispersions are the same for each site regardless whether $\varepsilon$ is considered or not. Although the MCE spectra acceleration $S_{a}$ for Seattle and St Louis are $1.57 \mathrm{~g}$ and $0.55 \mathrm{~g}$, respectively, the median $\varepsilon$ values observed for SE2/50 and SL2/50 are close (3.00 for SE2/50 and 3.07 for SL2/50). The suites of ground motions (LA2/50, BO2/50, and SE2/50) were developed to be used in the SAC project [87]. While the ground motions provide satisfactory evaluation for seismic performance (e.g. $[1,88])$, collapse fragility obtained from these ground motions might need to be adjusted to account for $\varepsilon$ effects in order to appropriately estimate the collapse risk.

\subsection{Collapse capacity considering resistance uncertainty}

Past studies on seismic performance of light-frame wood structures (e.g. [1, 2, 89]) used deterministic hysteresis models, in which the resistance uncertainty has not been considered. In this section, the resistance uncertainty in light-frame wood buildings is to be examined. The uncertainty inherent in the structural system has been investigated through several ap- 


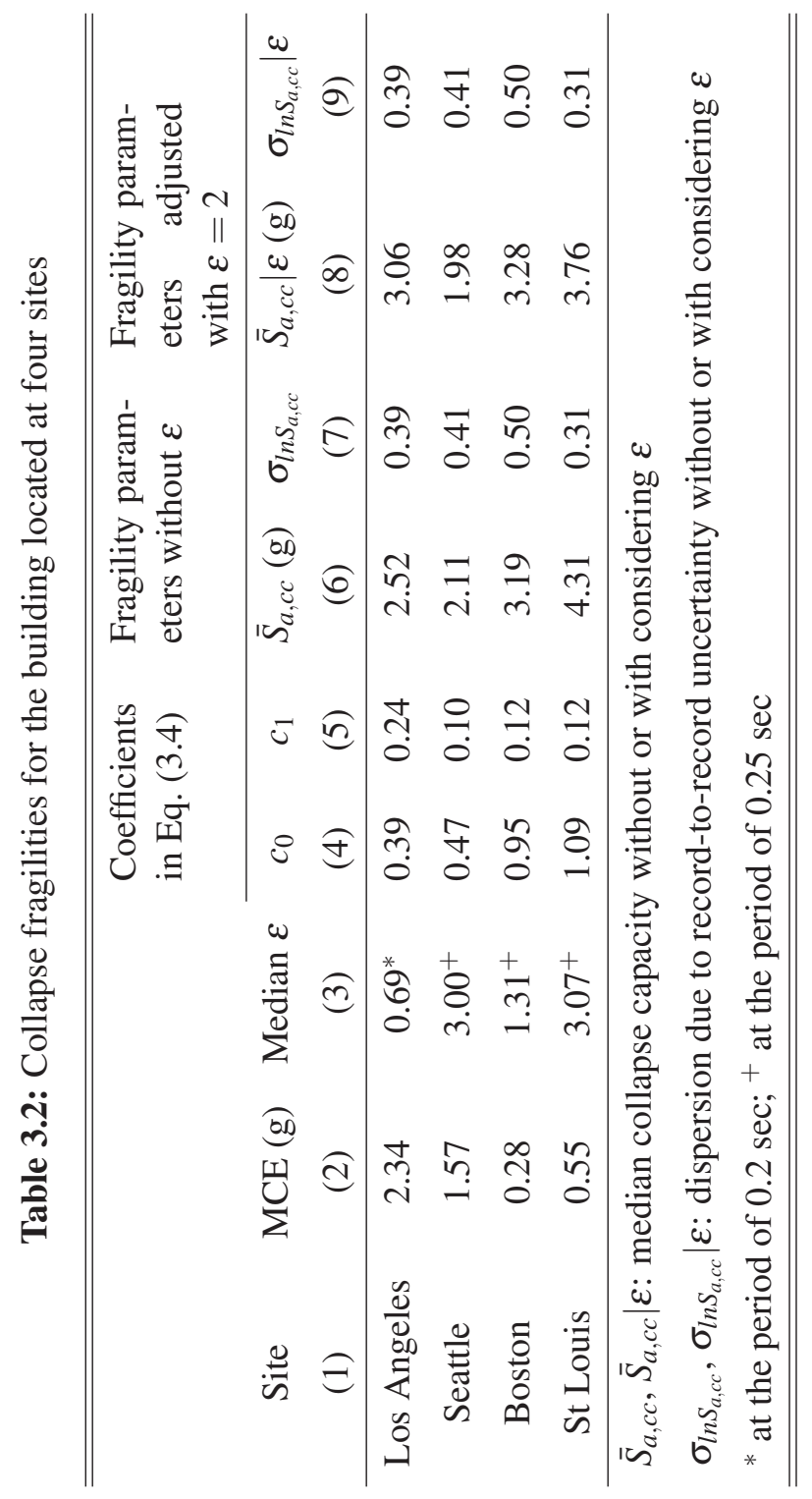


proaches including sensitivity analysis [72, 90, 91], first-order-second-moment (FOSM) methods, and Monte Carlo methods. Sensitivity analysis indicates the parameter effects on the structural performance to a limited depth. FOSM methods can be used to propagate modeling uncertainties to evaluate the effect on collapse capacity, but might be problematic when the limit state functions are highly nonlinear [38]. The Monte Carlo method is the most comprehensive but the most computationally expensive approach [71].

\subsubsection{Resistance uncertainty}

Typical light-frame wood buildings have several wood shear walls as the main lateral force resisting system. The resistance of each shear wall is reflected in 10 hysteresis parameters as discussed in Section 3.2. In Section 3.3, these hysteresis parameters are taken as constants (median values) when IDA is performed to obtain collapse fragilities. In this section, the uncertainty associated with these hysteresis parameters (referred to as resistance uncertainty later) is investigated. The numerical model of the light-frame wood building (Figure 3.1) includes four shear walls (to be modeled with 40 random variables). In order to alleviate the computation burden, an individual wood shear wall (the south shear wall in the building B) instead of the whole building is investigated for the variation of resistance, which then is used in the whole building analysis. This simplified procedure is based on the assumption that the dispersion of collapse fragility, in terms of coefficient of variation $(\mathrm{COV})$, due to the resistance uncertainty found in the individual shear wall is at the same level as that in the whole building.

As there is no data available for determining the probability distribution of the hysteresis parameters. The normal distribution is assumed in this study for each of the hysteresis parameters. Table 3.3 lists the distribution parameters. The median values of these parameters are determined using the CASHEW program [45, 78]. The normal distributions have to be truncated considering the following factors. First, there are physical limitations on the hysteresis parameters. For example, parameter $r_{2}$ should always be less than 0 since it indicates the strength degradation after the ultimate displacement $D_{u}$ is reached, as shown in Figure 3.2. Second, there is a 95\% probability that a normal distribution assigns values in the range of $\mu \pm 2 \sigma$ ( $\mu$ is the mean value and $\sigma$ is the standard deviation). So sampling in the range of $\mu \pm 2 \sigma$ can provide a high enough confidence level and save computation resources. The bounding ranges listed in Table 3.3 are set considering both factors. Since 
there is no enough experimental data, the $\mathrm{COV}$ of each hysteresis parameter is assumed to be 0.5 herein. Vamvatsikos and Fragiadakis [71] examined the resistance uncertainty of a steel frame and assumed COV of the hysteresis parameters to be 0.4 .

Table 3.3: Probabilistic distributions of the hysteresis parameters (Units: $\mathrm{kN}-\mathrm{mm}$ )

\begin{tabular}{lccc}
\hline \hline $\begin{array}{l}\text { Hysteresis } \\
\text { parameter }\end{array}$ & Probabilistic distribution & Distribution parameter & Truncation range \\
\hline$K_{0}$ & Truncated Normal & $\mathrm{M}_{K_{0}}=2.73, \mathrm{COV}_{K_{0}}=0.5$ & {$[0.65,5.46]$} \\
$D_{u}$ & Truncated Normal & $\mathrm{M}_{D_{u}}=58.9, \mathrm{COV}_{D_{u}}=0.5$ & {$[12.0,117.8]$} \\
$r_{1}$ & Truncated Normal & $\mathrm{M}_{r_{1}}=-2.49, \mathrm{COV}_{r_{1}}=0.5$ & {$[0,0.166]$} \\
$r_{2}$ & Truncated Normal & $\mathrm{M}_{r_{2}}=-2.54, \mathrm{COV}_{r_{2}}=0.5$ & {$[-0.16,-0.02]$} \\
$r_{3}$ & Truncated Normal & $\mathrm{M}_{r_{3}}=1.29, \mathrm{COV}_{r_{3}}=0.5$ & {$[1,2.57]$} \\
$r_{4}$ & Truncated Normal & $\mathrm{M}_{r_{4}}=0.048, \mathrm{COV}_{r_{4}}=0.5$ & {$[0,0.096]$} \\
$F_{0}$ & Truncated Normal & $\mathrm{M}_{F_{0}}=24.95, \mathrm{COV}_{F_{0}}=0.5$ & {$[5.29,38.24]$} \\
$F_{1}$ & Truncated Normal & $\mathrm{M}_{F_{1}}=5.29, \mathrm{COV}_{F_{1}}=0.5$ & {$[0.8,10.59]$} \\
$\alpha$ & Truncated Normal & $\mathrm{M}_{\alpha}=0.73, \mathrm{COV}_{\alpha}=0.5$ & {$[0,1.46]$} \\
$\beta$ & Truncated Normal & $\mathrm{M}_{\beta}=1.09, \mathrm{COV}_{\beta)}=0.5$ & {$[1,2.18]$} \\
\hline \multicolumn{4}{l}{ M: median value; COV: coefficient of variance } \\
\hline
\end{tabular}

\subsubsection{Monte Carlo simulation with Latin Hypercube Sampling}

As discussed in Section 3.3.1, IDA requires many runs of NDA. In this study, 40 runs of NDA are performed for each ground motion. A single collapse fragility requires 800 runs of NDA using the LA2/50 ground motions $(20 \times 40=800)$. A classic Monte Carlo Simulation requires a large sampling number $N$ so that the target variable (i.e., structural collapse fragility in this section) distribution can be estimated. By sampling $N$ times from the parameter distributions listed in Table 3.3, Monte Carlo simulation generates a population of $N$ shear walls. Each of the $N$ shear wall needs 800 runs of NDA to obtain a collapse fragility. The computational demand can be overwhelming given a large number $N$.

The classic Monte Carlo Simulation can be further improved by the Latin Hypercube Sampling (LHS) technique [92]. The sampling number $N$ can be significantly reduced while keeping the same accuracy level as a classic Monte Carlo Simulation [71]. Generally, LHS randomly selects $n$ different values from each of $k$ variables $X_{1}, X_{2}, \ldots, X_{k}$. The range of 
each variable is divided into $n$ nonoverlapping intervals, each of which has equal area under its probability density function (PDF) curve. One value is selected at random from each interval with respect to its PDF. So a $n \times k$ matrix of samples are generated using LHS for the $k$ variables. The $i^{\text {th }}$ column contains $n$ randomly selected samples for variable $X_{i}$. More details about LHS can be found in Iman et al. [93, 94].

The hysteresis parameters for the light-frame wood shear wall are statistically and/or physically correlated [91]. However, the available literature does not provide any information on the correlations. Recent studies on steel and concrete structures (e.g. Vamvatsikos and Fragiadakis [71], Celik and Ellingwood [74]) assume that each parameter is independent from the others. In this study the same assumption is made and each hysteresis parameter is examined independently. While one hysteresis parameter is sampled using LHS, the other 9 hysteresis parameters remain unchanged and hold their mean values. Each hysteresis parameter is sampled 100 times and so 1,000 realizations of a single wood shear wall are created. For Los Angeles, each shear wall realization is analyzed by IDA using the LA2/50 ground motions. Figure 3.7 shows 100 median IDA drift curves, each of which corresponds to one realization of a shear wall (modeled by one sample value of $r_{3}$ from LHS and 9 mean values of other hysteresis parameters). The collapse capacity $S_{a, c c}$ of one realization of a shear wall is determined using its median IDA drift curve that is obtained by the process discussed in Section 3.3.1. For each median IDA curve, a collapse capacity $S_{a, c c}$ is reached when a small increase of $S_{a}$ leads to a large increase of drift as discussed previously. Each black dot in Figure 3.7 corresponds to a $S_{a, c c}$ for a shear wall realization. After 100 collapse capacities $S_{a, c c}$ are determined, the collapse capacity dispersion due to uncertainty in parameter $r_{3}, \beta_{r_{3}}=\sigma_{l n S_{a, c c}}$, can then be determined. The same procedure is performed for the other 9 hysteresis parameters.

A tornado chart that indicates the dispersion due to each hysteresis parameters is shown in Figure 3.8. The vertical axis is located at $1.07 \mathrm{~g}$, which is the median collapse capacity of the shear wall with all hysteresis parameters holding their mean values. It can be observed that the effect of each parameter on the collapse capacity of the single wood shear wall varies significantly. The statistics of the dispersions of the 10 hysteresis parameters in Figure 3.8 are listed in Table 3.4, in which the dispersions due to uncertainty in $K_{0}, F_{0}$, $F_{1}$, and $\alpha$ are much larger than that of other parameters. The first three items $\left(K_{0}, F_{0}, F_{1}\right)$ are related to material strength, while the last item $(\alpha)$ is related to the energy dissipation mechanism of the structural system. It can be observed that the energy dissipation capacity 
and material strength have significant influence on collapse risk assessment of light-frame wood structures.

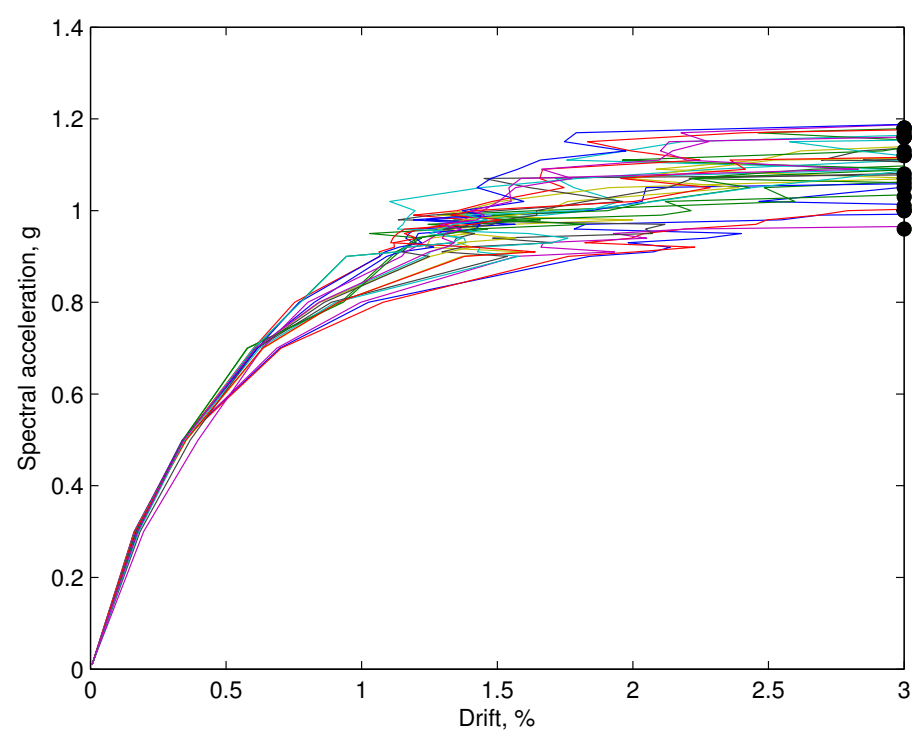

Figure 3.7: Effect of uncertainty in hysteresis parameter $r_{3}$ (shown in Figure 3.2) on the median collapse capacity

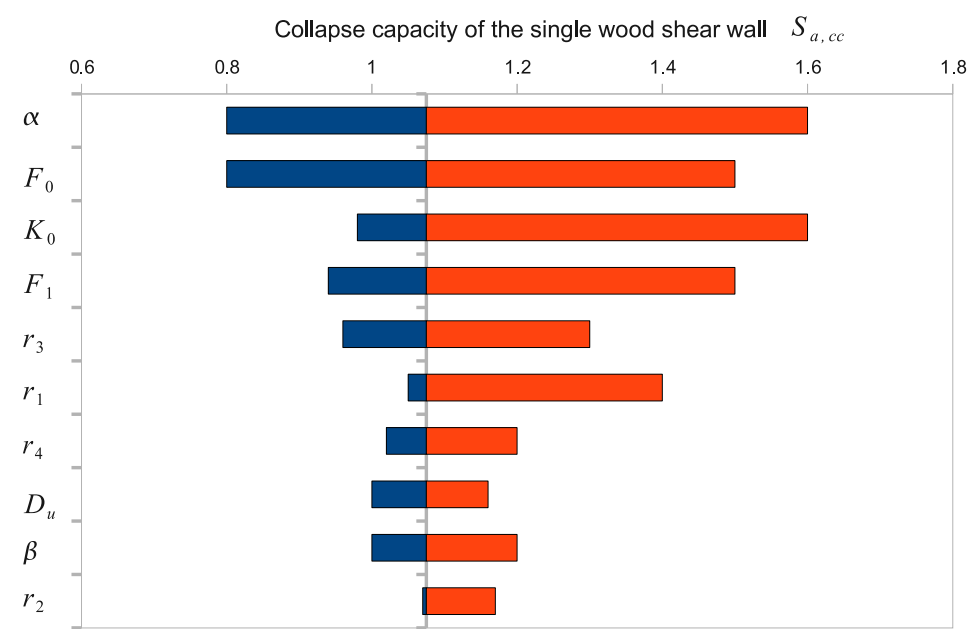

Figure 3.8: Effect of hysteresis parameters on dispersion of collapse capacity

In comparison, Vamvatsikos and Fragiadakis [71] found the yield moment, the ultimate ductility, the capping ductility, and the negative stiffness ratio have significant impact on steel structure performance. For concrete structures, the viscous damping ratio and concrete strength were found to have the greatest impact on the structural performance eval- 
Table 3.4: Single shear wall collapse capacity $S_{a, c c}$ statistics due to resistance uncertainty

\begin{tabular}{|c|c|c|c|c|c|}
\hline $\begin{array}{l}\text { Hysteresis } \\
\text { parameter }\end{array}$ & $\begin{array}{c}\text { Median } \\
\text { value }(\mathrm{g})\end{array}$ & $\begin{array}{c}\sigma_{l n S_{a, c c}} \\
(\%)\end{array}$ & $\begin{array}{l}\text { Hysteresis } \\
\text { parameter }\end{array}$ & $\begin{array}{c}\text { Median } \\
\text { value }(\mathrm{g})\end{array}$ & $\begin{array}{c}\sigma_{l n S_{a, c c}} \\
(\%)\end{array}$ \\
\hline$K_{0}$ & 1.11 & 15.1 & $F_{0}$ & 1.11 & 15.5 \\
\hline$D_{u}$ & 1.16 & 5.3 & $F_{1}$ & 1.16 & 14.2 \\
\hline$r_{1}$ & 1.15 & 7.6 & $r_{2}$ & 1.7 & 4.1 \\
\hline$r_{3}$ & 1.11 & 8.4 & $r_{4}$ & 1.15 & 6.8 \\
\hline$\alpha$ & 1.15 & 16.4 & $\beta$ & 1.15 & 4.4 \\
\hline
\end{tabular}

uation [74]. Celik and Ellingwood [74] investigated the effect of uncertainty in viscous damping ratio $\xi$ for reinforced concrete structures. Studies [78, 91, 95] have found that the viscous damping ratio of wood frame structures is in the range of $0 \sim 2 \%$, lower than that of reinforced concrete structures (e.g. Celik and Ellingwood [74] assumed a mean $\xi$ value of $4.6 \%$ for reinforced concrete structures). The reason for this is there is significant hysteretic damping in wood structures and the hysteretic damping is typically incorporated into the hysteresis model[91]. In this study, viscous damping ratio $\xi=1 \%$ is assumed as constant while the uncertainty in the structural system is modeled through the hysteresis parameter.

Let $\beta_{r}$ indicate the collapse capacity dispersion due to resistance uncertainty that was investigated earlier in this section. $\beta_{r}$ was obtained using the LA2/50 ground motions so that the record-to-record uncertainty $\beta_{r 2 r}$ was included. Using the procedure discussed in Section 3.3.1, a single shear wall modeled by 10 hysteresis parameters at their mean values is analyzed and a dispersion $\beta_{r 2 r}=0.30$ is obtained, which is due to the record-to-record uncertainty. Assuming the 10 hysteresis parameters are independent, the collapse capacity dispersion due to resistance uncertainty can be determined by Eq. (3.9) to be 0.18.

$$
\beta_{r}=\sqrt{\beta_{\text {total }}^{2}-\beta_{r 2 r}^{2}}
$$

where,

$$
\beta_{\text {total }}=\sqrt{\sum_{i=1}^{10} \beta_{p, i}^{2}}
$$


In Eq. (3.10), $\beta_{p, i}$ coresponds to the dispersion items due to each of the ten hysteresis parameters $K_{0}, F_{0}, F_{1}, D_{u}, r_{1}, r_{2}, r_{3}, r_{4}, \alpha$, and $\beta$ (i.e. $\beta_{K_{0}}, \beta_{F_{0}}, \beta_{F_{1}}, \beta_{D_{u}}, \beta_{r_{1}}, \beta_{r_{2}}, \beta_{r_{3}}, \beta_{r_{4}}$, $\beta_{\alpha}$, and $\beta_{\beta}$ ). The values of $\beta_{p, i}, i=1, \cdots, 10$ are listed in Table 3.4.

To determine whether $\beta_{r}=0.18$ obtained in Eq. (3.9) is reasonable, an alternative method used by Vamvatsikos and Fragiadakis [71] is also examined here. $\beta_{r}$ can be determined by:

$$
\beta_{r}=\sqrt{\frac{\sum_{j=1}^{N}\left(\ln \bar{S}_{(a, c c), j}-\overline{\ln \bar{S}_{a, c c}}\right)^{2}}{N-1}}
$$

where $N$ is the number of structure samples (i.e. 1000 realization of shear walls), $\bar{S}_{(a, c c), j}$ is the median collapse capacity for the $j^{\text {th }}$ shear wall, and $\overline{\ln \bar{S}_{a, c c}}$ is the mean value of all the $\ln \bar{S}_{a, c c} . \beta_{r}$ is found to be 0.17 using Eq. (3.11). Therefore, dispersion in collapse capacity due to resistance uncertainty is approximately 0.18 .

\subsection{Collapse risk with aleatoric and epistemic uncertain- ties}

\subsubsection{Collapse fragility with uncertainty}

In Section 3.3 and Section 3.4, aleatoric uncertainties in earthquake records and structural resistance are investigated. Another significant source of uncertainty is epistemic uncertainty. It comes from the fact that numerical models (e.g. attenuation equations and hysteresis models in this study) can only capture part of the real system. The epistemic uncertainty is termed modeling uncertainty in this study. Let $\beta_{m}$ indicate the dispersion of collapse capacity due to modeling uncertainty. The square-root-sum-of-squares (SRSS) method has been used to assess structural performance in the presence of various sources of uncertainties (e.g. [56, 65, 71, 88, 96]). Using SRSS, the dispersion of collapse capacity considering both aleatoric and epistemic uncertainties can be determined by:

$$
\beta=\sqrt{\beta_{r 2 r}^{2}+\beta_{r}^{2}+\beta_{m}^{2}}
$$


where $\beta$ is the collapse capacity dispersion considering both aleatoric and epistemic uncertainties, $\beta_{r 2 r}$ is the dispersion due to record-to-record uncertainty discussed in Section 3.3. $\beta_{r}$ is the dispersion due to resistance uncertainty discussed in Section 3.4 and $\beta_{m}$ is the epistemic uncertainty. The structural collapse fragility dispersion parameter $\sigma_{l n S_{a, c c}}$ defined in Eq. (3.2) is to be updated in this section to account for all sources of uncertainties. Table 3.5 tabulates all the related dispersion quantities. In column (9) of Table 3.5, the epistemic uncertainty caused dispersion in collapse capacity, $\beta_{m}$, is set with three levels, 0.2 , 0.4, and 0.6, which represents small, moderate, and high modeling uncertainties, respectively. Similar assumptions have been adopted in other studies investigating the uncertainty effect on seismic performance assessment [41, 88]. The annual collapse probability, $P_{c, 1}$, and the collapse probability in 50 years, $P_{c, 50}$, shown in columns $(6) \sim(7)$ and $(11) \sim(13)$ in Table 3.5, will be discussed in Section 3.5.3.

Figure 3.9 illustrates collapse fragilities of the light-frame building in Los Angeles, Seattle, Boston, and St Louis. It can be observed from this figure that all the collapse fragility curves rotate about the median capacities. The reason is that the median capacity for each collapse fragility is unchanged. For example, the median collapse capacity for Los Angeles is $2.52 \mathrm{~g}$. The five fragility curves shown in Figure 3.9 for Los Angeles are defined by the median value $2.52 \mathrm{~g}$ and five dispersions that corresponds to different combinations of uncertainties. Similar results are observed in ATC [62], Liel et al. [69].

\subsubsection{Probability of collapse at MCE}

The collapse probabilities at MCE of the light-frame wood building at the four sites are summarized in Table 3.6. In Los Angeles, given an MCE event, the collapse probability of building A considering both aleatoric and epistemic uncertainties is $46.1 \%$, while it is $34.7 \%$ for building B in Seattle subjected to an MCE event. Note that the median collapse capacity of building A is $2.52 \mathrm{~g}$, higher than $2.11 \mathrm{~g}$ of building B. The difference between the MCE collapse probability is due to differences in seismicity between the two sites (e.g., MCE in Los Angeles and Seattle are $2.34 \mathrm{~g}$ and $1.57 \mathrm{~g}$, respectively).

Collapse fragility curves generated considering the $\varepsilon$ effect are shown in Figure 3.10, Given an MCE event (i.e. $S_{a}=2.34 \mathrm{~g}$ ) in Los Angeles, the collapse probability is $24.6 \%$ consid- 


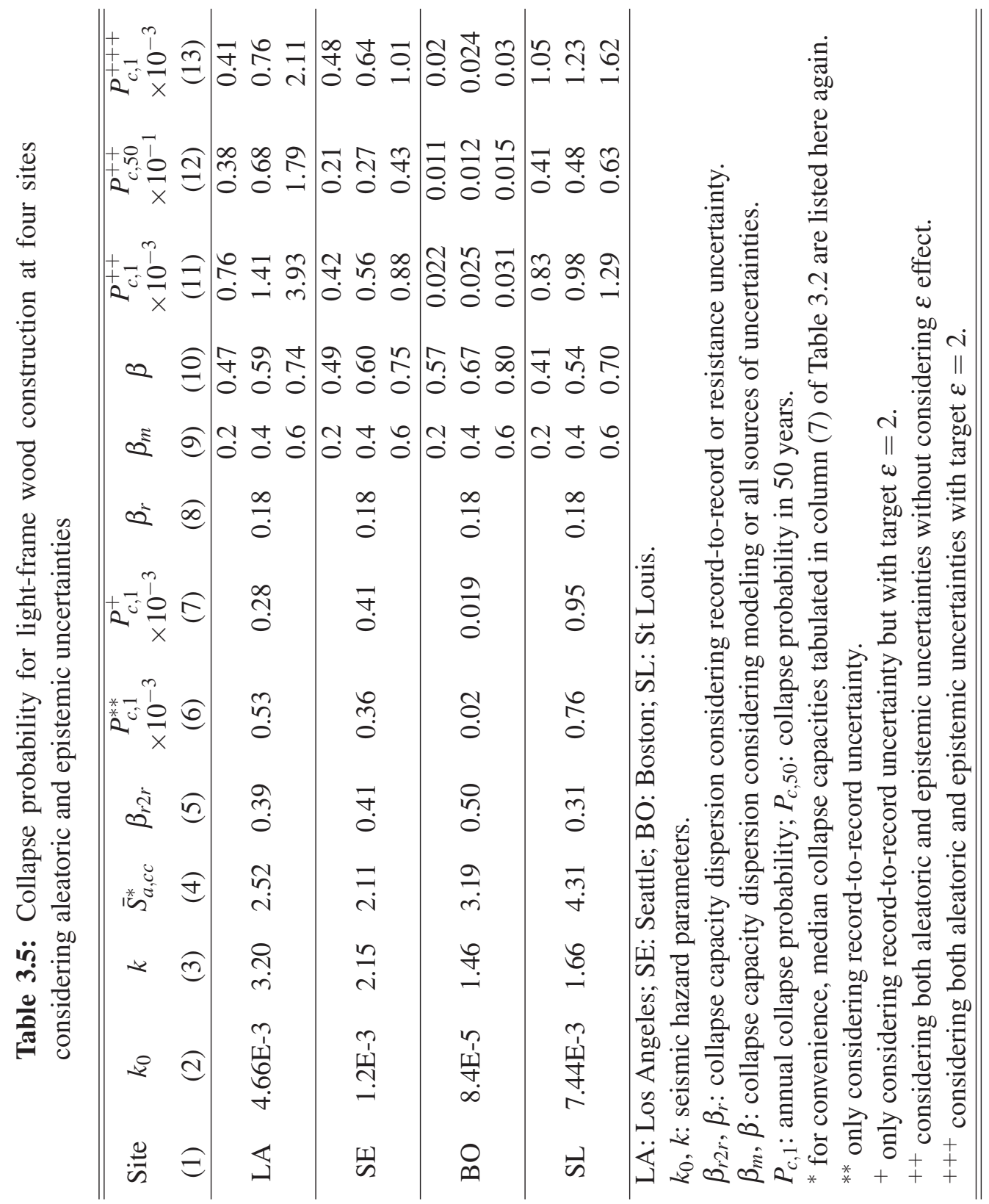



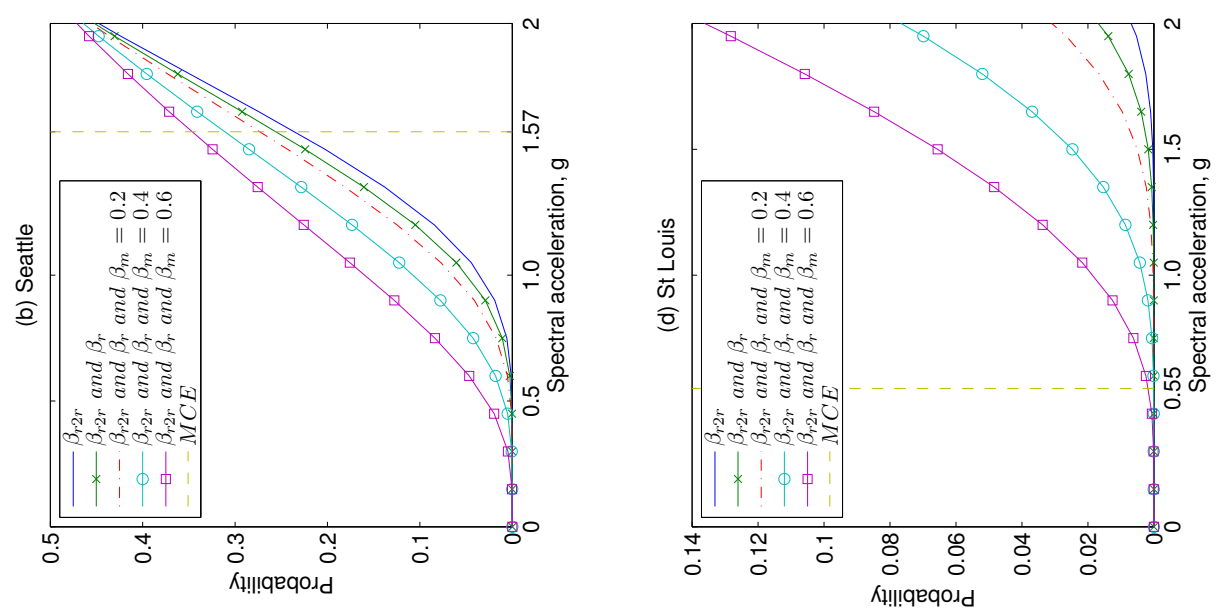

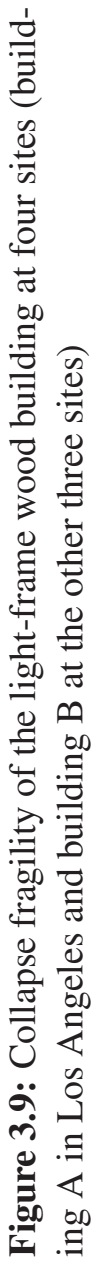
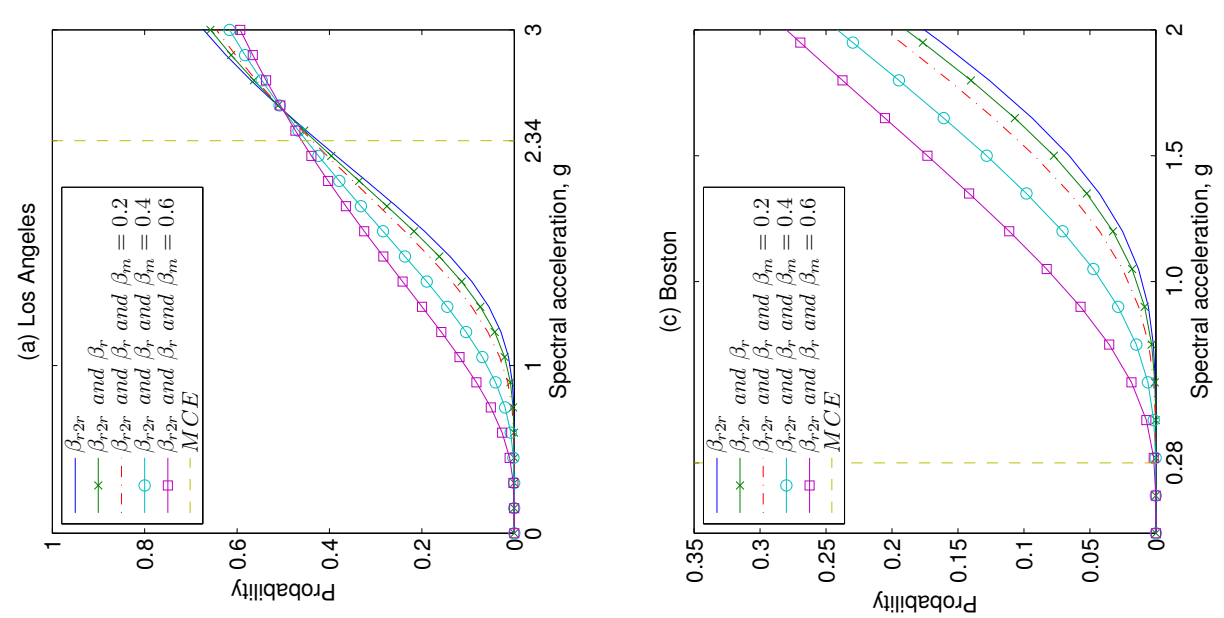

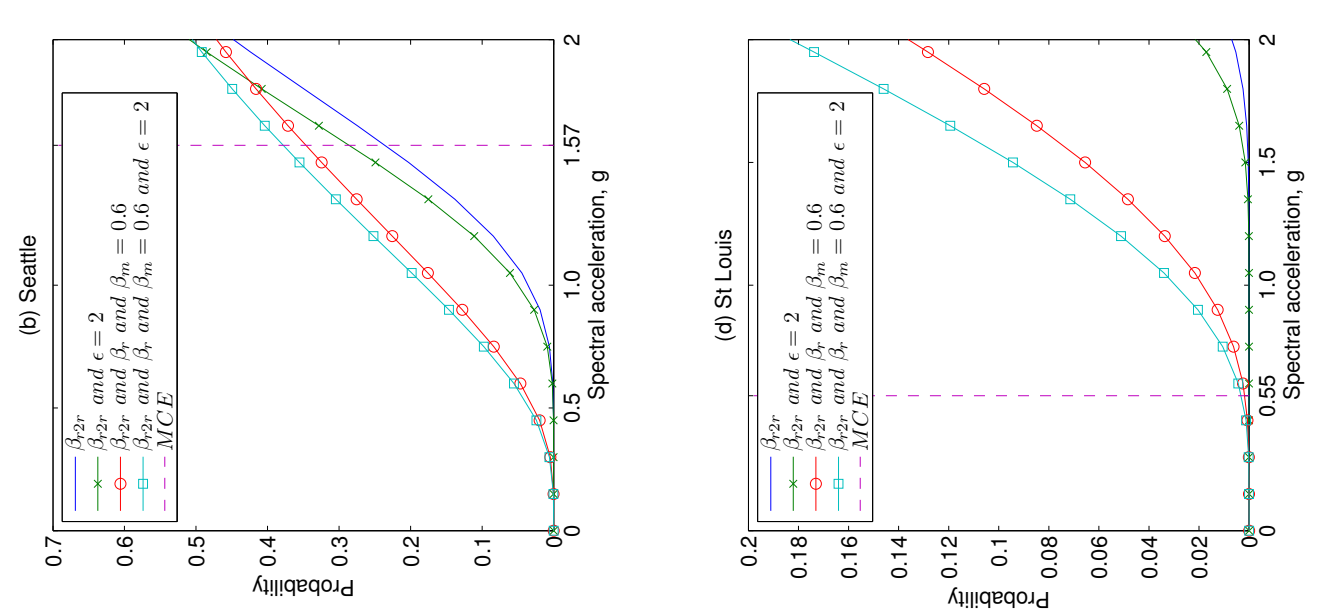

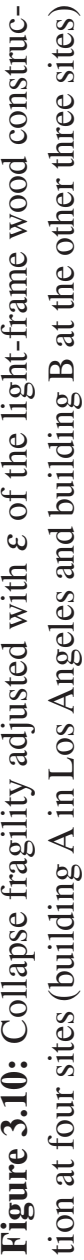
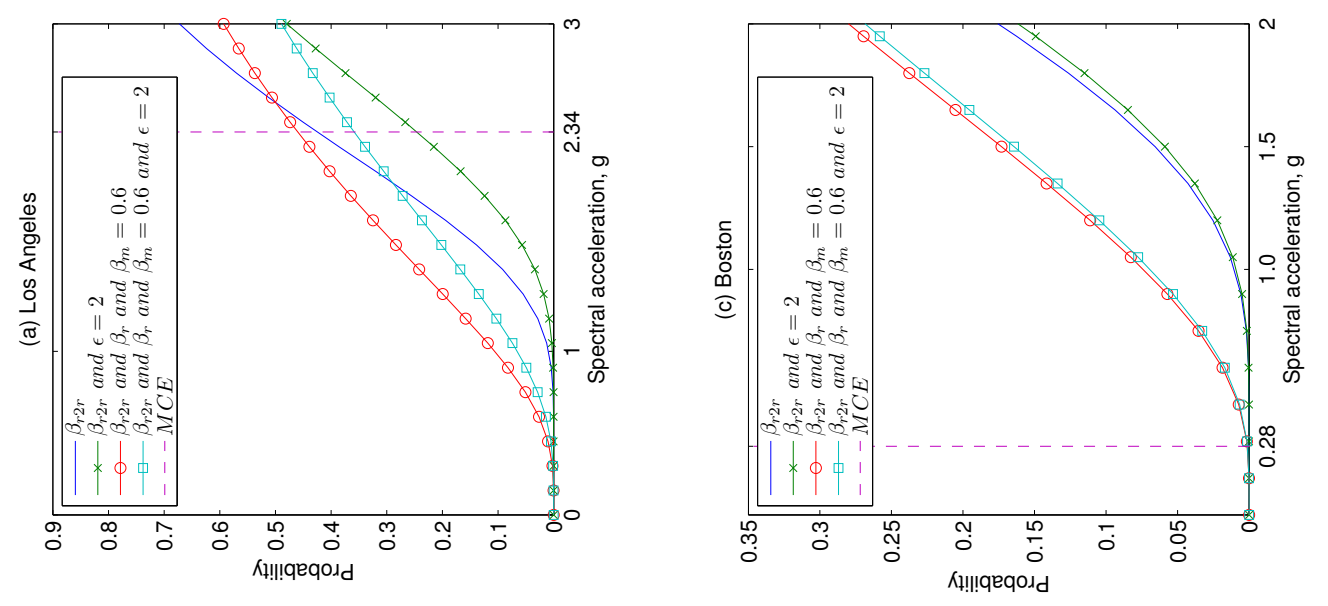
ering record-to-record uncertainty and a target $\varepsilon$ of 2 . The probability increases to $35.9 \%$ while considering record-to-record, resistance, and modeling uncertainties (see column (8) in Table 3.6). Considering the same cases in Seattle, the collapse probability rises from $28.6 \%$ up to $37.8 \%$ (see columns (7) and (8) in Table 3.6). For St Louis and Boston, the collapse probabilities given an MCE event are almost zero for all the cases, as can be observed from Figures 3.9 3.10. Note that in this study the same construction details are assumed for the four sites.

Table 3.6: Collapse probability (\%) of the light-frame wood building at four Sites in the United States at MCE

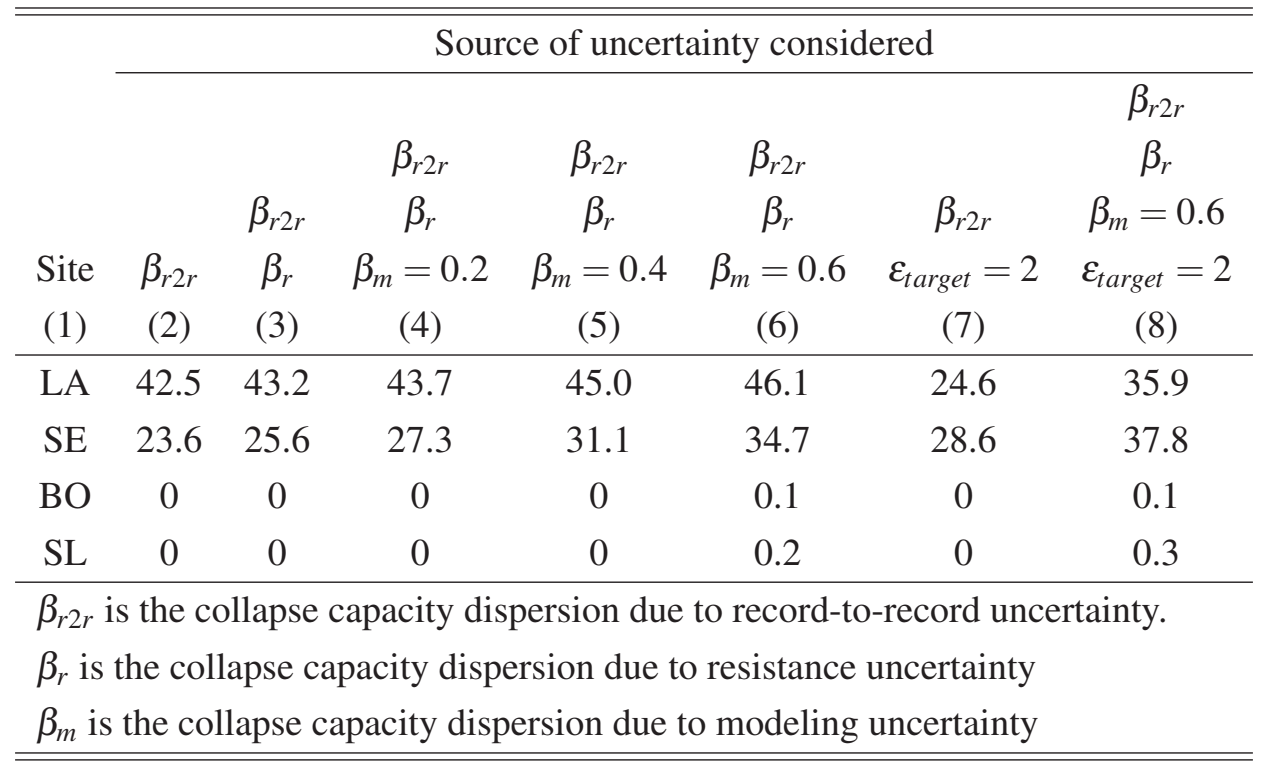

\subsubsection{Annual and 50-year collapse probabilities}

By convolving the collapse fragilities with seismic hazard curves, the annual collapse risk can be evaluated. Several studies ([42, 56, 64, 65],) have used Eq. (3.13) to estimate the annual collapse probability. In Eq. (3.13), $P_{c, 1}$ is the annual collapse probability, $\bar{S}_{a, c c}$ is the median collapse capacity (the spectral acceleration corresponding to $50 \%$ probability of collapse fragility curve), $\beta$ is the dispersion of the collapse fragility, and $k_{0}$ and $k$ are two site specific parameters defining the seismic hazard [56].

Using Eq. (3.13) and (3.14), the annual collapse probability and the collapse probability 
in 50 years $\left(P_{c, 50}\right)$ of the light-frame wood building in Los Angeles, Boston, Seattle, and St Louis are determined and summarized in Table 3.5. The median values $\bar{S}_{a, c c}$ used in the calculation are listed in Table 3.2, Seismic parameter $k_{0}$ and $k$ for the four sites are obtained from the USGS [97]. The collapse capacity dispersion, $\beta_{r}=0.18$, is assumed to be the same as that in the single shear wall as discussed in Section 3.4

$$
\begin{gathered}
P_{c, 1}=k_{0} \bar{S}_{a, c c}^{-k} e^{0.5(k \beta)^{2}} \\
P_{c, 50}=1-\left(1-P_{c, 1}\right)^{50}
\end{gathered}
$$

The annual collapse probabilities considering record-to-record uncertainty and spectral shape effects are listed in column (7) of Table 3.5, while the annual collapse probabilities considering only record-to-record uncertainty without spectral shape effects are listed in column (6). With median collapse capacity adjusted with target $\varepsilon=2$, the annual collapse probability in Los Angeles decreases from 0.53E-3 to $0.28 \mathrm{E}-3$ (or $46 \%$ less). For Boston, the difference between columns (6) and (7) is negligible. This results are consistent with what was recommended in other studies [76, 86] that the spectral shape has significant influence on collapse risk assessment for high seismicity areas like western United States. For low seismicity areas like Boston $(\mathrm{MCE}=0.28 \mathrm{~g})$, the spectral shape might not be as important as other factors such as resistance and modeling uncertainties.

The annual collapse probability in Boston only considering record-to-record was found to be $2 \mathrm{E}-5$, which increases by $25 \%$ to $2.5 \mathrm{E}-5$ considering an epistemic disperison $\beta_{m}=0.4$ and resistance uncertainty $\beta_{r}=0.18$. The resistance uncertainty and epistemic uncertainty do not have significant influence on the collapse risk of light-frame wood construction in Boston. While in Los Angeles the annual collapse probability increases $168 \%$ from $0.53 \mathrm{E}-3$ to $1.41 \mathrm{E}-3$.

Compared with the record-to-record uncertainty, $\beta_{r 2 r}$, the resistance uncertainty contributes to the overall collapse risk, especially when the modeling uncertainty is at moderate or high level (i.e., $\beta_{m}=0.4 \sim 0.6$ ). Note that the dispersion $\beta_{r}$ listed in Table 3.5 assumes the resistance uncertainty effect on a single shear wall is the same as that on a whole wood building. This assumption needs to be further investigated later. According to these observations, it can be seen that the uncertainty from earthquake 'demand' and effect of spectral shape are 
more significant than the resistance uncertainty on the collapse risk analysis for light-frame wood structures. However, neglect of resistance uncertainty will lead to unconservative estimation of seismic collapse risk of the light-frame wood structure. In comparison, studies on concrete and steel structures (e.g. [53, 65, 69, 74]) found that uncertainties in structural systems have significant influence on seismic collapse performance.

\subsection{Discussion}

The record-to-record dispersion $\beta_{r 2 r}$ found in this study for the four sites ranges between 0.31 and 0.50. This is comparable to what has been found by Haselton and Deierlein [54], who evaluated the collapse risk of 30 reinforced concrete moment frames of varying height. In their study, the dispersions due to record-to-record uncertainty, $\beta_{r 2 r}$, were found to range between 0.35 and 0.45 . The modeling uncertainty found in their study [54] was around 0.45 . Note that the modeling uncertainty in their study corresponds to the combination of $\beta_{r}$ (column (8) in Table 3.5) and $\beta_{m}$ (column (9) in Table 3.5) in this study using SRSS. Taking a moderate epistemic uncertainty, $\beta_{m}=0.40$, a combined dispersion $\beta_{r+m}=0.44$ is obtained, which is comparable to the results in Haselton and Deierlein [54].

The ongoing ATC-63 project [62] is developing a methodology for quantifying structural seismic performance parameters (i.e., response modification coefficient $R$, system overstrength factor $\Omega_{0}$, and deflection amplification factor $C_{d}$ ) for use in seismic design. Although the ATC-63 project includes seismic performance evaluation for light-frame wood buildings, a direct comparison of results from the ATC-63 project and those from this study is confounded by several factors. First, the focus of this study is different from that of the ATC-63. This chapter aims to evaluate effects of uncertainty on the seismic performance of a typical light-frame wood buildings, while the ATC-63 focuses on providing reliable performance factors for design purpose. The collapse risk of existing buildings is not considered in the ATC- 63 project but is studied in this chapter. Second, the ground motions used in the two studies are different. The SAC and Wen-Wu ground motions are used in this study while the ATC-63 used ground motions from the PEER NGA database [98]. Different sources of ground motions lead to different collapse capacities, as can be seen from Table 3.2. Third, the definitions of collapse capacity are different. The median collapse capacity in the ATC-63 project was obtained by scaling all the records to the MCE intensity 
and then increasing intensity until half of the scaled ground motion records cause collapse. The median collapse capacity determined in this study is discussed in Section 3.3.1.

\subsection{Conclusions}

Collapse risk of light-frame wood construction at four sites in the United States was assessed in this study, considering both aleatoric uncertainty (i.e., record-to-record uncertainty, and resistance uncertainty) and epistemic uncertainty (i.e., modeling uncertainty). The spectral shape $(\varepsilon)$ effect on the collapse risk was investigated. Collapse probabilities at MCE and collapse probabilities (annual and 50-year) for four sites were estimated.

Record-to-record uncertainty found in light-frame wood construction in this study ranged between 0.31 and 0.50 , which is consistent with what has been found in steel and concrete structures. The spectral shape $\varepsilon$ of ground motion was found to have significant effect on the collapse risk of light-frame wood construction, especially for high seismicity areas like the west coast of United States. Considering a moderate modeling uncertainty (i.e. $\beta_{m}=0.4$ in this chapter), the dispersion due to both resistance and modeling uncertainties was found to be approximately 0.44 , which led to an increase of annual collapse probability ranging between $25 \%$ and $168 \%$ depending on the site. Therefore, resistance and modeling

uncertainty contributions cannot be neglected in light-frame wood construction collapse risk assessment. 


\section{Chapter 4}

\section{Stochastic modeling of snow loads using a Filtered Poisson process}

\subsection{Introduction}

Snow hazard causes significant damage to buildings and threatens life safety. For example, The March 1993 east coast storm in the United States caused $\$ 1.75$ billion economic losses [4]. On January 28 2006, at least 66 were killed and 160 were injured in the Katowice Trade Hall roof collapse due to heavy snow loads in Poland [5]. In January 2006, a roof collapse due to heavy snow loads in Bad Reichenhall, Germany, killed 15 (including 8 children) and injured more than 30 [6]. In February 2008, a snow storm in southern China caused a direct economic loss of 54 billion yuan ( $\$ 7.7$ billion) [7].

The Bernoulli pulse process (referred to as the Bernoulli model later) has been used for snow load simulation. For example, the Bernoulli model was used to investigate the 'creeprupture' characteristic of timber structures (e.g. [99-101]), The Bernoulli pulse process works well for sites with intermittent snow loads (i.e. pulse loads). However, it cannot be used for sites with snow accumulation because the assumption of independence between time intervals is invalid under such conditions. Details are discussed in the following sections. 
The load combinations in ASCE Standard 7-05 [75] were developed based on Turkstra's rule [102], which assumes the maximum combined load effect occurs when one load attains its maximum value while other loads are at their arbitrary point-in-time values. For some areas in the United States (e.g. the mountainous areas in the west coast), where both earthquake and snow hazards are significant for an extended period of time, Turkstra's rule may not be appropriate [103]. In order to investigate the load combinations involving snow loads (e.g. seismic and snow loads, wind and snow loads), a proper snow load model is required to simulate the time history of ground snow loads so that the snow load at any point of time can be obtained.

This study considers a model for snow load simulation proposed by Yin et al. [104]. This model is based on a Filtered Poisson Process (FPP). Weather records for three sites, Tahoe City, CA, Stampede, WA, and Buffalo, NY, are obtained from the National Climatic Data Center (NCDC) and used to calibrate the FPP model. Tahoe City and Stampede represent areas with snow accumulation, while Buffalo represents an intermittent snow load area.

\subsection{Bernoulli model and its limitations}

In the Bernoulli model, a snow season $T$ is divided into $n$ time intervals, $\tau_{i}, i=1,2, \cdots, n$, and the load pulse value remains constant during each interval and independent between intervals. For each time interval, a probability $p$ is assumed such that the load pulse is nonzero at that probability [99]. Eq. (4.1) shows the relationship between the cumulative distribution functions $(\mathrm{CDF})$ of the maximum values, $F_{\max }(x)$, (e.g., the annual maximum ground snow loads) and the single load pulse values, $F(x)$, (e.g., the daily ground snow loads). Typically, the annual maximum ground snow loads for most sites in the United States fit a lognormal distribution with parameters that are site specific [105-107].

$$
F_{\text {max }}(x)=[(1-p)+p F(x)]^{n}
$$

Based on the assumptions, snow load simulation is performed using Eq. (4.1) and appropriate $F_{\max }$ parameters (e.g., $\lambda$ and $\xi$ for a lognormal distribution). Fig. 4.1(a) shows a 
simulated snow load record using the Bernoulli model with a probability $p=0.2$ and 2week time interval. Fig. 4.1(b)] shows the ground snow loads of Buffalo, NY from Nov., 1963 to Apr., 1964 obtained from the NCDC [108]. It can be observed that the Bernoulli model approximately captures the load pulse characteristic that is common for intermittent snow load sites.

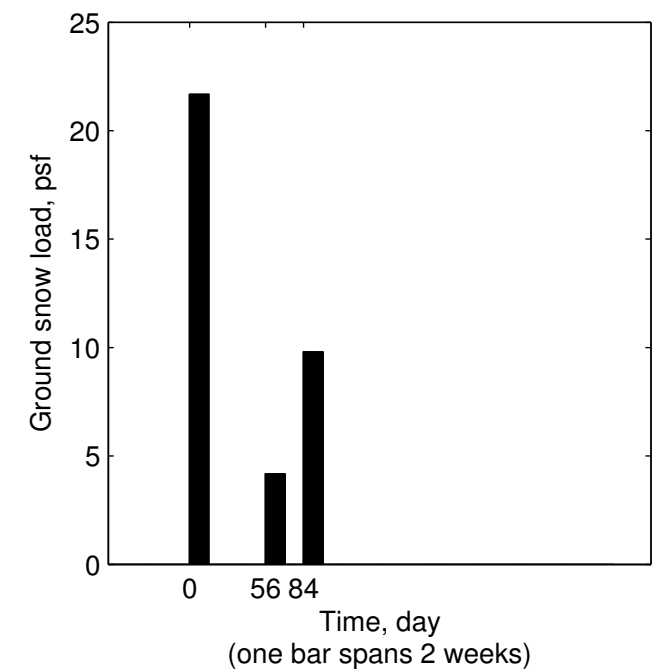

(a) Simulated records using the Bernoulli model $(p=0.2)$

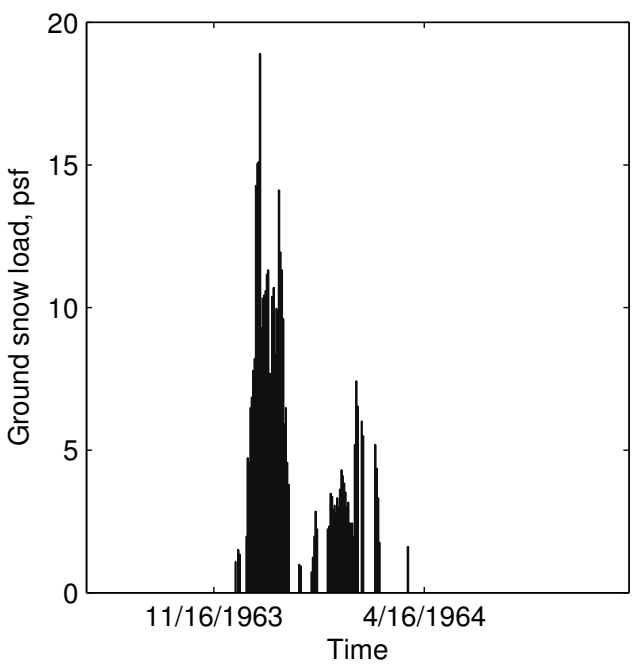

(b) NCDC recrods

Figure 4.1: Ground snow load record of Buffalo, NY

Fig. 4.2(a) shows the ground snow loads of Stampede, WA from Nov., 1954 to Jul., 1955 obtained from the NCDC. The gaps in the record are caused by missing data of the NCDC weather records. In comparison to the Buffalo snow load record 4.1(b), the Stampede ground snow loads increase to a high level because of snow accumulation and then decrease as the weather gets warmer. For such a case, to use the Bernoulli model, the probability $p$ is set to 1 (i.e., nonzero snow loads present all the time during the snow season). Fig. 4.2(b) shows a simulated snow load record using the Bernoulli model with $p=1$. The Bernoulli model fails to capture the snow accumulation characteristic of the snow load record of Stampede. The reason is that the assumption that the load pulse is independent between intervals does not hold for such a case. The snow load at the $i$ time interval is related to those in the previous intervals and will affect those in the following intervals.

Furthermore, the parameter $p$ of the Bernoulli model has been determined arbitrarily and cannot be validated [109]. Consequently, it is difficult to calibrate the simulations modeled 
by the Bernoulli model. Lastly, using the Bernoulli model, it is not feasible to obtain a snow load history (e.g., daily ground snow load) that may be needed for structural performance evaluation for buildings located in certain areas.

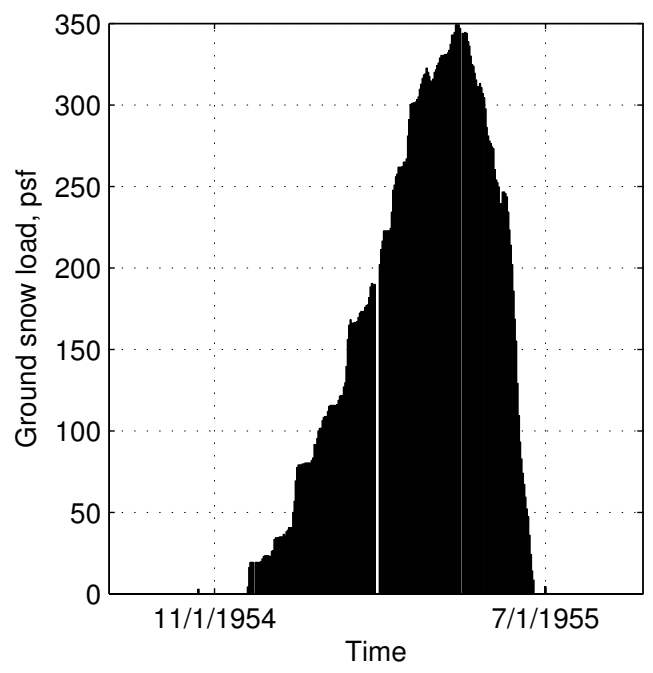

(a) NCDC records

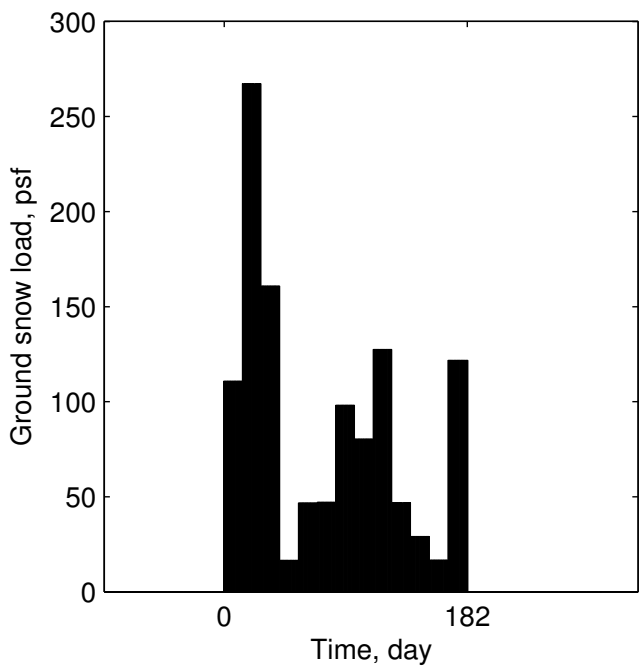

(b) Simulated records using the Bernoulli model $(p=1.0)$

Figure 4.2: Ground snow load records of Stampede, WA

\subsection{Filtered Poisson Process}

The concept of the FPP was proposed by Parzen [110]. Rahman and Grigoriu [111] used the FPP to model seismic hazards. Yoon and Kavvas [112] proposed a FPP model to simulate rainfall. Lefebvre and Guibault [113] proposed a FPP river flow model. Yin et al. [104] proposed a FPP model for snow load simulation as shown by Eq. (4.2), which is a stochastic model driven by Poisson processes.

$$
\begin{gathered}
X(t)=\sum_{i=1}^{N(t)} A_{i} S\left(t, t_{i}, Y_{i}\right), \text { where } 0<t<T \\
S\left(t, t_{i}, Y_{i}\right)=\left\{\begin{array}{cl}
1, & \text { if } t \in\left[t_{i}, t_{i}+Y_{i}\right) ; \\
0, & \text { otherwise } .
\end{array}\right.
\end{gathered}
$$


The FPP model consists of a sequence of Poisson events $X_{i}=A_{i} S\left(t, t_{i}, Y_{i}\right)$. Fig. 4.3 shows some generic Poisson events. Note that it is possible for Poisson events to overlap. In Eq. (4.2), $X(t)$ is the time history of snow loads; $N(t), 0<t<T$ is a Poisson process with a mean arrival rate $v ; T$ is the time period in which Poisson events occur; $A_{i}$ is a sequence of independent and identically distributed (IID) random variables that model Poisson event intensities; $Y_{i}$ is another sequence of IID random variables that model Poisson event durations; $S$ is a step function defined by Eq. 4.3, in which $A_{i}$ and $Y_{i}$ are assumed to be independent and lognormally distributed with parameters determined using a genetic algorithm that is presented next.

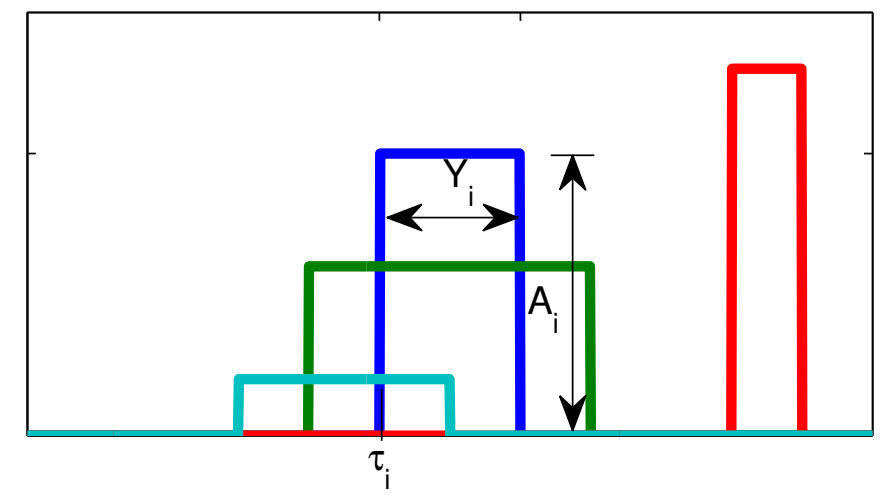

Figure 4.3: Generic Poisson events

\subsection{Genetic algorithm}

As defined in Eq. (4.2), several variables, the occurrence rate $v$, the amplitude $A_{i}$, the time period $T$, and the duration $Y_{i}$, are involved with the FPP model. Each variable can assume a probability distribution with one or more parameters. All these parameters should properly fit to the NCDC weather records. The determination of these parameters for a specific site requires many iterations. In each iteration, the parameters are optimized with feedbacks from the previous iteration until the simulated results fit the NCDC weather records.

In this study, the genetic algorithm (GA) is used to determine the 6 parameters ( 2 for the Poisson event duration, 2 for the Poisson event intensity, 1 for the Poisson event occurring rate, and 1 for the snow season length) of the FPP model. While there might be alternative methods to determine the FPP model parameters, to compare the GA with other methods 
is beyond the scope of this chapter. In the future, it may be of interest to use alternative methods for comparison purposes.

The genetic algorithm, proposed by Holland [114], has been applied to many areas (e.g., [115-118]). It is an optimization method inspired by biological genetics and evolution. The genetic algorithm includes selection of parents (i.e., chromosomes), propagation of babies (i.e., new chromosomes), mutation, and genetic filtering (i.e., keeping good chromosomes and dropping the bad ones) according to cost, which is determined by a cost function such that the optimization objectives are obtained.

Eq. (4.4) shows a genetic matrix with $m$ rows and $n$ columns. Each row corresponds to a chromosome, chromosome $_{i}, i \in[1, m]$. Each column corresponds to a parameter, $\alpha_{i}, i \in$ $[1, n]$. The cost vector, $\left(\operatorname{cost}_{1}, \operatorname{cost}_{2}, \cdots, \operatorname{cost}_{m}\right)^{T}$, is determined by a cost function using the simulated records and the data records (simulated snow records and NCDC weather records in this study). Each chromosome, chromosome $_{i}$, corresponds to a cost value, cost $_{i}$. The cost function varies with the simulation objectives. In this study, the cost functions as shown in Equations (4.5) and (4.6) were investigated. In Eq. (4.5), $\mu_{\text {sim }}$ and $\sigma_{\text {sim }}$ are the mean and standard deviation of simulated annual maximum ground snow loads, respectively; $\mu_{N C D C}$ and $\sigma_{N C D C}$ are the mean and standard deviation of annual maximum ground snow

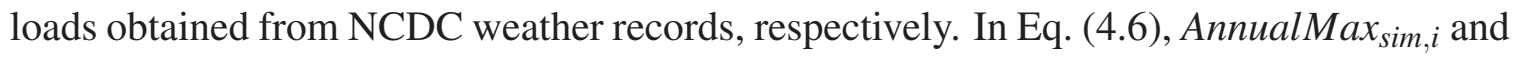
AnnualMax $_{N C D C, i}$ are annual maximum ground snow loads for the $i$ year of the simulated and NCDC weather records, respectively. The number of years, $n$, during which the NCDC ground snow load records are available varies by site.

$$
\begin{aligned}
& {[\text { GAMatrix }]=\left[\begin{array}{cccc}
\alpha_{11} & \alpha_{12} & \ldots & \alpha_{1 n} \\
\vdots & \vdots & \vdots & \vdots \\
\alpha_{i 1} & \alpha_{i 2} & \ldots & \alpha_{i n} \\
\vdots & \vdots & \vdots & \vdots \\
\alpha_{m 1} & \alpha_{m 2} & \cdots & \alpha_{m n}
\end{array}\right] \leftarrow \text { chromosome }_{i} \quad\left\{\begin{array}{c}
\text { cost }_{1} \\
\vdots \\
\text { cost }_{i} \\
\vdots \\
\text { cost }_{m}
\end{array}\right\}} \\
& \operatorname{cost}_{1}=\left(\mu_{\text {sim }}-\mu_{N C D C}\right)^{2}+\left(\sigma_{s i m}-\sigma_{N C D C}\right)^{2} \\
& \text { cost }_{2}=\sum_{i=1}^{n}\left[\text { AnnualMax }_{\text {sim }, i}-\text { AnnualMax }_{N C D C, i}\right]^{2}
\end{aligned}
$$


Crossover is a process by which two chromosomes pair up and exchange sections. There are several crossover methods used for generating baby chromosomes from parent chromosomes [116]. The single random weight method and the Heuristic method are used in this study. For the first method, the two parent chromosomes are multiplied by a uniform random number $r(r \in[0,1])$, as shown:

$$
\begin{aligned}
& (\text { mother })=\left(\begin{array}{llll}
\alpha_{i 1} & \alpha_{i 2} & \cdots & \alpha_{i n}
\end{array}\right) \\
& (\text { father })=\left(\begin{array}{llll}
\alpha_{j 1} & \alpha_{j 2} & \cdots & \alpha_{j n}
\end{array}\right)
\end{aligned}
$$

to generate two babies

$$
\begin{aligned}
& \left(\text { baby }_{1}\right)=r *(\text { mother })+(1-r) *(\text { father }), \\
& \left(\text { baby }_{2}\right)=(1-r) *(\text { mother })+r *(\text { father }) .
\end{aligned}
$$

For the second method, the parent chromosomes are multiplied by the random number $r$ as shown by:

$$
\begin{aligned}
& \left(\text { baby }_{1}\right)=(\text { mother })-r *[(\text { father })-(\text { mother })] \\
& \left(\text { baby }_{2}\right)=(\text { mother })+r *[(\text { father })-(\text { mother })] .
\end{aligned}
$$

A careful check is necessary after each crossover because some members of the baby chromosomes might be negative, which is not valid in this study. If a negative value does appear after a crossover, it is replaced with a random number. For example, if $\alpha_{i j}, i \in[1, r n]$, $j \in[1, c n]$ is negative after a crossover, it will be assigned a new value determined by

$$
\alpha_{i, l o}+r *\left(\alpha_{i, h i}-\alpha_{i, l o}\right)
$$

where $\alpha_{i, l o}$ and $\alpha_{i, h i}$ constitute a reasonable range, $\left[\alpha_{i, l o}, \alpha_{i, h i}\right]$, for $\alpha_{i}$ that corresponds to a column in the [GAMatrix]; $r n$ and $c n$ are row and column dimensions of the chromosome population that is a matrix; and $r$ is a uniform random number on $[0,1]$.

Mutation induces variation into the chromosome population. The mutation rate is the portion of members that will be changed. The rate is set to be $5-10 \%$ in this study. The members to be mutated are randomly selected throughout the chromosome population. A selected member is replaced with a random number generated by the way that is used to replace the negative value in a crossover operation. 
Fig. 4.4 illustrates the main processes of the hazard simulation program (HASP) developed in this study. At the beginning of HASP, the [GAMatrix] is initialized based on a reasonable range for each of the $n$ variables. The COST module performs ground snow loads simulation by running SIMULATOR, which is a subroutine to generate ground snow load records, and calculates costs using the cost functions shown in Eq. (4.5)-(4.6). The GA module performs iteration and contains crossover and mutation algorithms.

The initial [GAMatrix] is sorted in ascending order according to the cost vector, as shown in Eq. (4.4). The sorted [GAMatrix] is equally divided into two parts and the top half (i.e., with smaller costs) becomes a working population $[P O P]$ that evolves as the iteration in the GA module proceeds. The working population $[P O P]$ is also equally divided into two parts. The top half is named $[K E E P]$, from which the parent chromosomes are selected. The bottom half of $[P O P]$ is replaced with baby chromosomes generated by crossover of the parent chromosomes selected from $[K E E P]$. For each loop, a mutation process is performed after crossover is finished. At the end of a loop, the new working population $[P O P]$ is sorted in ascending order according to the corresponding costs. The iteration in the GA module is controlled by a maximum iteration number. Convergence criteria are also used to determine if a good result is reached before termination at the maximum iteration number.

\subsection{NCDC weather records}

\subsubsection{NCDC weather stations}

There are about 1600 first-order stations operated by the National Weather Service (NWS), 19,000 NWS Cooperative Observer Program (COOP) stations, and other stations in the United States and its territories. Each station has a specific COOPID number. The NCDC processes and provides weather records observed from these stations. The weather record data are classified into types such as the daily snow depth (SNWD), daily maximum temperature (TMAX), daily minimum temperature (TMIN), and daily water equivalent snow depth (WTEQ). The first-order stations provide all these types of weather records. But WTEQ is not provided by other stations. In this study, Tahoe City, CA, Stampede, WA, and Buffalo, NY, were selected for case studies. The simulated ground snow load records 


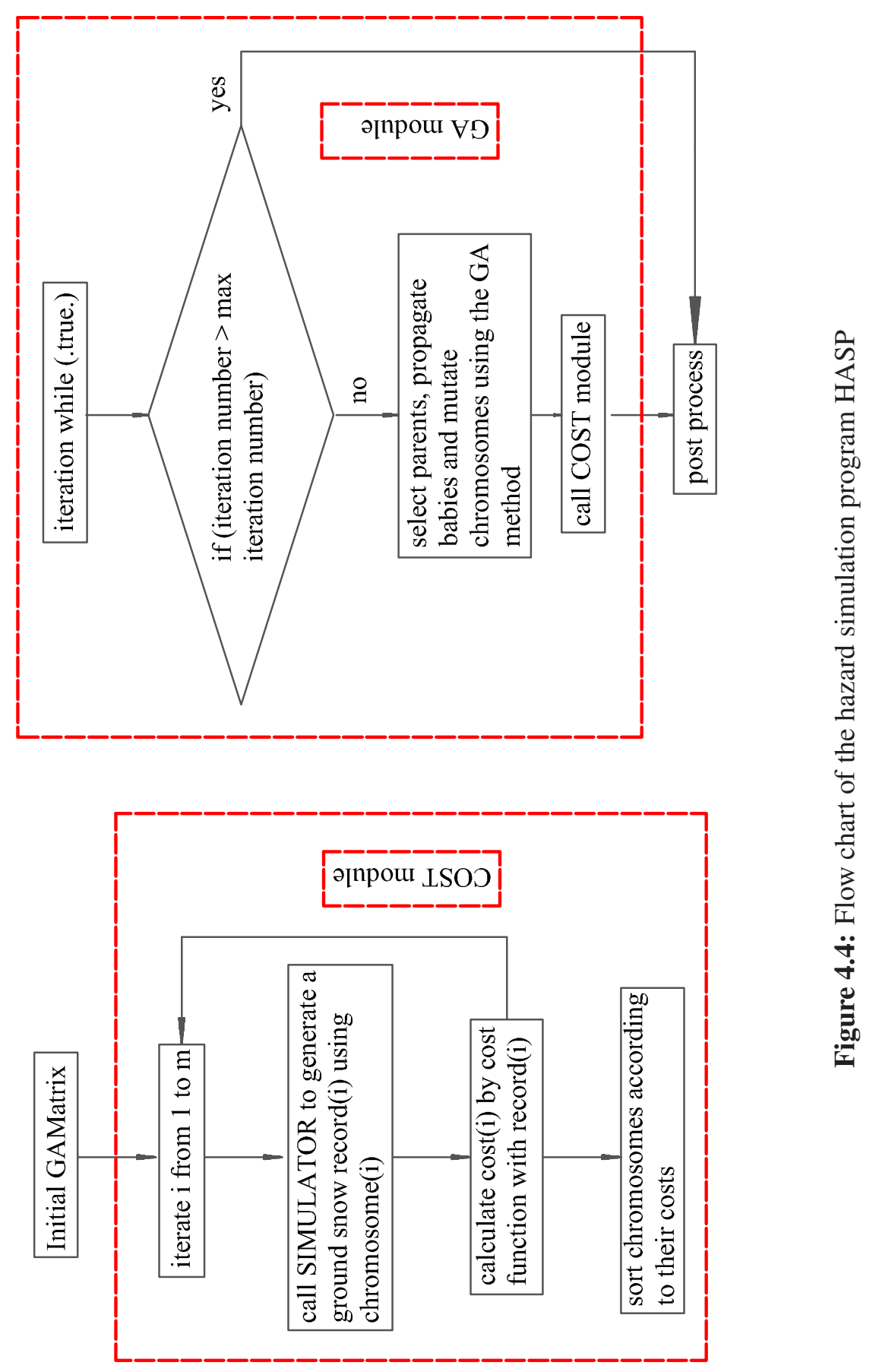


for these sites, using the FPP model, were validated by comparing them with those obtained from the NCDC. Table 4.1 lists the weather stations from which weather records were obtained. Among the four stations, all but Tahoe City are first-order stations. The Blue canyon station is the closest first-order station to Tahoe City and was used to estimate WTEQ for Tahoe City using the method discussed in the next section.

Table 4.1: Selected weather stations

\begin{tabular}{llllll}
\hline \hline COOPID & Station Name & State & Latitude & Longitude & Elevation (ft.) \\
\hline 040897 & Blue Canyon Airport (Ap.) & CA & $39^{\circ} 17^{\prime}$ & $-120^{\circ} 43^{\prime}$ & 1608.1 \\
048758 & Tahoe City & CA & $39^{\circ} 10^{\prime}$ & $-120^{\circ} 9^{\prime}$ & 1898.9 \\
458009 & Stampede Pass & WA & $47^{\circ} 18^{\prime}$ & $-121^{\circ} 20^{\prime}$ & 1206.4 \\
301012 & Buffalo Niagara International Ap. & NY & $42^{\circ} 56^{\prime}$ & $-78^{\circ} 44^{\prime}$ & 214.9 \\
\hline \hline
\end{tabular}

\subsubsection{WTEQ estimation using climatological data}

As snow density varies by time and site, it is difficult to convert snow depth to snow load by simply multiplying by a factor, while WTEQ can be conveniently converted to snow loads by multiplying a factor of 5.19 psf per inch of water. Fridley et al. [119] proposed a method to estimate WTEQ using snow depth and temperature data. In this study, this method is used to obtain the daily ground snow load for Tahoe City, where WTEQ is unavailable.

First, a first-order weather station, Blue Canyon Airport (Ap.), which is located 31.4 miles to the west of Tahoe City was selected such that the weather correlation analysis can be performed. For Tahoe City, 106-year (1903-2008) weather records were available and 69year (1940-2008) weather records were available for Blue Canyon Ap. However, some data were missing for both stations for some days. Four variables, TMAX, TMIN, SNWD, and daily average temperature (TAVG), were checked for each day to make sure that each variable assumed a valid value (i.e., not missing or damaged) for both stations. During the common period of both stations (i.e., 1940-2008), 15,614 days of data were found to be valid. The correlation coefficient for each of the four variables was determined using the available data between both stations. As shown in Table 4.2, the weather conditions are strongly correlated (i.e., the weather conditions are similar). 
Second, nonlinear regression analysis was performed to determine the coefficients $C_{1}, C_{2}$, and $C_{3}$ as shown in

$$
W T E Q=C_{1} \cdot S N W D+C_{2} \cdot T A V G+C_{3} \cdot T A V G^{3},
$$

which was proposed by Fridley et al. [119]. A total of 4,082 days of weather data for Blue Canyon is analyzed and the estimated WTEQ is compared with the recorded WTEQ, as shown in Fig.4.5. Table 4.3 lists the regression analysis results.

Lastly, WTEQ for Tahoe City is determined using the coefficients obtained in the previous step. 71-season WTEQ records are estimated using Eq. (4.14) and coefficients in Table 4.3.

Table 4.2: Weather correlation analysis results

\begin{tabular}{l|c|cccc}
\hline \hline \multicolumn{2}{c}{} & \multicolumn{4}{c}{ Blue Canyon Ap. } \\
\cline { 3 - 6 } \multicolumn{1}{c}{ Tahoe City } & SNWD & TMAX & TMIN & TAVG \\
\hline \multirow{5}{*}{ SNWD } & 0.900 & & & \\
& TMAX & & 0.877 & & \\
& TMIN & & & 0.826 & \\
& TAVG & & & & 0.882 \\
\hline
\end{tabular}

SNWD: daily snow depth; TMAX: daily maximum temperature

TMIN: daily minimum temperature; TAVG: daily average temperature

Table 4.3: Nonlinear regression analysis results

\begin{tabular}{lcccccc}
\hline \hline site & $R^{2}$ & $\begin{array}{c}C_{1} \\
\text { in./in. }\end{array}$ & $\begin{array}{c}C_{2} \\
\text { in. } /{ }^{\circ} F\end{array}$ & $\begin{array}{c}C_{3} \\
\text { in. } /{ }^{\circ} F^{3}\end{array}$ & $\begin{array}{c}\sigma_{\text {error }} \\
\text { in. }\end{array}$ & $\begin{array}{c}\mu_{\text {error }} \\
\text { in. }\end{array}$ \\
\hline Blue Canyon Ap. & $9.340 \mathrm{E}-1$ & $3.099 \mathrm{E}-1$ & $1.435 \mathrm{E}-2$ & $-1.988 \mathrm{E}-6$ & $2.529 \mathrm{E} 0$ & $-6.697 \mathrm{E}-2$ \\
\hline$R^{2}$ : correlation coefficient between station recorded WTEQ and estimated WTEQ; \\
Error = station recorded WTEQ - estimated WTEQ; \\
$\sigma_{\text {error }}$ : standard deviation of the error. $\mu_{\text {error }}$ : mean value of the error. \\
\hline \hline
\end{tabular}

\subsection{Fitting model parameters}

As discussed earlier, six parameters are required in this study for a specific site using the FPP model to simulate snow loads. These parameters are $\lambda_{d}$ and $\xi_{d}$ for Poisson event 


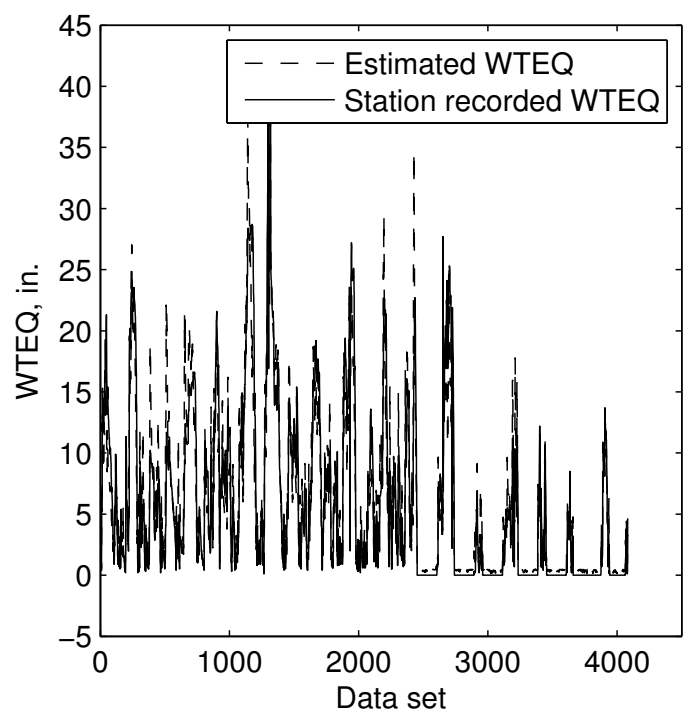

Figure 4.5: Estimated water equivalent snow depth (WTEQ) vs. recorded WTEQ for Blue Canyon

duration, $\lambda_{i}$ and $\xi_{i}$ for Poisson event intensity, time period $T$, and Poisson event arrival rate v. $\lambda\left(\lambda_{d}\right.$ or $\left.\lambda_{i}\right)$ and $\xi\left(\xi_{d}\right.$ or $\left.\xi_{i}\right)$ are parameters of the lognormal distribution, as shown in the probability density function (PDF):

$$
f(x ; \lambda, \xi)=\frac{1}{x \xi \sqrt[2]{2 \pi}} e^{\frac{-[\ln (x)-\lambda]^{2}}{2 \xi^{2}}}
$$

The six parameters are determined using the genetic algorithm discussed earlier. Depending on the cost function, crossover method, and mutation rate, there are differences between each set of parameters. Once a set of six parameters are determined for a specific site, snow load simulation can then be performed using the FPP model with the determined parameters.

\subsection{Case studies}

In this section, the FPP model is to be validated by comparisons between simulated snow loads and NCDC recorded snow loads for three sites in the U.S. For each site, one compar- 
ison is made between the shapes of the records, another one is made between the annual maximum probability distributions, and the last one is to compare the empirical CDF (i.e. the rank order statistics) of daily ground snow loads.

\subsubsection{Tahoe City, CA}

Fig. 4.6(a) shows four estimated ground snow load records of Tahoe City (referred to as NCDC ground snow loads later). The records are plotted as a function of time ranging from Aug. 16 to the next Aug. 15. The snow accumulation pattern can be identified from Fig. 4.6(a), The gaps in the figure are caused by missing data. A Kolmogorov-Smirnov (KS) test at 5\% significance level is performed to show that the NCDC annual maximum ground snow loads for the site are lognormally distributed. The statistics of the annual maximum ground snow loads of Tahoe City are listed in Table 4.4, where $\lambda$ and $\xi$ are parameters of the lognormal distribution.

Using the FPP model, the ground snow load records of Tahoe City are generated. Four simulated ground snow load records of Tahoe City are shown in Figure 4.6(b), Comparing to the NCDC snow load records, the simulated snow load records properly modeled the snow accumulation characteristic. The simulated annual maximum ground snow loads are also checked using the KS test at $5 \%$ significance level and found to be lognormally distributed (see Table 4.4). The crossover methods and mutation rate did not make a significant difference as long as the same cost function is specified. Fig. 4.7(a) shows the CDF plot for both the NCDC and simulated annual maximum ground snow load using both cost functions. The empirical CDF is determined by ranking order of data. In comparison of the CDF plots, the simulated snow loads with the first cost function (Eq. 4.5) are closer to the NCDC snow loads than those with the second cost function (Eq. 4.6).

In addition to the comparison of annual maximum snow loads, the daily ground snow loads are also compared. The empirical CDF of the NCDC recorded and FPP simulated daily ground snow loads are obtained and shown in Fig. 4.7(b), The simulated daily ground snow loads are fit to exponential, Weibull, lognormal, and Gumbel distributions. None of the four distributions fits the data. Then the same process is performed for the NCDC recorded daily ground snow loads. It is also found that none of the four distributions fit the data. Although no probability distribution is found to fit the daily ground snow loads, 
Table 4.4: Statistics of the annual maximum ground snow load for three sites

\begin{tabular}{llccccc}
\hline \hline Site & Data & Mean(psf) & Std(psf) & Distribution & $\lambda$ & $\xi$ \\
\hline Tahoe City & NCDC & 91.480 & 40.471 & lognormal & 4.431 & 0.411 \\
& FPP1 & 93.363 & 43.784 & lognormal & 4.413 & 0.536 \\
& FPP2 & 85.040 & 19.108 & lognormal & 4.418 & 0.229 \\
Stampede & NCDC & 241.669 & 85.869 & lognormal & 5.421 & 0.387 \\
& FPP1 & 238.160 & 76.880 & lognormal & 5.404 & 0.358 \\
& FPP2 & 209.505 & 40.244 & lognormal & 5.327 & 0.191 \\
Buffalo & NCDC & 18.038 & 22.763 & lognormal & 2.531 & 0.787 \\
& FPP1 & 21.782 & 15.684 & lognormal & 2.824 & 0.793 \\
& FPP2 & 23.4151 & 5.624 & lognormal & 3.122 & 0.259 \\
\hline
\end{tabular}

Std: standard deviation

FPP1: simulated results using the FPP model with the first cost function in Eq. (4.5)

FPP2: simulated results using the FPP model with the second cost function in Eq. (4.6)

the simulated daily ground snow loads approximately match the NCDC daily ground snow loads. For example, there is a probability of $70 \%$ that the NCDC daily ground snow load of Tahoe City is less than 50 psf, while the simulated daily ground snow loads at the same level with the probability between $62 \%$ and $76 \%$, implying that the FPP model captures the variation of the daily ground snow loads fairly well.

\subsubsection{Stampede, WA}

For Stampede, WA, 39-season ground snow load records are obtained from the NCDC. Fig. 4.8(a) shows four seasons of NCDC ground snow load records for this site. The ground snow load records are also simulated using the FPP model, as shown in Fig. 4.8(b), Snow accumulation can be observed in both Fig. 4.8(a) and Fig. 4.8(b), indicating that the FPP model is capable of modeling this characteristic. However, some different patterns between Fig. 4.8(a) and Fig. 4.8(b) still exist. In Fig. 4.8(a), snow load increases slower than it decreases, while it goes the opposite way in Fig. 4.8(b), The length of some simulated snow seasons is slightly shorter than that of the NCDC snow seasons. The reason for these differences is that these characteristics (i.e., the record shape and snow season length) are not incorporated in the cost function. 

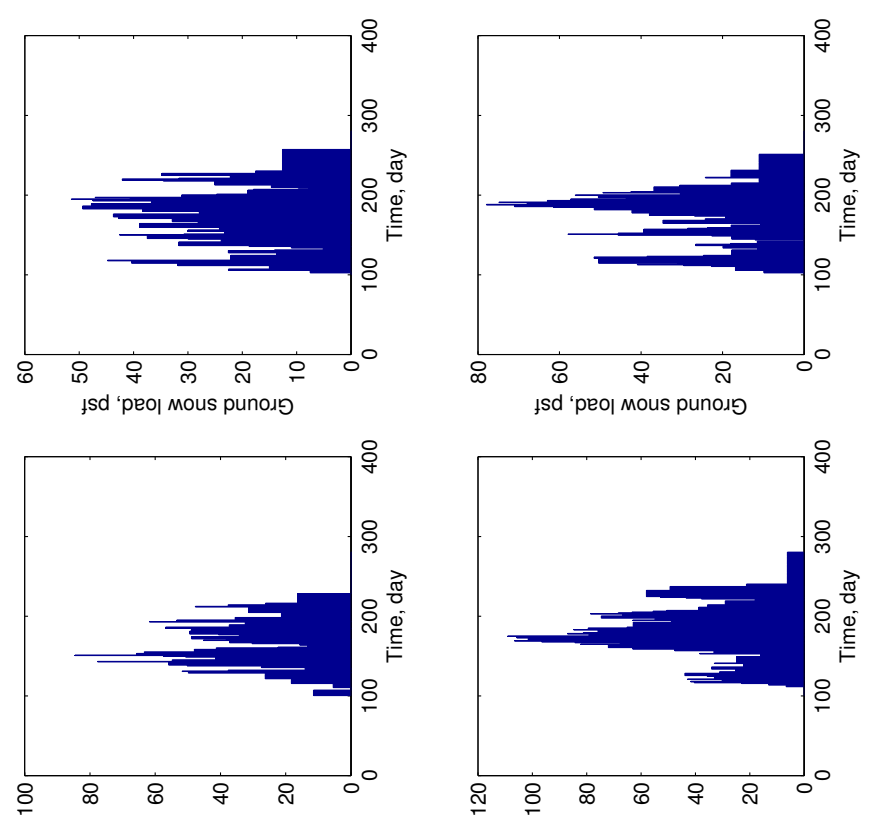

Isd 'peol Mous punoıg

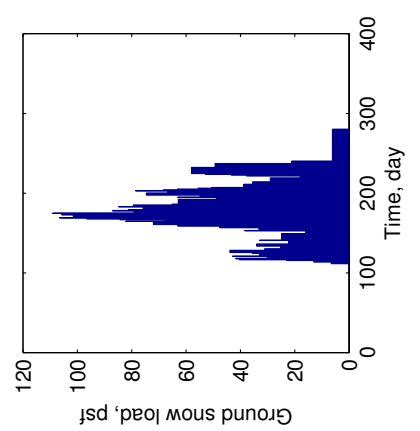

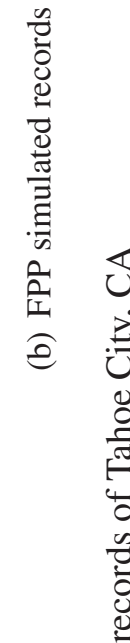
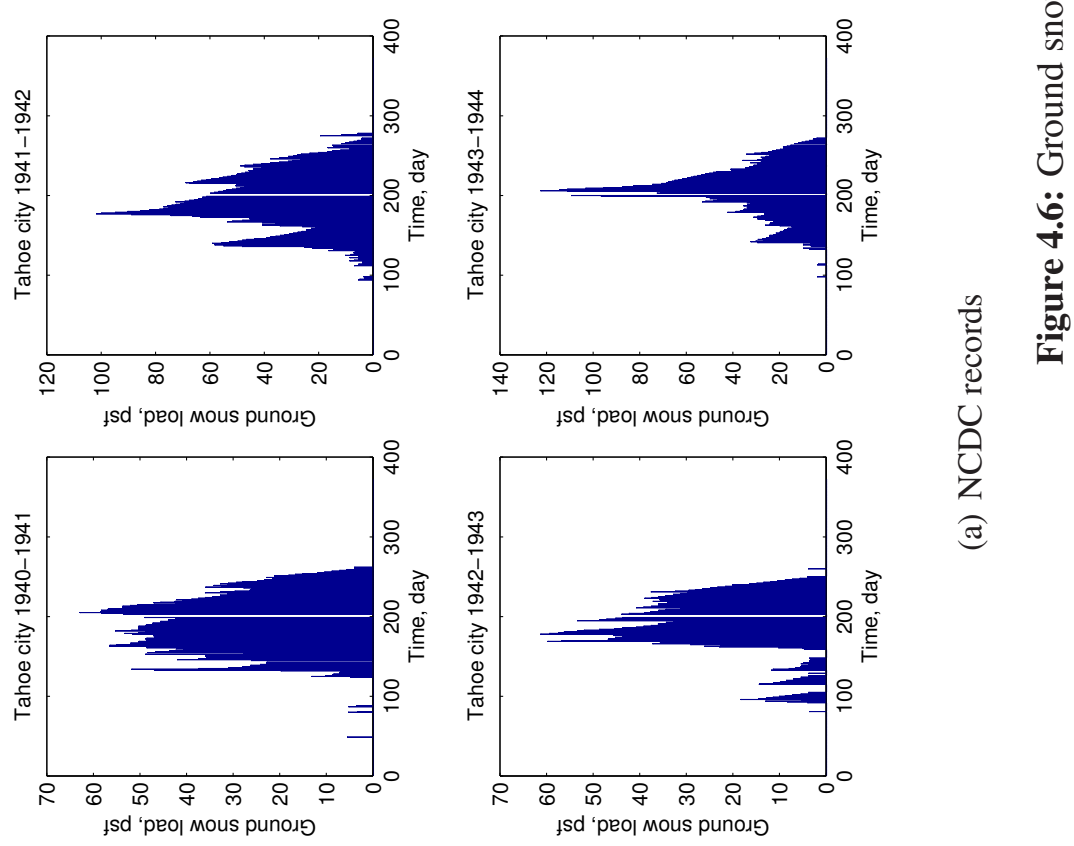


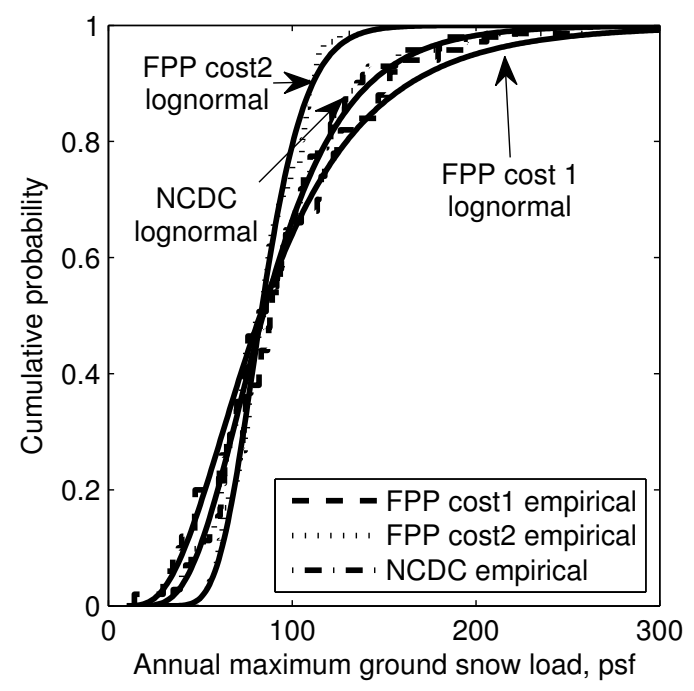

(a) Annual maximum ground snow load

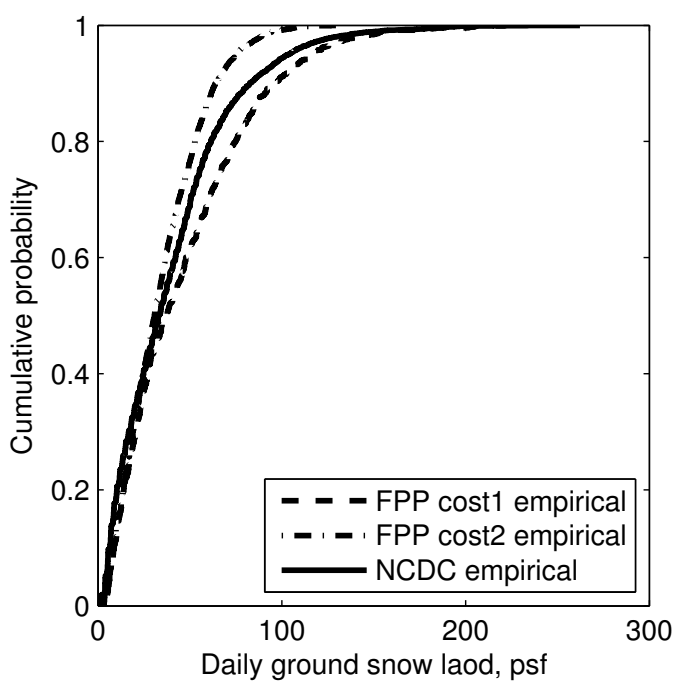

(b) Daily ground snow load

Figure 4.7: CDF plot of snow load of Tahoe City, CA

Both the NCDC and simulated annual maximum ground snow loads for Stampede were found to be lognormally distributed. The statistics of the lognormal distribution are listed in Table 4.4. The CDF plot of the annual maximum ground snow loads of Stampede is shown in Fig. 4.9. Similar to the case of Tahoe City, the exponential, Weibull, lognormal, and Gumbel distributions do not fit the daily ground snow loads of Stampede (both NCDC and simulated). Fig. 4.10 shows the CDF of the daily ground snow loads. The simulated records with the first cost function match the NCDC records better than those with the second cost function. There is a probability of $76 \%$ that the NCDC daily ground snow load of Stampede is less than 200 psf, while the simulated records with the first cost function indicate a probability of $81 \%$.

\subsubsection{Buffalo, NY}

For Buffalo, NY, 53-season NCDC ground snow load records are obtained from the NCDC. Similar procedures are performed for Buffalo. Fig. 4.11(a) 4.11(b) show the NCDC and simulated ground snow load records. The lognormal distribution still fits the annual maximum ground snow loads. Table 4.4 lists the parameters. Fig. 4.12 shows the CDF plot of the annual maximum ground snow loads of Buffalo. 
Different from Tahoe City and Stampede, snow loads of Buffalo keep 'on' and 'off' intermittently (Fig. 4.11(a) ), which is typically referred to as the load pulse pattern. This pattern can also be observed from the simulated records (Fig. (4.11(b) ), indicating that the FPP model can simulate both snow accumulation and load pulse patterns. The difference between Fig. 4.11(a) and Fig. 4.11(b) is that the simulated snow load pulses are 'compressed' in shorter timer periods than those of the NCDC snow records. The reason is that the length of snow season is not incorporated in the cost function. Similar to the cases of Tahoe City and Stampede, none of the four distributions (i.e., exponential, Weibull, lognormal, and Gumbel) fits the daily ground snow loads of Buffalo. However, the FPP model captures the daily ground snow loads fairly well, as can be seen from Figure 4.12 .

\subsubsection{Discussion}

The probability distribution of the annual maximum ground snow loads as well as the corresponding parameters are typically of interest and set as the 'control property' in Table 4.4 such that the simulated snow load records using different cost functions can be compared.

The differences between the lognormal distribution parameters (Table 4.4) determined from the NCDC and simulated snow load records using the frst cost function, are caused by the stochastic property of the simulated snow load records and cost function residue. Theoretically, cost 1 in Eq. (4.5) tends to be zero as realization number (i.e., numbers of snow season simulated) goes to infinity. In fact, only limited numbers of realization can be performed so there always is a residue of cost $_{1}$. Even for the same set of parameters (i.e., the best chromosome selected by the genetic algorithm as shown in Eq. (4.4)), the annual maximums statistics vary slightly for each run (i.e., a Monte Carlo simulation with certain number of realizations). The relatively large differences between the parameters determined from the NCDC and simulated snow load records using the second cost function are because the second cost function has the objective of the least sum of squared differences of annual maximums, which is different from the 'control property'(Eq. 4.6). 


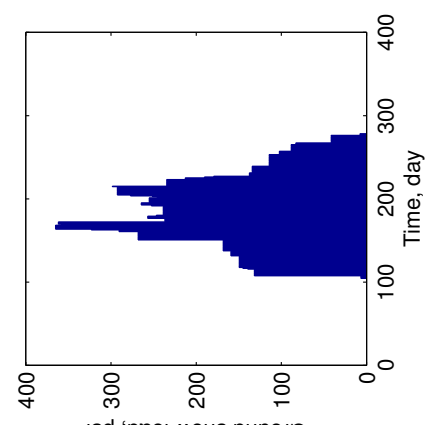

Isd 'peol Mous punoxg
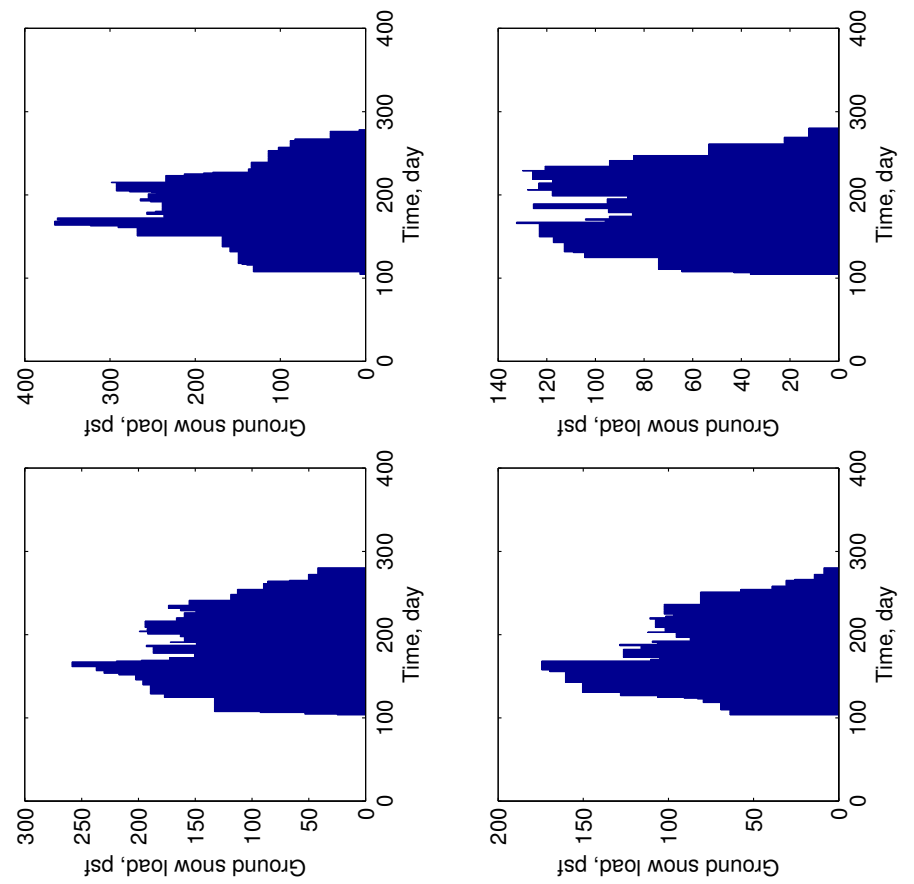

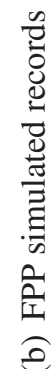
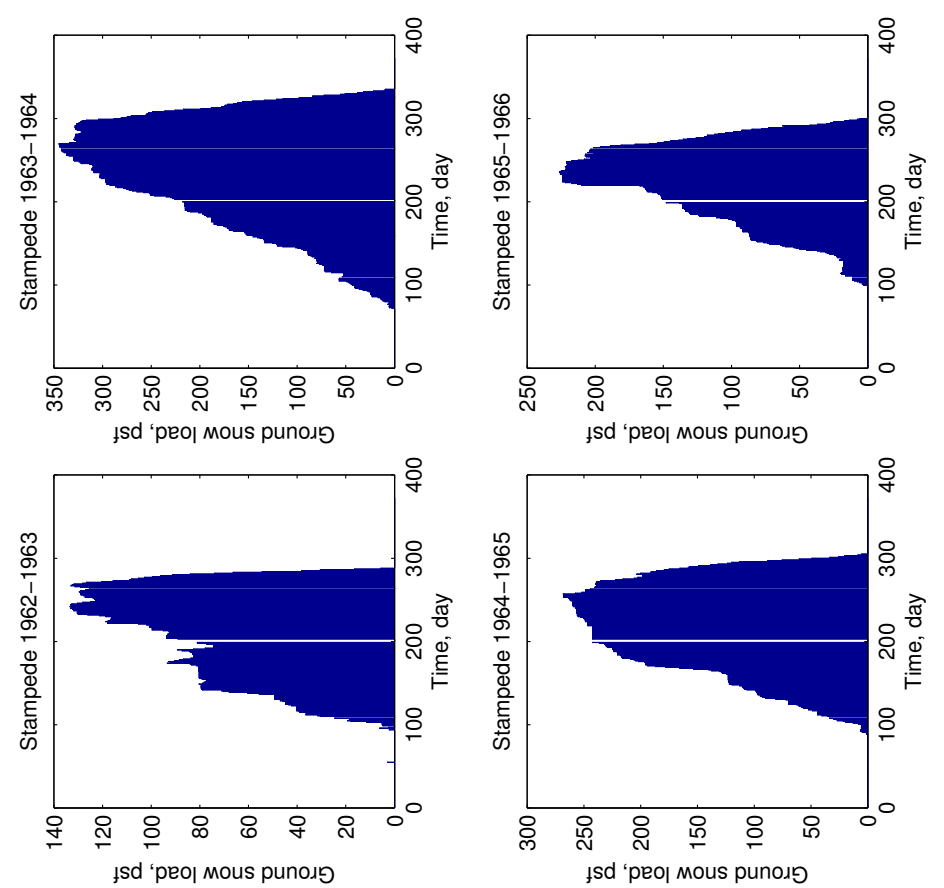

రే 


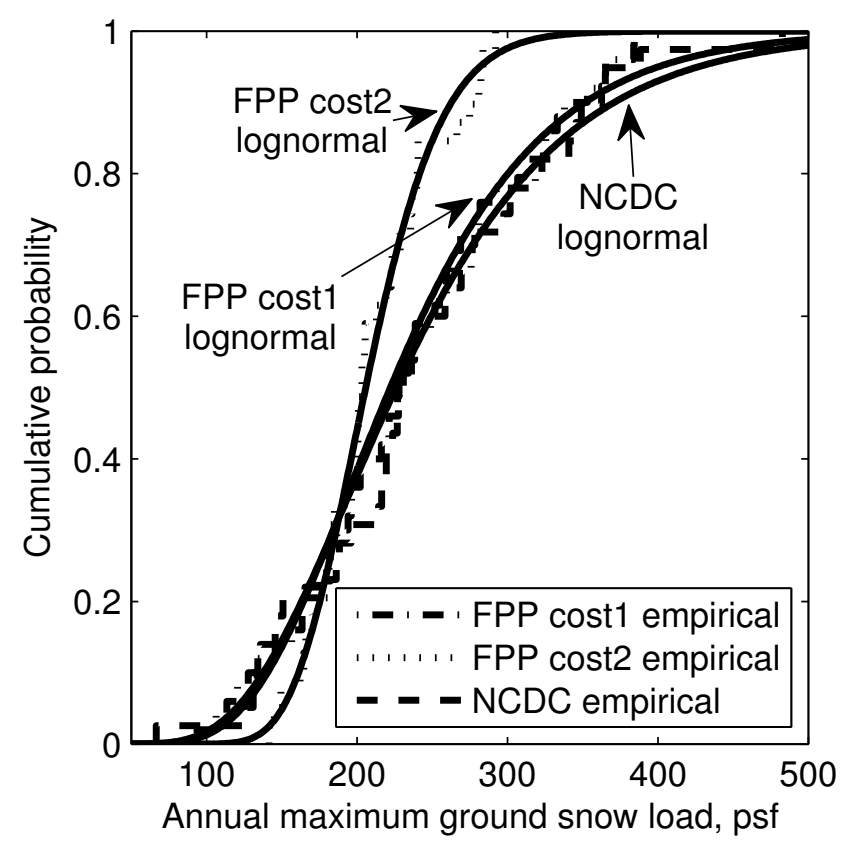

Figure 4.9: CDF plot of the annual maximum ground snow load of Stampede, WA

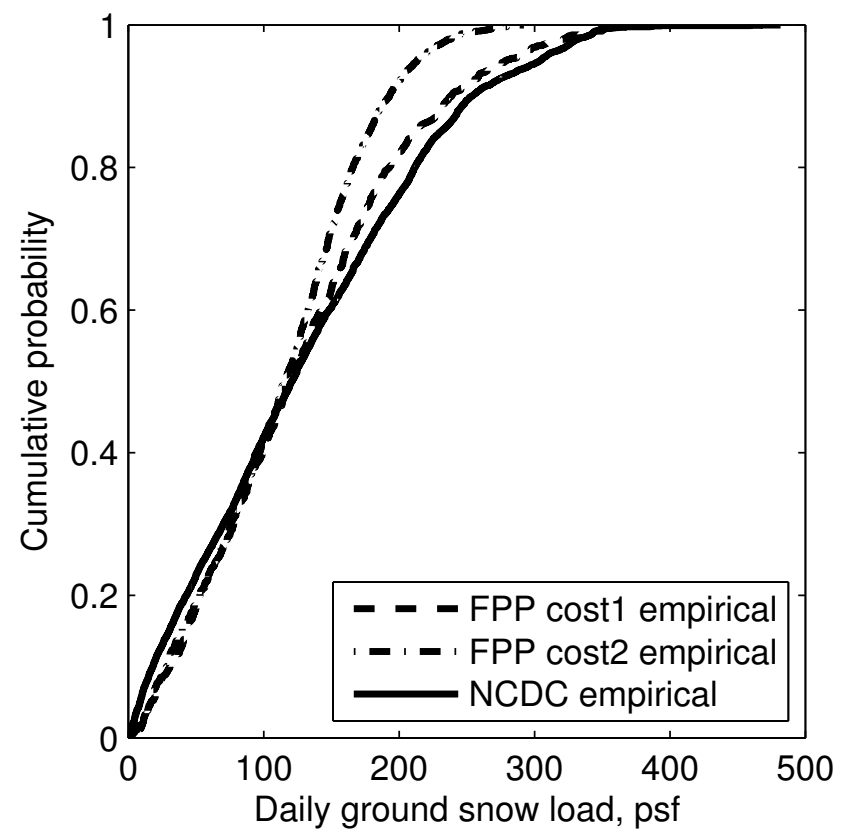

Figure 4.10: CDF plot of the daily ground snow load for Stampede, WA 

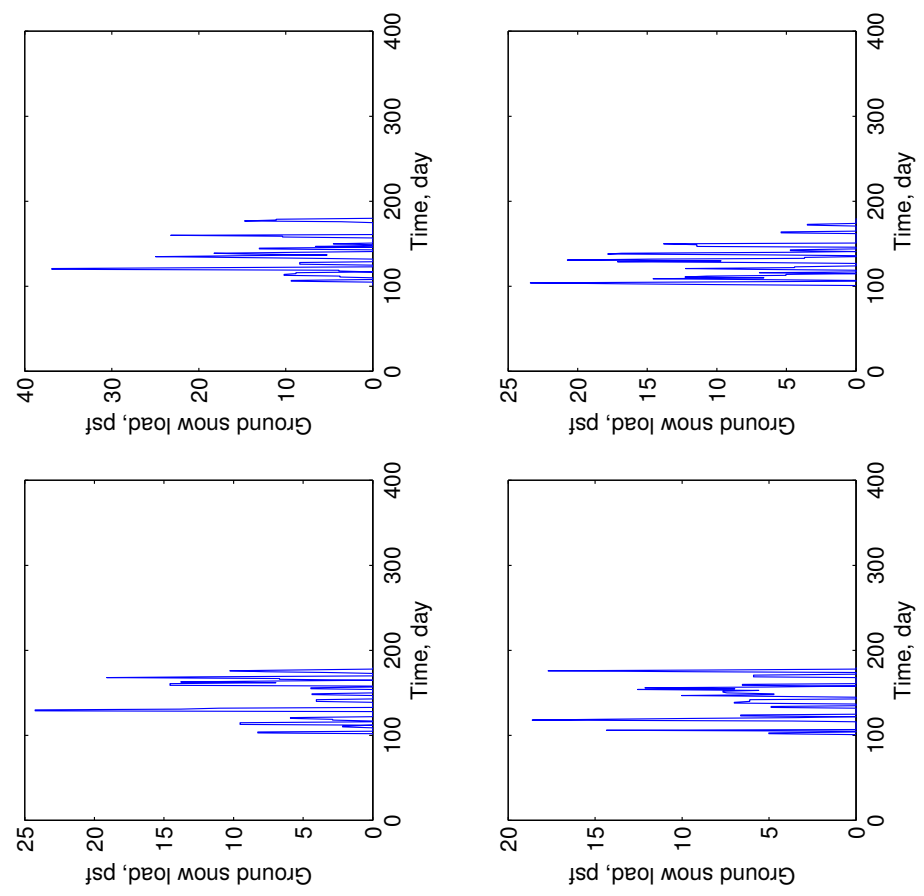

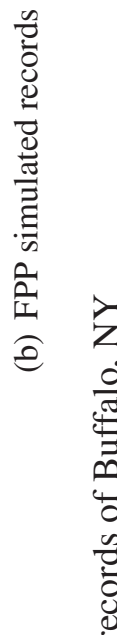
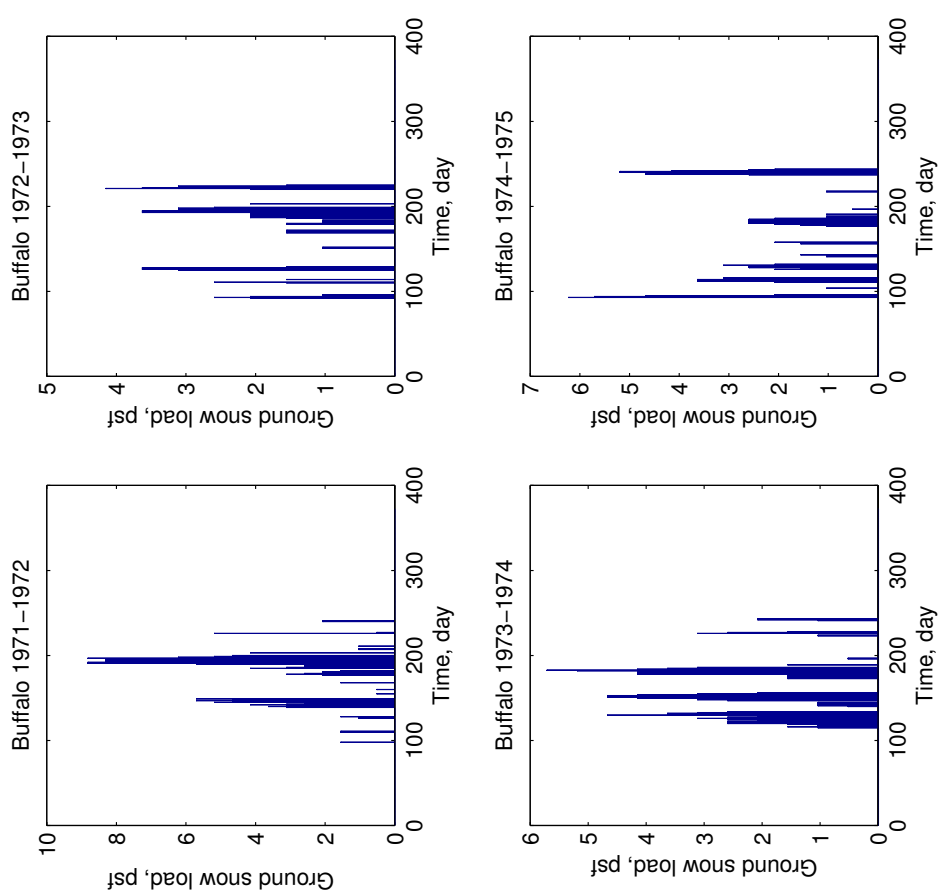


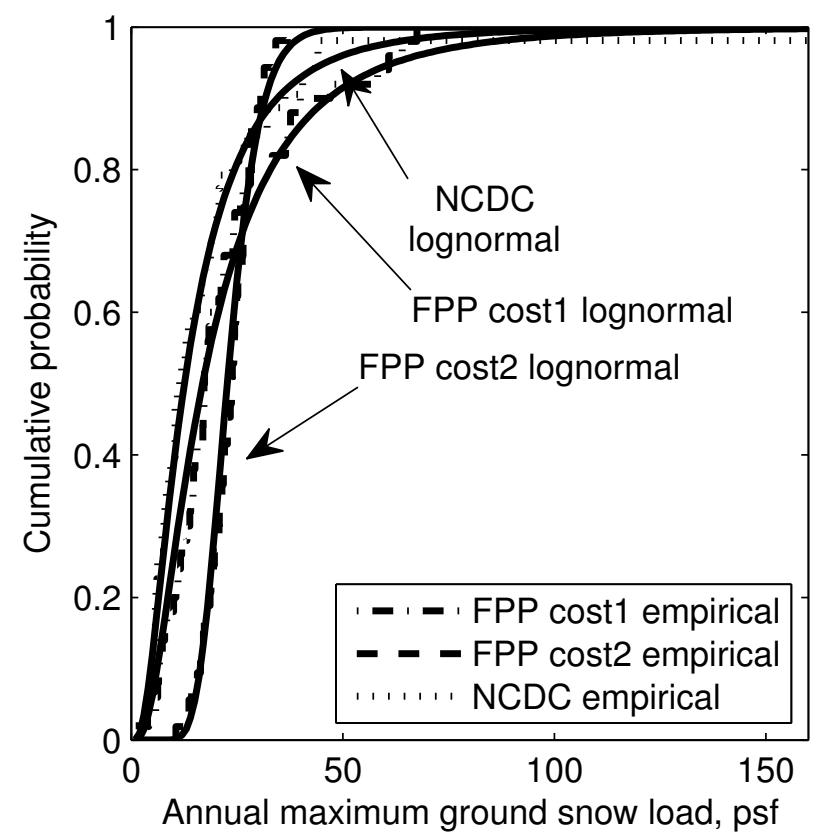

Figure 4.12: CDF of the annual maximum ground snow load for Buffalo, NY

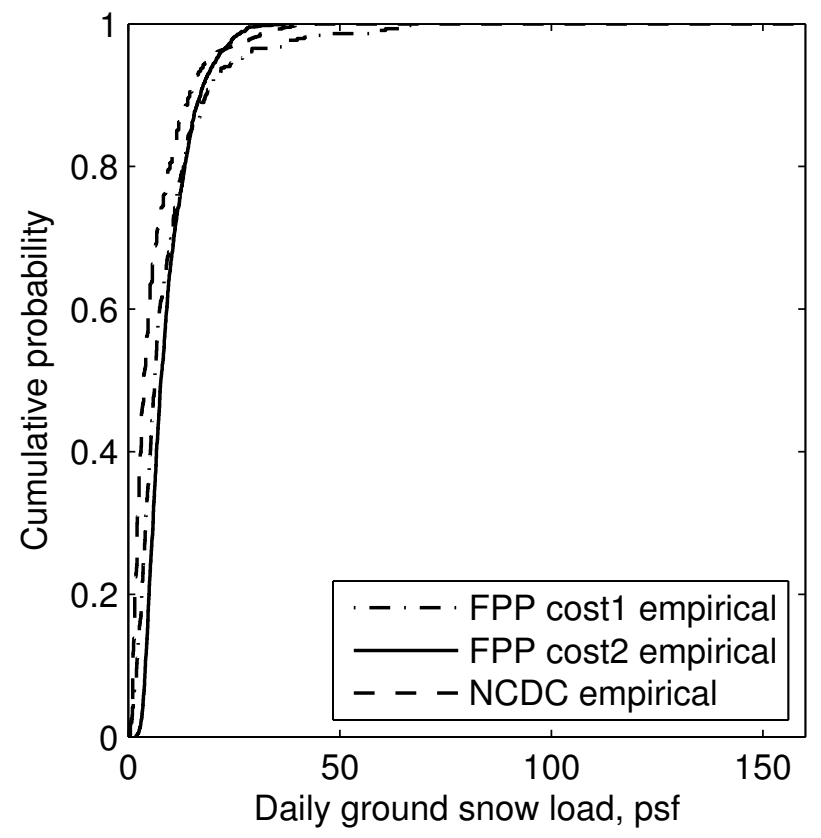

Figure 4.13: CDF of the daily ground snow load for Buffalo, NY 


\subsection{Future work}

Some characteristics of the ground snow load record are not thoroughly examined in this study, including the length of snow season and the shape of the snow load record with accumulation. The daily ground snow loads were examined by comparing the empirical $\mathrm{CDF}$ of both NCDC and simulated records (for the purpose of model validation). In the future, other cost functions should be considered to investigate such characteristics of snow load records so that the FPP model will be capable of modeling snow loads more accurately.

This study is a part of ongoing research by the authors to investigate quantified risks (i.e. economic losses) of light framed wood constructions subject to combined seismic and snow loads. The FPP model is to be used for stochastically modeling snow loads so that the load combination (at any point of time) of seismic and snow loads can be obtained. For such an application, snow season length (or snow covered period), snow load shape (i.e. snow accumulation or pulse like), and annual maximums are required, all of which can be provided by the FPP model.

Application may also include the investigation of the 'creep-rupture' behavior for timber structures subject to accumulated snow loads. As discussed earlier in this chapter, the Bernoulli model was typically used in such an application but it is not an appropriate model for heavy snow load areas. In comparison, the FPP model works well for both heavy and intermittent snow load areas. For timber structures located in heavy snow load areas, the FPP model can be used to simulate stochastic snow load histories to investigate the accumulated damage in timber structures using available damage models, e.g., [120-122].

\subsection{Summary}

The Bernoulli model has been used in the past to model snow loads. However, the model cannot be used for sites with heavy snow loads because it might lead to unconservative design of buildings located in such areas, for not being able to model the snow accumulation. In this study, the FPP model was investigated as a stochastic tool to simulate snow loads. Weather records from three sites were obtained from the NCDC to calibrate the 
FPP model. Both snow accumulation (Tahoe City, CA and Stampede, WA) and load pulse (Buffalo, NY) characteristics for different sites can be effectively simulated using the FPP model. A genetic algorithm was employed successfully to select parameters for the FPP model.

One of the merits of the FPP model is that different simulation objectives can be fulfilled by using different cost functions, while the Bernoulli model can only fit to the probability distribution of the annual maximum ground snow loads. The time variation (i.e., the daily ground snow loads) approximately match those of the NCDC snow records, which the Bernoulli model cannot achieve. 


\section{Chapter 5}

\section{Loss estimation of light-frame wood construction subjected to mainshock-aftershock sequences}

\subsection{Introduction}

It is found that aftershocks occur following an earthquake of large magnitude (referred to as the mainshock). In 24 hours after the 8.8 earthquake in Chile on Feb. 27, 2010, about 90 aftershocks with magnitudes equal to or larger than 5.0 were recorded by the United States Geological Survey [24]. In the Wen-Chuan earthquake on May 12, 2008 in China, 12 aftershocks with magnitudes larger than 5.0 were observed on the same day [25] after the mainshock. Figure 5.1 shows the recorded aftershocks in the 1999 Taiwan Chichi earthquake [26]. ' $M$ ' in the figure legend indicates the mainshock while ' $A$ ' indicates aftershocks. It can be observed that there are 3 aftershocks with magnitudes around 6.0 in 4 hours after the mainshock. Therefore, it is not realistic that the building is rebuilt to its intact state immediately, or before the next earthquake event, which is typically assumed in seismic loss estimation (e.g., [27, 28]). Depending on the damaged building status and the aftershock intensities, it can take 2 years or longer to reopen the building damaged in the mainshock [29], which results in significant economic losses. 


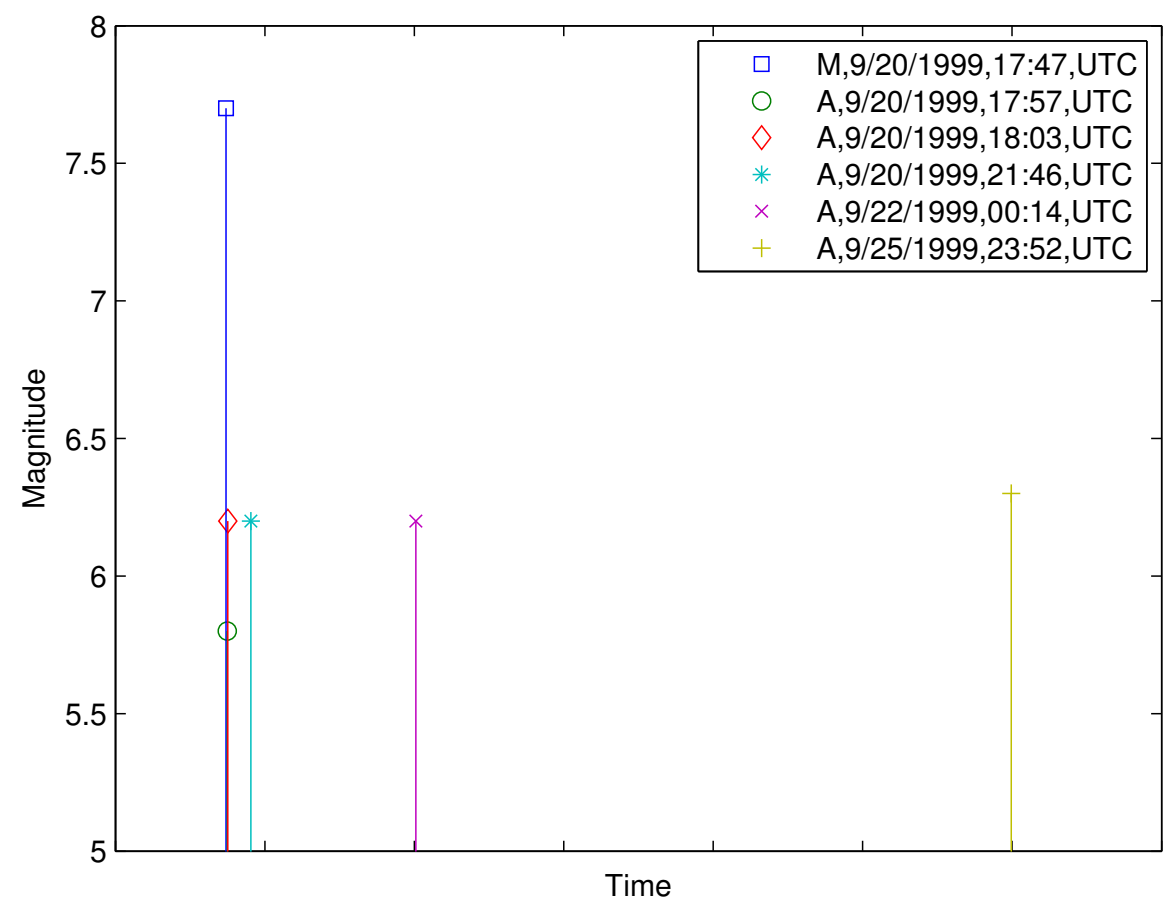

Figure 5.1: Recorded aftershocks in the 1999 Taiwan Chi-chi earthquake

Risk assessment of structures in the post-mainshock environment is critical and needs to be addressed properly [123]. A conceptional framework for seismic loss estimation was proposed by the Pacific Earthquake Engineering Research (PEER) Center [36, 37]. In the PEER framework, the seismic loss analysis consists of four components that are ground motion hazard, structural response, damage to components, and repair costs. Based on the PEER framework, several application frameworks for seismic loss estimation were proposed recently. For example, Pei and van de Lindt [27] developed a seismic loss estimation methodology for light-frame wood construction. The ATC-58 project [41] developed three methods, i.e., intensity-, scenario-, and time-based assessments for structural performance quantification. In these approaches, the building was assumed to be rebuilt to its intact state immediately after an earthquake, which is not realistic in the post-mainshock environment [29]. In addition, aftershocks were not considered in these approaches while aftershocks may have significant effects on the seismic loss estimation [29].

Light-frame wood construction is the most widely built structure in the United States (U.S.). Approximately $90 \%$ of residential buildings are light-frame wood construction. In the 1994 
Northridge earthquake, damage or collapse of wood residential construction caused $\$ 20$ billion in economic losses [1]. Some studies (e.g., [29, 30]) investigated the performance of steel and concrete buildings and risks due to mainshock and aftershock sequences. Markov models were investigated in the study by Yeo and Cornell [29]. In the study by Li and Ellingwood [30], only the intensities in terms of magnitude of mainshock and aftershock were simulated, while occurrence time of earthquakes and economic losses were not investigated. van de Lindt [124] conducted an experimental tests to investigate the behavior of light-frame wood structure subjected to multiple earthquakes in a sequence. However, the impact of aftershocks on light-frame wood construction is unclear.

To demonstrate the proposed framework, mainshock-aftershock sequences are simulated and applied to a typical wood residential building in the U.S., and the economic loss over a period of time is estimated. Mainshocks are simulated as a homogeneous Poisson process, while aftershocks are simulated as a nonhomogeneous Poisson process. The ground acceleration records from the ATC-63 project [62] are randomly selected and applied to the structural model to perform nonlinear dynamic analysis (NDA). The maximum inter-story drift obtained from the NDA is then used to determine the damage state of the building. At last the expected losses of the building subjected to mainshock and aftershock sequences are examined through Monte Carlo Simulation (MCS), considering both transition cost and downtime cost. The transition cost includes structural and nonstructural damage cost of the building due to one occurrence of the shock, as well as the evacuation cost of occupants in the building [29]. The downtime cost is the economic loss due to closed operation or limited function of the building [29].

Baker and Cornell [38] examined the uncertainty propagation for the PEER framework using the first-order second-moment (FOSM) method. Bradley and Lee [125] examined that approximation method by comparing it with direct numerical integration and concluded that great care should be taken in the use of such approximation because of the error (up to $50 \%$ ) in the results. In this study, the MCS method is used to estimate the seismic loss. The next-generation performance-based seismic design procedure, with its emphasis on risk quantification, is being developed by the ATC-58 project [41] and viewed as an improvement in performance-based engineering. The proposed framework in this chapter is an effort contributing to such an improvement. 


\subsection{Framework for seismic risk assessment}

Figure 5.2 shows a typical framework for seismic loss estimation (e.g., [27, 41]), which is termed fragility-based framework herein. The fragility curves (i.e., conditional probability functions) are essential components in such a framework. In the fragility-based frameworks, the aftershock sequences, including the number and magnitudes of aftershocks as well as the inter arrival time, are not explicitly examined. For example, in the ATC-58 project [41], seismic loss was estimated using a loss function, which is a cumulative probability function of losses conditioned on the earthquake hazard level. Since aftershocks may have significant effects on seismic loss of buildings as shown in recent studies, an approach is needed so that the effects of aftershocks on seismic loss can be explicitly examined.

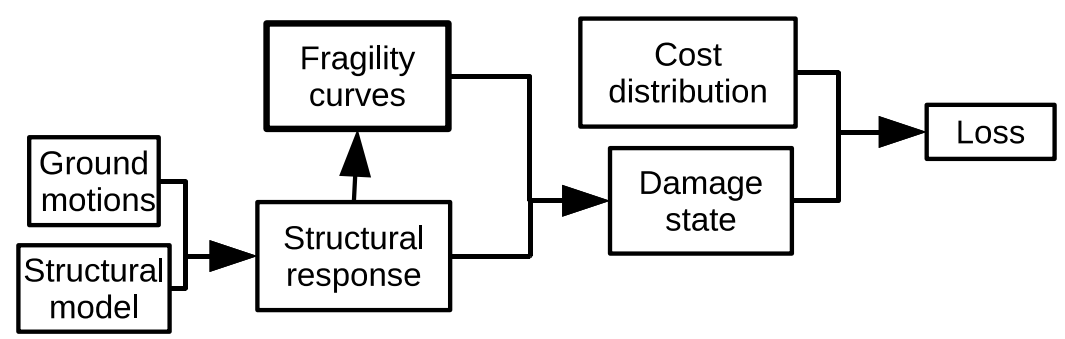

Figure 5.2: Fragility-based frameworks for seismic loss estimation

Object-oriented $(\mathrm{OO})$ technology has been found to be a proper tool to develop flexible and reusable programs for computer-aided engineering since the 1990's (e.g., [126, 127]). The object in the $\mathrm{OO}$ technology simulates an entity (e.g., earthquake in this study) with built-in numerical models [127]. To overcome the difficulties of fragility-based frameworks on the investigation of seismic loss including both mainshock and aftershock, an object-oriented framework (shown in Figure 5.3) is proposed herein with the merits listed as follows.

$\dagger$ It is object-oriented. The four components of the PEER framework are represented by three objects, i.e., shock simulation, structural analysis, and loss analysis, as shown in Figure 5.3. Each object has an interface through which external procedures can exchange data with it. The built-in numerical models in the objects can be updated or replaced by alternative models, without affecting other objects. For example, aftershock simulation can be removed from the shock simulation object and the ultimate results will be economic losses due to mainshocks only. In comparison, 
the fragility-based frameworks have limited options for aftershocks and downtime cost, which may significantly underestimate the seismic risk.

$\dagger$ All sources of uncertainties can be explicitly propagated in the framework. The framework has the potential to examine the effects of various sources of uncertainties on the estimated losses.

$\dagger$ It is extensible. For example, the framework can be extended for multiple hazards risk assessment, by adding more hazard objects. The OO framework is applied in Chapter 6 on risk assessment of buildings subjected to combined snow and seismic load.

In the following sections, the three objects of the proposed framework are discussed separately.

\subsubsection{Simulation of mainshock-aftershock sequences}

\subsubsection{Mainshock simulation}

The mainshock occurrence is typically simulated as a homogeneous Poisson process. Let $N_{e q}$ be the number of earthquakes occurred in a period of time, $T$. The occurring time, $t_{e q, i}$, of each earthquake can be determined by:

$$
t_{e q, i}=T_{0}+\sum_{j=1}^{i} \tau_{j}
$$

where $T_{0}$ is the starting point of time and $\tau_{i}, i=1,2, \ldots, N_{e q}$ is exponentially distributed. Note that $T_{0} \leq t_{e q, i} \leq T$.

The probability density function (PDF) of mainshock magnitude $\left(M_{m}\right)$ can be determined by the Gutenberg-Richter relationship [128] as:

$$
f_{M_{m}}(x)=\frac{\beta e^{-\beta x}}{e^{-\beta M_{m, \min }}-e^{-\beta M_{m, \max }}}
$$




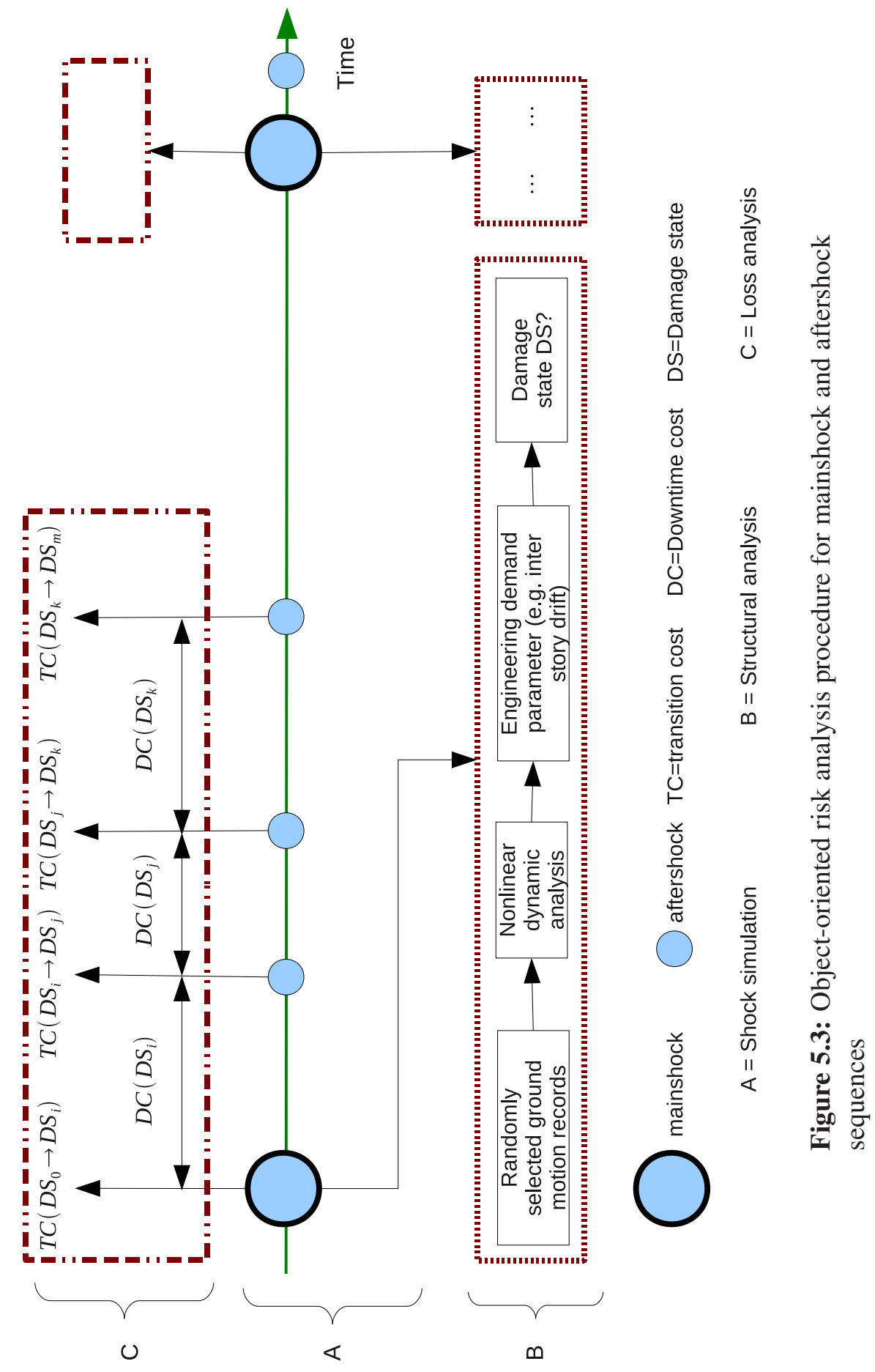


where $M_{m, \min }$ and $M_{m, \max }$ are the minimum and maximum magnitudes considered for the site, respectively, and $\beta$ is a site specific parameter.

\subsubsection{Aftershock simulation}

The occurrences of aftershock are usually modeled as a nonhomogeneous Poisson process [123, 129]. The mean daily rate of aftershock can be calculated by the modified Omori's Law [130, 131] as:

$$
\lambda\left(t, M_{m}\right)=\frac{10^{a+b\left(M_{u}-M_{l}\right)}-10^{a}}{(t+c)^{p}}
$$

where $\lambda\left(t, M_{m}\right)$ is the mean daily rate of aftershock with magnitude between $M_{l}$ and $M_{u}$ at time $t$ (in days) following a mainshock with a magnitude of $M_{m}$, and $M_{l}$ represents the minimum aftershock magnitude of engineering interest. In this study, $M_{l}$ is taken to be 5.0 [29, 132]. $M_{u}$ is typically considered to be the mainshock magnitude $M_{m}$. The aftershock sequence parameters in Eq. (5.3) are site specific. For California, they were found to be $a=-1.67, b=0.91, p=1.08$ and $c=0.05$ [129, 133].

In the insurance industry, the nonhomogeneous Poisson process is used to simulate the claim arrival process [134]. A 'rejecting' method has been proved efficient to simulate the nonhomogeneous Poisson process [134-136]. Let $T_{1}$ and $T_{2}$ indicate the occurring time of two mainshocks. Let $N_{a}$ be the number of aftershocks in the period $\left(T_{1}, T_{2}\right)$. The occurring time of the $N_{a}$ aftershocks are to be simulated using the 'rejecting' method. As shown in Eq. (5.3), the mean daily rate of aftershock decreases rapidly as days elapse. Therefore, $\lambda(t) \leq \bar{\lambda}$, where $t \in\left[T_{1}, T_{2}\right]$ and $\bar{\lambda}=\lambda\left(T_{1}\right)$. Note that $\lambda(t)$ can be determined by Eq. (5.3) given a mainshock magnitude. The 'rejecting' algorithm is summarized as follows:

Step 1: $\operatorname{set} T^{*}=0$

Step 2: for $i=1,2, \ldots, N_{a}$

Step 2.1: generate an exponential random number $u_{e}$ using the parameter $\bar{\lambda}$

Step 2.2: let $T^{*}=T^{*}+u_{e}$ 
Step 2.3: generate a random number $u$ uniformly distributed in $(0,1)$. If $u>\lambda\left(T^{*}\right) / \bar{\lambda}$, go back to Step 2.1 (i.e., rejecting $T^{*}$ ), otherwise, $T(i)=T^{*}$

Step 3: $T(i)+T_{1}, i=1,2, \ldots, N_{a}$ are occurring time of aftershocks

Figure 5.4 shows the simulated and analytical mean daily rate of aftershock, following a mainshock with a magnitude $M_{m}=7.3$ in California. 100 runs of MCS are shown in Figure 5.4 by circles (o). The $y$ coordinate of a circle indicates the number of aftershocks, while the $x$ coordinate indicates the day on which the aftershocks are 'observed'. Note that many circles may overlap each other and seem as one circle in the figure. The simulated mean occurrence rate is shown by the dash line, while the median occurrence rate is shown by the dotted line. It can be observed that the simulated mean rate using the 'rejecting' method well matches the analytical mean rate given by Eq. (5.3). Figure 5.5 shows histograms of the number of simulated aftershocks on the $1^{\text {st }}$ and $20^{\text {th }}$ days after the mainshock. On the $1^{\text {st }}$ day, the simulated mean number of aftershocks (i.e., the mean daily rate) is $2.55 /$ day, with a coefficient of variation (COV) of 0.65 . On the $20^{\text {th }}$ day, the mean rate is 0.08 /day with a COV of 3.84. The analytical mean rates, given by Eq. (5.3), on the $1^{s t}$ and $20^{\text {th }}$ days are 2.49/day and 0.10/day, respectively. Figure 5.6 shows a simulated aftershock sequence following a mainshock with a magnitude $M_{m}=7.3$ in California.

\subsubsection{Selecting and scaling of ground motions}

Once the shock sequence, including the occurrence time and magnitudes of mainshocks and aftershocks, is obtained by simulation, ground acceleration records are to be selected for each shock. One approach is to numerically simulate ground motion records. In this study, another approach is used, which is to select recorded data from an earthquake database. This approach was also used by Huang et al. [137]. The Far-Field bin in the ATC-63 project [62], including 44 ground motions, is used for NDA in this study. The 44 ground motions are carefully selected so that they are statistically sufficient to represent the recordto-record uncertainty [62].

The spectral acceleration is assumed to be lognormally distributed [41]. For each shock (either mainshock or aftershock), the median spectral acceleration $\bar{S}_{a}$ and dispersion $\sigma_{\ln S_{a}}$ can be determined using the attenuation model. Then a spectral acceleration $S_{a, 0}$ is sampled 


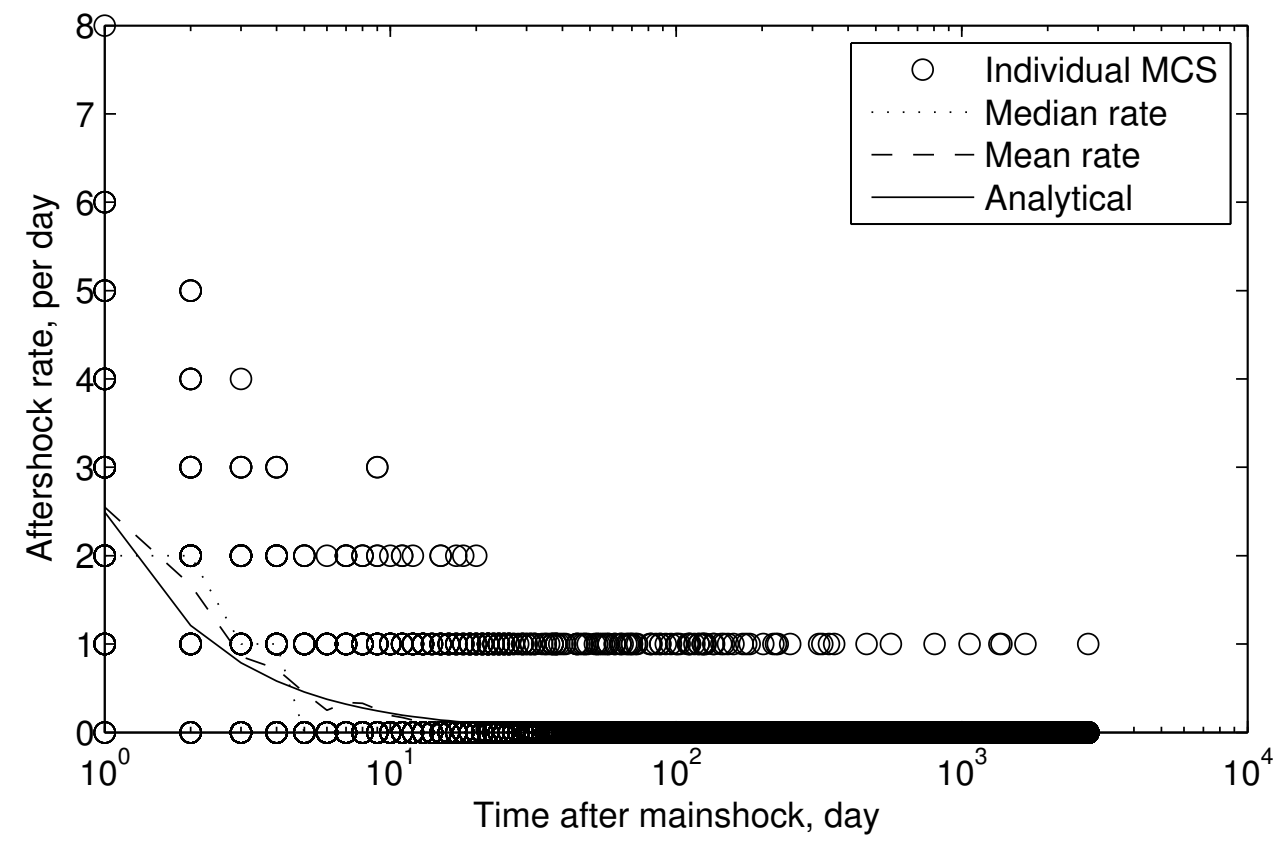

Figure 5.4: Daily aftershock rate after a mainshock of $M_{m}=7.3$ in California (only aftershocks with magnitudes $M \geq 5$ are considered in the simulation)

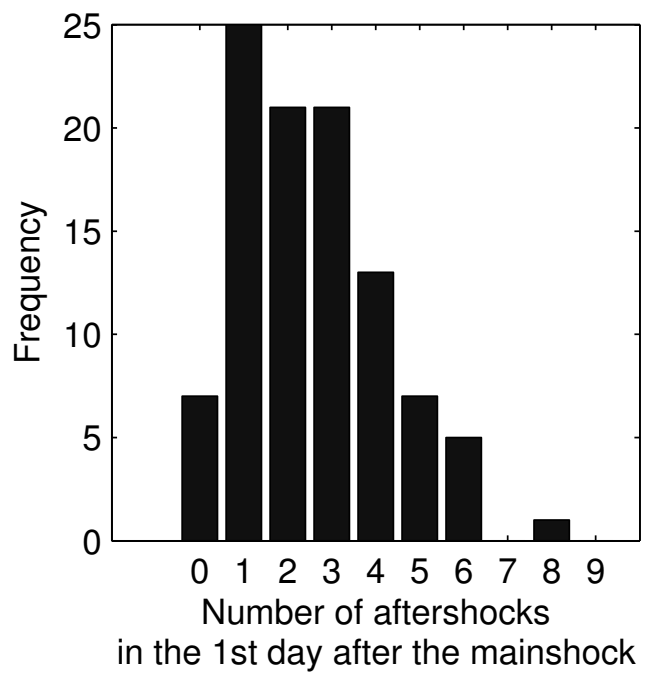

(a) $1^{\text {st }}$ day after the mainshock

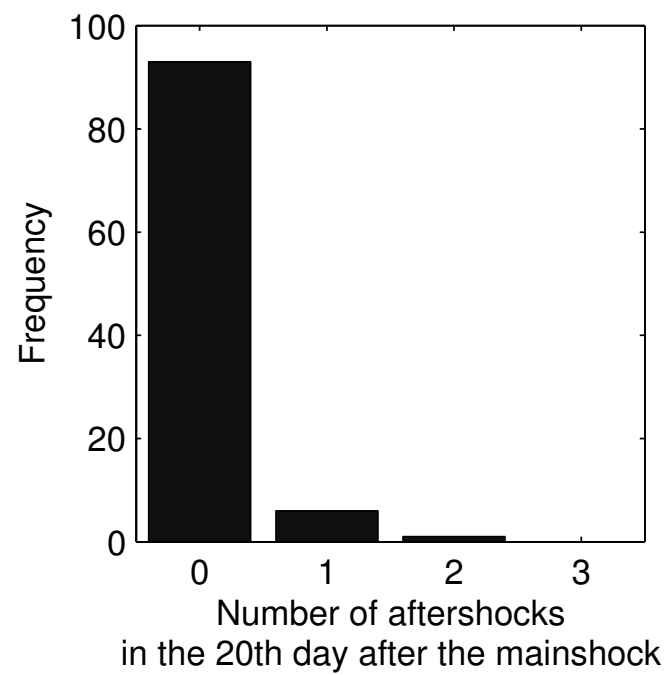

(b) $20^{\text {th }}$ day after the mainshock

Figure 5.5: Histogram of simulated number of aftershocks following a mainshock with the magnitude $M_{m}=7.3$ in California (only aftershocks with magnitudes $M \geq$ 5 are considered in the simulation) 


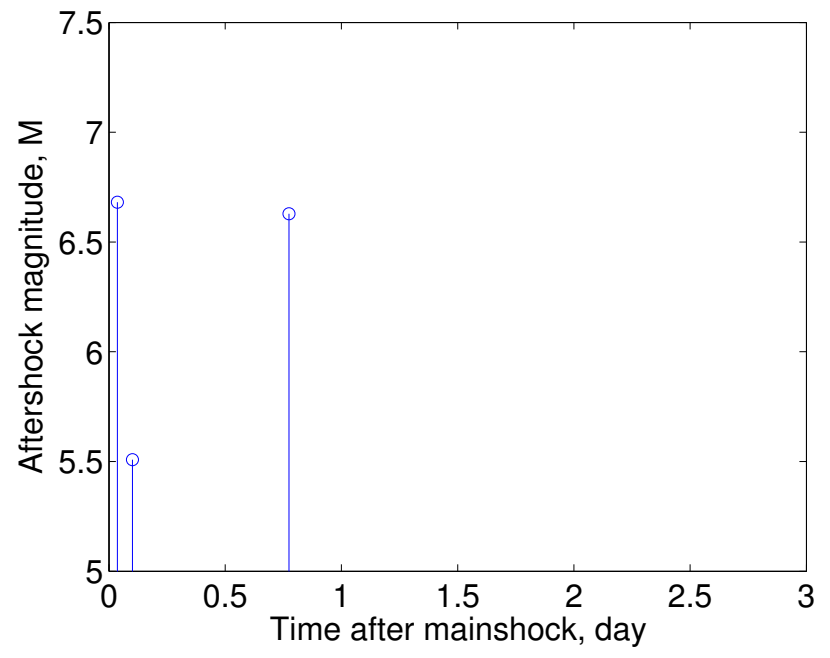

Figure 5.6: Simulated aftershocks following a mainshock with magnitude $M_{m}=$ 7.3 (only aftershocks with magnitudes $M \geq 5$ are considered in the simulation)

from the lognormal distribution using the two parameters $\overline{S_{a}}$ and $\sigma_{l n S_{a}}$. The source-tosite distance used in the attenuation equation is assumed to be uniformly distributed. The attenuation model developed by Abrahamson and Silva [83] is used in this chapter. Other attenuation models may also be used. Following the sampling of $S_{a, 0}$, a ground motion record is to be randomly selected from the Far-Field bin. Let $S_{a, 1}$ stand for the $S_{a}\left(T_{1}\right)$ of the selected ground motion record. The randomly selected ground motion record is scaled by a factor $C_{s}=S_{a, 0} / S_{a, 1}$ and applied to the structural model to perform NDA.

\subsubsection{Structural model and nonlinear dynamic analysis}

In this study, the proposed framework is applied to a typical one-story light-frame wood residential building located in California. Wood shear walls are the main lateral forceresisting system of the building. The configuration of the building is shown in Figure 5.7, where details of openings for the south shear wall are illustrated. The dimensions of the building are $9.75 \mathrm{~m}(32 \mathrm{ft})$ long, $6.10 \mathrm{~m}(20 \mathrm{ft})$ wide and $2.44 \mathrm{~m}(8 \mathrm{ft})$ high. The shear walls are covered by $1.22 \times 2.44 \mathrm{~m}(4 \times 8 \mathrm{ft})$ sheathing panels, which might be modified, as appropriate, to allow for door and window openings. The sheathing of the shear walls is provided by $9.5 \mathrm{~mm}$ (0.375 in) oriented strand board (OSB) panels. Studs are spaced at $610 \mathrm{~mm}$ ( $24 \mathrm{in}$ ) on centers. The sheathing is connected to the studs with $8 \mathrm{~d}$ common nails, 
which are $3.33 \mathrm{~mm}(0.131 \mathrm{in})$ in diameter. The nails are spaced $152.4 \mathrm{~mm}$ (6 in) along the sheathing panel perimeter and $304.8 \mathrm{~mm}$ (12 in) in the panel interior. The fundamental period of the wood building is 0.25 second. The construction details for this residence represent common light-frame wood construction practice in the U.S.

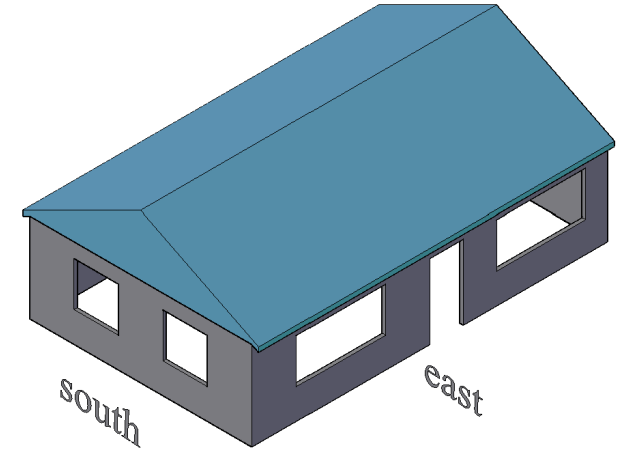

(a) 3-D model for the light-frame wood building

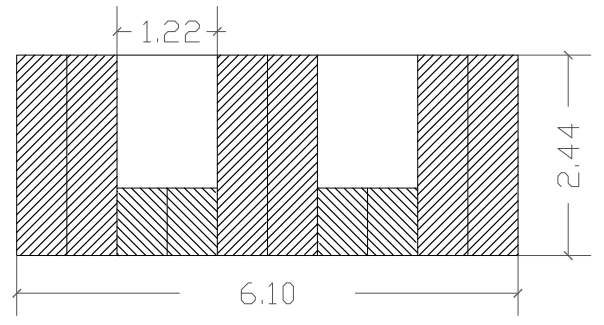

(b) South shear wall (unit: meter)

Figure 5.7: Schematic of one-story wood frame residence

The response of a wood-frame construction subjected to seismic load is highly nonlinear and shows pinched hysteretic behavior with strength and stiffness deterioration. Figure 5.8 shows the load-displacement response of a typical wood-frame shear wall subjected to a ground motion record. The backbone curve (i.e., the envelope of the hysteresis curves) was developed by Folz and Filiatrault [78] and defined by:

$$
F= \begin{cases}\operatorname{sgn}(\boldsymbol{\delta})\left(F_{0}+r_{1} K_{0}|\delta|\right)\left(1-e^{-K_{0}|\delta| / F_{0}}\right) & \text { if }|\delta| \leq\left|D_{u}\right| \\ \operatorname{sgn}(\boldsymbol{\delta}) F_{u}+r_{2} K_{0}\left[\delta-\operatorname{sgn}(\delta) D_{u}\right] & \text { if }\left|D_{u}\right|<|\delta| \leq\left|D_{F}\right| \\ 0 & \text { if }|\delta|>\left|D_{F}\right|\end{cases}
$$

where $K_{0}$ is the initial stiffness, $D_{u}$ and $F_{u}$ correspond to the shear wall ultimate capacity in terms of displacement and base shear force, after which the load bearing capacity decreases with a slope of $r_{2}$. Five more parameters $r_{3}, r_{4}, F_{1}, \alpha$, and $\beta$ were also introduced in the model by Folz and Filiatrault [78]. The hysteresis curves in Figure 5.8 are obtained using the model. $r_{3}$ is the unloading stiffness from the backbone curve. $r_{4}$ is the pinching line slope. $F_{1}$ indicates the point where the pinched hysteresis curves pass through. $\alpha$ and $\beta$ are two parameters considering stiffness and strength degradation, respectively. Details about 
these parameters are provided in Folz and Filiatrault [78]. Using this hysteresis model, Folz and Filiatrault [79] developed the SAWS program to perform NDA for light-frame wood construction. In this study, the dynamic response of the one-story light-frame wood building shown in Figure 5.7 is obtained using the SAWS program.

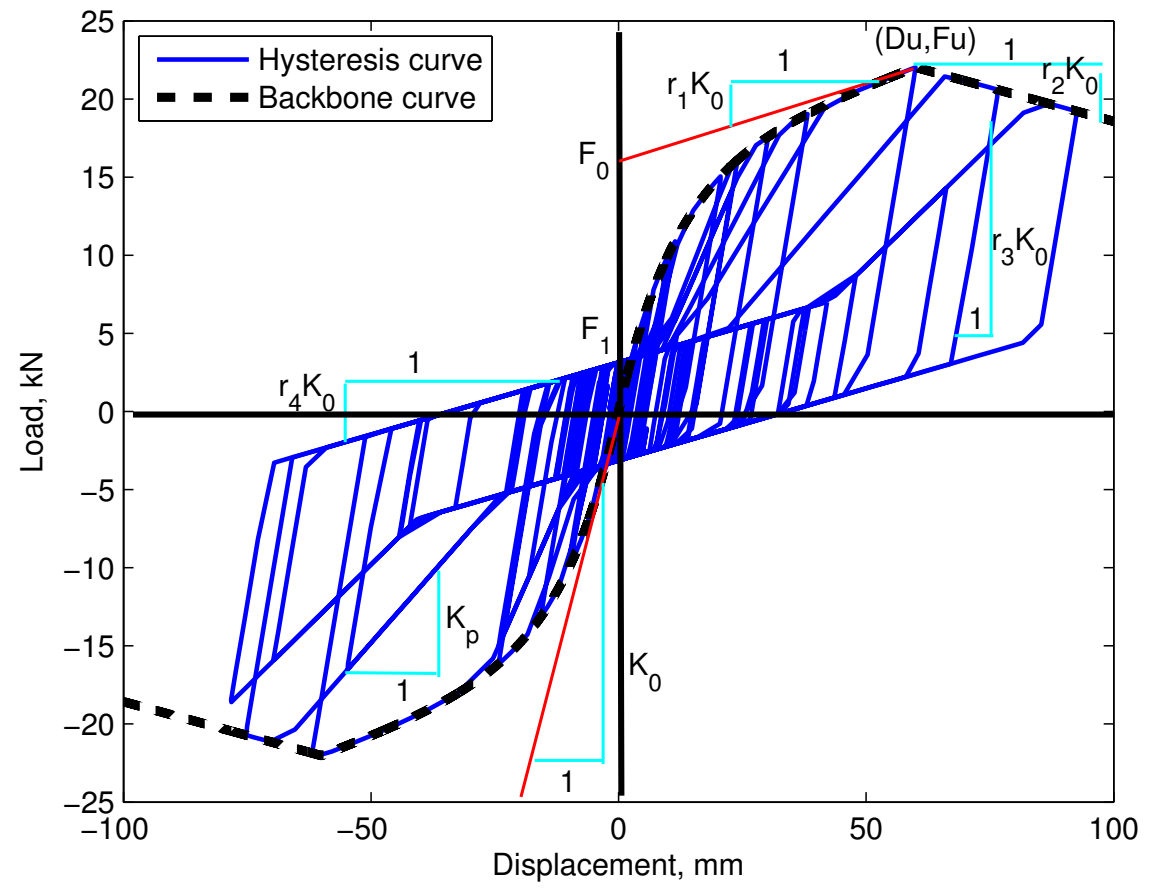

Figure 5.8: Hysteresis model of light-frame wood shear wall

For each shock in a simulated mainshock-aftershock sequence, a ground motion is selected and scaled as discussed in Section "Selecting and scaling of ground motions". Then an extended ground acceleration time history is formed by putting the ground motions of each shock "back to back". The nonlinear NDA performed using the extended ground acceleration time history is termed back-to-back NDA [138]. For the one-story building in Figure 5.7(a), it is found that the inter-story drift due to ground motion along the west-east direction is larger than that due to the same ground motion applied along the south-north direction. The back-to-back ground motion is then applied to the structural model along the west-east direction to perform NDA. Figure 5.9 shows the inter-story drift time history of the one-story building subjected to a back-to-back ground motion record, including a mainshock and an aftershock. 


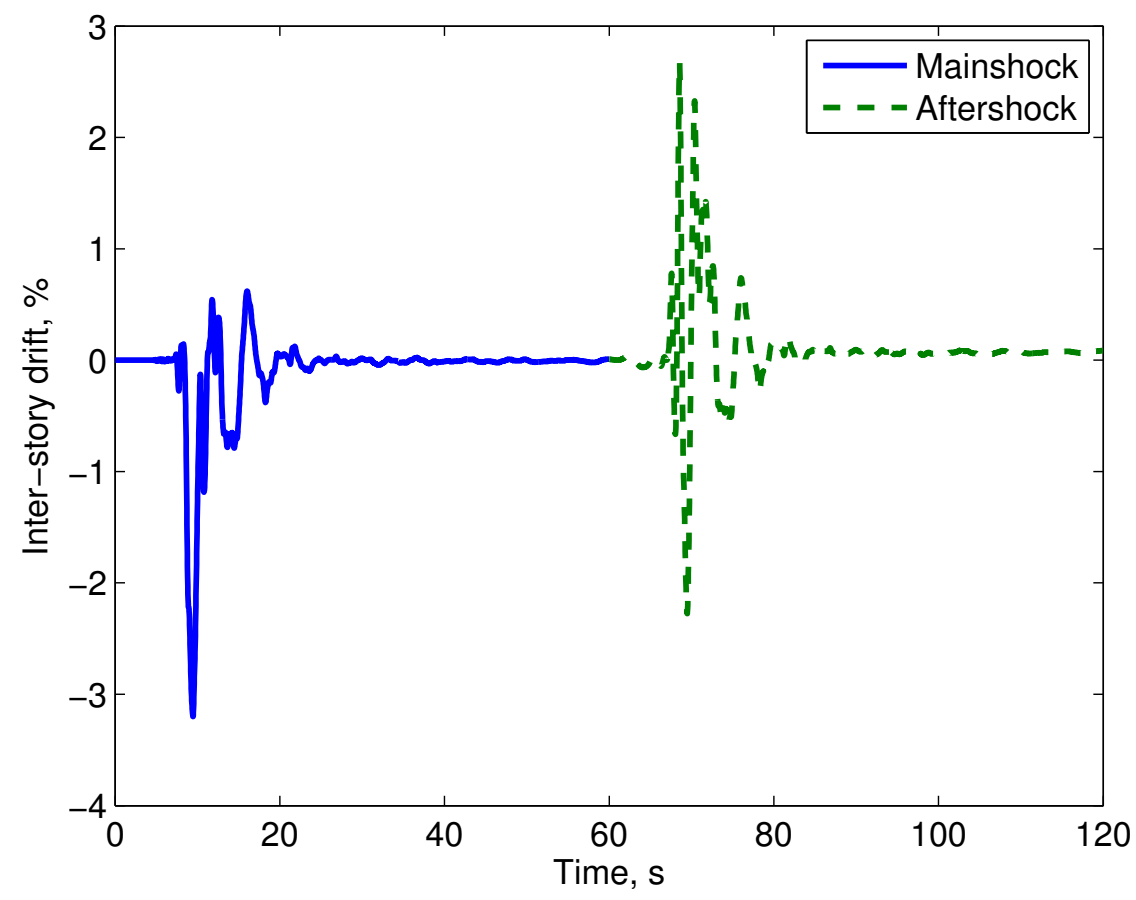

Figure 5.9: Drift time history of the building subjected to a back-to-back ground motion

\subsubsection{Damage and loss estimation}

The maximum instantaneous inter-story drift obtained in the NDA is recorded as the engineering demand parameter (EDP) that is used to determine the damage state. Five damage states are used in this study, including three damage states $\left(\mathrm{DS}_{1}, \mathrm{DS}_{2}, \mathrm{DS}_{3}\right)$ defined in the ATC-58 project [41], the undamaged state $\left(\mathrm{DS}_{0}\right)$, and the collapse state $\left(\mathrm{DS}_{4}\right)$. Figure 5.10 shows the fragilities of $\mathrm{DS}_{0}, \mathrm{DS}_{1}, \mathrm{DS}_{2}$, and $\mathrm{DS}_{3} . \mathrm{DS}_{1}, \mathrm{DS}_{2}$, and $\mathrm{DS}_{3}$ are assume to be lognormally distributed [41]. The median values are $1 \%, 1.75 \%$, and $2.5 \%$, respectively. The dispersion is 0.4 for the three damage states.

For an EDP level, say 1.5\% inter-story drift, a uniform random number $u \in(0,1)$ is generated and compared to the damage state exceedance probabilities, $0.10,0.35$, and 0.84 as shown in Figure 5.10. The building is in $\mathrm{DS}_{3}$ if $u \leq 0.10$; or $\mathrm{DS}_{2}$ if $0.10<u \leq 0.35$; or $\mathrm{DS}_{1}$ 


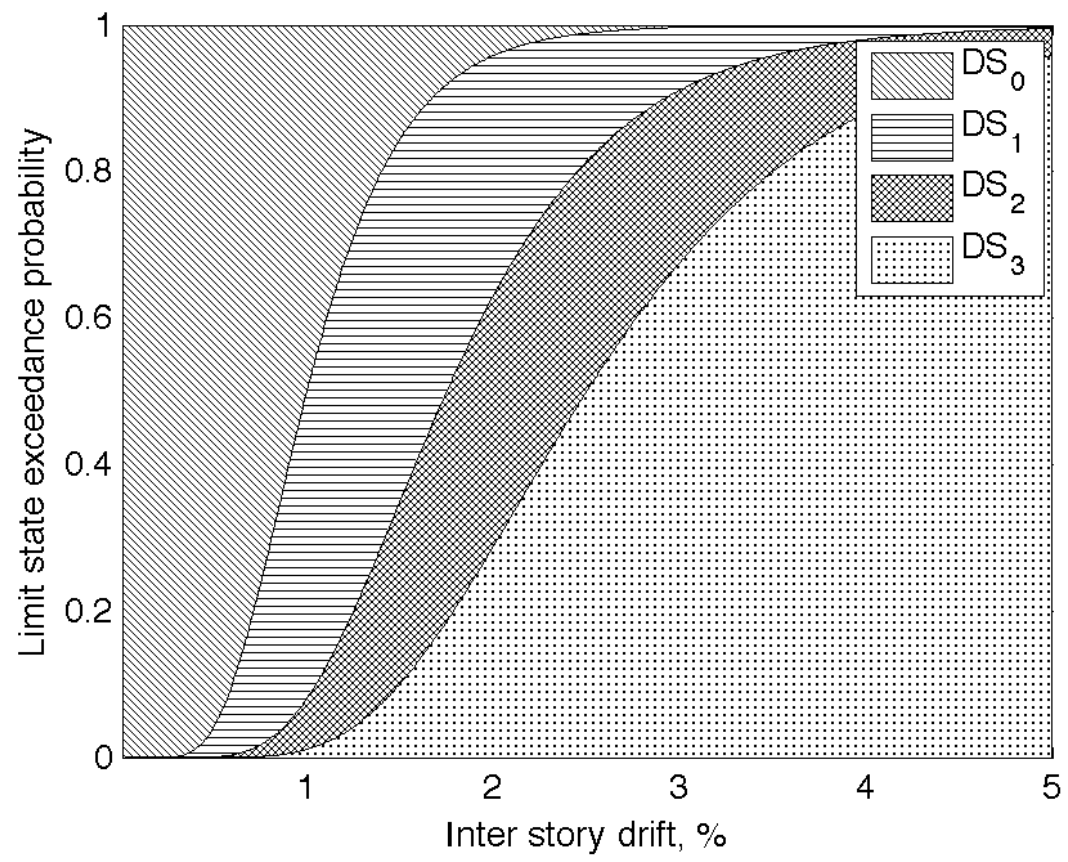

Figure 5.10: Damage state fragility of the light-frame wood building

if $0.35<u \leq 0.84$. It is intact $\left(\mathrm{DS}_{0}\right)$ if $u>0.84$. Note that the building might be totally damaged (or collapse) if the inter-story drift is larger than its collapse capacity, which is assumed to be an inter-story drift of 7\% for light-frame wood buildings [2, 62]. Therefore, it is necessary to check whether the structural collapse capacity has been exceeded for each EDP.

The seismic loss includes transition cost (TC) and downtime cost (DC). Table 5.1 lists the transition and downtime cost. Given the assumption that no repair is taken in the aftershock environment, transition costs for $\mathrm{DS}_{i} \rightarrow \mathrm{DS}_{j}, i \geq j$, are not available. Since $\mathrm{DS}_{4}$ is the collapse state, there is no downtime cost associated with it.

Let $t_{1}$ be the time of an earthquake (either mainshock or aftershock) occurs, and $t_{2}$ be the time of the following earthquake, the present value of the transition cost due to the first shock, $\operatorname{PVTC}\left(t_{1}\right)$, can be obtained as [139]:

$$
\operatorname{PVTC}\left(t_{1}\right)=\mathrm{TC} e^{-\alpha t_{1}}
$$


where TC is the transition cost listed in Table 5.1, and $\alpha$ is the discount rate. Assuming the building is in damage state $\mathrm{DS}_{i}, i=0,1,2,3$, after the shock at $t_{1}$, the downtime cost during the time between $t_{1}$ and $t_{2}$ can be obtained by:

$$
\operatorname{PVDC}\left(\mathrm{DS}_{i}\right)=\int_{t_{1}}^{t_{2}} \mathrm{DC}\left(\mathrm{DS}_{i}\right) e^{-\alpha t} d t
$$

where $\mathrm{DC}\left(\mathrm{DS}_{i}\right)$ is the downtime cost (listed in Table 5.1) in damage state $\mathrm{DS}_{i}$.

Table 5.1: Downtime and transition costs for three damage states

\begin{tabular}{cccccccc}
\hline \hline \multirow{2}{*}{ Damage state } & \multicolumn{6}{c}{ Downtime cost(\$k/day) } & \multicolumn{5}{c}{ Transition cost (\% of building value) } \\
\cline { 2 - 8 } & Set 1 & Set 2 & $\mathrm{DS}_{0}$ & $\mathrm{DS}_{1}$ & $\mathrm{DS}_{2}$ & $\mathrm{DS}_{3}$ & $\mathrm{DS}_{4}$ \\
\hline $\mathrm{DS}_{0}$ & $\mathrm{n} / \mathrm{a}$ & $\mathrm{n} / \mathrm{a}$ & $\mathrm{n} / \mathrm{a}$ & 0.25 & 0.5 & 0.75 & 1.0 \\
$\mathrm{DS}_{1}$ & 0.05 & 0.1 & $\mathrm{n} / \mathrm{a}$ & $\mathrm{n} / \mathrm{a}$ & 0.25 & 0.5 & 0.75 \\
$\mathrm{DS}_{2}$ & 0.075 & 0.15 & $\mathrm{n} / \mathrm{a}$ & $\mathrm{n} / \mathrm{a}$ & $\mathrm{n} / \mathrm{a}$ & 0.25 & 0.5 \\
$\mathrm{DS}_{3}$ & 0.1 & 0.2 & $\mathrm{n} / \mathrm{a}$ & $\mathrm{n} / \mathrm{a}$ & $\mathrm{n} / \mathrm{a}$ & $\mathrm{n} / \mathrm{a}$ & 0.25 \\
\hline \hline
\end{tabular}

Note that the data listed in Table 5.1 were derived for a commercial steel building located in California [29]. The downtime cost (listed in Table 5.1) are adjusted for the residential building studied here to illustrate the proposed framework. Typically the market value of a building includes the building replacement value and land value. The land value is not considered in this chapter. Assuming the replacement value of the one-story building in California is $\$ 300 \mathrm{k}(\$ 1 \mathrm{k}=\$ 1,000)$. The property in the building is assumed to be $50 \%$ of the building value [29, 140]. The total replacement value (TRV) of the building is $\$ 450 \mathrm{k}$. The downtime cost for the commercial building in $\mathrm{DS}_{1}$ in [29] is $\$ 50 \mathrm{k} / \mathrm{day}, 0.02 \%$ of the TRV. For the residential building in this chapter, two sets of downtime cost are examined to cover a range of possible costs. Downtime costs for $\mathrm{DS}_{1}$ in the three sets are $\$ 0.05 \mathrm{k}$ and $\$ 0.1 \mathrm{k}$, approximately $0.01 \%$ and $0.02 \%$ of the TRV, respectively, as listed in Table 5.1 . The downtime cost for such a residential building may be caused by situations that after an earthquake, residents will have to order some living necessities (e.g., food, water), or have to find a temporary dwelling place. More data specifically developed for light-frame wood construction will be used to improve the loss estimation when it becomes available. 


\subsection{Uncertainty in seismic loss estimation}

The PEER seismic loss estimation framework can be expressed as [38]:

$$
\begin{gathered}
G_{\mathrm{TC} \mid \mathrm{IM}}(z \mid x)=\int_{u} \int_{v} \int_{y} G_{\mathrm{TC} \mid \mathrm{DVE}}(z \mid u) f_{\mathrm{DVE} \mid \mathrm{DM}}(u \mid v) f_{\mathrm{DM} \mid \mathrm{EDP}}(v, y) f_{\mathrm{EDP} \mid \mathrm{IM}}(y \mid x) d u d v d y \\
\lambda_{\mathrm{TC}}(z)=\int_{x} G_{\mathrm{TC} \mid \mathrm{IM}}(z \mid x)\left|\frac{d \lambda_{\mathrm{IM}}(x)}{d x}\right| d x
\end{gathered}
$$

where $f_{\mathrm{EDP} \mid \mathrm{IM}}$ is the probability density function (PDF) of EDP conditioned on the hazard intensity IM, $f_{\mathrm{DM} \mid \mathrm{EDP}}$ is the PDF of damage state conditioned on EDP, $f_{\mathrm{DVE} \mid \mathrm{DM}}$ is the PDF of repair cost conditioned on damage state, $G_{\mathrm{TC} \mid \mathrm{IM}}$ is the complementary CDF of total cost, TC, conditioned on the hazard intensity, and $\lambda_{\mathrm{TC}}$ is the annual exceedance rate of total repair cost. Details of the notations in Eq. (5.7) and (5.8) are in Baker and Cornell [38].

Baker and Cornell [38] investigated the propagation of the uncertainty in the PEER framework. In their study, the FOSM method was used to determine the mean value and variance of the total repair cost distribution conditioned on the hazard intensity (i.e. $G_{\mathrm{TC} \mid \mathrm{IM}}$ in Eq.(5.7)). Then the mean value and variance of $\lambda_{\mathrm{TC}}$ in Eq. (5.8) were determined by numerical integration of $G_{\mathrm{TC} \mid \mathrm{IM}}$ with the seismic hazard function. Recently, this approach was examined by Bradley and Lee [125] by comparing the approach with direct numerical integration. It was found that the accuracy of the FOSM method depends on the uncertainty in the conditional function $f_{\mathrm{EDP} \mid \mathrm{IM}}[125]$.

In this study, an MCS approach is used to propagate the uncertainties in seismic loss estimation. Various sources of uncertainties and the propagation methods in the MCS approach are discussed in the following paragraphs.

The uncertainty in seismic hazard (or ground motion) is the most significant contributor to the variance of seismic loss estimation [38, 69]. Typically, the main contributor of uncertainty in ground motion is represented by site-specific seismic hazard curve [69, 70], which can be obtained from the USGS, while the additional uncertainties are usually termed as 'record-to-record' uncertainty [69]. Another approach to treat the ground motion uncertainty is to sample a large number of earthquake scenarios with different magnitudes and source-to-site distances, using the attenuation model. This approach was discussed 
by Bommer and Crowley [70] and is used in this study. The uncertainty associated with the earthquake occurrence is considered in the Poisson process. The record-to-record uncertainty is considered by using the ATC-63 ground motions.

Since the ground motions are randomly selected in this study from a database, there may lie significant uncertainty in the process of selecting and scaling of ground motions. Four methods of selecting ground motions were compared by Baker and Cornell [76] to investigate their influences on structural collapse risk. Ground motions selected using four methods were applied on a seven-story reinforce concrete building, whose fundamental period is $0.8 \mathrm{sec}$, to develop drift hazard curves. It was found that methods considering the spectral shape parameter $\varepsilon$ produced unbiased drift hazard curves while methods without considering $\varepsilon$ produced larger exceedance probabilities. The ground motion selection method used in this chapter does not consider $\varepsilon$. The effect of different ground motion selection methods on seismic loss estimation will be investigated in a future study, in which the proposed framework can be used. The PEER GMSM (ground motion selection and modification) program [141] is developing guidances that can be used to appropriately select and modify ground motions for NDA. These guidances, once available, can be incorporated into the proposed framework to examine the ground motion uncertainties.

There are uncertainties in the structural resistance. For the building examined in this chapter, the resistance (e.g., the stiffness, strength, and energy dissipation characteristics) of wood shear wall is reflected in the hysteresis parameters shown in Figure 5.8. The effects of resistance uncertainty on the collapse risk of light-frame wood buildings were investigated in Chapter 3, In this chapter, the resistance uncertainty is not considered.

The uncertainty associated with relating EDP to DS is incorporated damage state fragilities (Figure 5.10). Uncertainty in the cost estimation conditioned on DS is not considered in this study. The variation in the cost estimation given a DS can be examined by treating the transition costs in Table 5.1 as random variables, if such information is available. 


\subsection{Illustrative example}

The total replacement of the building is $\$ 450 \mathrm{k}$. The annual discount rate is assumed to be $3.5 \%$ [29]. The mainshock occurrence rate is assumed to be 0.03 per year [103]. The minimum and maximum considered magnitudes for mainshocks are 6.5 and 7.5, respectively. The minimum considered magnitude for aftershocks is 5.0. The source-to-site distance is assumed to be uniformly distributed between $10 \mathrm{~km}$ and $100 \mathrm{~km}$ [132].

MCS is performed for three reference periods of time (i.e., 30, 50, and 75 years). 1 million runs of MCS are performed for each period of time following the scheme, as shown in Figure 5.11, For a reference period of time $T$, the shock simulation and structural analysis objects (see Figure 5.3 for details) are executed in the outer loop for 1000 (i.e., $\mathrm{NMCS}_{1}=$ 1000) times. For the $i^{t h}$ outer loop, sequences of mainshock (MS) and aftershock (AS) are simulated using the methods discussed before. Let $\operatorname{MS}\left(t_{i, 1}\right), \operatorname{AS}\left(t_{i, 2}\right), \operatorname{AS}\left(t_{i, 3}\right), \operatorname{MS}\left(t_{i, 4}\right), \cdots$, be a sequence of simulated MS and AS, where $t_{i, 1}, t_{i, 2}, t_{i, 3}, t_{i, 4}, \cdots$ are the occurring time of shocks simulated in the shock simulation object.

Subsequently, the EDP sequences due to MS and the occurring time of AS are feed to the inner loop in Figure 5.11, where another 1000 runs of loss analysis are performed (i.e., $\left.\mathrm{NMCS}_{2}=1000\right)$. For the $j^{t h}$ inner loop in the $i^{t h}$ outer loop, a series damage states (DS) are obtained and noted as $\mathrm{DS}\left(t_{i, 1}, j\right), \mathrm{DS}\left(t_{i, 2}, j\right), \mathrm{DS}\left(t_{i, 3}, j\right), \mathrm{DS}\left(t_{i, 4}, j\right), \cdots$, as shown in Figure 5.11. Then the transition and downtime cost can be determined and noted as $\mathrm{TC}\left(t_{i, 1}, j\right), \mathrm{DC}\left(t_{i, 1} \rightarrow t_{i, 2}, j\right), \mathrm{TC}\left(t_{i, 2}, j\right), \mathrm{DC}\left(t_{i, 2} \rightarrow t_{i, 3}, j\right), \mathrm{TC}\left(t_{i, 3}, j\right), \cdots$. The total loss is then calculated as

$$
\operatorname{Loss}(i, j)=\sum_{m=1}^{\mathrm{NS}(i)} \mathrm{TC}\left(t_{i, m}, j\right)+\sum_{k=1}^{\mathrm{NS}(i)-1} \mathrm{DC}\left(t_{i, k} \rightarrow t_{i, k+1}, j\right)
$$

in which NS(i) is the total number of shocks in the $i^{\text {th }}$ outer loop. At the end of simulation, a matrix of loss value [Loss] of dimension $\mathrm{NMCS}_{1}$ by $\mathrm{NMCS}_{2}$ is obtained.

The expected present values of economic losses of the building due to earthquake hazard are shown in Figure 5.12, in which DC sets 1 and 2 are the two downtime cost sets in Table 5.1. In Figure 5.12, the two curves of transition losses overlap each other because the transition losses are not affected by the downtime cost sets. In 50 years, considering DC 


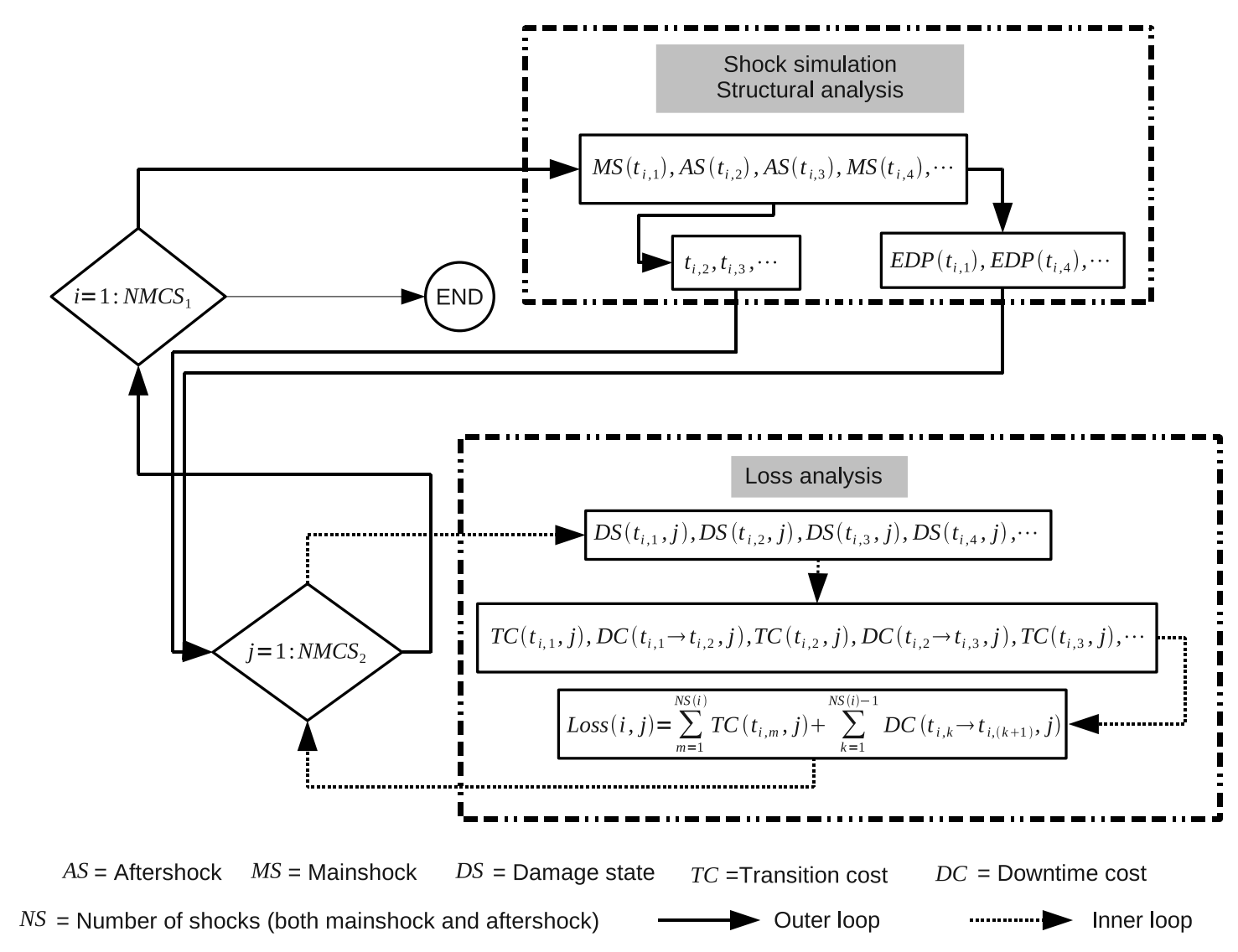

$N M C S_{1}, N M C S_{2}=$ Number of Monte Carlo Simulation in the outer and inner loop

Figure 5.11: Monte Carlo Simulation scheme for seismic loss estimation considering mainshock and aftershock

set 1, downtime losses account for $32.8 \%$ and $49.0 \%$ of the total losses of the MS and MSAS cases, respectively. MS indicates that only mainshocks are considered while MS-AS indicates both mainshocks and aftershocks are considered. When DC set 2 is considered, the downtime loss is about the same as the transition loss for the MS case (Figure 5.12(a)), while the downtime loss is much larger than the transition loss for the MS-AS case (Figure 5.12(b) . In 75 years, the downtime losses contribute $50.5 \%$ and $66.3 \%$ to the total losses, for the MS and MS-AS cases, respectively.

The expected loss values are listed in Table 5.2, indicating that the MS-AS losses are 40\%$61 \%$ higher than those of MS cases. Figure 5.13 shows the expected total loss as well as the breakdown of loss due to transition or downtime cost. When DC set 1 is considered (Figure 5.13(a)], losses due to mainshocks are higher than those caused by aftershocks. In 


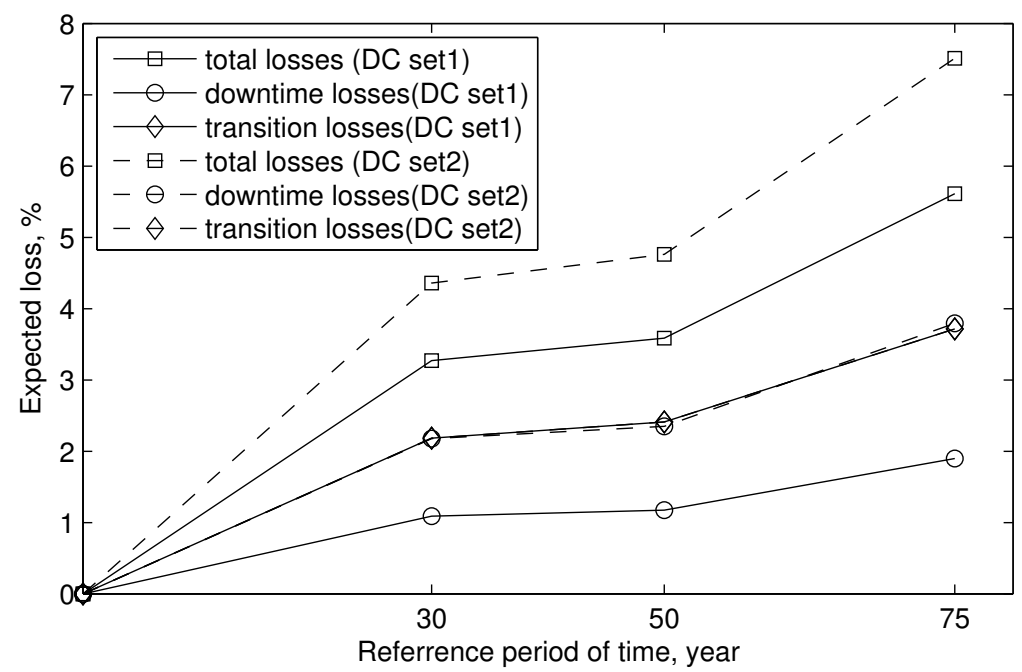

(a) Only considering mainshocks

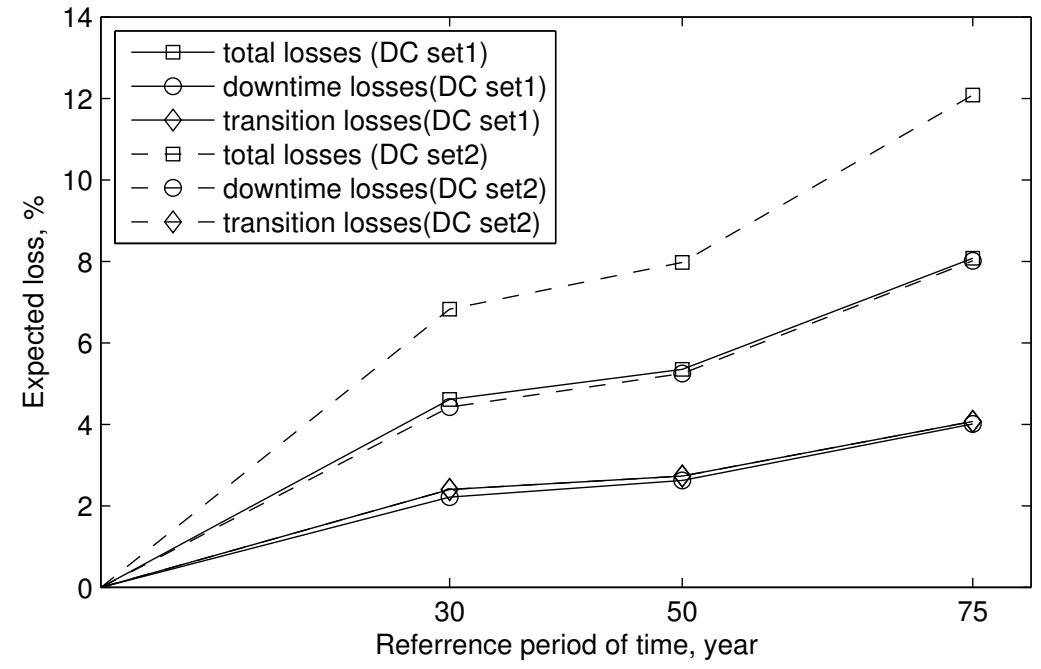

(b) Considering both mainshocks and aftershocks

Figure 5.12: Expected seismic losses (in percentage of the total replacement value) of a light-frame wood building in California

50 years, $51 \%$ of the total loss is due to mainshocks. When DC set 2 is considered (Figures 5.13(b)], the losses caused by aftershocks are higher than those caused by mainshocks. In 50 years, aftershocks contribute $62.1 \%$ (DC set 2 ) of the total losses. Given the particular assumptions made in the example, aftershocks have significant impact on the seismic loss estimation. This observation is comparable to the study by Yeo and Cornell [29] on a commercial steel building, in which the seismic loss was found to increase by $25 \%$ if aftershocks were considered. 


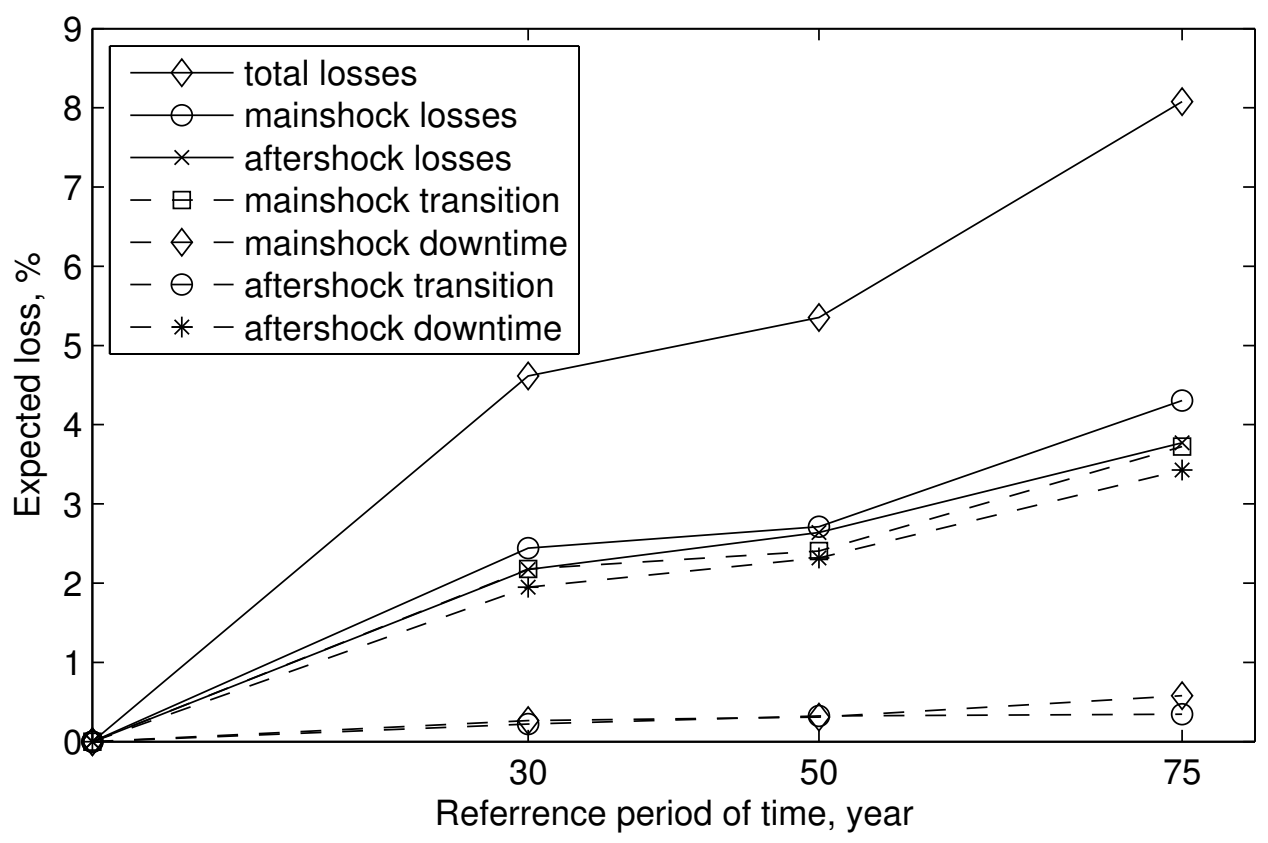

(a) DC set 1

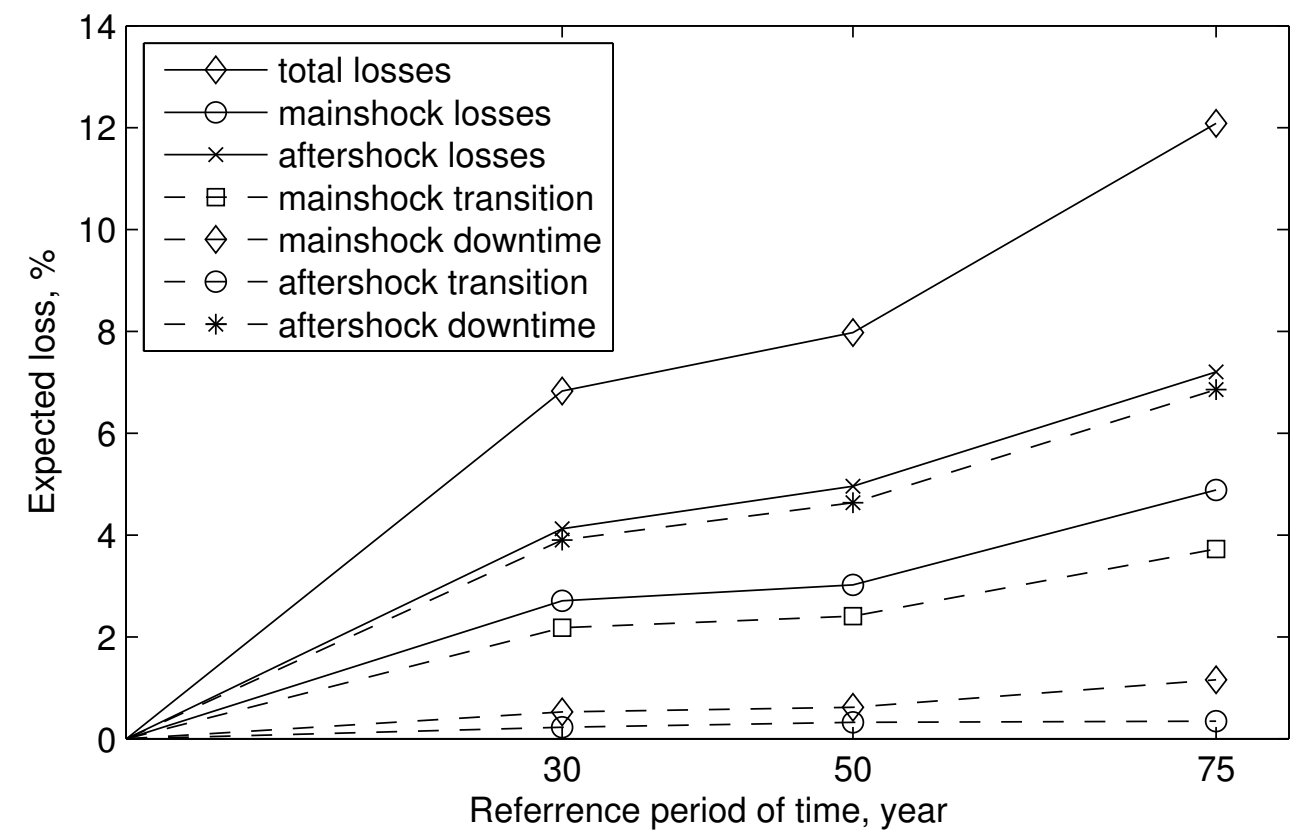

(b) DC set 2

Figure 5.13: Expected seismic losses of the one-story building at a site in California 
Table 5.2: Expected losses (in percentage of the total replacement value) of the one-story residential building in California

\begin{tabular}{ccccccc}
\hline \hline T (year) & 30 & 30 & 50 & 50 & 70 & 75 \\
\hline Case & DC set 1 & DC set 2 & DC set 1 & DC set 2 & DC set 1 & DC set 2 \\
\hline MS-AS & 4.6 & 6.8 & 5.4 & 8.0 & 8.1 & 12.1 \\
MS & 3.3 & 4.4 & 3.6 & 4.8 & 5.6 & 7.5 \\
\hline \multicolumn{7}{l}{ MS-AS: mainshock and aftershock sequences; MS: mainshock only } \\
\hline \hline
\end{tabular}

In Figure 5.13, transition cost is the main contributor to the losses caused by mainshocks. For example, in 50 years, $76 \%-89 \%$ of the losses caused by mainshocks is due to transition cost. However, downtime cost is the main contributor to the loss caused by aftershocks. In 75 years, considering DC set 2, 95\% of the losses caused by aftershocks is contributed by downtime cost.

If DC set 2 is considered, the expected losses of the building in 50 years are $8 \%$ and $4.8 \%$ of the TRV, for the MS-AS and MS cases, respectively, as listed in Table 5.2. The coefficient of variation (COV) associated with the two expected values is around 190\%, indicating the large uncertainty in the seismic loss estimation. Therefore, the stake holders or home owners can hardly be well informed about the potential risk by merely a point estimation. A probability distribution of the estimated loss is desirable. The histogram of the losses (DC set 2 is considered) for the building in 50 years considering both mainshocks and aftershocks is shown in Figure 5.14, the y-axis of which is in logarithmic scale. It can be observed that the distribution of losses is highly skewed. There is a probability of $87 \%$ that there will be no seismic losses to the building in 50 years. There is a probability of $5 \%$ that the loss will be larger than $62 \%$ of the TRV of the building in 50 years considering the mainshock and aftershock sequences.

The exceedance probability of seismic losses in a period of time can be obtained by ranking order of the 1 million loss values obtained from MCS. For example, for the one-story lightframe wood residential building, the exceedance probabilities of an expected loss of 50\% of the TRV are $5.7 \%, 6.5 \%$, and $8.5 \%$, in 30, 50, and 75 years, respectively, as shown in Figure 5.15, Note that the DC set 2 is considered in the assessment. 


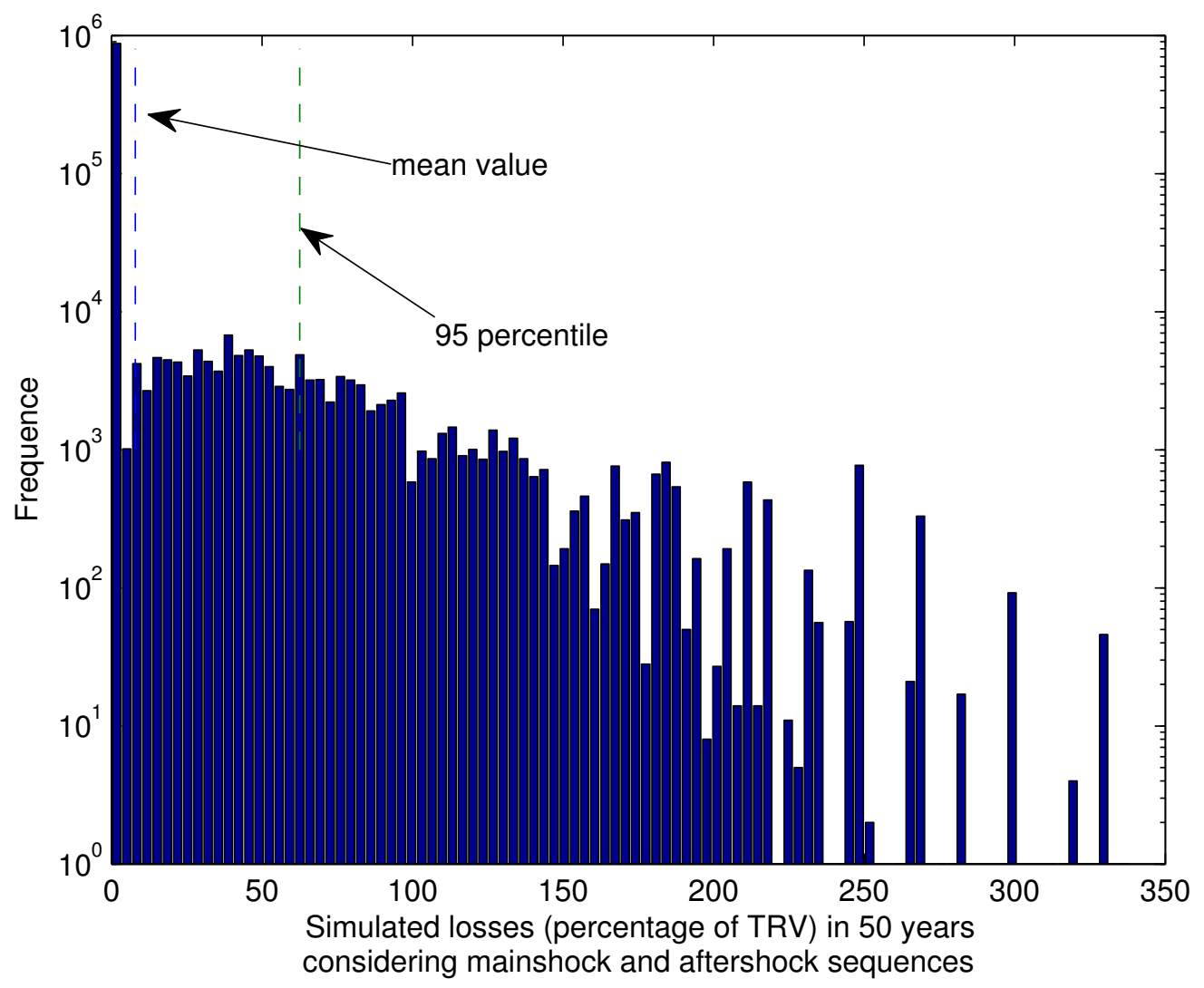

Figure 5.14: Histogram of economic losses in 50 years considering mainshock and aftershock sequences (DC set 2 is considered)

\subsection{Discussions and future work}

The focus of this chapter is to propose an object-oriented framework of seismic loss estimation of light-frame wood buildings subjected to mainshock and aftershock sequences. The preliminary results are comparable to what has been found in other studies (e.g., [29, 30]), indicating that the framework is a proper tool for seismic loss assessment for buildings subjected to mainshock and aftershock sequences.

The following future work in conjunction with the proposed framework will improve the loss estimation of buildings subjected to mainshock and aftershock sequences.

$\dagger$ Investigation of other ground motion selection and scaling methods (e.g., [76]) and 


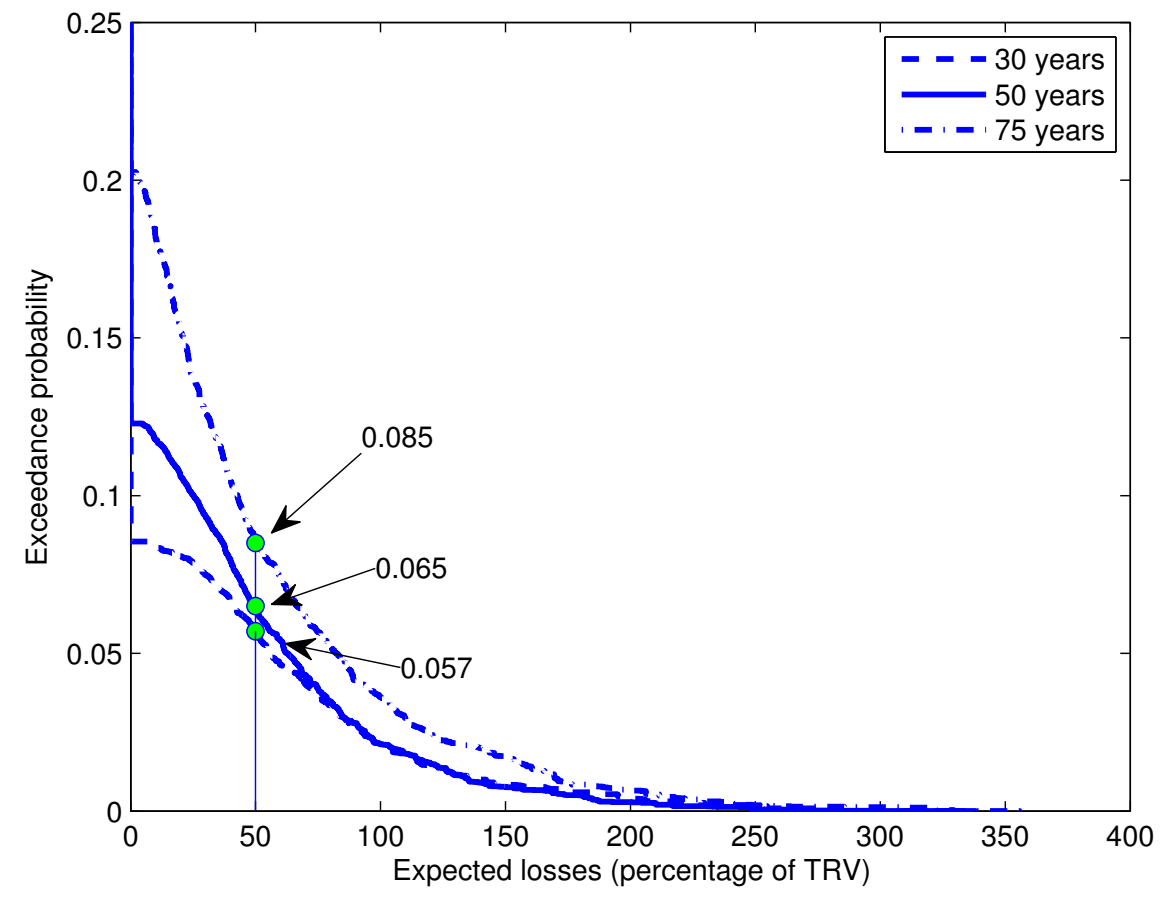

Figure 5.15: Exceedance probability of seismic losses of the building (DC set 2 is considered)

their effects on loss estimation considering mainshock and aftershock sequences.

$\dagger$ Consideration of retrofit or repair activities after the earthquake. The economic losses will include the loss due to the interruption of repair activities.

$\dagger$ Incorporation of damage fragilities for non-structural components in the loss estimation.

\subsection{Summary}

An object-oriented framework of seismic loss estimation for light-frame wood buildings subjected to mainshock and aftershock sequences is proposed in this chapter. The framework is modular and can explicitly consider the effects of aftershocks and downtime cost, as well as various sources of uncertainties. The seismic hazard is simulated and applied to buildings to estimate the transition and downtime losses, which constitute the total seismic 
loss. A illustrative light-frame wood building is examined using the proposed framework. The probability distribution of the seismic loss is obtained by Monte Carlo Simulation. Various sources of uncertainties are considered in the analysis. Aftershocks and downtime cost are found to be two important factors in seismic loss assessment. For the illustrative building in this study, the seismic losses considering both mainshocks and aftershocks are approximately $40 \%-61 \%$ higher than those only considering mainshocks. If the remaining service life of the buildings are 75 years, downtime losses contribute more than $50 \%$ of the total seismic losses of the building. 


\section{Chapter 6}

\section{Probabilistic loss assessment of light-frame wood construction subjected to combined seismic and snow loads}

\subsection{Introduction}

Light-frame wood construction is widely built in the United States (U.S.). Approximately $90 \%$ of residential buildings are light-frame wood construction. In the 1994 Northridge earthquake, 24 fatalities and $\$ 20$ billion insured losses were claimed due to damage of wood buildings [1]. Snow hazard also threatens life safety and causes economic losses. In January 2006, 65 people died and 170 people were injured in the Katowice Trade Hall roof collapse due to heavy snow loads in Poland [5]. The March 1993 east coast storm in the U.S. caused economic losses of $\$ 1.75$ billion [4]. In February 2008, the snow hazard in China caused direct economic losses of $\$ 7.7$ billion [7].

Extensive studies have been performed to investigate the performance of light-frame wood construction subjected to seismic loads. For example, Li and Ellingwood [1] performed fragility analysis to light-frame wood shear walls. van de Lindt and Gupta [142] investigated damage of light-frame wood shear walls due to earthquake. Pei and van de Lindt [27] developed a framework for loss estimation of wood construction subjected to seismic 
loads. However, limited research has been performed considering combined seismic and snow hazards.

The Bernoulli pulse process (referred to as the Bernoulli model later in this paper) was used to model the snow load. Ellingwood and Rosowsky [103] examined the snow and earthquake load combination for limit state design. In their study, the snow load was simulated using the Bernoulli model. Snow accumulation was modeled by rectangular or triangular load shape. Lee and Rosowsky [20] performed fragility analysis for a light-frame wood building subjected to combined snow and earthquake loads. In those studies, the stochastic characteristic of the snow load was not explicitly considered, which might underestimate the effect of snow accumulation on buildings in areas with heavy snow loads. In addition, the Bernoulli model cannot simulate the snow accumulation, which is a common phenomenon in areas with heavy snow load. In some areas of the Western U.S., both earthquake and snow hazards are significant for an extended period of time. But limited research has been performed to investigate the seismic risk of light-frame wood construction considering combined earthquake and snow loads. In this study, this topic is investigated and a Filter Poisson Process (FPP) model [143] is used for the snow load simulation.

The snow participation factor used in the load combination (e.g., combination of snow and seismic loads [75]) for seismic structural design has been investigated (e.g., [103]). Recently, fragility analyses [20] were applied to wood construction subjected to combined seismic and snow loads. While some of the above studies provide tools to obtain better structural design or make retrofit schedules, the results from those analyses (e.g., exceedance probability of a certain drift limit) are not easily understood by home owners or other decision makers. For them, economic losses can be more effectively communicated in the decision making process. The ongoing ATC-58 project [41] is to develop a performance-based seismic design process in which structural performance will be explicitly expressed as economic losses. This study contributes in this aspect by proposing a framework for risk assessment of light-frame wood construction subjected to combined seismic and snow loads. 


\subsection{Framework of risk analysis}

A generic (conceptional) framework for the seismic loss estimation was proposed by the Pacific Earthquake Engineering Research (PEER) Center [36]. In the framework, the seismic loss analysis consists of four components: ground motion hazard, structural response, damage to components and repair cost. Based on the PEER framework, several applicational frameworks for seismic loss estimation were proposed recently. Pei and van de Lindt [27] developed a seismic loss estimation methodology for light-frame wood construction. The ATC-58 project [41] developed three methods, i.e., intensity-based, scenario-based, and time-based assessments for structural performance quantification. The frameworks in [27, 41] is termed the fragility-based framework (FBF) here. Figure 6.1 shows the FBF of risk assessment for single hazard. In the FBF, the fragility curves provide exceedance probabilities of a certain limit state (e.g., 1\% inter story drift) conditioned on a certain hazard level (e.g., spectral acceleration $S_{a}$ ), while the seismic hazard curves describe the occurrence frequencies of the seismic hazard. The distribution of the failure event can be obtained by integrating the fragility curves and hazard curves over a range of seismic hazard intensity (from minimum considered $S_{a, \min }$ that causes negligible damage to maximum considered $S_{a, \max }$ that may cause collapse. Details can be found in [41]). The failure event is defined as an occurrence that a certain limit state is reached or exceeded. Finally, economic losses can be determined by integrating the failure event distribution with consequence models (e.g., conditional probability distribution of the repair cost given a failure event).

Theoretically, the risk assessment for multiple hazards can be achieved by extending the FBF. The fragility curve for single hazard is to be substituted by a fragility surface that can be developed for combined hazards, as discussed in [20] for wood construction due to combined seismic and snow loads. Once the fragility surface is obtained, the failure probability can be determined by:

$$
P_{f}=\int_{\text {snow }} \int_{\text {earthquake }} F(L S \mid x, y) f(x) f(y) d x d y
$$

in which $x$ is the snow load intensity (e.g., ground snow load) and $y$ is the seismic load intensity (e.g., $\left.S_{a}\right), F(L S \mid x, y)$ is the fragility surface function that gives a conditional exceedance probability of a limit state (LS), and $f(\cdot)$ is the notation for the hazard curve 


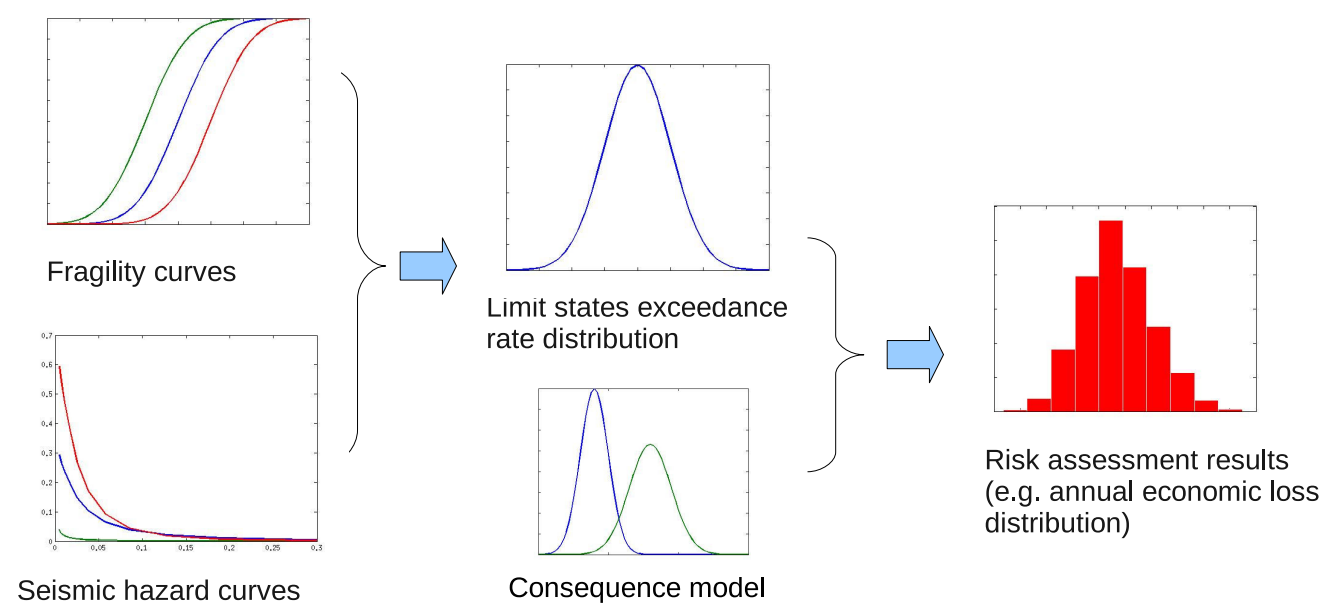

Figure 6.1: Risk assessment for a single hazard

function. However, the closed-form expression of the fragility surface is difficult to obtain. Even if possible, the computational demands are overwhelming.

An object-oriented framework (OOF) is proposed in this study to perform the risk assessment for buildings subjected to combined seismic and snow hazards, as shown in Figure 6.2. An OOF is modular, allowing each module (or object) to be modeled, updated, and executed independently. The output of one module (e.g., the earthquake module) will be taken as the input of another module (e.g., the structural module). As can be seen from Figure 6.2, the OOF contains four modules (objects), the earthquake module, the snow module, the structural module and the loss module. In the OOF, time is explicitly included in the hazard modules (i.e., earthquake and snow modules). Details are discussed in Section 6.6.2.

The simulation of hazard events for a period of time $T$ is achieved in the hazard modules, using site specific hazard information. A ground acceleration record database containing records with a range of earthquake magnitudes and source-to-site distances are included in the earthquake module. If no recorded records are available for the site of interest, two alternative methods can be used. One is to select and scale records obtained in other sites, while another is to generate acceleration records using attenuation models. For the snow hazard, weather records with daily snow precipitation and daily snow depth (water-equivalent) should be obtained. In addition, earthquake occurrence models, earthquake intensity models, snow load models, as well as the corresponding parameters are also included in the 
hazard modules. The probabilistic hazard models are discussed in Section 6.3.

The structural module contains the information about the structure to be analyzed. In this study, a one-story light-frame wood building is considered in the structural module. It can be replaced by other type of buildings or structures for other applications. The simulated hazard records are passed to the structural module to perform nonlinear dynamic analysis (NDA). The obtained engineering demand parameters (EDP) (e.g., maximum inter-story drift, maximum shear force) through NDA are used in the loss module for risk assessment. The structural model included in this module is discussed in Section 6.4.

Risk assessment is performed in the loss model. For a building subjected to combined snow and seismic hazards, risks come from three sources (as shown in Figure 6.2): (1) Losses caused only by earthquakes such as casualties, down-time cost, and damage of properties. (2) Losses caused by combined seismic and snow hazards, which is to account for the case that snow load on roof will increase the seismic weight, which subsequently leads to larger base shear force and damage. (3) Losses caused only by the snow hazard. As discussed in Section 6.1, the snow hazard alone can cause significant losses. However, this case is not considered in this study. The loss module is discussed in Section 6.5. 


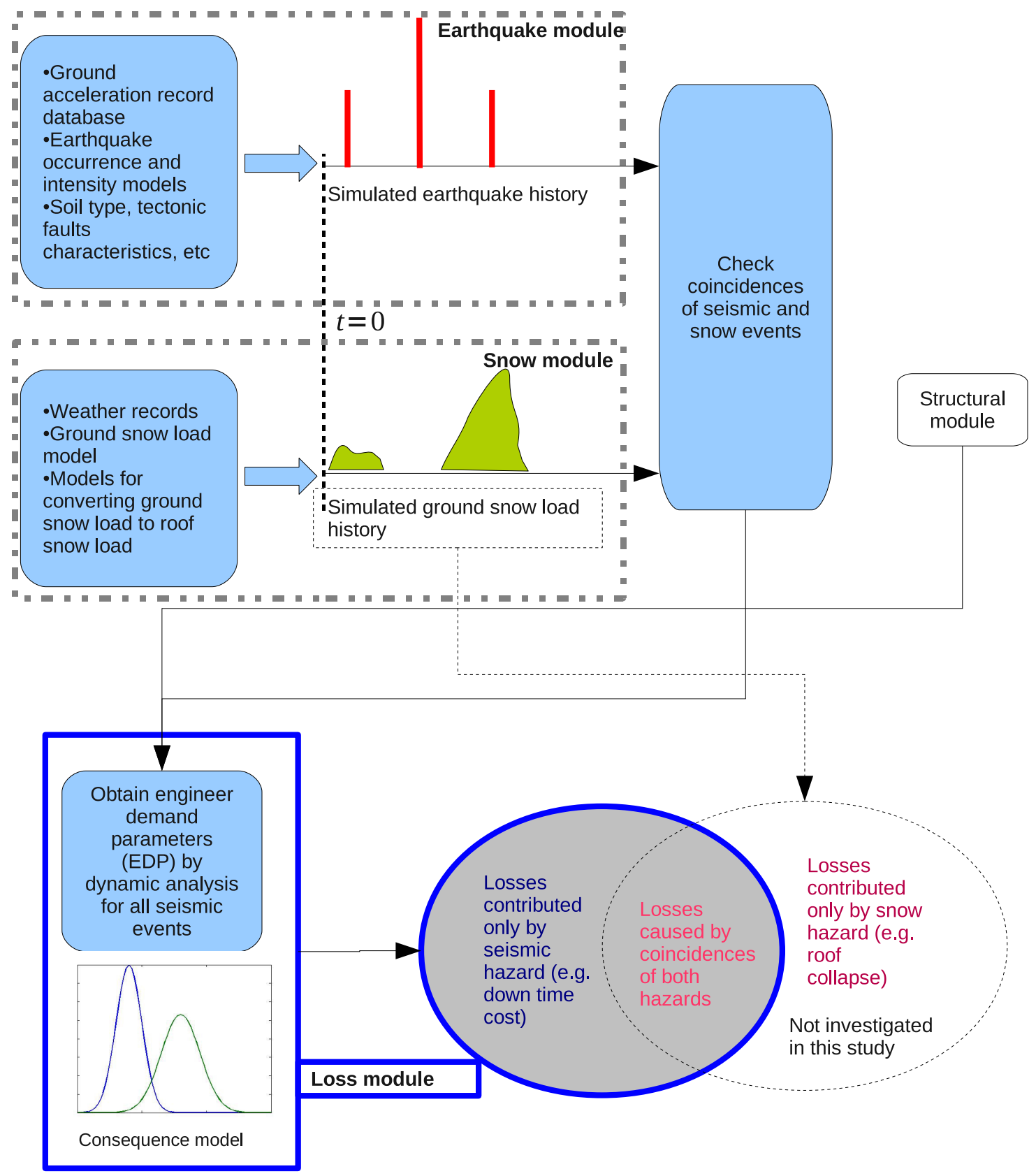

Figure 6.2: Object oriented framework (OOF) of risk assessment for combined seismic and snow hazards 


\subsection{Hazard modules}

\subsubsection{Earthquake load}

\subsubsection{Occurrence of earthquake}

Earthquake includes mainshocks and aftershocks. Mainshocks are typically modeled as a homogeneous Poisson process, while aftershocks can be simulated as a non-homogeneous Poisson process. In this study, only mainshocks are considered. Let $N_{e q}$ be the number of earthquakes occurred in a period of time, $T$. The occurring time, $t_{e q, i}$, of each earthquake can be determined by

$$
t_{e q, i}=T_{0}+\sum_{j=1}^{i} \tau_{j}
$$

where $T_{0}$ is the starting point of time and $\tau_{i}, i=1,2, \ldots, N_{e q}$ are exponentially distributed. Note that $T_{0} \leq t_{e q, i} \leq T$.

\subsubsection{Intensity of earthquake}

The intensities of earthquake events can be measured in terms of the peak ground acceleration (PGA) or $S_{a}$. In this section, both intensity measurements are discussed.

The maximum earthquake event in 50 years can be described by a Type II distribution of largest values [20, 103, 144], as shown:

$$
P\left(A_{v}>x\right)=1-F_{A, \max }(x)=1-\exp \left[-(u / x)^{k}\right]
$$

where $u$ is the location parameter and $k$ is the shape parameter, both of which are site specific. $A_{v}$ is the earthquake intensity (PGA or $S_{a}$ ) with a certain exceedance probability in 50 years, and $F_{A, \max }$ is the cumulative distribution function (CDF) of the maximum earthquake event intensity in 50 years. 
The probability distribution of the maximum event to occur during a reference period $T$ can be expressed as [103]:

$$
F_{A, \max }(x)=\exp \left\{-\lambda_{A} T\left[1-F_{X}(x)\right]\right\}
$$

where $\lambda_{A}$ is the mean rate of individual earthquake event (in terms of PGA). $F_{A, \max }$ is the $\mathrm{CDF}$ of the maximum event while $F_{X}$ is the CDF of the individual event.

The distribution of the individual earthquake intensity can be obtained by combining Eq. (6.3) and (6.4), as shown:

$$
F_{X}(x)=1-\frac{1}{\lambda_{A} T}\left(\frac{u}{x}\right)^{k}
$$

in which $\lambda_{A}$ is the annual occurrence rate of earthquakes.

Parameters $k$ and $u$ for $S_{a}$ can be determined using the seismic hazard curves obtained from the U.S. Geological Survey (USGS) [97]. For example, the 5\% damped $S_{a}$ at $0.2 \mathrm{sec}$ with $2 \%$ and $10 \%$ exceedance probabilities at Stampede, WA are $0.72 \mathrm{~g}$ and $0.36 \mathrm{~g}$, respectively. Substituting these values into Eq. (6.3), one obtains,

$$
\begin{aligned}
& 0.02=1-\exp \left(-(u / 0.72)^{k}\right) \\
& 0.10=1-\exp \left(-(u / 0.36)^{k}\right)
\end{aligned}
$$

By solving Eq. (6.6) and (6.7), $k$ and $u$ can be obtained. The seismic hazard parameters for $S_{a}$ at $0.2 \mathrm{sec}$ for several sites are listed in Table 6.1. For the case that PGA is used for the earthquake intensity, the seismic hazard parameters $k$ and $u$ can also be determined using the USGS seismic hazard maps. Parameter values for three sites in the U.S. are listed in Table 6.1 .

Table 6.1: Seismic hazard parameters for the earthquake intensity

\begin{tabular}{ccccc}
\hline \hline & \multicolumn{2}{c}{ PGA } & \multicolumn{2}{c}{$S_{a}$} \\
\cline { 2 - 5 } Site & $k$ & $u$ & $k$ & $u$ \\
\hline Stampede, WA & 11.41 & 0.818 & 2.381 & 0.139 \\
St. Louis, MO & 10.21 & 0.867 & 1.717 & 0.052 \\
Boston, MA & 10.81 & 0.877 & 1.459 & 0.020 \\
\hline \hline
\end{tabular}

Once the occurrence and intensity of the earthquake hazard are simulated, ground motion 
records are required for each earthquake in order to perform NDA. One approach is to generate records using numerical models. Another approach is to randomly select recorded data from the available earthquake database (e.g., the SAC ground motions [51]). The second method is used in this paper as discussed in Section 6.6.

\subsubsection{Snow load}

\subsubsection{Bernoulli model and its limitations}

In the Bernoulli model, a snow season $T$ is divided into $n$ time intervals, $\tau_{i}, i=1,2, \cdots, n$, and the load pulse value remains constant during each interval and independent between intervals. For each time interval, a probability $p$ is assumed so that the load pulse is nonzero at that probability. Eq. (6.8) is used in the Bernoulli model. In Eq. (6.8), $F_{\max }(x)$ and $F(x)$ are $\mathrm{CDF}$ of the annual maximum snow load and individual pulse load.

$$
F_{\text {max }}(x)=[(1-p)+p F(x)]^{n}
$$

Figure 6.3(a) shows a simulated snow load record using the Bernoulli model with a probability $p=0.2$ and 2-week time interval. Figure 6.3(b) shows the ground snow loads of Buffalo, NY from Nov., 1963 to Apr., 1964 obtained from the National Climatic Data Cen-

ter (NCDC) [108]. It can be observed that the Bernoulli model approximately captures the load pulse characteristic that is common for high snow load sites.

Figure 6.4(a) shows the ground snow loads of Stampede, WA from Nov., 1954 to Jul., 1955 obtained from the NCDC. The gaps in the record are caused by missing data of the NCDC weather records. In comparison to the snow load record of Buffalo (Figure 6.3(b)], the ground snow load of Stampede increases to a high level because of snow accumulation and then decreases as the weather gets warmer. In such a case, to use the Bernoulli model, the probability $p$ is set to be 1.0 (i.e., nonzero snow loads present all the time during the snow season). Figure 6.4(b) shows a simulated snow load record using the Bernoulli model with $p=1.0$. The Bernoulli model fails to capture the snow accumulation characteristic of the snow load record of Stampede. The reason is that the assumption that the load pulse 
is independent between intervals is invalid for such a case. The snow load at the $i$ time interval is related to those in the previous intervals and will affect those in the following intervals.

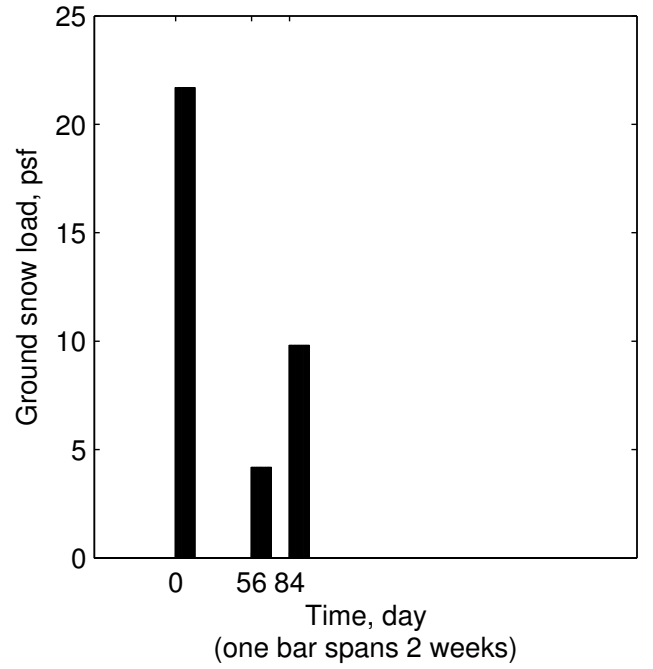

(a) Simulated snow load records using the Bernoulli model

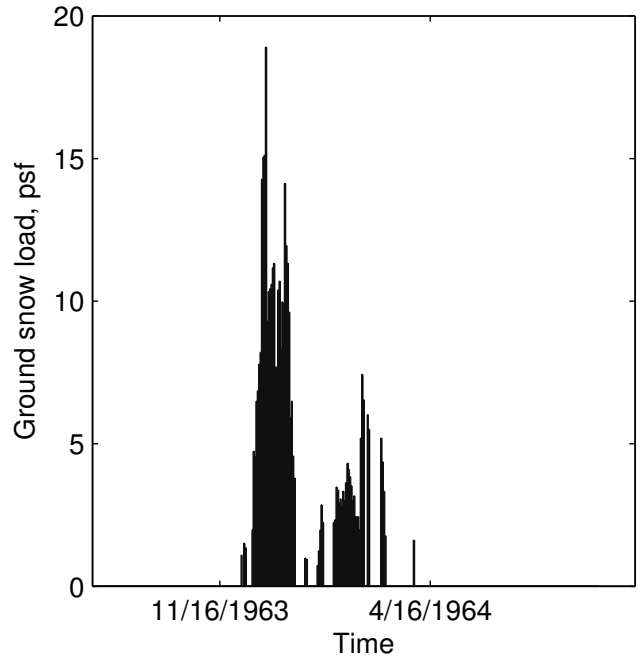

(b) NCDC recorded ground snow load

Figure 6.3: Ground snow load records of Buffalo, NY

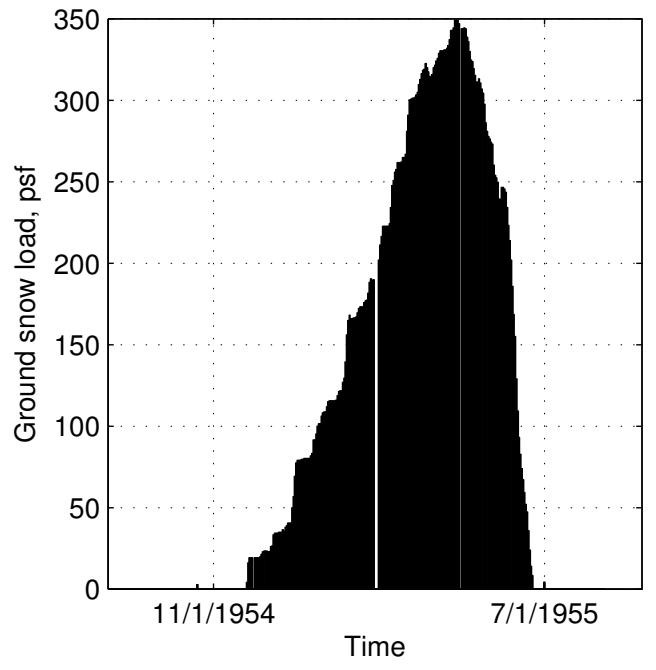

(a) NCDC recorded ground snow load

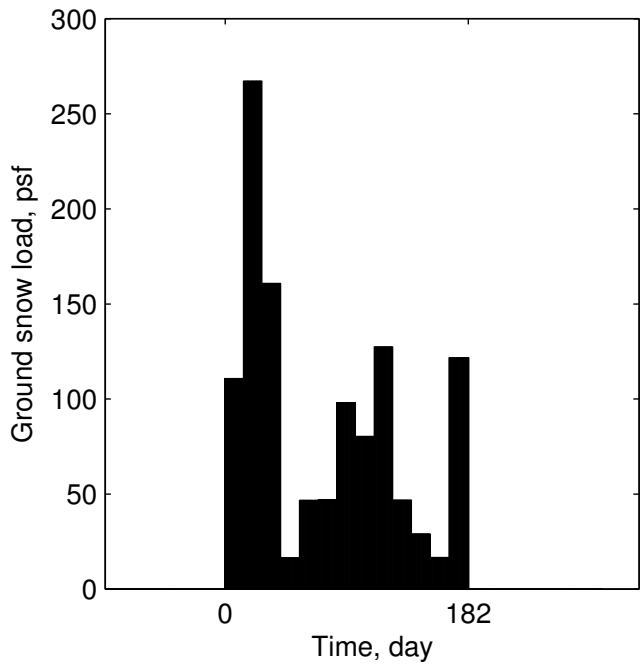

(b) Simulated snow load using the Bernoulli model

Figure 6.4: Ground snow load records of Stampede, WA 


\subsubsection{Filtered Poisson Process model}

In order to overcome the shortcomings of the Bernoulli model, Yin et al. [143] proposed a model based on the Filtered Poisson Process (FPP) for the snow load simulation. The FPP is a stochastic model composed of a set of Poisson processes, as shown by:

$$
X(t)=\sum_{i=1}^{N(t)} A_{i} S\left(t, t_{i}, Y_{i}\right), \quad 0<t<T
$$

where, $A_{i} S\left(t, t_{i}, Y_{i}\right)$ are a sequence of Poisson events; $X(t)$ is the time history of snow loads; $N(t), 0<t<T$ is a Poisson process with a mean arrival rate $v ; T$ is the time period in which Poisson events occur; $A_{i}$ is a sequence of independent and identically distributed (IID) random variables that model Poisson event intensities; $Y_{i}$ is another sequence of IID random variables that model Poisson event durations; $S$ is a step function defined by:

$$
S\left(t, t_{i}, Y_{i}\right)= \begin{cases}1, & \text { if } t \in\left[t_{i}, t_{i}+Y_{i}\right) \\ 0, & \text { otherwise }\end{cases}
$$

In Eq. 6.9, $A_{i}$ and $Y_{i}$ are assumed to be independent. Figure 6.5 shows the generic Poisson events. Note that it is possible for Poisson events to overlap, which allows modeling of the snow accumulation. Figure 6.6 shows four simulated ground snow load records for Stampede, WA. Details of the FPP model are in [143].

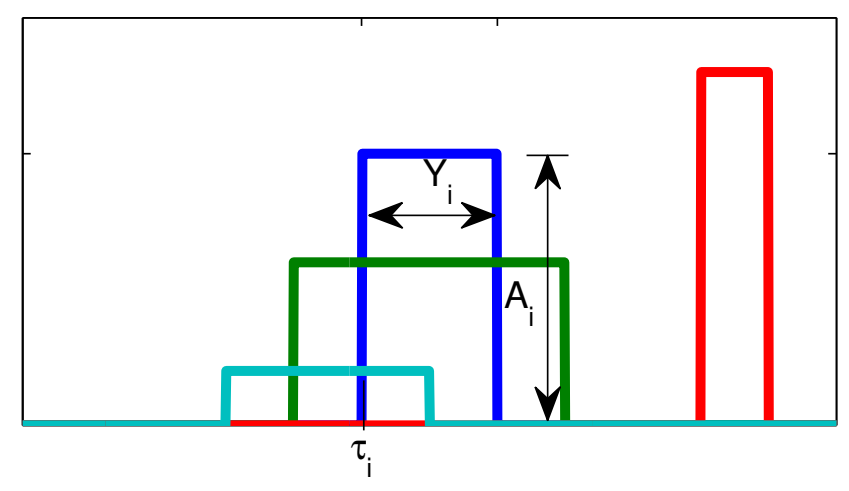

Figure 6.5: Generic Poisson events 

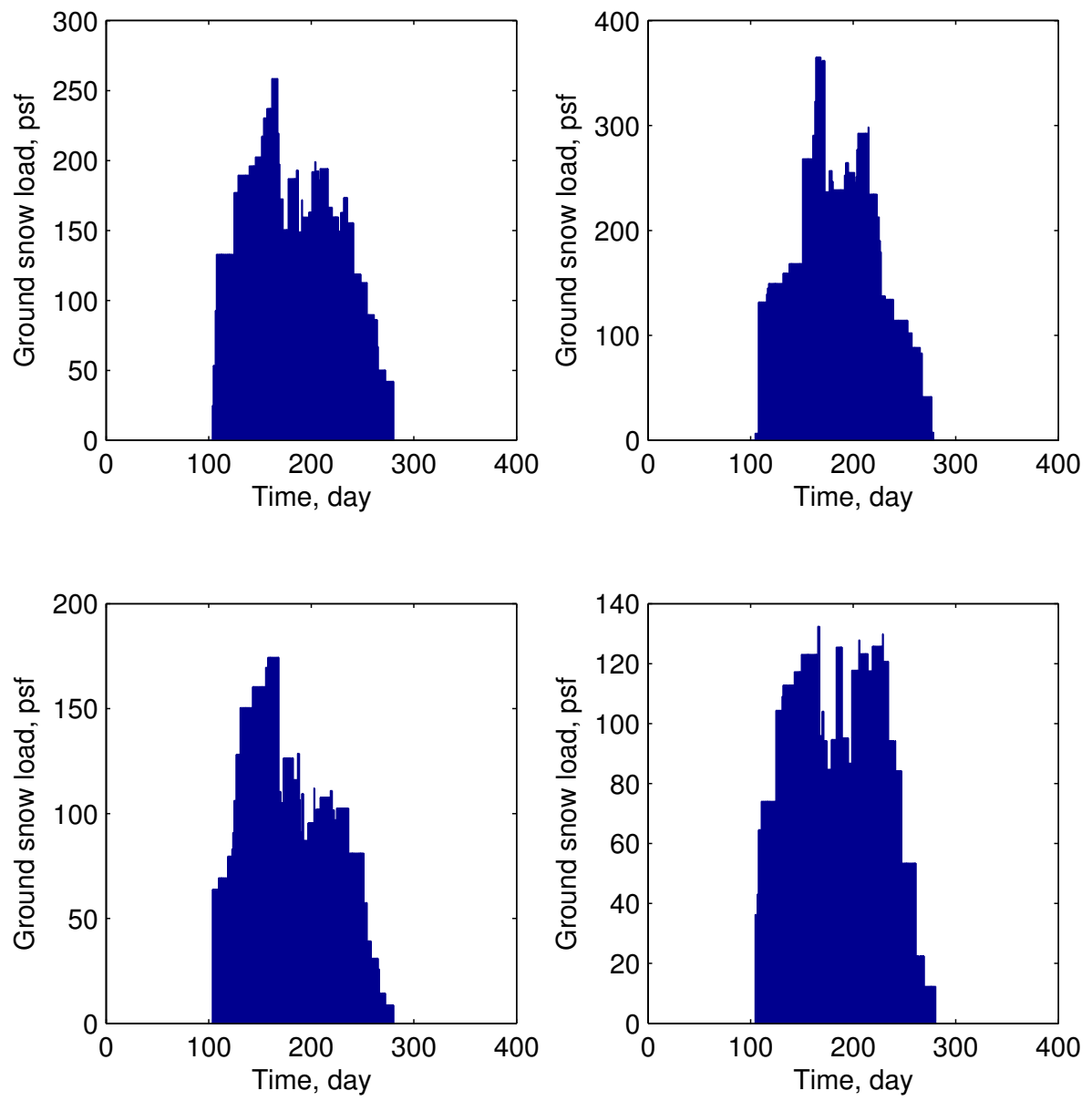

Figure 6.6: FPP simulated ground snow load records for Stampede, WA 


\subsubsection{Uncertainty in hazard load}

The uncertainty in the seismic hazard is the most significant contributor to the seismic loss variance [69, 145]. In this study, the ground motion uncertainty is reflected in the probability distributions of the earthquake intensity (PGA or $S_{a}$ ) and the seismic hazard curve, as discussed in Section 6.3.1. Another source of the ground motion uncertainty lies in the selection and modification (i.e., scaling in accordance to $S_{a}$ ) of ground motions. A guidance of ground motion selection and modification for NDA is under development by the Pacific Earthquake Engineering Research (PEER) Center [141]. The proposed OOF in this paper can be updated to incorporate this guidance when it is available in the future.

Typically, the uncertainty in snow load is considered using the probability distribution of the annual maximum snow load (e.g., [20]) or the Bernoulli model (e.g., [103]). In this paper, the snow load is simulated using the FPP model, in which uncertainties in the annual maximum and daily ground snow load are considered. Details can be found in [143].

\subsection{Structural module}

The proposed OOF of risk assessment is applied on a typical one-story light-frame residential house in the U.S., with wood shear walls as its main lateral force-resisting system. The configuration of the building is shown in Figure 6.7 The dimensions of the building are $9.75 \mathrm{~m}(32 \mathrm{ft})$ long, $6.10 \mathrm{~m}(20 \mathrm{ft})$ wide and $2.44 \mathrm{~m}(8 \mathrm{ft})$ high. The shear walls are covered by $1.22 \times 2.44 \mathrm{~m}(4 \times 8 \mathrm{ft})$ sheathing panels, which might be modified, as appropriate, to allow for door and window openings. The sheathing of the shear walls is provided by 9.5 $\mathrm{mm}(0.375 \mathrm{in})$ oriented strand board (OSB) panels. Studs are spaced at $610 \mathrm{~mm}$ (24 in) on centers. The sheathing is connected to the studs with $8 \mathrm{~d}$ common nails, which are 3.33 $\mathrm{mm}(0.131 \mathrm{in})$ in diameter. The nails are spaced $152.4 \mathrm{~mm}$ (6 in) along the sheathing panel perimeter and $304.8 \mathrm{~mm}$ (12 in) in the panel interior. The seismic weight of the building is 15 kip. The fundamental period of the wood building is 0.25 second. The construction details for this residence represent common light-frame wood construction practice in the United States. 


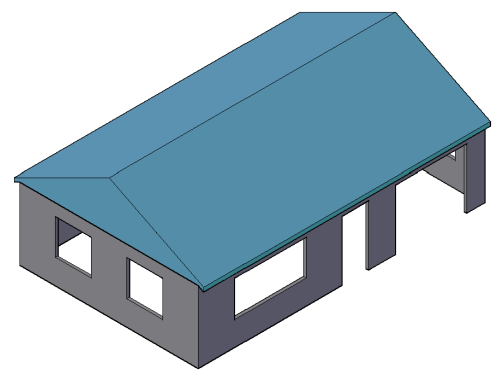

Figure 6.7: Schematic of one-story wood frame residence

Inter story drift is taken as the engineering demand parameter (EDP) herein. The drift limit state has been used as an appropriate performance metric for light-frame wood buildings (e.g., [22, 42]). The exceedance probabilities of four drift limit states, 1\%, 2\%, 3\%, and $7 \%$, are investigated for the light-frame wood building in this study. $1 \%, 2 \%$, and $3 \%$ correspond to immediate occupancy, life safety, and collapse prevention [23], respectively. $7 \%$ is a collapse limit state found by recent studies [2, 62] of light-frame wood buildings. The EDP is obtained through NDA of the building using the SAWS program developed by Folz and Filiatrault [48, 79]. In the NDA using the SAWS program, a $1 \%$ viscous damping ratio is used. The $1 \%$ viscous damping ratio is reasonable for wood buildings due to the significant hysteretic responses of wood buildings under the seismic loading [79].

Recent studies [74, 145] indicate that the structural resistance uncertainty cannot be neglected when the collapse risk of the building is considered. The resistance uncertainty lies in the damping, stiffness, mass, and energy dissipation characteristics of the structure as well as the modeling process [41]. The effect of the resistance uncertainty of the light-frame wood buildings on the collapse risk was investigated by the authors [145]. In this study, the resistance uncertainty is not included as the focus is on the development of a framework of risk assessment of buildings subjected to combined seismic and snow hazards. 


\subsection{Loss module}

The economic loss of the one-story building due to combined seismic and snow hazards over a period of time is estimated using the loss estimation model as discussed in this section.

First, the damage state of the building needs to be determined according to the EDP (i.e., inter-story drift herein) obtained in the structural analysis (i.e., NDA). Three damage states (DS), $\mathrm{DS}_{1}-\mathrm{DS}_{3}$, defined in the ATC-58 project [41] are used in this study, as shown in Figure 6.8. For a specific EDP, say $1.5 \%$ inter-story drift, a uniform random number $u \in$ $(0,1)$ is generated and compared to three DS exceedance probabilities, $0.10,0.35$, and 0.84 as shown in Figure 6.8. The building is in $\mathrm{DS}_{3}$ if $u \leq 0.10$, or $\mathrm{DS}_{2}$ if $0.10<u \leq 0.35$, or $\mathrm{DS}_{1}$ if $0.35<u \leq 0.84$. It is intact (i.e., undamaged state $\mathrm{DS}_{0}$ ) if $u>0.84$. Note that the building might be totally damaged (or collapse) if the inter-story drift is larger than its collapse capacity, which is around $7 \%$ for light-frame wood buildings [2, 62]. Therefore, it is necessary to check whether the structural collapse capacity has been exceeded for each EDP during the analysis.

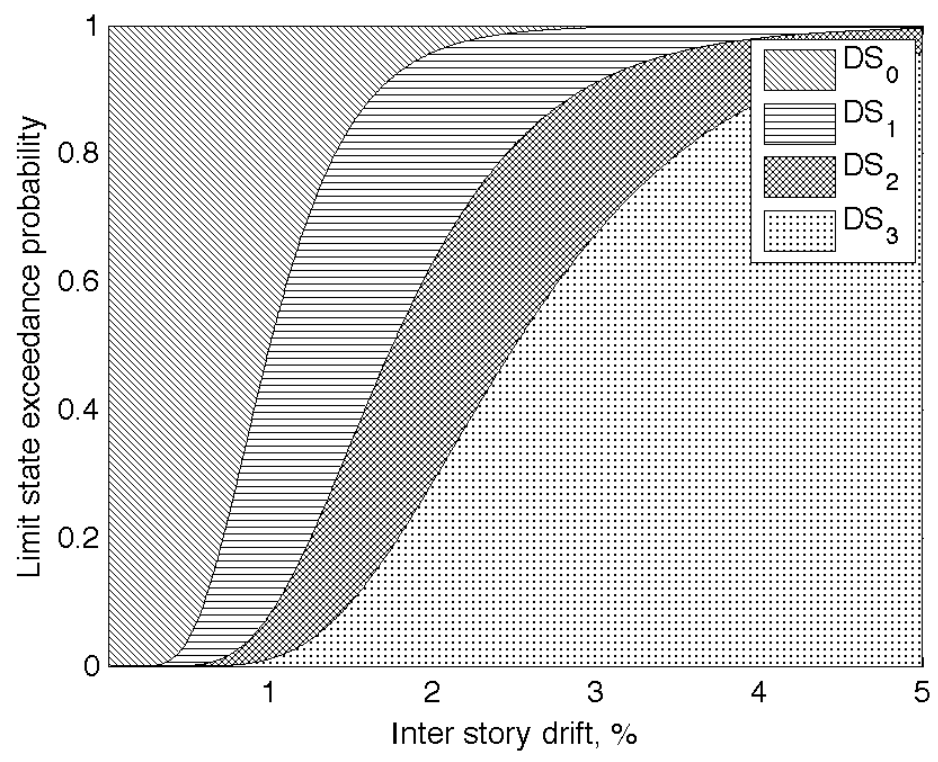

Figure 6.8: Damage state fragility of a light-frame wood building 
Second, to simulate the loss (repair or replacement cost in this study) given the damage state determined in the first step. A set of loss distributions defined in the ATC-58 project [41] are used in this study. The economic losses can be obtained from these distributions by Monte Carlo Simulation (MCS).

The damage states in Figure 6.8 and the corresponding repair cost distributions are assumed to be lognormally distributed [41] with parameters listed in Table 6.2. where $X_{m}$ is the median value and $\beta$ is the dispersion (i.e., the standard deviation of $\ln X$ ). The loss estimation process discussed above is applied to the one-story wood building in Section 6.6.2. Note that it is assumed that the building is immediately restored to its intact status after each earthquake event. Similar assumption was made in other studies (e.g., [27, 28]) of seismic loss estimation for bridges and buildings. This assumption simplifies the loss estimation process by omitting the inter transition possibilities between damage states (i.e., a damaged building may endure more damage from another earthquake) and the downtime cost calculation. An updated loss estimation methodology to account for damage state transitions (e.g., due to mainshock and aftershock sequences) and downtime costs will be developed in a future study.

There are also uncertainties in the damage states and cost distributions. As discussed earlier, these uncertainties are propagated by MCS using the assumed distributions. The same technique was used in other studies (e.g., [38]).

Table 6.2: Damage state fragility and repair cost distribution parameters for lightframe wood construction

\begin{tabular}{clcc}
\hline \hline \multicolumn{4}{c}{ Damage state $^{1}$ (inter story drift, \%) } \\
\hline DS & Description & $X_{m}$ & $\beta$ \\
\hline I & Slight separation of sheathing or nails pulled out slightly & 1.50 & 0.40 \\
II & Permanent rotation of sheathing, pull out of nails & 1.75 & 0.40 \\
III & Fracture of studs, sill plate cracking & 2.50 & 0.40 \\
\hline \multicolumn{2}{c}{ Repair cost ${ }^{2}\left(\$\right.$ per 5.95 $\left.\mathrm{m}^{2}\right)$} \\
\hline DS & Description & $X_{m}$ & $\beta$ \\
\hline I & Re-nail wood sheathing & 131 & 0.3 \\
II & Replace wood sheathing & 254 & 0.3 \\
III & Replace shear wall & 377 & 0.3 \\
\hline${ }^{1}$ Data obtained from [41]; ${ }^{2}$ Data obtained from [146] & & \\
\hline \hline
\end{tabular}




\subsection{Case study}

The light-frame wood residential building is assumed to be located in Stampede, WA. Since there are no ground acceleration records available for Stampede, acceleration records for Seattle, WA, developed in the SAC steel project [51] are used for NDA in this study. Figure 6.9 shows the uniform hazard spectra (UHS) for both sites. The seismic hazard in Seattle is more severe than that in Stampede. The earthquake records for Seattle are scaled so that their $S_{a}$ at the fundamental period of the building (i.e., $0.25 \mathrm{sec}$ ) match the UHS of Stampede.

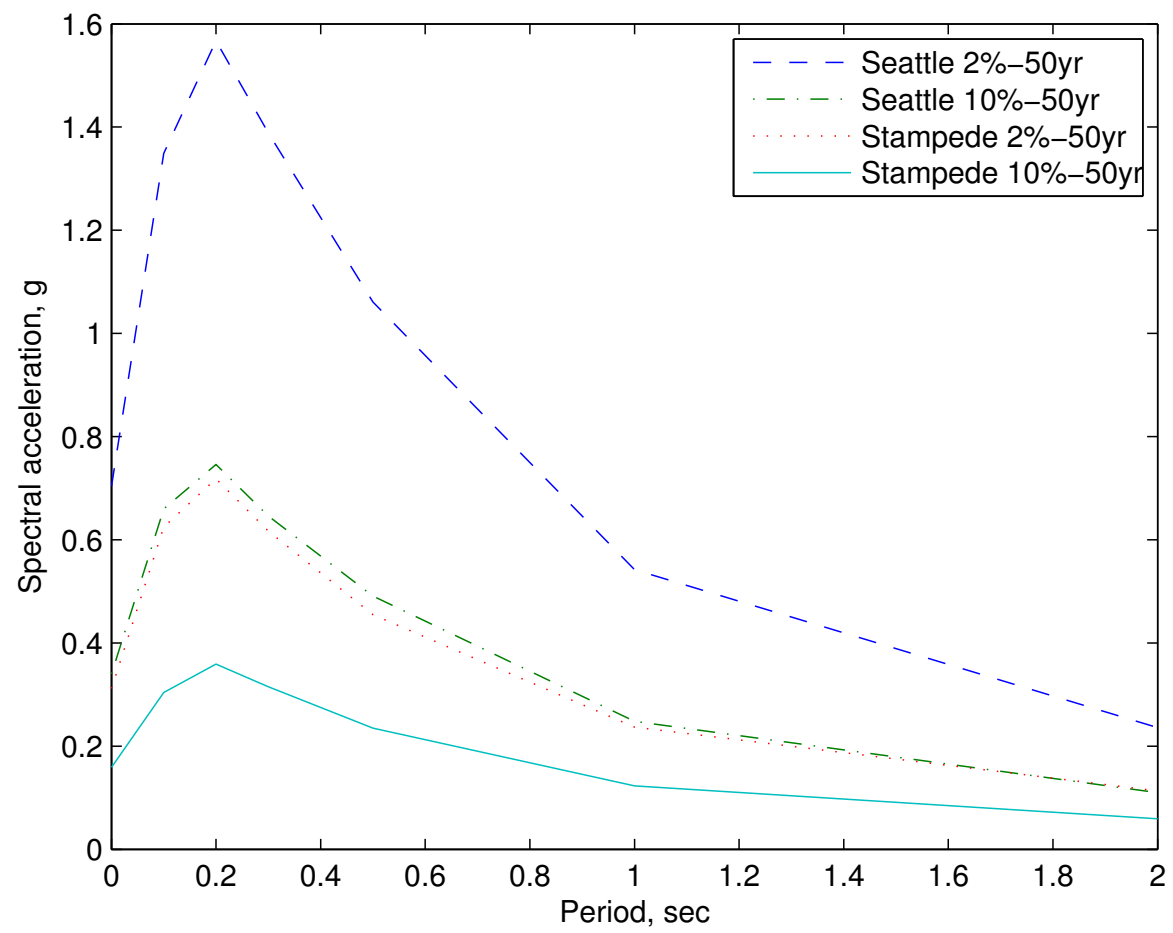

Figure 6.9: Uniform hazard spectra of Seattle and Stampede, WA

For a specific earthquake event, a ground acceleration record is randomly selected and scaled to perform NDA. As discussed in Section 6.3.1.2, the intensity of a simulated earthquake event can be measured in terms of PGA or $S_{a}$. If the intensity is in terms of PGA, PGA is converted to $S_{a}$ using a factor $c$, which is determined by:

$$
c=\overline{S_{a}\left(T_{1}\right)} / \overline{P G A}
$$


where $\overline{S_{a}\left(T_{1}\right)}$ and $\overline{P G A}$ are the mean values of $S_{a}\left(T_{1}\right)$ and PGA of ground motions that are selected for a specific site. $S_{a}\left(T_{1}\right)$ is the spectral acceleration at the fundamental period of the building ( $T_{1}=0.25 \mathrm{sec}$ for the illustrative building in this paper). For Stampede, the values of $c$ are 2.505 for the ground motions with $10 \%$ exceedance probability in 50 years, and 2.278 for those with $2 \%$ exceedance probability in 50 years. Once PGA is converted to $S_{a}$ (termed target $S_{a}$ herein), the random selected ground motion record is scaled so that its $S_{a}$ matches the target $S_{a}$.

The ground snow load record of Stampede is simulated using the FPP model as discussed in Section 6.3.2. The roof snow load $p_{f}$ is converted from the ground snow load $p_{g}$ by

$$
p_{f}=0.7 C_{s} C_{e} C_{t} I p_{g}
$$

where $C_{s}$ is the roof slope factor, $C_{e}$ is the exposure factor, $C_{t}$ is the thermal factor, and $I$ is the importance factor. In this study, it is assumed that, the building roof is warm and with slope less than $30^{\circ}\left(C_{s}=1\right)$; the building is located in exposure $\mathrm{C}$ with fully exposed roof $C_{e}=0.9$ and is normally heated $\left(C_{t}=1\right)$. Importance factor $I$ is 1.0 . These factors are obtained from the ASCE 7-05 standard [75].

In the simulation, the randomly selected acceleration record is applied along the $X$ direction and then the $Y$ direction. The roof snow load is converted to seismic weight using four factors (referred to as the snow participation factor $\alpha_{s}$ later) 1.0, 0.5, 0.2 and 0. For each simulated earthquake event, there are up to 8 runs of NDA. If the snow load is larger than zero, 8 NDAs are performed ( $4 \alpha_{s}$ on both $X$ and $Y$ directions). Only 2 NDAs will be performed if the snow load is zero. The snow participation factor $\alpha_{s}=1.0$ indicates that the roof snow stays on the roof during the earthquake, while $\alpha_{s}=0$ implies that all the snow on the roof drops off because of the ground shaking. Given these two factors, the range of snow load effect on the seismic risk of the building can be determined. Other two factors 0.5 and 0.2 are intermediate values used for further evaluation of snow load effects on seismic risk of the building. Note that the snow participation factor 0.2 in ASCE 7-05 [75] is based on the annual maximum ground snow load distribution. It cannot be directly compared with $\alpha_{s}$ specified herein. 


\subsubsection{Limit states exceedance probabilities}

Each run of MCS simulates a 10,000-year period of time, by which the simulations are found to be converged. The simulated ground snow loads are calibrated with the weather records obtained from the NCDC, as discussed in Section 6.3.2.2. The earthquake occurrence rate is approximately 0.05 per year [103]. A maximum inter-story drift can be obtained by NDA for each earthquake occurrence. The obtained maximum inter-story drift is compared with the four limit states, $1 \%, 2 \%, 3 \%$, and $7 \%$, so that the annual rate of exceedance of the limit states can be obtained. For example, 487 earthquakes are observed in one run of MCS (10,000 years) and 39 of them caused inter-story drifts larger than $1 \%$ (considering snow participation factor $\alpha_{s}=1$ ). The annual exceedance rate of $1 \% \mathrm{drift}$ can be calculated as $\lambda=39 / 10,000=0.0039 /$ year. Assuming the exceedance event follows the Poisson distribution, the annual exceedance probability can be determined by:

$$
p_{\text {annual }}=1-\operatorname{POISSCDF}(0, \lambda)
$$

where POISSCDF is the CDF of the Poisson distribution, $\lambda$ is the occurrence rate [147].

Figure 6.10 shows the expected (mean values) annual exceedance probabilities of the four limit states obtained using MCS. Table 6.3 lists the expected annual exceedance probabilities. As discussed in Section 6.3.1.2, earthquake intensity can be measured in terms of PGA or $S_{a}$, both of which are investigated for the building in Stampede. The exceedance probabilities of the four limit states determined using both measurements have the same order of magnitude, as shown in Figures 6.10(a) and 6.10(b), In the discussion of economic losses in Section 6.6.2, only PGA is considered as the earthquake intensity measurement.

The coefficient of variation (cov) of the annual exceedance probabilities are listed in Table 6.3. It can be observed that the cov of the $7 \%$ and $3 \%$ limit states are much higher than those of the other two limit states, indicating that high variation in the exceedance probability of the $7 \%$ and $3 \%$ limit states. 
Table 6.3: Annual exceedance probabilities of four drift limit states of a light-frame wood building in Stampede, WA

\begin{tabular}{cccccccccc}
\hline \hline & \multicolumn{2}{c}{$\alpha_{s}=1$} & \multicolumn{2}{c}{$\alpha_{s}=0.5$} & \multicolumn{2}{c}{$\alpha_{s}=0.2$} & \multicolumn{2}{c}{$\alpha_{s}=0$} \\
\cline { 2 - 9 } Limit state & $\begin{array}{c}\text { mean } \\
\times 10^{-3}\end{array}$ & cov & $\begin{array}{c}\text { mean } \\
\times 10^{-4}\end{array}$ & cov & $\begin{array}{c}\text { mean } \\
\times 10^{-4}\end{array}$ & cov & $\begin{array}{c}\text { mean } \\
\times 10^{-5}\end{array}$ & cov \\
\hline $1 \%$ & 4.1 & 0.15 & 16 & 0.26 & 4.0 & 0.4 & 10 & 0.73 \\
$2 \%$ & 1.0 & 0.28 & 5.0 & 0.45 & 1.8 & 0.78 & 4.5 & 1.41 \\
$3 \%$ & 0.51 & 0.56 & 2.1 & 0.81 & 0.78 & 1.32 & 0.54 & 4.11 \\
$7 \%$ & 0.13 & 0.85 & 0.52 & 1.2 & 0.20 & 1.42 & 0.49 & 4.31 \\
\hline$\alpha_{s}:$ snow participation factor & & & & & & \\
\hline \hline
\end{tabular}

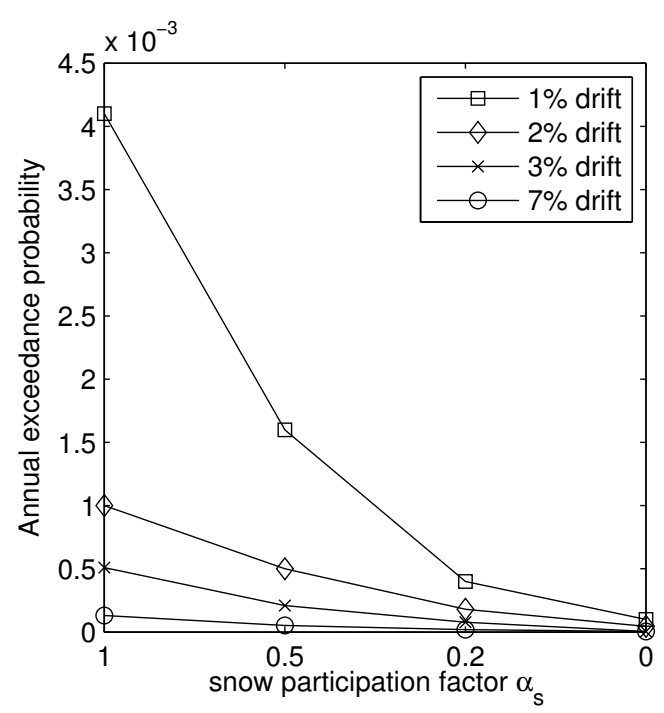

(a) PGA as the earthquake intensity measurement

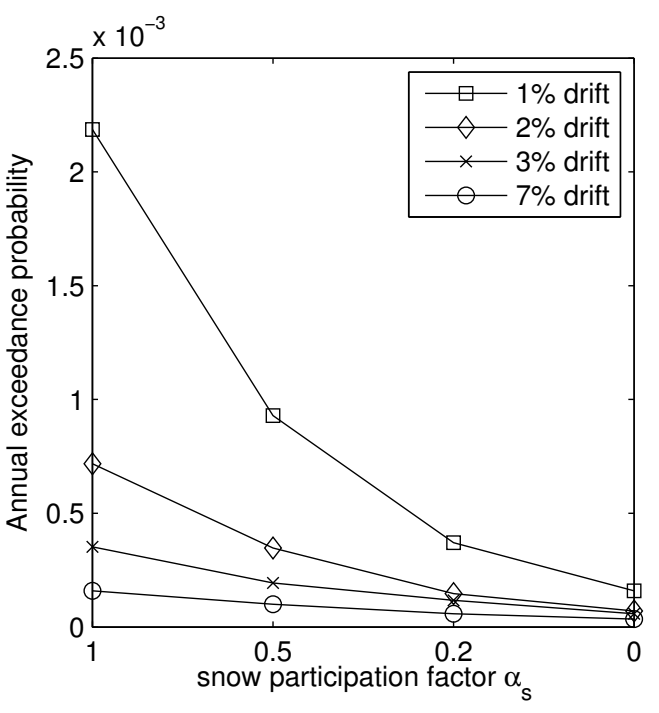

(b) $S_{a}$ as the earthquake intensity measurement

Figure 6.10: Expected annual exceedance probabilities of four limit states in Stampede, WA

\subsubsection{Estimation of economic losses}

the seismic risk in terms of economic loss may be easier to understand for stake holders or home owners than engineering terms such as the drift limit exceedance probability. Economic loss in a period of time $T$ (e.g., 50 years) is examined for the one-story building in Stampede, WA, using the proposed OOF. The annual discount rate is taken to be 
$3.5 \%$ [29]. The loss in 5 different periods of time (10, 25, 50, 80 and 100 years) are simulated for comparison purposes, considering 4 snow participation factors $\left(\alpha_{s}\right)$. Generally, the market value of a building includes the building replacement value and the land value. In this study, the land value is not included in the analysis. The value of the building (i.e, replacement value) is assumed to be $\$ 150 \mathrm{k}(\$ 1 \mathrm{k}=\$ 1,000)$ and the value of the contents of the building is taken to be $50 \%$ of the building value [29, 140]. So the total replacement value is $\$ 225 \mathrm{k}$. If the inter-story drift is larger than $7 \%$, indicating a collapse state of the building, the loss is assumed to be the total replacement value.

The loss accumulated over a period of time $T$ is a random variable, the distribution of which is examined using MCS in this section, in terms of mean and percentile values of the loss in time $T$. Let $\mathbf{E D P}_{n \times 1}$, in which $n$ is the number of $\operatorname{EDP}$ (equal to the number of earthquakes in $T$ ), indicate the simulated maximum EDP (i.e., inter-story drift in this study) in time $T$. The loss in time $T$ can be simulated by performing MCS $m$ times following the procedure described in Section 6.5. For the $j^{\text {th }}$ run of $\operatorname{MCS}, \operatorname{Loss}(T, j)$ is calculated by:

$$
\operatorname{Loss}(T, j)=\sum_{i=1}^{n} \frac{\mathrm{L}(i, j)}{\left(1+r_{d}\right)^{t_{i}}}
$$

where $\mathrm{L}(i, j)$ is the economic loss due to $\mathbf{E D P}(i), i \in[1, n]$, in the $j(j \in[1, m])$ run of MCS, $r_{d}$ is the annual discount rate, and $t_{i}$ is the occurring time of $\operatorname{EDP}(i)$. According to this process, a vector of loss, $\mathbf{L o s s}_{m \times 1}$, can be obtained for a vector $\mathbf{E D P}_{n \times 1}$. For a 10,000-year simulation of the earthquake and snow hazards combination, 100 EDP are obtained if the reference time of interest for loss is 100 years (i.e., $T=100$ years in Eq. (6.14)), leading to a loss matrix, $\mathbf{L o s s}_{m \times 100}$. Using this matrix $\mathbf{L o s s}_{m \times 100}, 100$ values of a certain percentile value can be calculated.

Figure 6.11 shows the $90^{\text {th }}$ percentile of the loss for the one-story wood building, considering 5 reference times and 4 snow participation factors. For the most conservative case (i.e., $\alpha_{s}=1$ indicating all the snow on roof is taken as the seismic weight), there is a $90 \%$ probability that the loss in 100 years is no more than $13 \%$ of the house total replacement value. However, if assuming that $50 \%$ of the roof snow drops off the roof (i.e., $\alpha_{s}=0.5$ ), the loss in 100 years has a $90 \%$ probability to be no more than $3.7 \%$ of the house total replacement value, decreasing significantly compared to the case with $\alpha_{s}=1$. It indicates the snow load in such areas with significant snow accumulation as Stampede has a significant effect on the seismic risk assessment for light-frame wood construction. 


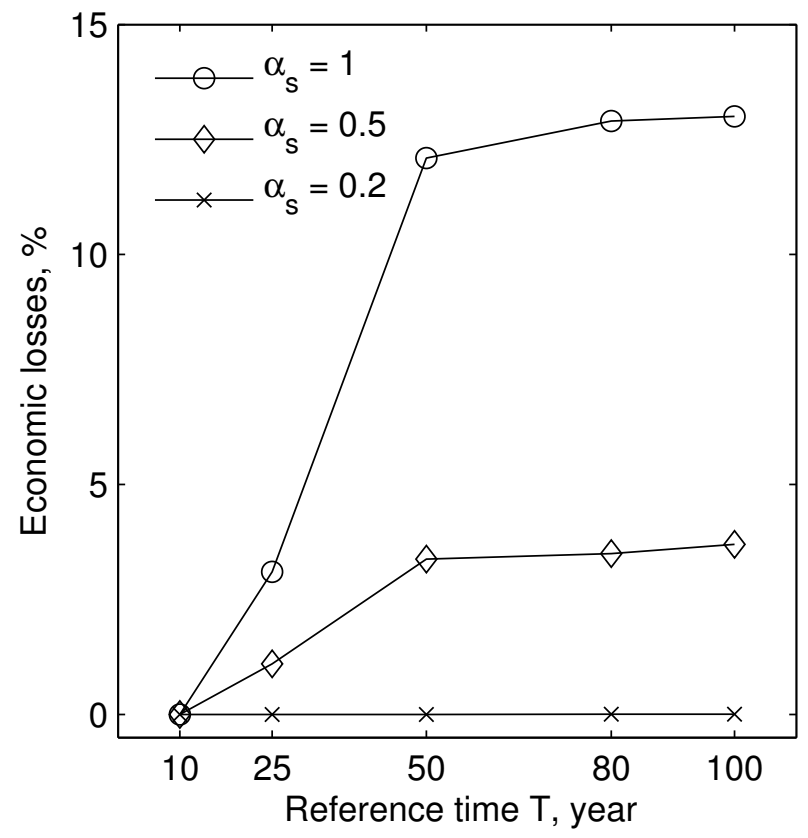

Figure 6.11: $90^{\text {th }}$ percentile of the simulated economic losses (in percentage of the total replacement value) of the one-story light-frame building in Stampede, WA $\left(\alpha_{s}\right.$ : snow participation factor)

Figure 6.12 shows the mean (i.e., expected) values of the loss of the building. Given those parameters listed in Table 6.2 and the earthquake hazard information listed in Table 6.1, without considering roof snow load (i.e., $\alpha_{s}=0$ ), the expected loss is almost negligible for all the 5 reference times. For example, the mean loss in 50 years with $\alpha_{s}=0$ is $0.1 \%$ of the total replacement value, as shown in Table 6.4. It increases by $300 \%$ to $0.4 \%$ if the snow participation factor $\alpha_{s}=0.2$. The mean values, median values (i.e., $50^{\text {th }}$ percentiles), and $90^{\text {th }}$ percentiles of the economic losses for all the cases examined are listed in Table 6.4.

The loss curves in Figures 6.11 and 6.12 tend to be flat as the reference period of time becomes longer. This is due to the time discounting effects. The histogram of the simulated economic losses in 50 years with the snow participation factor $\alpha_{s}=1$ is shown in Figure 6.13(a), in which the y-axis is in log scale in order to show the upper tail of the distribution. It can be seen that there is a high probability that the economic losses are zero. The high probability of no loss is due to the low exceedance probabilities of the drift limit states. For example, the exceedance probability of the $1 \%$ drift limit state with $\alpha_{s}=0$ in 50 years can be calculated by the data in Table 6.3 as $1-\left(1-10^{-4}\right)^{50}=0.005$. 


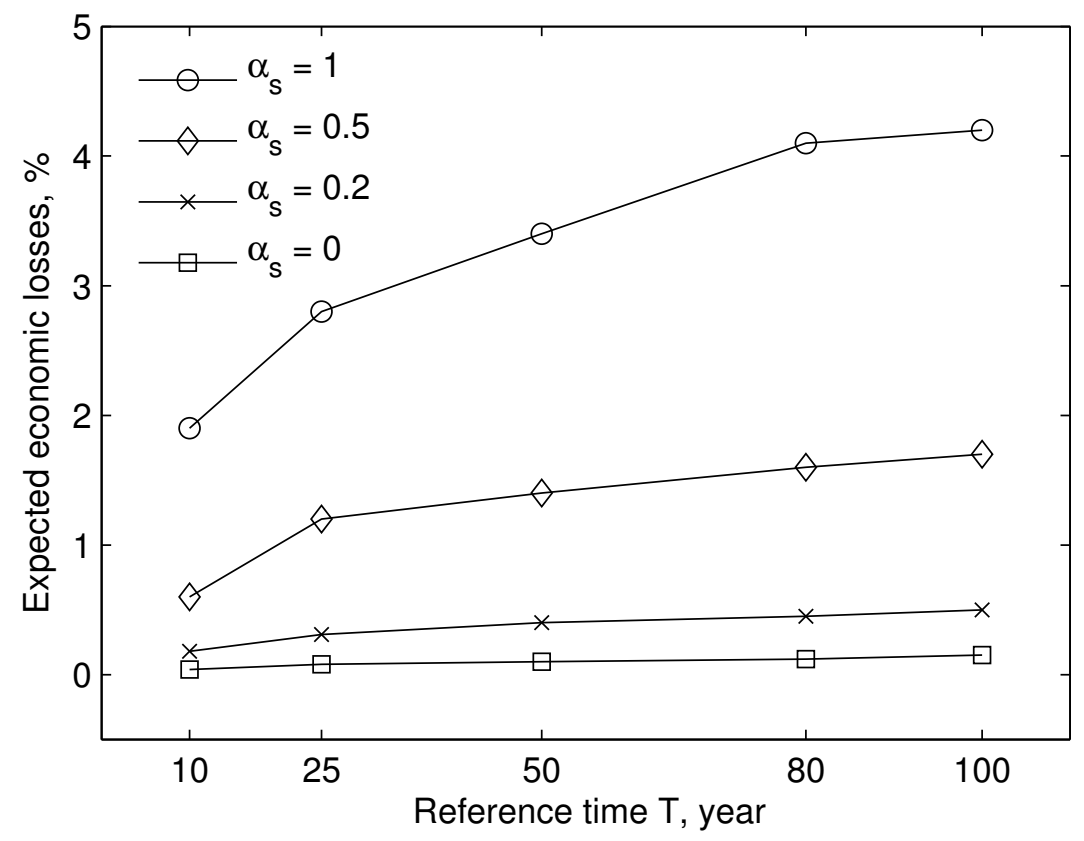

Figure 6.12: Expected economic losses (in percentage of the total replacement value) of the one-story light-frame building in Stampede, WA ( $\alpha_{s}$ is the snow participation factor)

Table 6.4: Economic losses (in percentage of the total replacement value) of the one-story building in Stampede, WA

\begin{tabular}{c|c|ccccc}
\hline \hline \multirow{2}{*}{ Snow participation factor } & \multirow{2}{*}{ Statistics } & \multicolumn{5}{|c}{ Reference time $T$ (year) } \\
\cline { 3 - 7 }$\alpha_{s}=1.0$ & 10 & 20 & 50 & 80 & 100 \\
\hline & $90^{\text {th }}$ percentile & 0 & 3.1 & 12.1 & 12.9 & 13.0 \\
& median & 0 & 0 & 0 & 0 & 0 \\
& mean & 1.9 & 2.8 & 3.4 & 4.1 & 4.2 \\
\hline \multirow{3}{*}{$\alpha_{s}=0.5$} & $90^{\text {th }}$ percentile & 0 & 1.1 & 3.38 & 3.5 & 3.7 \\
& median & 0 & 0 & 0 & 0 & 0 \\
& mean & 0.6 & 1.2 & 1.4 & 1.6 & 1.7 \\
\hline$\alpha_{s}=0.2$ & $90^{\text {th }}$ percentile & 0 & 0 & 0 & 0.006 & 0.008 \\
& median & 0 & 0 & 0 & 0 & 0 \\
& mean & 0.18 & 0.31 & 0.40 & 0.45 & 0.5 \\
\hline$\alpha_{s}=0$ & $90^{\text {th }}$ percentile & 0 & 0 & 0 & 0.001 & 0.001 \\
& median & 0 & 0 & 0 & 0 & 0 \\
& mean & 0.038 & 0.079 & 0.10 & 0.12 & 0.15 \\
\hline \hline
\end{tabular}


For the "low-frequency, high-consequence" hazard such as earthquake, the stake holders can hardly be informed about the potential risk by merely the mean values. The probability distribution of the loss is essential to answer questions such as "what is the probability that the loss will exceed the expected value in 50 years with $\alpha_{s}=1.0$ (i.e., $3.4 \%$ of the total replacement value as listed in Table 6.4)?". Figures 6.13(a) and 6.13(b) provide information to answer such a question. For example, the probabilities of the loss in 50 years exceeding $3.4 \%$ of the total replacement value are $19 \%, 10 \%, 2.4 \%$, and $0.79 \%$, considering the snow participation factor $\alpha_{s}$ of $1.0,0.5,0.2$, and 0 , respectively.

In order to examine the significance of snow accumulation on the economic loss of the building, the proposed OOF is used again, with the snow load simulated by the Bernoulli model, to examine the expected loss in 50 years for the wood building in Stampede, WA. The probability $p$ in Eq.(6.8) is set to be 1.0 since the ground snow load pulse is always 'on' throughout the snow season. The loss estimated by such a method is found to be approximately half of that estimated using the FPP model. For example, with snow participation factor $\alpha_{s}=1.0$, the expected losses in 50 years obtained using the Bernoulli and FPP models are $1.8 \%$ and $3.4 \%$, respectively. Therefore, for areas with the snow accumulation, the Bernoulli model underestimates the losses.

\subsection{Summary}

A probabilistic framework was proposed for risk assessment of structures subjected to combined seismic and snow hazards. The fragility surface for multiple hazards is a main challenge for the fragility-based frameworks. However, it is no longer a challenge for the proposed object-oriented framework, in which the effects and coincidences of multiple hazards are determined through MCS. The fragility surface is not needed in the proposed framework. Benefited from the object-oriented features, the proposed framework can also be extended to investigate other natural hazards, or be applied on other types of buildings, by adding modules into the framework.

The framework was applied to a typical light-frame wood residential building in Stampede, WA where both seismic and snow loads are significant for an extended period of time. The seismic load was simulated as a Poisson process, with ground acceleration records ran- 


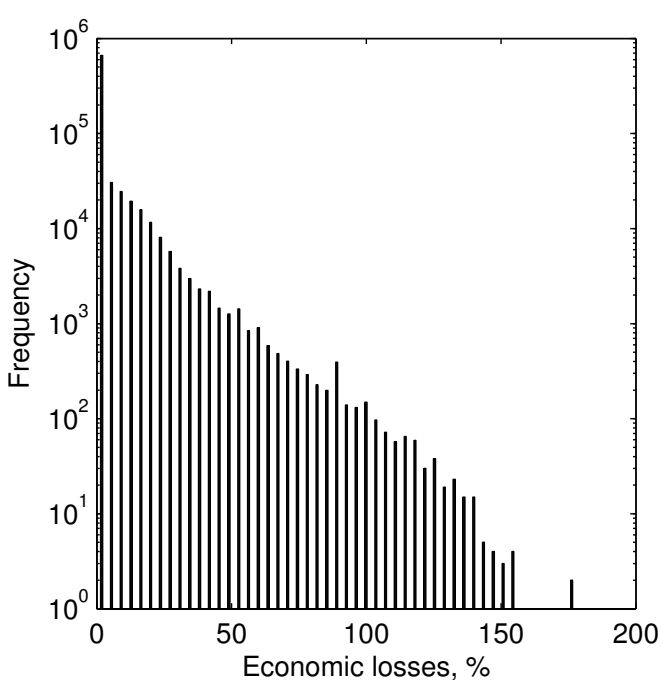

(a)

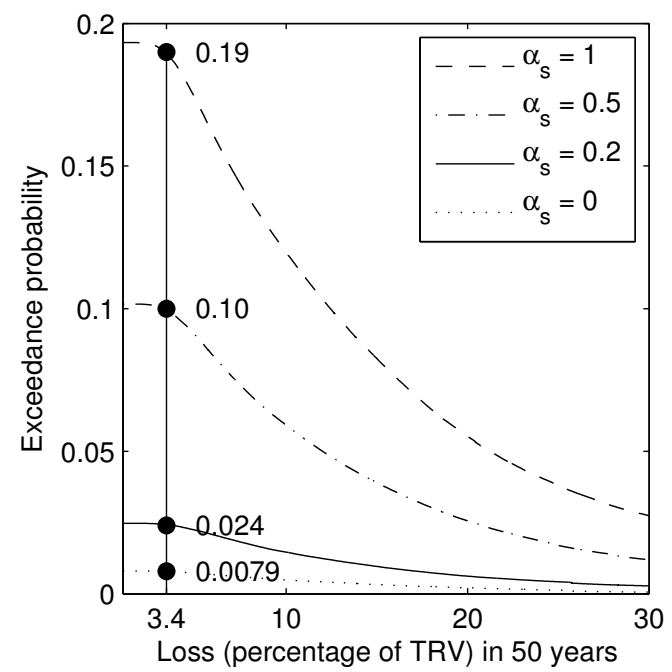

(b)

Figure 6.13: (a) Histogram of the simulated economic losses (in percentage of the total replacement value) in 50 years of the one-story building in Stampede, WA; (b) Exceedance probabilities of the 50-year economic loss (in percentage of the total replacement value) of the one-story building in Stampede, WA (the snow participation factor $\alpha_{s}=1$ )

domly selected from available databases. The snow load was simulated using the Filtered Poisson process model. Uncertainties in earthquake ground motions, structural response, damage state and damage cost are propagated in the framework by MCS. The snow load in areas with snow accumulation was found to contribute significantly to the economic losses of the light-frame wood building. The Bernoulli snow model underestimates the loss of buildings located in areas with snow accumulation. With snow participation factor $\alpha_{s}=1.0$, the expected losses with and without considering snow accumulation in 50 years were found to be $3.4 \%$ and $1.8 \%$, respectively. 


\section{Chapter 7}

\section{Summary, conclusions and future work}

\subsection{Summary and conclusions}

In this study, the risk of light-frame wood construction subjected to multiple hazards is evaluated. The contributions and conclusions of this study are summarized as follows.

1. Collapse fragilities of light-frame wood buildings, accounting for differences in construction practices and site-specific seismic hazard were investigated from a series of Incremental Dynamic Analysis (IDA). The ground motions developed in the SAC project [51] and by Wen and $\mathrm{Wu}$ [52] were used to represent the inherent (aleatoric) uncertainty in earthquake demand. The collapse capacity of wood-frame construction was found to be sensitive to the ground motions selected for the analysis. The probability of collapse under a spectrum of possible earthquakes was determined by convolving the collapse fragility with the seismic hazard specified by the USGS. Despite the recent changes in seismic hazard mapping practices in ASCE Standard 705, the collapse probabilities of light-frame wood residential construction in western, eastern, and central regions of the U.S. remain geographically non-uniform, implying that current seismic design requirements in ASCE Standard 7-05 do not lead to uniform risk (i.e., collapse probability). Collapse margins of typical shear walls in the WUS are significantly lower than those in the CEUS. If the goal of uniform risk 
for light-frame wood construction is to be achieved, the proposed performance levels in PBE and current seismic design maps may need to be modified.

2. Collapse risk of light-frame wood construction at four sites in the U.S. were further investigated, considering both aleatoric uncertainty (i.e., record-to-record uncertainty, and resistance uncertainty) and epistemic uncertainty (i.e., modeling uncertainty). The spectral shape $\varepsilon$ effect on the collapse risk was also examined. Collapse probabilities at Maximum Considered Earthquake (MCE) and collapse probabilities (annual and 50-year) for four sites were estimated.

Record-to-record uncertainty found in light-frame wood construction in this study ranged between 0.31 and 0.50 , which is consistent with what has been found in steel and concrete structures. The spectral shape $\varepsilon$ of ground motion was found to have significant effect on the collapse risk of light-frame wood construction, especially for high seismicity areas like the west coast of the U.S. Considering a moderate modeling uncertainty (i.e., $\beta_{m}=0.4$ in this study), the dispersion due to both resistance and modeling uncertainties was found to be approximately 0.44 , which led to an increase of annual collapse probability ranging between $25 \%$ and $168 \%$ depending on the site. Therefore, resistance and modeling uncertainty contributions can not be neglected in light-frame wood construction collapse risk assessment.

3. The Bernoulli model has been used in the past to model snow loads. However, the model cannot be used for sites with significant snow accumulation because it might lead to unconservative designs of buildings located in such areas, for not being able to model the snow accumulation. In this study, the Filtered Poisson process (FPP) model was investigated as a stochastic tool to simulate snow loads. Weather records from three sites in the U.S. were obtained from the National Climatic Data Center (NCDC) to calibrate the FPP model. Both snow accumulation (Tahoe City, CA and Stampede, WA) and load pulse (Buffalo, NY) characteristics for different sites can be effectively simulated using the FPP model. A genetic algorithm was employed successfully to select parameters for the FPP model.

One of the merits of the FPP model is that different simulation objectives can be fulfilled by using different cost functions, while the Bernoulli model can only fit to the probability distribution of the annual maximum ground snow loads. The time variation (i.e., the daily ground snow load) approximately match those of the NCDC snow records, which the Bernoulli model cannot achieve. 
4. An object-oriented framework (OOF) was proposed in this study, for loss estimation of buildings subjected to multiple hazards. The OOF is modular and can explicitly consider various sources of uncertainties in the loss estimation process. The difficulties of using fragility-based framework were overcome. The OOF was proved to be an appropriate tool for risk assessment of light-frame wood buildings.

The framework was applied to light-frame wood construction subjected to mainshock and aftershock sequences to estimate the economic losses. The seismic hazard was simulated and applied to buildings to estimate the transition and downtime losses, which constitute the total seismic loss. The probability distribution of the seismic loss was obtained by Monte Carlo Simulation (MCS). Aftershock and downtime cost were found to be two important factors in the seismic loss assessment.

The OOF was also used to assess the economic risk of a light-frame wood building subjected to combined seismic and snow loads. The snow load was simulated using the Filtered Poisson process model. The seismic load was simulated as a Poisson process, with ground acceleration records randomly selected from available database. Uncertainties in earthquake ground motions, structural response, damage state and damage cost are propagated in the framework by MCS. The snow load in areas with snow accumulation was found to contribute significantly to the economic losses of the light-frame wood construction. The Bernoulli model might underestimate the loss for areas with snow accumulation. With snow participation factor $\alpha_{s}=1.0$, the expected losses with and without consideration of snow accumulation in 50 years were found to be $3.1 \%$ and $1.6 \%$, respectively, which indicates that without proper considering snow accumulation, the risk is under estimated by almost $100 \%$.

\subsection{Future work}

Although the proposed methodologies and framework in this study provide insights to performance and risk of light-frame wood buildings subjected to multiple hazards, further investigations are suggested as follows for light-frame wood construction and other types of buildings and structures.

1. Some characteristics of the ground snow load record have not been thoroughly ex- 
amined in the FPP model, including the length of snow season and the shape of the snow load record with accumulation. The daily ground snow load was examined by comparing the empirical CDF of both NCDC and simulated records. In the future, other cost functions should be considered to investigate such characteristics of snow load records so that the FPP model will be capable of modeling snow loads more accurately. The FPP model can also be used in the investigation of the 'creep-rupture' behavior for timber structures subjected to accumulated snow loads.

2. As discussed in Chapter 5, there is a high probability that aftershocks will occur in a short time after the mainshock, leaving very limited time for decision makers to make critical decisions, such as resident evacuation, repair action, and building re-occupancy. Typical risk assessment processes are too time consuming to be applicable for decision making on such situations. A rapid and efficient risk assessment tool is necessary for real-time decision making in the aftershock environment. Such a tool can be developed based on the OOF and the transition probability matrix developed in future work 2 .

3. The proposed OOF can be applied to concrete and steel buildings, as well as infrastructure subjected to multiple hazards. In the OOF, the structural object is defined to include structural models. In this study, the structural model is the hysteresis model defined in the SAWS program [48]. Other structural models can be incoporated into the structural object to investigate risk of other types of construction. Other objects in the OOF (e.g., the seismic hazard object and the loss assessment object) will not be affected by such a change in the structural object.

4. Ground motion selection and scaling are used in this study, but the uncertainty in the process has not been thoroughly investigated. Recent studies (e.g., [76, 141]) indicate that the ground motions selection and scaling methods might have significant influence on the risk assessment of buildings. Guidances on this subject are under development in the PEER GMSM program [141]. These guidances, once available, can be incorporated into the proposed framework to examine the influences on the risk assessment. 


\section{References}

[1] Yue Li and Bruce R. Ellingwood. Reliability of woodframe residential construction subjected to earthquakes. Structural Safety, 29(4):294-307, 2007.

[2] Ioannis P. Christovasilis, Andre Filiatrault, Michael C. Constantinou, and Assawin Wanitkorkul. Incremental dynamic analysis of woodframe buildings. Earthquake Engineering \& Structural Dynamics, 38(4):477-496, 2009.

[3] Vivian Melysund, Kim Robert Lis, Jan Siem, and Kristoffer Apeland. Increased snow loads and wind actions on existing buildings: Reliability of the Norwegian building stock. Journal of Structural Engineering, 132(11):1813-1820, 2006.

[4] Michael O'Rourke and Peter D. Wrenn. Snow Loads: A Guide to the Use and Understanding of the Snow Load Provisions of ASCE 7-02. ASCE, 2004.

[5] Associate Press. At least 66 killed in polish roof collapse. http://news . bbc.co.uk/2/hi/asia-pacific/7221456.stm, 2006. [visited on April $3,2009]$.

[6] British Broadcast Company. 'final body' found at german rink. http://news . bbc.co.uk/cbbcnews/hi/newsid_4580000/newsid_4584100/ 4584106.stm, 2006. [Visited on Dec. 7, 2009].

[7] British Broadcast Company. China freeze 'has cost billions'. http://www . msnbc.msn.com/id/10663279/, 2008. [visited on May 2, 2009].

[8] California Institute of Technology. Protecting wood frame buildings the goal of new earthquake grant to Caltech. http://media.caltech.edu/press_ releases/11929, 1998. [visited on Jan.24 2010]. 
[9] Consortium of Universities for Research in Earthquake Engineeirng (CUREE). CUREE-Caltech woodframe project. http://www.curee.org/projects/ woodframe/index.html, 2008. [visited on Jan. 24 2010].

[10] John van de Lindt, Yue Li, William Bulleit, Rakesh Gupta, and Morris Paul. The next step for AF\&PA/ASCE 16-95: Performance-based design of wood structures. Journal of Structural Engineering, 135(6):611-618, 2009.

[11] NEESWOOD. http://www.engr.colostate.edu/NEESWood/ newsletter.shtml, [visited on Jan. 24 2010].

[12] ASCE. Standard for load and resistance factor design (LRFD) for engineering wood construction (ASCE 16-95), 1996. American Society of Civil Engineers.

[13] Andre Filiatrault and Bryan Folz. Performance-based seismic design of wood framed buildings. Journal of Structural Engineering, 128(1):39-47, 2002.

[14] M. J. N. Priestley. Performance based seismic design. In Proc. 12th World Conf. on Earthquake Engineering, Auckland, New Zealand, 2000. Paper No. 2831.

[15] M. J. N. Priestley. Displacement-based approaches to rational limit states design of new structures. In 11th European Conf. on Earthquake Engineering, Paris, 1998.

[16] M. J. N. Priestley. Myths and fallacies in earthquake engineering-conflicts between design and reality. Bull. New Zealand National Soc. for Earthquake Eng., 26(3): 329-341, 1993.

[17] David V. Rosowsky and Bruce R. Ellingwood. Performance-based engineering of wood frame housing: Fragility analysis methodology. Journal of Structural Engineering, 128(1):32-38, 2002.

[18] Bruce R. Ellingwood and David V. Rosowsky. Fragility assessment of structural systems in light-frame residential construction subjected to natural hazards. In George E. Blandford, editor, Structures 2004 - Building On The Past: Securing The Future, Nashville, Tennessee, 2004. ASCE.

[19] Bruce R. Ellingwood, David V. Rosowsky, Yue Li, and Jun Hee Kim. Fragility assessment of light-frame construction subjected to wind and earthquake hazards. Journal of Structural Engineering, 130(12):1921-1930, 2004. 
[20] Kyung Ho Lee and David V. Rosowsky. Fragility analysis of woodframe buildings considering combined snow and earthquake loading. Structural Safety, 28(3):289303, 2006.

[21] Applied Technological Coucil. NEHRP guidelines for the seismic rehabilitation of buildings (FEMA publication 273), 1997. Prepared for the Building Seismic Safety Council with funding by Federal Emergency Management Agency.

[22] Federal Emergency Management Agency (FEMA). FEMA356 Prestandard and commentary for the seismic rehabilitation of buildings, 2000.

[23] ASCE. Seismic rehabilitation of existing buildings ASCE/SEI 41-06, 2007. ASCE/SEI 41-06.

[24] USGS. Aftershocks rattle Chile after earthquake. http: / / earthquake usgs . gov/earthquakes/recenteqsww/Maps/10/290_-35.php, 2010.

[25] China Earthquake Administration. Aftershock statistics of the WenChuan earthquake. http://www.cea.gov.cn/manage/html/ 8a8587881632fa5c0116674a018300cf/_content/09_02/17/ 1234834558685 . html, 2009. [in Chinese, visited on Jan. 18 2009].

[26] Guo-Quan Wang, David M. Boore, Heiner Igel, and Xi-Yuan Zhou. Comparisons of ground motions from five aftershocks of the 1999 Chi-Chi, Taiwan, earthquake with empirical predictions largely based on data from california. Bulletin of the Seismological Society of America, 94:2198-2212, 2004.

[27] S. Pei and John W. van de Lindt. Methodology for earthquake-induced loss estimation: An application to woodframe buildings. Structural Safety, 31(1):31-42, 2009.

[28] Jamie E. Padgett, Kristina Dennemann, and Jayadipta Ghosh. Risk-based seismic life-cycle cost-benefit (LCC-B) analysis for bridge retrofit assessment. Structural Safety, 32(3):165-173, 2010. (in press).

[29] Gee Liek Yeo and C. Allin Cornell. Building life-cycle cost analysis due to mainshock and aftershock occurrences. Structural Safety, 31(5):396-408, 2009.

[30] Quanwang Li and Bruce R. Ellingwood. Performance evaluation and damage assessment of steel frame buildings under main shock-aftershock earthquake sequences. Earthquake Engineering \& Structural Dynamics, 36(3):405-427, 2007. 
[31] Michael J. Markow. Highway management systems: State of the art. Journal of Infrastructure Systems, 2(3):118-126, 1996.

[32] K. Golabi, P. D. Thompson, and W. A. Hyman. Points technical manual. Technical Report FHWA-SA-94-031, Federal Highway Administration, Washington, D.C., 1993. Optima Inc. and Cambridge Systematics, Inc., Cambridge, Mass.

[33] ATC. Earthquake damage evaluation data for California, 1985.

[34] National Institute of Building Sciences (NIBS). HAZUS Earthquake Loss Estimation Methodology: Technical Manual, Volumes I, II, and III, NIBS document number 5210. Federal Emergency Management Agency, Washington, D.C., 1997.

[35] Philip J. Schneider and Barbara A. Schauer. HAZUS-Its development and its future. Natural Hazards Review, 7(2):40-44, 2006.

[36] C. Allin Cornell and Helmut Krawinkler. Progress and challenges in seismic performance assessment. http://peer.berkeley.edu/news/2000spring/ performance.html, 2000. PEER Center News.

[37] G. G. Deierlein. Overview of a comprehensive framework for earthquake performance assessment. In Fajfar P. and Krawinkler H., editors, Proceedings of international workshop on performance-based seismic design - concepts and implementation, pages 15-26, Bled, Slovenia, 2004.

[38] Jack W. Baker and C. Allin Cornell. Uncertainty propagation in probabilistic seismic loss estimation. Structual Safety, 30(3):236-252, 2008.

[39] K. A. Porter. Assembly-Based Vulnerability of Buildings and Its Uses in Seismic Performance Evaluation and Risk-Management Decision-Making. PhD thesis, Stanford University, Stanford, CA, 2000.

[40] Keith A. Porter, Anne S. Kiremidjian, and Jeremiah S. LeGrue. Assembly-based vulnerability of buildings and its use in performance evaluation. Earthquake Spectra, 17(2):291-312, 2001.

[41] ATC. Guidelines for seismic performance assessment of buildings, atc-58 50\% draft report. http://www.atcouncil.org/pdfs/ ATC-58-50percentDraft.pdf, 2009. 
[42] Yue Li, Yue-Jun Yin, Bruce R. Ellingwood, and W. M. Bulleit. Uniform hazard vs. uniform risk bases for performance-based earthquake engineering of light-frame wood construction. Earthquake Engineering \& Structural Dynamics, 2010. (2010, in press, preview available online).

[43] NAHB Research Center, Inc. Residential structural design guide: 2000 edition, 2000. U.S. Department of Housing and Urban Development Office of Policy Development and Research, National Association of Home Builders Housing Affordability Through Design Efficiency Program, Washington, DC.

[44] American Forest \& Paper Association (AFPA) and Wood Frame Construction Manual (WFCM). Design of wood frame buildings for high wind, snow and seismic loadings, 2001.

[45] Bryan Folz and Andre Filiatrault. CASHEW-version 1.0: A computer program for cyclic analysis of wood shear walls. Technical report, Division of Structural Engineering, University of California, San Diego, 2000. Report No.: SSRP-2000/10.

[46] Andre Filiatrault, David Fischer, Bryan Folz, and Chia-Ming Uang. Seismic testing of two-story woodframe house: Influence of wall finish materials. Journal of Structural Engineering, 128(10):1337-1345, 2002.

[47] J. D. Dolan and C. P. Heine. Sequential phased displacement cyclic tests of twostory wood frame house: influence of wall finish materials, 1997. VPI\&SU Report No. TE-1997-002, Virginia Polytechnic Institute and State University.

[48] Bryan Folz and Andre Filiatrault. Seismic analysis of woodframe structures. I: Model formulation. Journal of Structural Engineering, 130(9):1353-1360, 2004.

[49] NAHB Research Center. Manufactured of housing shear wall tests using ASTM method E72 and E564, 1990. Department of Housing and Urban Development.

[50] Bruce R. Ellingwood, David V. Rosowsky, and Weichiang Pang. Performance of light-frame wood residential construction subjected to earthquakes in regions of moderate seismicity. Journal of Structural Engineering, 134(8):1353-1363, 2008.

[51] SAC steel project. Suites of earthquake ground motions for analysis of steel moment frame structures. http://nisee.berkeley.edu/data/strong_ motion/sacsteel/ground_motions.html, 2000. 
[52] Y. K. Wen and C. L. Wu. Uniform hazard ground motions for Mid-America cities. Earthquake Spectra, 17(2):359-384, 2001.

[53] L. Ibarra. Global Collapse of Frame Structures under Seismic Excitations. PhD thesis, Department of Civil and Environmental Engineering, Stanford University, 2003.

[54] Curtis B Haselton and Gregory G. Deierlein. Assessing seismic collapse safety of modern reinforced concrete moment frame buildings. Technical report, Department of Civil and Environmental Engineering, Stanford University, 2007.

[55] Bryan Folz and Andre Filiatrault. Saws-version 1.0 A computer program for seismic analysis of woodframe structures. Technical report, Division of Structural Engineering, University of California, San Diego, La Jolla, California, 2001.

[56] C. Allin Cornell, Fatemeh Jalayer, Ronald O. Hamburger, and Douglas A. Foutch. Probabilistic basis for 2000 SAC Federal Emergency Management Agency steel moment frame guidelines. Journal of Structural Engineering, 128(4):526-533, 2002.

[57] Dimitrios Vamvatsikos and C. Allin Cornell. Incremental dynamic analysis. Earthquake Engineering \& Structural Dynamics, 31(3):491-514, 2001.

[58] Farzin Zareian and Helmut Krawinkler. Assessment of probability of collapse and design for collapse safety. Earthquake Engineering \& Structural Dynamics, 36(13): 1901-1914, 2007.

[59] Bruce R. Ellingwood, Ozan Cem Celik, and Kursat Kinali. Fragility assessment of building structural systems in Mid-America. Earthquake Engineering \& Structural Dynamics, 36(13):1935-1952, 2007.

[60] Masanobu Shinozuka, M. Q. Feng, Jongheon Lee, and Toshihilo Naganuma. Statistical analysis of fragility curves. Journal of Engineering Mechanics, 126:1224-1231, 2000 .

[61] Federal Emergency Management Agency. NEHRP recommended provisions and commentary for seismic regulations for new buildings and other structures, 2003.

[62] ATC. Quantification of building seismic performance factors, FEMA P695, 2009. 
[63] N. Luco. Risk-targeted approach to selecting return periods for design maps. In Proceedings of the 3rd ATC-35/USGS National Earthquake Ground-Motion Mapping Workshop, Redwood City, CA, USA. Applied Technology Council, 2006.

[64] N. Luco, B. R. Ellingwood, R. O. Hamburger, J. D. Hooper, J. F. Kimball, and C. A. Kircher. Risk-targeted versus current seismic design maps for the conterminous United States. In SEAOC 76th Annual Convention (Structural Engineers Association of California), 2007.

[65] Bruce R. Ellingwood and Kursat Kinali. Quantifying and communicating uncertainty in seismic risk assessment. Structual Safety, 31(2):179-187, 2009.

[66] Jack W. Baker and C. Allin Cornell. A vector-valued ground motion intensity measure consisting of spectral acceleration and epsilon. Earthquake Engineering \& Structural Dynamics, 34(10):1193-1217, 2005.

[67] Bruce R. Ellingwood, J. G. MacGregor, T. V. Galambos, and C. A. Cornell. Probability based load criteria: Load factors and load combinations. Journal of Structural Engineering, 108(5):978-997, 1982.

[68] Christine A. Goulet, Curt B. Haselton, Judith Mitrani-Reiser, James L. Beck, Gregory G. Deierlein, Keith A. Porter, and Jonathan P. Stewart. Evaluation of the seismic performance of a code-conforming reinforced-concrete frame building - from seismic hazard to collapse safety and economic losses. Earthquake Engineering \& Structural Dynamics, 36(13):1973-1997, 2007.

[69] Abbie B. Liel, Curt B. Haselton, Gregory G. Deierlein, and Jack W. Baker. Incorporating modeling uncertainties in the assessment of seismic collapse risk of buildings. Structural Safety, 31(2):197-211, 2009.

[70] Julian J. Bommer and Helen Crowley. The influence of ground-motion variability in earthquake loss modelling. Bulletin of Earthquake Engineering, 4(3):231-248, 2006.

[71] Dimitrios Vamvatsikos and Michalis Fragiadakis. Incremental dynamic analysis for estimating seismic performance sensitivity and uncertainty. Earthquake Engineering \& Structural Dynamics, 39:141-163, 2010. 
[72] Keith A. Porter, James L. Beck, and Rustem V. Shaikhutdinovc. Sensitivity of building loss estimates to major uncertain variables. Earthquake Spectra, 18(4):719-743, 2002.

[73] Tae-Hyung Lee and Khalid M. Mosalam. Seismic demand sensitivity of reinforced concrete shear-wall building using fosm method. Earthquake Engineering \& Structural Dynamics, 117(14):32-40, 2005.

[74] Ozan Cem Celik and Bruce R. Ellingwood. Seismic fragilities for non-ductile reinforced concrete frames-role of aleatoric and epistemic uncertainties. Structural Safety, 32(1):1-12, 2010.

[75] ASCE. ASCE 7-05 minimum design loads for buildings and other structures, 2006. American Society of Civil Engineering.

[76] J. W. Baker and C. A. Cornell. Spectral shape, epsilon and record selection. Earthquake Engineering \& Structural Dynamics, 35:1077-1095, 2006.

[77] David V. Rosowsky, Weichiang Pang, Yue Wang, and Bruce R. Ellingwood. Fragility of conventional woodframe structures built in regions of low-to-moderate seismicity. In 10th International Conference on Structural Safety and Reliability, 2009.

[78] Bryan Folz and Andre Filiatrault. Cyclic analysis of wood shear walls. Journal of Structural Engineering, 127(4):433-441, 2001.

[79] Bryan Folz and Andre Filiatrault. Seismic analysis of woodframe structures. II: Model implementation and verification. Journal of Structural Engineering, 130(9): 1361-1370, 2004.

[80] H. Krawinkler, F. Parisi, L. Ibarra, A. Ayoub, and R. Medina. Development of a testing protocol for wood frame structures. Technical report, Stanford University, Stanford, Calif, CA, 2001. CUREE-Caltech Woodframe Project Report No. W-02.

[81] Kip Gatto and Chia-Ming Uang. Effects of loading protocol on the cyclic response of woodframe shearwalls. Journal of Structural Engineering, 129(10):1384-1393, 2003.

[82] Raul D. Bertero and Vitelmo V. Bertero. Performance-based seismic engineering: the need for a reliable conceptual comprehensive approach. Earthquake Engineering \& Structural Dynamics, 31(3):627-652, 2002. 
[83] N. A. Abrahamson and W. J. Silva. Empirical response spectral attenuation relations for shallow crustal earthquake. Seismological Research Letters, 68(1):94-127, 1997.

[84] C. Haselton and J. W. Baker. Ground motion intensity measures for collapse capacity prediction: Choice of optimal spectral period and effect of spectral shape. In Proceedings of 8th National Conference on Earthquake Engineering, San Francisco, California, 2006.

[85] F. Zareian. Simplified performance-based earthquake engineering. PhD thesis, Department of Civil and Environmental Engineering, Stanford University, 2006.

[86] C. Haselton, J. W. Baker, A. B. Liel, and G. G. Deierlein. Accounting for ground motion spectral shape characteristics in structural collapse assessment through an adjustment for epsilon. Journal of Structural Engineering, 2009. (in press).

[87] P. Somerville, N. Smith, S. Puntamurthula, and J. Sun. Development of ground motion time histories for phase 2 of the FEMA/SAC steel project. Technical report, SAC Joint Verture, 1997.

[88] Seung-Yul Yun, Ronald O. Hamburger, C. Allin Cornell, and Douglas A. Foutch. Seismic performance evaluation for steel moment frames. Journal of Structural Engineering, 128:534-545, 2002.

[89] Yue-Jun Yin and Yue Li. Probabilistic analysis of light-frame wood building subjected to combined snow and earthquake loads. In Inaugural International Conference of the Engineering Mechanics Institute, Minneapolis, MN, USA, 2008.

[90] Luis Esteva and Sonia E. Ruiz. Seismic failure rates of multistory frames. Journal of Structural Engineering, 115(2):268-284, 1989.

[91] David V. Rosowsky. Reliability-based seismic design of wood shear walls. Journal of Structural Engineering, 128(11):1439-1453, 2002.

[92] M. D. McKay, W. J. Conover, and R. J. Beckman. A comparision of three methods fro selecting values of input variables in the analysis of output from a computer code. Technometrics, 221:239-245, 1979.

[93] R. L. Iman, J. C. Helton, and J. E. Campbell. An approach to sensitivity analysis of computer models: Part I: Introduction, input variable selection and preliminary variable assessment. Joural of Quality Technology, 13:174-183, 1981. 
[94] R. L. Iman, J. C. Helton, and J. E. Campbell. An approach to sensitivity analysis of computer models: Part II: Ranking of input variables, response surface validation, distribution effect and technique synopsis. Joural of Quality Technology, 13:232240, 1981.

[95] Greg C. Foliente. Hysteresis modeling of wood joints and structural systems. Journal of Structural Engineering, 121:1013-1022, 1995.

[96] ATC. ATC-58 project. http://wWw.atcouncil.org/atc-58.shtml, 2001.

[97] USGS. Earthquake ground motion parameters version: 5.0.9 - 10/06/2008, 2008. URL http://earthquake.usgs.gov/research/hazmaps/design/. U.S. Geological Survey.

[98] Pacific Earthquake Engineering Research Center (PEER). Pacific earthquake engineering research center: NGA database. http://peer.berkeley.edu/ nga/, 2005.

[99] Erik M. Hendrickson, Bruce Ellingwood, and Joseph Murphy. Limit state probabilities for wood structural members. Journal of Structural Engineering, 113(1): 88-106, 1987.

[100] David V. Rosowsky and William M. Bulleit. Load duration effects in wood members and connections: order statistics and critical loads. Structural Safety, 24(2-4):347$362,2002$.

[101] Bruce R. Ellingwood and D. Rosowsky. Duration of load effects in LRFD for wood construction. Journal of Structural Engineering, 117(2):584-599, 1991.

[102] Carl J. Turkstra and Henrik O. Madsen. Load combinations in codified structural design. Journal of the Structural Division, 106(ST12):67-81, 1980.

[103] Bruce R. Ellingwood and D. Rosowsky. Combining snow and earthquake loads for limit states design. Journal of Structural Engineering, 122(11):1364-1368, 1996.

[104] Y. J. Yin, Y. Li, and W. M. Bulleit. Snow and earthquake load combination considering snow accumulaiton. In Proc., 14th World Conference on Earthquake Engineering, Beijing, China, 2008. 
[105] M. J. O’Rourke, R. Redfield, and P. V. Bradsky. Uniform snow loads on structures. Journal of the Structural Division, 108(12):2781-2798, 1982.

[106] Bruce. R. Ellingwood and R. Redfield. Ground snow loads for structural design. Journal of Structural Engineering, 109(4):950-964, 1983.

[107] K. H. Lee and D. V. Rosowsky. Site-specific snow load models and hazard curves for probabilistic design. Natural Hazards Review, 6(3):109-120, 2005.

[108] National Climatic Data Center (NCDC). NCDC climate data online. http:// cdo.ncdc.noaa.gov/pls/plclimprod/somdmain.somdwrapper, 2008.

[109] Bruce R. Ellingwood, Theodore V. Galambos, James G. MacGregor, and C. Allin Cornell. Development of a probability based load criterion for American National Standard A58. Technical report, U.S. Department of Commerce and National Bureau of Standards, 71980.

[110] E Parzen. Stochastic Processes. Holden-Day, Inc., 1962.

[111] Sharif Rahman and Mircea Grigoriu. Markov model for seismic reliability analysis of degrading structures. Journal of Structural Engineering, 119(6):1844-1865, 1993.

[112] Jaeyoung Yoon and M. Levent Kavvas. Probabilistic solution to stochastic overland flow equation. Journal of Hydrologic Engineering, 8(2):54-63, 2003.

[113] Mario Lefebvre and Jean-Luc Guibault. using filtered Poisson processes to model a river flow. Applied Mathematical Modelling, 32(12):2792-2805, 2008.

[114] John H. Holland. Adaption in Natural and Artificial Systems. University of Michigan Press, Ann Arbor, 1975.

[115] Jasmina Arifovic. Genetic algorithm learning and the cobweb model. Journal of Economic Dynamics and Control, 18(3):3-28, 1994.

[116] R. L. Haupt and D. H. Werner. Genetic Algorithms in Electromagnetics. Wiley-IEEE Press, 2007.

[117] Ricardo Perera and Francisco B. Varona. Flexural and shear design of frp plated rc structures using a genetic algorithm. Journal of Structural Engineering, 135:14181429, 2009. 
[118] Khewal Bhupendra Kesur. Advances in genetic algorithm optimization of traffic signals. Journal of Transportation Engineering, 135(4):160-173, 2009.

[119] Kenneth J. Fridley, Kathy A. Roberts, and J. Bryan Mitchell. Estimating ground snow loads using local climatological data. Journal of Structural Engineering, 120 (12):3567-3576, 1994.

[120] J.D. Barrett and R.O. Foschi. Duration of load and probability of failure in wood. Part I. modelling creep rupture. Canadian Journal of Civil Engineering, 5(4):505514, 1978.

[121] C. C. Gerhards and C. L. Link. Effect of loading rate on bending strength of Douglasfir 2 by 4'S. Forest Products Journal, 36(2):63-66, 1986.

[122] R. O. Foschi, Bryan Folz, and F. Z. Yao. Reliability-based design of wood structures. Technical report, Dept. of Civil Engineering, University of British Columbia, Vancouver, Canada, 1989. Report No. 34.

[123] Gee Liek Yeo and C. Allin Cornell. Post-quake decision analysis using dynamic programming. Earthquake Engineering \& Structural Dynamics, 38(1):79-93, 2009.

[124] John W. van de Lindt. Experimental investigation of the effect of multiple earthquakes on woodframe structural integrity. Practice Periodical on Structural Design and Construction, 13(3):111-117, 2008.

[125] Brendon A. Bradley and Dominic S. Lee. Accuracy of approximate methods of uncertainty propagation in seismic loss estimation. Structual Safety, 32:13-24, 2010.

[126] G. Yu and H. Adeli. Object-oriented finite element analysis using EER model. Journal of Structural Engineering, 119(9):2763-2781, 1993.

[127] Xiaomo Jiang and Hojjat Adeli. Object-oriented model for freeway work zone capacity and queue delay estimation. Computer-Aided Civil and Infrastructure Engineering, 19:144-156, 2004.

[128] B. Gutenberg and C. F. Richter. Seismicity of the Earth and Associated Phenomena. Princeton, NJ, Princeton University Press, 1949.

[129] Paul A. Reasenberg and Lucile M. Jones. Earthquake hazard after a mainshock in California. Science, 243(4895):1173-1176, 1989. 
[130] F. Omori. On the aftershocks of earthquake. Journal of Coll. Science Imperial University Tokyo, 7:111-120, 1894.

[131] T. Utsu. The centenary of the omori formula for a decay law of aftershock activity. Journal of the Physics of the Earth, 43:1-33, 1995.

[132] Yoshio Sunasaka and Anne S. Kiremidjian. A method for structural safety evaluation under mainshock-aftershock earthquake sequences. Technical Report 105, The John A. Blume Earthquake Engineering Center, Stanford University, California, 1993.

[133] Paul A. Reasenberg and Lucile M. Jones. Earthquake aftershocks: update. Science, 265(5176):1251-1252, 1994.

[134] Krzysztof Burnecki, Wolfgang Hardle, and Rafal Weron. An introduction to simulation of risk processes. In Jozef Teugels and Bjorn Sundt, editors, Encyclopedia of Actuarial Science. Wiley, 2004.

[135] Paul Bratley, Benner L. Fox, and Linus E. Schrage. A guide to simulation. SpringerVerlag, 1987.

[136] P. A. W. Lewis and G. S. Shedler. Simulation of nonhomogeneous poisson process by thinning. Naval Research Logistics Quarterly, 26(3):403-413, 2006.

[137] Yin-Nan Huang, Andrew S. Whittaker, and Nicolas Luco. Performance assesment of coventional and based-isolated nuclear power plants for earthquake and blast loadings. Technical Report MCEER-08-0019, University at Buffalo, State University of New York, 2008.

[138] Nicolas Luco, Paolo Bazzurro, and C. Allin Cornell. Dynamic versus static computation of the residual capacity of a mainshock-damaged building to withstand an aftershock. In Proceedings of the 13th World Conference on Earthquake Engineering, Vancouver, B.C., Canada, 2004.

[139] Robert Parrino and David Kidwell. Fundamentals of corporate finance. Wiley, 1 edition, 2008.

[140] Mark G. Stewart. Cyclone damage and temporal changes to building vulnerability and economic risks for residential construction. Journal of Wind Engineering and Industrial Aerodynamics, 91(5):671-691, 2003. 
[141] PEER Center. PEER ground motion selection and modification program (GMSM). http://peer.berkeley.edu/gmsm/Mission.html, 2010. [visited on Jan. 8, 2010].

[142] John W. van de Lindt and Rakesh Gupta. Damage and damage prediction for wood shearwalls subjected to simulated earthquake loads. Journal of Performance of Constructed Facilities, 20(2):176-184, 2006.

[143] Yue-Jun Yin, Yue Li, and William M. Bulleit. Stochastic modeling of snow loads using a filtered Poisson process. Journal of Cold Regions Engineering, 2010. (accepted, availabel onlione http://dx.doi.org/10.1061/(ASCE) CR. 1943-5495.0000021).

[144] C. A. Cornell. Engineering seismic risk analysis. Bulletin of the seismological society of America, 58(5):1583-1606, 1968.

[145] Yue-Jun Yin and Yue Li. Seismic collapse risk of light-frame wood construction considering aleatoric and epistemic uncertainties. Structual Safety, 32(4):250-261, 2010.

[146] Keith A. Porter, James L. Beck, Hope A. Seligson, Charles R. Scawthorn, L. Thomas Tobin, Ray Young, and Tom Boyd. Improving loss estimation for woodframe buildings. Technical report, Consortium of Universities for Research in Earthquake Engineering (CUREE), 2002.

[147] The MathWorks, Inc. Matlab 7.9.0.529 (r2009b), 2008. 


\section{Appendix A}

\section{JOHN WILEY AND SONS LICENSE TERMS AND CONDITIONS}

This is a License Agreement between yuejun yin ("You") and John Wiley and Sons ("John Wiley and Sons") provided by Copyright Clearance Center ("CCC"). The license consists of your order details, the terms and conditions provided by John Wiley and Sons, and the payment terms and conditions.

All payments must be made in full to $\mathrm{CCC}$. For payment instructions, please see information listed at the bottom of this form.

License Number: 2396520721972

License date: Mar 26, 2010

Licensed content publisher John Wiley and Sons

Licensed content publication Earthquake Engineering and Structural Dynamics

Licensed content title Uniform hazard versus uniform risk bases for performance-based earthquake engineering of light-frame wood construction

Licensed content author Li Yue, Yin Yuejun, Ellingwood Bruce R., et al

Licensed content date $\operatorname{Jan} 27,2010$ 
Start page $n / a$

End page n/a

Type of use Dissertation/Thesis

Requestor type Author of this Wiley article

Format Print and electronic

Portion Full article

Will you be translating? No

Order reference number

Total 0.00 USD

\section{TERMS AND CONDITIONS}

This copyrighted material is owned by or exclusively licensed to John Wiley \& Sons, Inc. or one if its group companies (each a "Wiley Company") or a society for whom a Wiley Company has exclusive publishing rights in relation to a particular journal (collectively "WILEY"). By clicking "accept" in connection with completing this licensing transaction, you agree that the following terms and conditions apply to this transaction (along with the billing and payment terms and conditions established by the Copyright Clearance Center Inc., ("CCC's Billing and Payment terms and conditions"), at the time that you opened your Rightslink account (these are available at any time at http://myaccount . copyright.com).

1. The materials you have requested permission to reproduce (the "Materials") are protected by copyright.

2. You are hereby granted a personal, non-exclusive, non-sublicensable, non-transferable, worldwide, limited license to reproduce the Materials for the purpose specified in the licensing process. This license is for a one-time use only with a maximum distribution equal to the number that you identified in the licensing process. Any form of republication granted by this licence must be completed within two years of the date 
of the grant of this licence (although copies prepared before may be distributed thereafter). Any electronic posting of the Materials is limited to one year from the date permission is granted and is on the condition that a link is placed to the journal homepage on Wiley's online journals publication platform at wWw. interscience. wiley.com. The Materials shall not be used in any other manner or for any other purpose. Permission is granted subject to an appropriate acknowledgement given to the author, title of the material/book/journal and the publisher and on the understanding that nowhere in the text is a previously published source acknowledged for all or part of this Material. Any third party material is expressly excluded from this permission.

3. With respect to the Materials, all rights are reserved. No part of the Materials may be copied, modified, adapted, translated, reproduced, transferred or distributed, in any form or by any means, and no derivative works may be made based on the Materials without the prior permission of the respective copyright owner. You may not alter, remove or suppress in any manner any copyright, trademark or other notices displayed by the Materials. You may not license, rent, sell, loan, lease, pledge, offer as security, transfer or assign the Materials, or any of the rights granted to you hereunder to any other person.

4. The Materials and all of the intellectual property rights therein shall at all times remain the exclusive property of John Wiley \& Sons Inc or one of its related companies (WILEY) or their respective licensors, and your interest therein is only that of having possession of and the right to reproduce the Materials pursuant to Section 2 herein during the continuance of this Agreement. You agree that you own no right, title or interest in or to the Materials or any of the intellectual property rights therein. You shall have no rights hereunder other than the license as provided for above in Section 2. No right, license or interest to any trademark, trade name, service mark or other branding ("Marks") of WILEY or its licensors is granted hereunder, and you agree that you shall not assert any such right, license or interest with respect thereto.

5. WILEY DOES NOT MAKE ANY WARRANTY OR REPRESENTATION OF ANY KIND TO YOU OR ANY THIRD PARTY, EXPRESS, IMPLIED OR STATUTORY, WITH RESPECT TO THE MATERIALS OR THE ACCURACY OF ANY INFORMATION CONTAINED IN THE MATERIALS, INCLUDING, WITHOUT LIMITATION, ANY IMPLIED WARRANTY OF MERCHANTABILITY, ACCURACY, SATISFACTORY QUALITY, FITNESS FOR A PARTICULAR PURPOSE, US- 


\section{ABILITY, INTEGRATION OR NON-INFRINGEMENT AND ALL SUCH WAR- RANTIES ARE HEREBY EXCLUDED BY WILEY AND WAIVED BY YOU.}

6. WILEY shall have the right to terminate this Agreement immediately upon breach of this Agreement by you.

7. You shall indemnify, defend and hold harmless WILEY, its directors, officers, agents and employees, from and against any actual or threatened claims, demands, causes of action or proceedings arising from any breach of this Agreement by you.

8. IN NO EVENT SHALL WILEY BE LIABLE TO YOU OR ANY OTHER PARTY OR ANY OTHER PERSON OR ENTITY FOR ANY SPECIAL, CONSEQUENTIAL, INCIDENTAL, INDIRECT, EXEMPLARY OR PUNITIVE DAMAGES, HOWEVER CAUSED, ARISING OUT OF OR IN CONNECTION WITH THE DOWNLOADING, PROVISIONING, VIEWING OR USE OF THE MATERIALS REGARDLESS OF THE FORM OF ACTION, WHETHER FOR BREACH OF CONTRACT, BREACH OF WARRANTY, TORT, NEGLIGENCE, INFRINGEMENT OR OTHERWISE (INCLUDING, WITHOUT LIMITATION, DAMAGES BASED ON LOSS OF PROFITS, DATA, FILES, USE, BUSINESS OPPORTUNITY OR CLAIMS OF THIRD PARTIES), AND WHETHER OR NOT THE PARTY HAS BEEN ADVISED OF THE POSSIBILITY OF SUCH DAMAGES. THIS LIMITATION SHALL APPLY NOTWITHSTANDING ANY FAILURE OF ESSENTIAL PURPOSE OF ANY LIMITED REMEDY PROVIDED HEREIN.

9. Should any provision of this Agreement be held by a court of competent jurisdiction to be illegal, invalid, or unenforceable, that provision shall be deemed amended to achieve as nearly as possible the same economic effect as the original provision, and the legality, validity and enforceability of the remaining provisions of this Agreement shall not be affected or impaired thereby.

10. The failure of either party to enforce any term or condition of this Agreement shall not constitute a waiver of either party's right to enforce each and every term and condition of this Agreement. No breach under this agreement shall be deemed waived or excused by either party unless such waiver or consent is in writing signed by the party granting such waiver or consent. The waiver by or consent of a party to a breach of any provision of this Agreement shall not operate or be construed as a waiver of or consent to any other or subsequent breach by such other party. 
11. This Agreement may not be assigned (including by operation of law or otherwise) by you without WILEY's prior written consent.

12. These terms and conditions together with CCC's Billing and Payment terms and conditions (which are incorporated herein) form the entire agreement between you and WILEY concerning this licensing transaction and (in the absence of fraud) supersedes all prior agreements and representations of the parties, oral or written. This Agreement may not be amended except in a writing signed by both parties. This Agreement shall be binding upon and inure to the benefit of the parties' successors, legal representatives, and authorized assigns.

13. In the event of any conflict between your obligations established by these terms and conditions and those established by CCC's Billing and Payment terms and conditions, these terms and conditions shall prevail.

14. WILEY expressly reserves all rights not specifically granted in the combination of (i) the license details provided by you and accepted in the course of this licensing transaction, (ii) these terms and conditions and (iii) CCC's Billing and Payment terms and conditions.

15. This Agreement shall be governed by and construed in accordance with the laws of England and you agree to submit to the exclusive jurisdiction of the English courts.

BY CLICKING ON THE “I ACCEPT” BUTTON, YOU ACKNOWLEDGE THAT YOU HAVE READ AND FULLY UNDERSTAND EACH OF THE SECTIONS OF AND PROVISIONS SET FORTH IN THIS AGREEMENT AND THAT YOU ARE IN AGREEMENT WITH AND ARE WILLING TO ACCEPT ALL OF YOUR OBLIGATIONS AS SET FORTH IN THIS AGREEMENT.

V1.2

Gratis licenses (referencing \$0 in the Total field) are free. Please retain this printable license for your reference. No payment is required.

If you would like to pay for this license now, please remit this license along with your payment made payable to "COPYRIGHT CLEARANCE CENTER" otherwise you will be invoiced within 48 hours of the license date. Payment should be in the form 
of a check or money order referencing your account number and this invoice number RLNK10729887. Once you receive your invoice for this order, you may pay your invoice by credit card. Please follow instructions provided at that time.

Make Payment TO:

Copyright Clearance Center

Dept 001

P.O. Box 843006

Boston, MA 02284-3006

If you find copyrighted material related to this license will not be used and wish to cancel, please contact us referencing this license number 2396520721972 and noting the reason for cancellation.

Questions? customercaredcopyright . com or $+1-877-622-5543$ (toll free in the US) or +1-978-646-2777. 


\section{Appendix B}

\section{What rights do I retain as an author?}

The following contents are part of the article on the ELSEVIER website (http: // www.elsevier.com/wps/find/supportfaq.Cws_home/rightsasanauthor)

As an author, you retain rights for a large number of author uses, including use by your employing institute or company. These rights are retained and permitted without the need to obtain specific permission from Elsevier. These include:

$\dagger$ the right to make copies of the article for your own personal use, including for your own classroom teaching use;

$\dagger$ the right to make copies and distribute copies (including through e-mail) of the article to research colleagues, for the personal use by such colleagues (but not commercially or systematically, e.g. via an e-mail list or list serve);

$\dagger$ the right to post a pre-print version of the article on Internet web sites including electronic pre-print servers, and to retain indefinitely such version on such servers or sites (see also our information on electronic preprints for a more detailed discussion on these points.);

$\dagger$ the right to post a revised personal version of the text of the final article (to reflect changes made in the peer review process) on the author's personal or institutional 
web site or server, with a link to the journal home page (on External link elsevier.com);

$\dagger$ the right to present the article at a meeting or conference and to distribute copies of such paper or article to the delegates attending the meeting;

$\dagger$ for the author's employer, if the article is a 'work for hire', made within the scope of the author's employment, the right to use all or part of the information in (any version of) the article for other intra-company use (e.g. training);

$\dagger$ patent and trademark rights and rights to any process or procedure described in the article;

$\dagger$ the right to include the article in full or in part in a thesis or dissertation (provided that this is not to be published commercially)

$\dagger$ the right to use the article or any part thereof in a printed compilation of works of the author, such as collected writings or lecture notes (subsequent to publication of the article in the journal); and

$\dagger$ the right to prepare other derivative works, to extend the article into book-length form, or to otherwise re-use portions or excerpts in other works, with full acknowledgement of its original publication in the journal. 


\section{VITA}

Yuejun Yin obtained his BS and MS degrees in Shanghai Jiao Tong University (SJTU) in 2000 and 2006, respectively. He started his PhD research with Dr. Yue Li in the Fall of 2007. He has two kids, a two-year old boy Leroy and a one-month old girl Sarah. He can be reached by email yjyincj@gmail.com. 